Florida International University FIU Digital Commons

$11-7-2016$

\title{
Water Quality Modelling Using Multivariate Statistical Analysis and Remote Sensing in South Florida
}

Mohammad Hajigholizadeh

mhaji002@fiu.edu

DOI: $10.25148 /$ etd.FIDC001230

Follow this and additional works at: https://digitalcommons.fiu.edu/etd

Part of the Civil Engineering Commons, and the Environmental Engineering Commons

\section{Recommended Citation}

Hajigholizadeh, Mohammad, "Water Quality Modelling Using Multivariate Statistical Analysis and Remote Sensing in South Florida" (2016). FIU Electronic Theses and Dissertations. 2992.

https://digitalcommons.fiu.edu/etd/2992

This work is brought to you for free and open access by the University Graduate School at FIU Digital Commons. It has been accepted for inclusion in FIU Electronic Theses and Dissertations by an authorized administrator of FIU Digital Commons. For more information, please contact dcc@fiu.edu. 


\title{
FLORIDA INTERNATIONAL UNIVERSITY
}

Miami, Florida

\section{WATER QUALITY MODELLING USING MULTIVARIATE STATISTICAL ANALYSIS AND REMOTE SENSING IN SOUTH FLORIDA}

\author{
A dissertation submitted in partial fulfillment of \\ the requirements for the degree of \\ DOCTOR OF PHILOSOPHY \\ in \\ CIVIL ENGINEERING
}

by

Mohammad Hajigholizadeh 
To: Interim Dean Ranu Jung

College of Engineering and Computing

This dissertation, written by Mohammad Hajigholizadeh, and entitled Water Quality Modelling Using Multivariate Statistical Analysis and Remote Sensing in South Florida, having been approved in respect to style and intellectual content, is referred to you for judgment.

We have read this dissertation and recommend that it be approved.

Michael C. Sukop

Walter Z. Tang

Seung J. Lee

Hector R. Fuentes, Co-Major Professor

Assefa M. Melesse, Co-Major Professor

Date of Defense: November 7, 2016

The dissertation of Mohammad Hajigholizadeh is approved.

Interim Dean Ranu Jung College of Engineering and Computing

Andres G. Gil

Vice President for Research and Economic Development and Dean of the University Graduate School

Florida International University, 2016 
(C) Copyright 2016 by Mohammad Hajigholizadeh

All rights reserved. 


\section{DEDICATION}

To my mother, Afagh, who encouraged my curiosity and have always supported my aspirations no matter how fanciful they have been, also to my father, Heidar, who is no longer physically present in my life, I still feel his impact every day. And to Samira, whose love and wisdom has kept me grounded. 


\section{ACKNOWLEDGMENTS}

The work presented in this dissertation was not accomplished solely by the author. Many individuals assisted me throughout this process with mentorship and logistical support.

I would fist like to thank Dr. Assefa M. Melesse and Dr. Hector R. Fuentes, my co-major advisors. Your level of energy and excitement seem boundless and are often a needed reminder of what I love about science. Special thanks to Dr. Assefa M. Melesse. You have been an excellent role model for me, both professionally and personally. You believed in my ideas and allowed me to run with them. Working under your mentorship has given me the resources and confidence to pursue my career aspirations.

I am grateful for all of the members of my dissertation committee: Dr. Walter Z. Tang, Dr. Michael C. Sukop, and Dr. Seung Jae Lee. I appreciate your generous contributions of expertise and time during my research. Special thanks to Dr. Lakshmi Reddi for his support during the early stages of this research, when it was still a dissertation proposal.

During my research I was generously supported by the Department of Civil and Environmental Engineering, and University Graduate School of Florida International University through both the Presidential Fellowship and Graduate Assistantship. 


\title{
ABSTRACT OF THE DISSERTATION \\ WATER QUALITY MODELLING USING MULTIVARIATE STATISTICAL ANALYSIS AND REMOTE SENSING IN SOUTH FLORIDA
}

by

\author{
Mohammad Hajigholizadeh \\ Florida International University, 2016 \\ Miami, Florida

\begin{abstract}
Professor Assefa M. Melesse, Co-Major Professor
Professor Hector R. Fuentes, Co-Major Professor
\end{abstract}

The overall objective of this dissertation research is to understand the spatiotemporal dynamics of water quality parameters in different water bodies of South Florida. Two major approaches (multivariate statistical techniques and remote sensing) were used in this study. Multivariate statistical techniques include cluster analysis (CA), principal component analysis (PCA), factor analysis (FA), discriminant analysis (DA), absolute principal component score-multiple linear regression (APCS-MLR) and PMF receptor modeling techniques were used to assess the water quality and identify and quantify the potential pollution sources affecting the water quality of three major rivers of South Florida. For this purpose, a 15-year (2000-2014) data set of 12 water quality variables, and about 35,000 observations were used. Agglomerative hierarchical CA grouped 16 monitoring sites into three groups (low pollution, moderate pollution, and high pollution) based on their similarity of water quality characteristics. DA, as an important data reduction method, was used to assess the water pollution status and 
analysis of its spatiotemporal variation. PCA/FA identified potential pollution sources in wet and dry seasons, respectively, and the effective mechanisms, rules, and causes were explained. The APCS-MLR and PMF models apportioned their contributions to each water quality variable.

Also, the bio-physical parameters associated with the water quality of the two important water bodies of Lake Okeechobee and Florida Bay were investigated based on remotely sensed data. The principal objective of this part of the study is to monitor and assess the spatial and temporal changes of water quality using the application of integrated remote sensing, GIS data, and statistical techniques. The optical bands in the region from blue to near infrared and all the possible band ratios were used to explore the relation between the reflectance of a waterbody and observed data. The developed MLR models appeared to be promising for monitoring and predicting the spatiotemporal dynamics of optically active and inactive water quality characteristics in Lake Okeechobee and Florida Bay. It is believed that the results of this study could be very useful to local authorities for the control and management of pollution and better protection of water quality in the most important water bodies of South Florida. 


\section{TABLE OF CONTENTS}

CHAPTER

PAGE

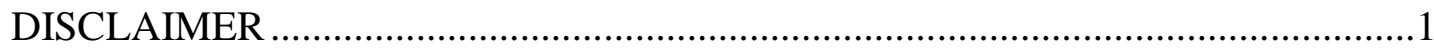

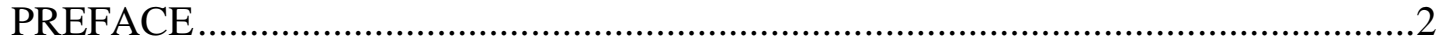

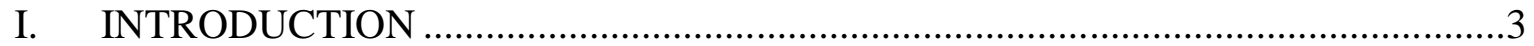

1. Introduction and research rationale .............................................................

2. Current water quality challenges in South Florida .................................................

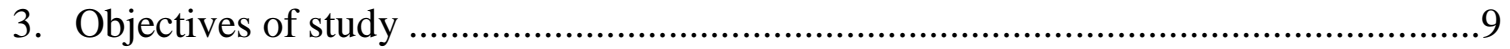

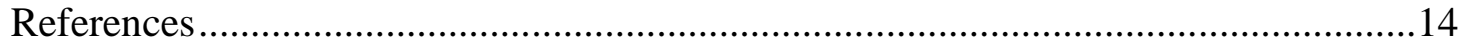

II. A COMPREHENSIVE REVIEW ON WATER QUALITY PARAMETERS ESTIMATION USING REMOTE SENSING TECHNIQUES ...............................19

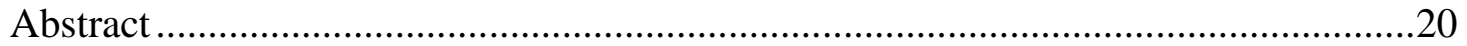

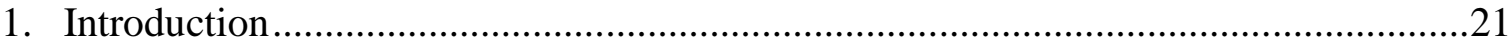

2. An overview of water quality assessment and remote sensing ..............................23

3. Spaceborne and airborne sensors for water quality studies ..................................25

4. Water quality investigations through remote sensing techniques .............................26

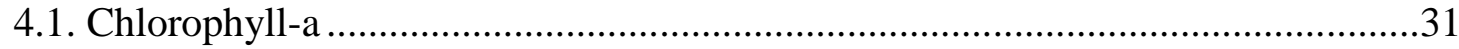

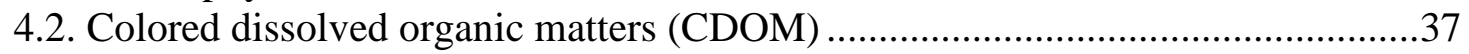

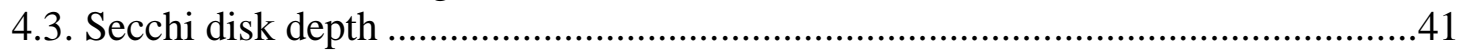

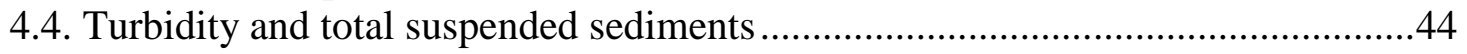

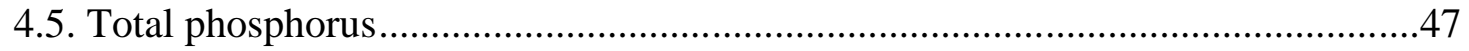

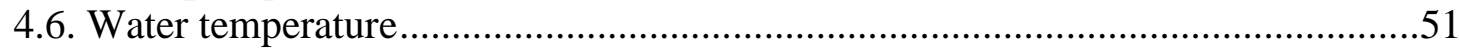

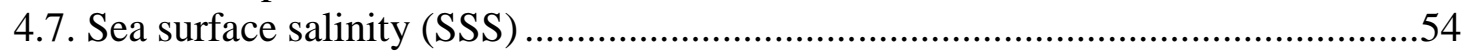

4.8. Dissolved oxygen (DO), biochemical oxygen demand (BOD) and chemical

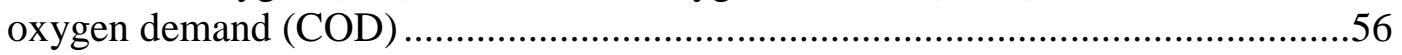

5. Limitations of remote sensing for the assessment of water quality parameters ...........59

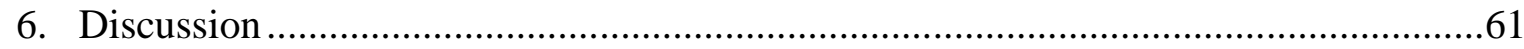

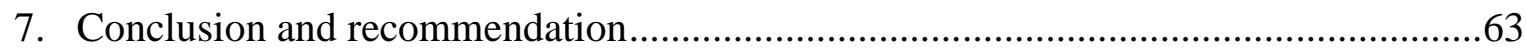

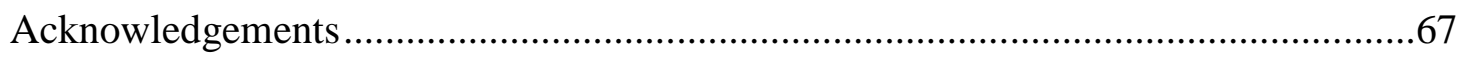

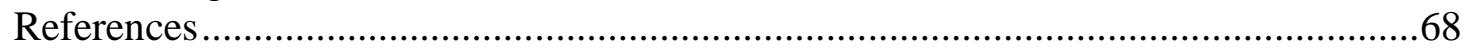

III. REGIONAL LAKE WATER QUALITY ASSESSMENT USING REMOTE SENSING: THE CASE STUDY OF LAKE OKEECHOBEE, FLORIDA, USA .......96

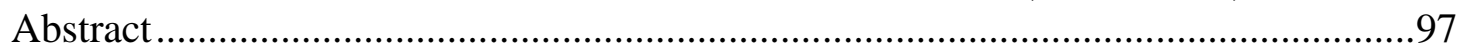

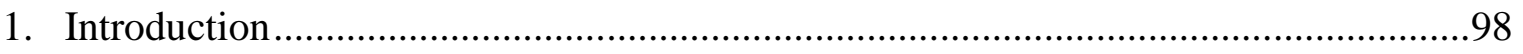

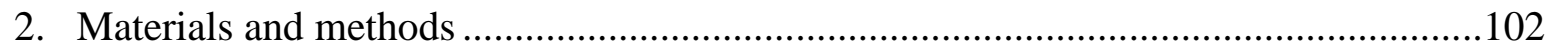

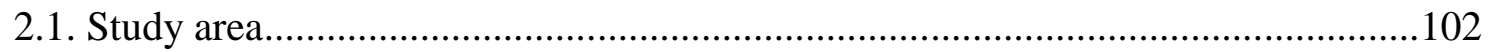

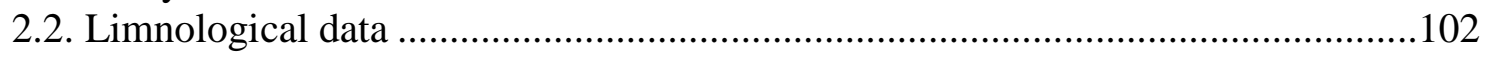

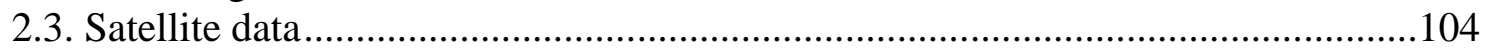

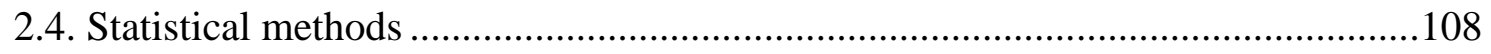

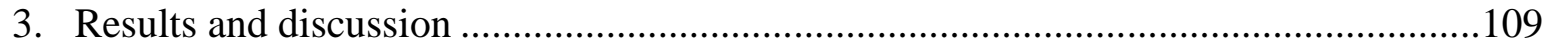




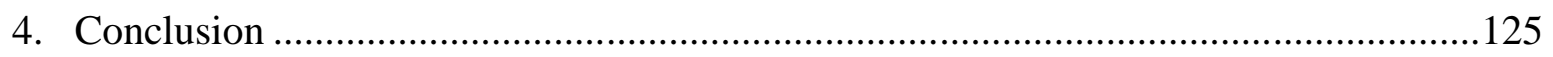

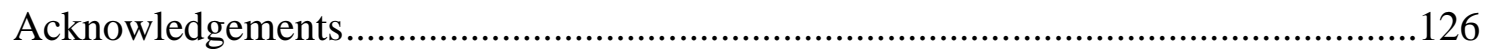

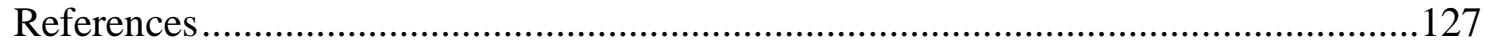

IV. STUDY ON SPATIOTEMPORAL VARIABILITY OF WATER QUALITY PARAMETERS IN FLORIDA BAY USING REMOTE SENSING ..........................132

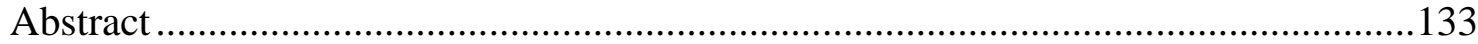

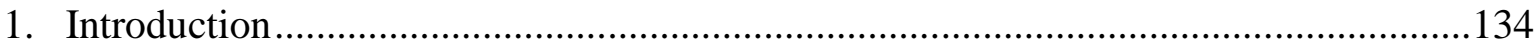

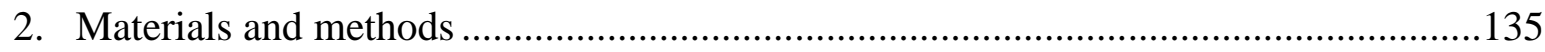

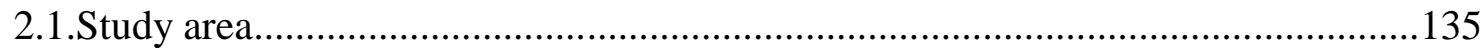

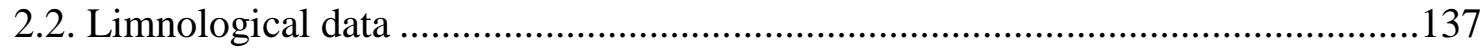

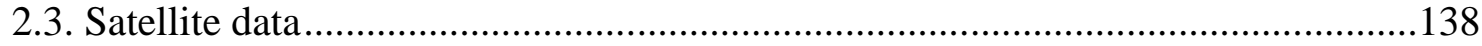

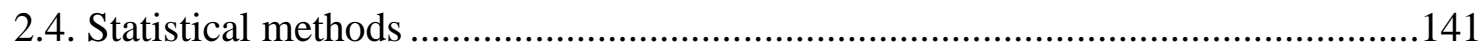

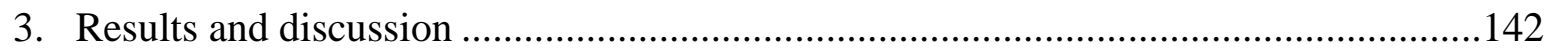

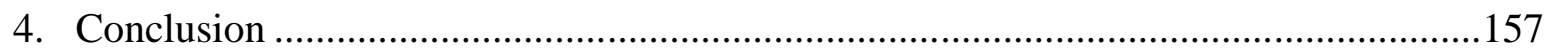

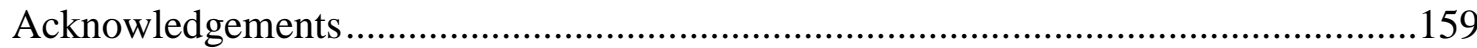

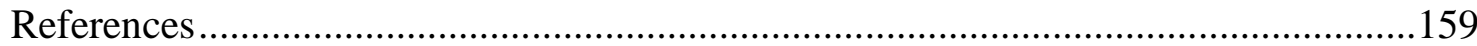

V. ASSORTMENT OF THE SURFACE WATER POLLUTION REGIONS AND STUDY ON SPATIOTEMPORAL VARIABILITY OF POLLUTION USING CLUSTER AND DISCRIMINANT ANALYSES .................................................165

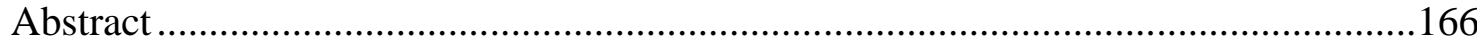

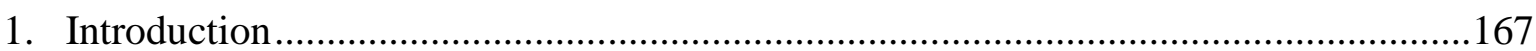

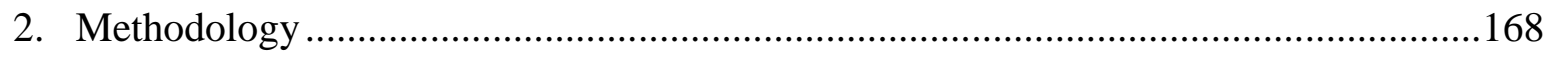

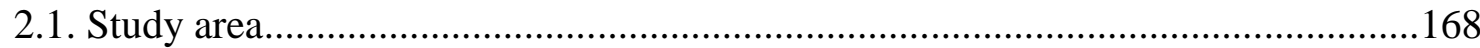

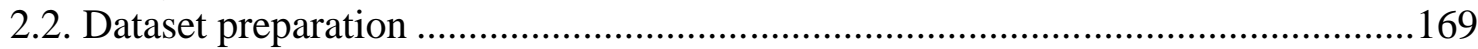

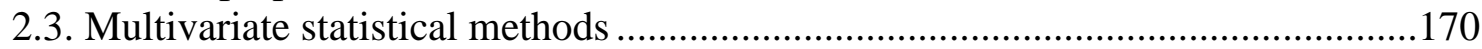

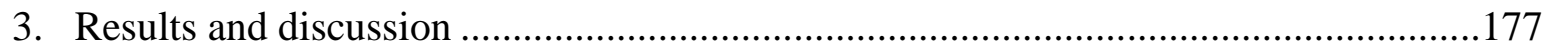

3.1. Spatiotemporal similarities and grouping the sampling sites by cluster analysis

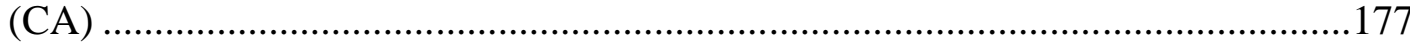

3.2. Spatiotemporal variations in river water quality using discriminant analysis ......181

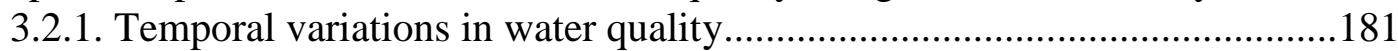

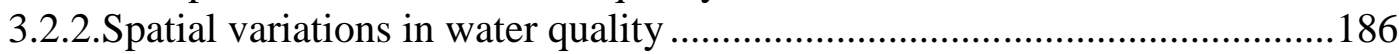

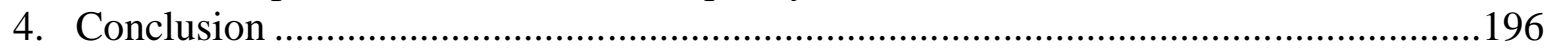

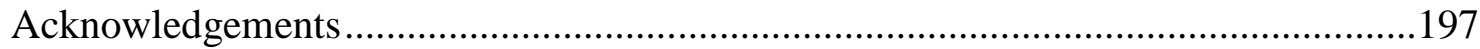

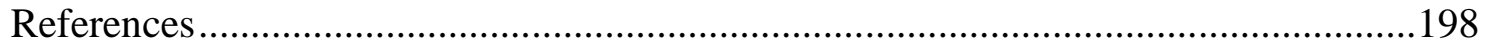

VI. WATER QUALITY ASSESSMENT AND APPORTIONMENT OF POLLUTION SOURCES USING APCS-MLR AND PMF RECEPTOR MODELLING TECHNIQUES IN THREE MAJOR RIVERS OF SOUTH FLORIDA.......................200

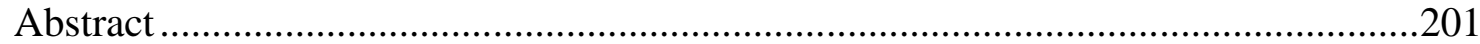

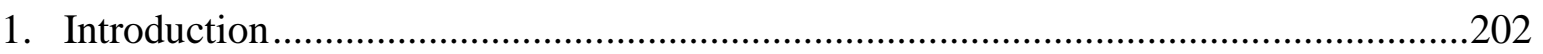

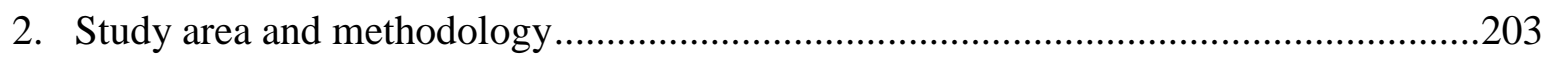

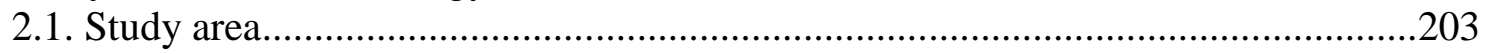

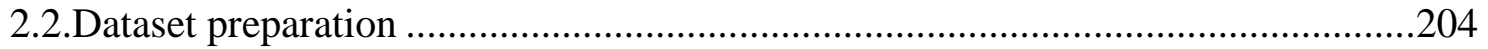




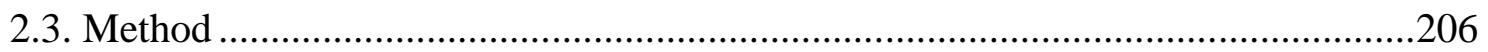

2.3.1. Principal component analysis and factor analysis ......................................206

2.3.2. Source apportionment using APCS-MLR receptor modeling technique ....211

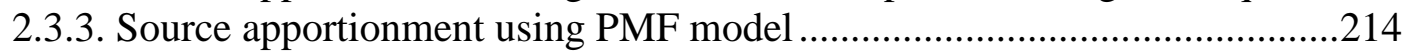

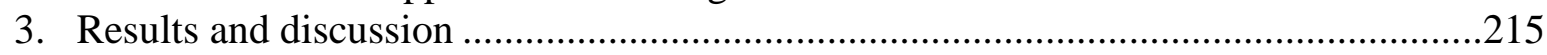

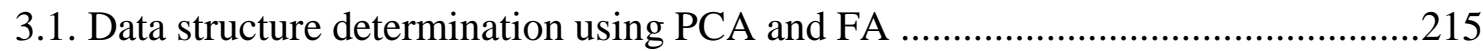

3.1.1. Identification of potential pollution sources in wet season ..........................217

3.1.2. Identification of potential pollution sources in dry season..........................223

3.2. Source apportionment using APCS-MLR and PMF models ................................226

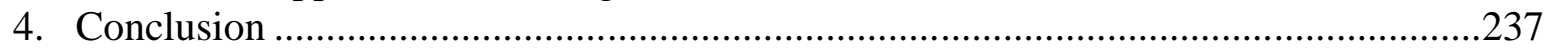

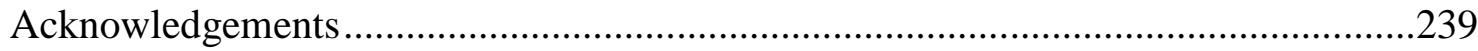

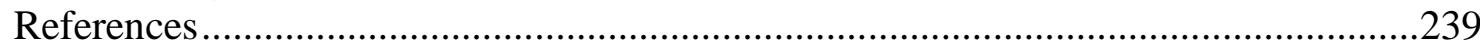

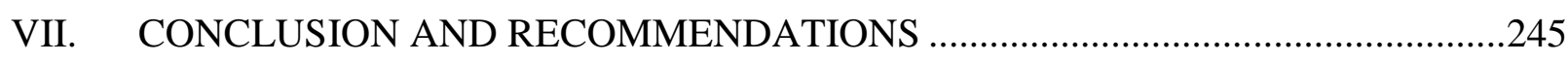

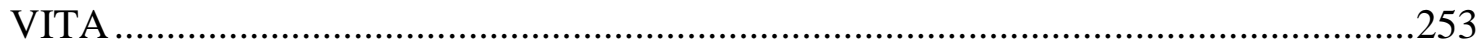




\section{LIST OF TABLES}

TABLE

PAGE

\section{CHAPTER II}

Table 2.1. List of the commonly used spaceborne sensors in water quality assessments. ....27

Table 2.2. Specification of the more commonly used airborne sensors in water quality assessments.

Table 2.3. Characteristics of the more commonly used microwave radiometers in oceanography and water quality studies.

Table 2.4. The most commonly measured qualitative parameters of water by means of remote sensing.

Table 2.5. Remotely measurements of chl-a using various spectral bands and their ratios.

Table 2.6. Remotely measurements of CDOM using various spectral bands and their ratios.

Table 2.7. Remotely measurements of SDD using various spectral bands and their ratios.....

Table 2.8. Remotely measurements of Turbidity and Total Suspended Sediments using various spectral bands and their ratios.....

Table 2.9. Remotely measurements of total phosphorus (TP) using various sensors and blue and green bands, and integration of red and green bands ratio

Table 2.10. Infrared thermal band applications to quantify the water temperature

Table 2.11. Remote sensing of Sea Surface Salinity (SSS) based on the used sensor ..... .57

Table 2.12. Remote sensing of dissolved oxygen (DO), biochemical oxygen demand (BOD), and chemical oxygen demand (COD) based on the used sensor

Table 2.13. Comparison between spaceborne and airborne sensors

\section{CHAPTER III}

Table 3.1. Descriptive statistics of chl-a, TSS, total phosphate, and TKN in the Lake Okeechobee 
Table 3.2. Pearson's R correlation between limnological data and Landsat bands and ratios $(* *)$ : significant correlation for $\mathrm{p}<0.05$

Table 3.3. Statistical values obtained from regression analyses for chl-a and TSS.

Table 3.4. Extracted equations based on regression analysis between limnological parameters and Landsat bands

Table 3.5. Pearson's R correlation between observed water quality parameters and Landsat bands and ratios $(* *)$ : significant correlation for $\mathrm{p}<0.05$.

Table 3.6. Statistical values obtained as a result of regression analyses for total phosphate and TKN.

Table 3.7. Extracted equations based on regression analysis between Total Phosphate and TKN, and Landsat bands and other water quality parameters

Table 3.8. The area based condition of water quality parameters in Lake Okeechobee in dry and wet seasons, and in three years of 2000, 2007, and $2015(\mathrm{Km} 2)$

\section{CHAPTER IV}

Table 4.1. Descriptive statistics of chl-a, turbidity, total phosphate, and TN in the Florida Bay

Table 4.2. Pearson's R correlation between limnological data and Landsat bands and ratios $(* *)$ : significant correlation for $\mathrm{p}<0.05$

Table 4.3. Statistical values obtained from regression analyses for chl-a and turbidity........

Table 4.4. Extracted equations based on regression analysis between limnological parameters and Landsat bands

Table 4.5. Pearson's $\mathrm{R}$ correlation between observed water quality parameters and Landsat bands and ratios $(* *)$ : significant correlation for $\mathrm{p}<0.05$.

Table 4.6. Statistical values obtained as a result of regression analyses for total phosphate and $\mathrm{TN}$

Table 4.7. Extracted equations based on regression analysis between Total Phosphate and $\mathrm{TN}$, and Landsat bands and other water quality parameters

Table 4.8. The area based condition of water quality parameters in Florida Bay in dry and wet seasons, and in three years of 2000, 2007, and 2015 (Km2) 


\section{CHAPTER V}

Table 5.1. Summary basic statistics of water quality parameters between 2000 and 2014

Table 5.2. Wilk's lambda and chi-square test for the temporal discriminant analysis of water quality variations across two wet and dry seasons

Table 5.3. Classification functions coefficients (CFs) for the temporal discriminant analysis of water quality variations in wet and dry seasons

Table 5.4. Classification matrix (CMs) for the temporal discriminant analysis of water quality variations in wet and dry seasons

Table 5.5. Wilk's lambda and chi-square test for the spatial discriminant analysis of water quality variations across three groups of sites in wet season

Table 5.6. Classification functions coefficients (CFs) for the spatial discriminant analysis of water quality variations across three clusters in wet season.

Table 5.7. Classification matrix $(\mathrm{CMs})$ for the spatial discriminant analysis in wet season

Table 5.8. Wilk's lambda and chi-square test for the spatial discriminant analysis of water quality variations across three groups of sites in dry season

Table 5.9. Classification functions coefficients (CFs) for the spatial discriminant analysis of water quality variations across three clusters in dry season

Table 5.10. Classification matrix (CMs) for the spatial discriminant analysis in dry season.

\section{CHAPTER VI}

Table 6.1. Summary basic statistics of water quality parameters between 2000 and 2014

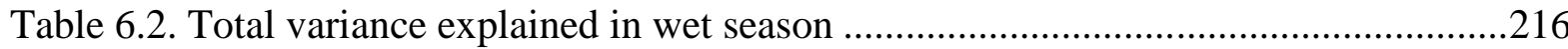

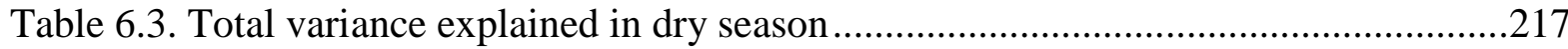

Table 6.4. Loadings of 12 selected variables on varimax rotated factors of different seasons in three major rivers of South Florida............................................................217

Table 6.5. Mean source contributions to different variables concentrations in

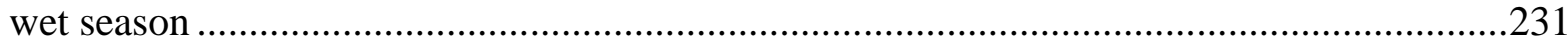

Table 6.6. Mean source contributions to different variables concentrations in dry season..... 


\section{LIST OF FIGURES}

FIGURE

PAGE

\section{CHAPTER II}

Figure 2.1. The Absorption Spectrum of chl-a and the Chl-b. 32

Figure 2.2. Two different kinds of Secchi disks

Figure 2.3. A suggested remote sensing based framework to predict and assessment of water quality variables

\section{CHAPTER III}

Figure 3.1. The location of the study area and the water quality monitoring sites

Figure 3.2. Spatial and temporal patterns of chl-a and TSS concentrations in Lake

Okeechobee.

Figure 3.3. The normal probability-probability (P-P) plots of regression standardized residuals for chl-a and TSS in dry and wet seasons

Figure 3.4. Spatial and temporal patterns of total phosphate and TKN in Lake Okeechobee.

Figure 3.5. The normal probability-probability (P-P) plots of regression standardized residuals for total phosphate and TKN in dry and wet seasons

\section{CHAPTER IV}

Figure 4.1. The location of the study area and the water quality monitoring sites

Figure 4.2. Spatial and temporal patterns of chl-a and turbidity concentrations in Florida

Bay

Figure 4.3. The normal probability-probability (P-P) plots of regression standardized residuals for chl-a and turbidity in dry and wet seasons

Figure 4.4. Spatial and temporal patterns of total phosphate and TN in Florida Bay

Figure 4.5. The normal probability-probability (P-P) plots of regression standardized residuals for total phosphate and $\mathrm{TN}$ in dry and wet seasons 


\section{CHAPTER V}

Figure 5.1. The location of study area and water quality monitoring sites

Figure 5.2. Dendrogram showing three clusters of monitoring sites in wet season (a) and dry season (b) using the Ward's linkage distance (Dlink/Dmax).....

Figure 5.3. Spatial distribution of three groups of sites based on their similarity and the level of impairment in the study area in the wet (a) and dry (b) seasons

Figure 5.4. Temporal trends of nutrients in the selected waterbodies of South Florida

Figure 5.5. Temporal variations in water quality of three major rivers of South Florida: Chl-a; Dissolved Oxygen, total kjeldahl nitrogen (TKN), total phosphorus (TP), and water temperature

Figure 5.6. Scatter plot for the spatial discriminant analysis of water quality variations across three clusters in wet season (stepwise mode)

Figure 5.7. Spatial variations in water quality of three clusters of sites in wet season: Chl-

a; DO, TKN, TP, magnesium, chloride, and sodium.

Figure 5.8. Scatter plot for the spatial discriminant analysis of water quality variations across three clusters in dry season (stepwise mode).....

Figure 5.9. Spatial variations in water quality of three clusters of sites in dry season: DO, TKN, TP, turbidity, magnesium, and chloride

\section{CHAPTER VI}

Figure 6.1. The location of the study area and the water quality monitoring sites

Figure 6.2. Component loadings for twelve variables after varimax rotation in wet season.

Figure 6.3. Component loadings for twelve variables after varimax rotation in dry season.

Figure 6.4. Average contributions of different pollution sources to water quality of three major rivers of South Florida in wet season (a) and dry season (b) using APCS-MLR model.

Figure 6.5. Average contributions of different pollution sources to nutrients, water murkiness, and salt ions in wet season (a) and dry season (b) using APCS-MLR model.

Figure 6.6. Factor Figureprints of twelve studied variables resulted from EPA PMF model in the wet (a) and dry (b) seasons 
Figure 6.7. Average contributions of different pollution sources to water quality of three major rivers of South Florida in wet season (a) and dry season (b) using EPA PMF model

Figure 6.8. Source contribution variations based on the results of PMF and APCS-MLR

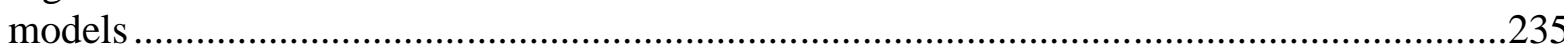

Figure 6.9. Scatter plots of the predicted and observed ratios for TKN, total phosphate, TP, ammonia-N, TSS, and turbidity in the wet season using the EPA PMF and APCSMLR models 


\section{GLOSSARY OF TECHNICAL TERMS AND ACRONYMS}

Absolute Principal Component Score-Multiple Linear Regression (APCS-MLR) Active Learning Method (ALM)

Airborne Imaging Spectroradiometer for Applications (AISA)

Ammonia Nitrogen (NH3-N)

Biochemical Oxygen Demand (BOD)

Chemical Oxygen Demand (COD)

Chlorophyll-a (chl-a)

Classification Function (CF)

Classification Matrices (CM)

Cluster Analysis (CA)

Colored Dissolved Organic Matter (CDOM)

Compact Airborne Spectrographic Imager (CASI)

Compact High Resolution Imaging Spectrometer (CHRIS)

DBHYDRO (environmental database of SFWMD)

Decision Support Systems (DSS)

Digital Number (DN)

Discriminant Analysis (DA)

Discriminant Function (DF)

Dissolved Organic Carbon (DOC)

Dissolved Oxygen (DO)

Dissolved Phosphorus (DP) 
Empirical Orthogonal Function (EOF)

Environmental Protection Agency (EPA)

Environmental Resource Permits (ERP)

ETM (Enhanced Thematic Mapper)

Everglades Agricultural Area (EAA)

Everglades National Park (ENP)

Factor Analysis (FA)

Florida Department of Environmental Protection (FDEP)

Geographical Information Systems (GIS)

Hyperspectral Imager for the Coastal Ocean (HICO)

Inherent Optical Properties (IOP)

Kaiser-Meyer-Olkin (KMO)

Land Cover/Land Use (LCLU)

Landsat Multispectral Scanner (MSS)

Medium Resolution Imaging Spectrometer (MERIS)

Microwave Radiometers (MWR)

MIM (Matrix Inversion Method)

Moderate Resolution Imaging Spectroradiometer (MODIS)

Multiple Linear Regression (MLR)

National Hydrography Dataset (NHD)

National Water Quality Monitoring Council (NWQMC)

Nitrate Nitrogen (NO3--N)

Normalized Green-Red Difference Index (NGRDI) 
OLI (Operational Land Imager)

PCU (Platinum-Cobalt Units)

Positive Matrix Factorization (PMF)

Principal Component (PC)

Principal Component Analysis (PCA)

Rayleigh-Corrected Reflectance (Rrc)

Remote sensing (RS)

Salinity, Temperature, and Roughness Remote Scanner (STARRS)

Scanning Low-Frequency Microwave Radiometer (SLFMR)

Sea Surface Salinity (SSS)

Sea Surface Temperature (SST)

Sea-viewing Wide Field-of-view Sensor (SeaWiFS)

Secchi Disk Depth (SDD)

South Florida Water Management District (SFWMD)

Synthetic Aperture Radar (SAR)

Thematic Mapper (TM)

Thermal-Infrared (TIR)

Total Nitrogen (TN)

Total Phosphorus (TP)

Total Suspended Sediments (TSS)

Unidentified Sources (UIS)

United States Geological Survey (USGS)

Varifactor (VF) 
Visible Near-Infrared (VNIR)

Water Quality Parameter (WQP)

Water Temperature (WT) 


\section{DISCLAIMER}

The author, dissertation committee members and the Department of Civil and Environmental Engineering of Florida International University:

1. Do not make any warranty or representation, expressed or implied, with respect to the accuracy and completeness of the information contained in this report.

2. Do not warrant that the use of any information, method or process described in this report may not infringe on privately owned rights; and

3. Do not assume any liabilities with respect to the use of or for damages resulting from the use of any information, method or process described in this report.

This dissertation does not reflect the official views or policies of the Department of Civil and Environmental Engineering at Florida International University and those of any sponsoring or participating organizations and individuals. 


\section{PREFACE}

The following chapters have been published and have been formatted for those publications.

\section{CHAPTER II}

Gholizadeh, Mohammad Haji, Assefa M. Melesse, and Lakshmi Reddi. "A Comprehensive Review on Water Quality Parameters Estimation Using Remote Sensing Techniques”. Sensors, 16(8), p.1298.

\section{CHAPTER VI}

Gholizadeh, Mohammad Haji, Assefa M. Melesse, and Lakshmi Reddi. "Water quality assessment and apportionment of pollution sources using APCSMLR and PMF receptor modeling techniques in three major rivers of South Florida." Science of The Total Environment 566 (2016): 1552-1567.

The following chapter has been submitted as an article and is under final review process, so the format of chapter has been set for that article. Also, the results of the second paper, which is already published, was used in CHAPTER V

\section{CHAPTER V}

Gholizadeh, M.H., and Melesse, A.M., 2016. Assortment and Spatiotemporal Analysis of Surface Water Quality Using Cluster and Discriminant Analyses. CATENA Journal (in review).

Gholizadeh, Mohammad Haji, Assefa M. Melesse, and Lakshmi Reddi. "Discriminant Analysis Application in Spatiotemporal Evaluation of Water Quality in South Florida." Journal of Hydroinformatics, p.jh2016023.

The following chapters are in the final stage of submission for publication, so the format of chapters has been set for those articles.

\section{CHAPTER III}

Gholizadeh, M.H., Melesse, A.M., Fuentes, H., Tang, W., Sukop, M., 2016. Regional Lake Water Quality Assessment Using Remote Sensing: The case study of Lake Okeechobee, Florida, USA. Commentary in preparation for Journal of Remote Sensing.

\section{CHAPTER IV}

Gholizadeh, M.H., Melesse, A.M., Fuentes, H., Tang, W., Sukop, M., 2016. Study on Spatiotemporal Variability of Water Quality parameters in Florida Bay Using Remote Sensing. Commentary in preparation for Applied Earth Observation and Geoinformation. 
CHAPTER I

INTRODUCTION 


\section{Introduction and research rationale}

Surface water quality has become a serious concern for policy makers and environmental managers in both urbanized and agricultural areas. Both natural factors such as discharge, rainfall, soil erosion, and physiographical characteristics of basins, and also anthropogenic factors like the urbanization, industrial and agricultural activities, etc., can affect the quality of surface waters [1,2]. Anthropogenic factors such as residential and industrial wastewater are the major polluting sources in urban areas, whereas, natural factors like rainfall, surface runoff and groundwater level are seasonal phenomenon which are mainly affected by climate [3]. The seasonal variations in natural factors can affect the concentration of different pollutants in rivers or other waterbodies that may receive water from surface rainfall and runoff [4]. Therefore, to better investigate and evaluate the water quality of watersheds, the study of temporal variations alongside spatial variations of water quality seems to be inevitable.

In addition, the behavioral properties of waterbodies in most cases are controlled by several hidden internal and external factors. Identification and interpretation of these controlling factors is increasingly becoming an important part of water quality management programs. Continuous monitoring programs are required in order to obtain reliable data about these inherent characteristics of water quality and to understand the spatiotemporal variations of water quality [5]. However, the generated databases are large and complex and their analyses require robust analytical tools. Traditional methods to determine different physical, chemical, and biological indicators of water quality include field sampling and analysis of samples in the laboratory. Although this in-situ measurement offers high accuracy, it is a labor intensive and time consuming process, 
and hence it is not feasible to provide a simultaneous water quality database on a regional scale [6]. Moreover, conventional point sampling methods are not easily able to identify spatial or temporal variations in water quality, which is vital for comprehensive assessment and management of waterbodies. Therefore, these difficulties of successive and integrated sampling become a significant obstacle to the monitoring and management of water quality.

Different multivariate statistical techniques have been widely applied to evaluate the spatiotemporal variations of water quality parameters and also to interpret large and complex datasets [3,5,7-20]. In addition, with advances in space science and the increasing use of computer applications and increased computing power over recent decades, remote sensing techniques have become useful tools to achieve this goal. Remote sensing techniques make it possible to monitor and identify large scale regions and waterbodies that suffer from water quality problems in a more effective and efficient

manner. The collection of remotely-sensed data occurs in digital form and therefore can be easily used for computer processing. Since the 1970s, remote sensing application to monitor and evaluate the water quality status of various waterbodies has tremendously increased [21-36].

\section{Current water quality challenges in South Florida}

Based on the Perry [37] investigations, the major water quality issues that exist in South Florida include eutrophication (particularly phosphorus), mercury, and contaminants from both agricultural and the urbanized areas. 
Ecosystem restoration of South Florida has been significantly affected by the eutrophication in the Everglades and Lake Okeechobee. Long-term adverse effects on water quality in the Lake Okeechobee were also observed due to the drainage and development of the Everglades watershed. Different land uses, such as livestock farms, dairies, and cattle lands that surround the lake have discharges with high nutrient concentrations and, together with other loads, have degraded water quality. However, state and federal agencies have established a number of restoration programs in order to improve the degraded water quality in Lake Okeechobee, and to control and reduce loading of phosphorus to the lake [37].

Different authorized purposes are considered in the management operations for Lake Okeechobee, its waterways, and the Everglades Agricultural Area (EAA) through a process of decision making. These include many projects, such as flood control, navigation, water supply for urban areas, industry, and agricultural irrigation, the Everglades National Park (ENP), control of regional salinity and groundwater, aquatic life, and recreation purposes. Different constraints including structural, meteorological, environmental, and hydrological conditions are among the important considerations that can restrict the management operations. There are also major physicochemical, legal, political, and social conflicts between authorized purposes in terms of flood control, water supply, environment, navigation and recreation that should be precisely considered in the process of the decision-making to better determine the details of water management operations in Lake Okeechobee [38].

These constraints and conflicts complicate the water management operations and can result in some issues that affect the environment, and specifically the quality of 
riverine and coastal waters. South Florida has several important waterbodies such as estuaries that contain important aquatic life. Discharges of high volumes of nutrient rich freshwater to these vulnerable environments may cause adverse effects on their water quality. Generally, authorities attempt to reduce the impact of high volume lake releases to the estuaries by monitoring the estuaries and make an effort to maintain a balance between different purposes and minimizing negative impacts of high volume lake releases on the estuaries. These include to reduce or make a delay in releases based on the estuaries conditions and also upon the regulations for water quality of these waterbodies mainly controlled by SFWMD, which acts on behalf of the state [38].

However, there are, for instance, a number of recently documented negative effects on the St. Lucie and Caloosahatchee estuarine ecology due to high volume releases from Lake Okeechobee. High volume releases generate changes in salinities that cause long-term negative effects, and also create critically low benthic oxygen situations at the transitional zone between the freshwater and the saltwater. Discharge of sediment rich in nutrients can also cause critical algal bloom growths. As an instance, in June and July 2016 toxic blue-green algae invasion was seen in Martin, St. Lucie, Lee and Palm Beach county beaches and estuaries. It was found that the release of nutrient-rich discharges that contain high levels of phosphorus and nitrogen from the lake into the St. Lucie Estuary in order to prevent flooding was the main cause of algae outbreaks. High water temperatures can also provide ideal conditions for massive, putrid algae blooms to thrive in these vulnerable waterbodies of South Florida [39-41].

Continuous monitoring programs and study the seasonal behavior of these waterbodies to understand the spatiotemporal variations in hydro-chemical and biological 
properties of water may help the decision-makers to better schedule the operational programs for Lake Okeechobee. Data analysis using the more powerful methods like multivariate statistical techniques can give such important information about both spatial and temporal patterns and variability of water quality in the lake. For example, cluster analysis can categorize the sampling sites into different classes based on their level of pollution and also discriminant analysis can help to find the most discriminant variables responsible for the seasonal and spatial variations of water quality parameters among the Lake's monitoring stations. Therefore, it makes the decision-makers and operational management planners to have better strategies for different parts of the lake in different seasons.

Florida Bay is the other important waterbody of South Florida that is a dynamic and biologically productive system that provides unique habitats. Based on the volume of freshwater flow coming from the Everglades, the salinity of Florida Bay varies in different wet and dry seasons. Therefore, in this area, the flow of freshwater from the Everglades determines conditions in Florida Bay. The regular inflow from the Everglades also contains significant amounts of nutrients, which provide the required energy for aquatic organisms, and the constant variation of inflow and sediments discharged into the region make Florida Bay and its surrounding estuaries one of the most biologically productive systems on earth [42].

South Florida has an extensive network of canals that drain water from various agricultural production and urban areas and carry different concentrations of chemicals, especially high concentrations of nutrients. These high concentrations in canals with very low slope may lead to the growth of a number of undesired aquatic plants. Algae blooms 
degrade the quality of these canals in terms of their recreational and aesthetic functions. In addition, dense growth of aquatic plants may contribute to increase the consumption of oxygen in these canals that can result in the death of a number of important aquatic lifeforms, such as like fish, and hence, noxious odors, and health hazards [44].

Due to the oligotrophic nutrient regime of the Everglades, phosphorus is considered as a high priority issue (DOI and USACE, 2005). Also, Lake Okeechobee, which in its upstream areas is surrounded by different types of agricultural production, load phosphorus and nitrogen originated from the upstream agricultural areas to the Everglades even during dry season. Because of these interactions between these two waterbodies, control of nutrient loading to Lake Okeechobee is an essential issue.

\section{Objectives of study}

The overall objective of this dissertation research is to understand the spatiotemporal dynamics of water quality parameters in different water bodies of South Florida. Two approaches (multivariate statistical techniques and remote sensing) were used in this study. A large data matrix obtained during 15 years (2000-2014), monitoring at 16 monitoring sites for 12 water quality parameters, and in two wet and dry seasons (about 35,000 observations) was subjected to different multivariate statistical techniques, including cluster analysis (CA), principal component analysis (PCA), factor analysis (FA), source apportionment analysis (APCS-MLR and PMF receptor modeling techniques), and discriminant analysis (DA) to extract information about:

(a) Classification of monitoring sites based on the level of pollution (CA). 
(b) Identification of discriminant variables responsible for spatiotemporal variations (DA)

(c) Finding the latent factors explaining the structure of the database (PCA).

(d) Exploring the possible sources of pollution (FA).

(e) Estimating the contribution of possible pollution sources (APCS-MLR and PMF).

Hierarchical agglomerative cluster analysis (CA) using Ward's method, as an unsupervised pattern recognition technique, was applied to group the monitoring stations (cases) into classes (clusters) based on their similarities within a class and dissimilarities between different classes in three major rivers of South Florida (Kissimmee River, Caloosahatchee River, and Miami Canal). The results of CA help to interpret the data and indicate patterns. Discriminant analysis (DA), as supervised pattern recognition technique, was employed to the dataset on water quality of three selected rivers of the study area to construct the discriminant functions on two different modes of standard and stepwise, and identify the most significant variables responsible for the spatial and temporal variations in water quality, and to optimize the monitoring program of the study area by decreasing the number of required parameters.

Also, PCA/FA is a technique that reduces the dimensionality of a data set with a large number of interrelated variables, in a manner that minimum original information is lost [45]. PCA/FA is generally used for data structure determination, and to provide qualitative information about potential pollution sources. However, PCA/FA alone cannot determine quantitative contributions of the identified pollution sources to each variable. Receptor-based models, such as APCS-MLR, can be used for this purpose. The 
application of APCS-MLR model was primarily tested for the identification and apportionment of pollution sources in atmospheric environment studies [46]. However, recently its application in water environments has increased [5,8,46-52]. Given the above considerations, the data matrix was subjected to PCA/FA, APCS-MLR, and PMF techniques to (1) identify the latent factors explaining the structure of the database and the influence of possible sources of pollution (natural and anthropogenic) on the water quality parameters, (2) estimate the contribution of possible sources of pollution on the concentration of selected parameters, and (3) comparison of PMF and APCS-MLR models for source apportionment in water quality studies. It is believed that the results of apportionment could be very useful to the local authorities for the control and management of pollution and better protection of important riverine water quality.

Also, the bio-physical parameters associated with water quality of two important waterbodies, Lake Okeechobee and Florida Bay, were investigated based on atmospherically corrected remotely sensed data. The principal objective of this part of the study was to monitor and assess the spatial and temporal changes of water quality using the application of integrated remote sensing, GIS data, and statistical techniques. Spatial and temporal changes of important water quality parameters including total suspended solids (TSS), chlorophyll-a (chl-a), total phosphate, and total kjeldahl nitrogen (TKN) in Lake Okeechobee, and turbidity, chlorophyll-a (chl-a), total phosphate, and total nitrogen (TN) in Florida Bay, were investigated using integrated remote sensing, GIS data, and statistical techniques. The simultaneous observed data of these parameters were obtained from 26 and 20 monitoring stations in Lake Okeechobee and Florida Bay, respectively, and were used for the development and validation of the models. The optical bands in the 
region from blue to near-infrared and all the possible band ratios were used to explore the relation between the reflectance of the waterbody and observed data.

The content of this dissertation is organized as follows.

Chapter II presents a comprehensive review of remote sensing applications in water quality parameter estimation. Various sensors and their capability are discussed. Case studies demonstrating this application are summarized. This chapter was published in Sensors.

Gholizadeh, Mohammad Haji, Assefa M. Melesse, and Lakshmi Reddi. "A Comprehensive Review on Water Quality Parameters Estimation Using Remote Sensing Techniques". Sensors, 16(8), p.1298. doi:10.3390/s16081298.

Chapter III and IV discuss the spatial and temporal changes of water quality parameters in Lake Okeechobee and Florida Bay using integrated remote sensing, GIS data, and statistical techniques. The optical bands in the region from blue to near-infrared and all the possible band ratios were used to explore the relation between the reflectance of the waterbody and observed data. These chapters are in the final stage of submission for publication in the Journal of Remote Sensing and Applied Earth Observation and Geoinformation.

Gholizadeh, M.H., Melesse, A.M., Fuentes, H., Tang, W., Sukop, M.C., 2016. Regional Lake Water Quality Assessment Using Remote Sensing: The case study of Lake Okeechobee, Florida, USA. Commentary in preparation for Journal of Remote Sensing.

Gholizadeh, M.H., Melesse, A.M., Fuentes, H., Tang, W., Sukop, M.C., 2016. Study on Spatiotemporal Variability of Water Quality parameters in Florida Bay Using 
Remote Sensing. Commentary in preparation for Applied Earth Observation and Geoinformation.

Chapter V propounds the application of cluster analysis (CA) and discriminant analysis (DA) to assess the water quality and evaluate the spatial and temporal variations in surface water quality of three major rivers of South Florida: the Kissimmee River, Caloosahatchee River, and Miami Canal. This chapter is written based on one published paper in the journal of Hydroinformatics and one under final review process in the CATENA journal.

Gholizadeh, Mohammad Haji, Assefa M. Melesse, and Lakshmi Reddi. "Discriminant Analysis Application in Spatiotemporal Evaluation of Water Quality in South Florida." Journal of Hydroinformatics, p.jh2016023.

Gholizadeh, M.H., and Melesse, A.M., 2016. Assortment of the Surface Water Pollution Regions and Study on Spatiotemporal Variability of Pollution Using Cluster and Discriminant Analyses. CATENA Journal (in review).

Chapter VI more precisely explains the water quality of three major rivers of South Florida and applied the principal component analysis (PCA), factor analysis (FA), and the absolute principal component score-multiple linear regression (APCS-MLR) receptor modeling technique to identify and quantify the potential pollution sources affecting the water quality of these waterbodies. This chapter was published in Science of The Total Environment.

Gholizadeh, Mohammad Haji, Assefa M. Melesse, and Lakshmi Reddi. "Water quality assessment and apportionment of pollution sources using APCS-MLR and PMF 
receptor modeling techniques in three major rivers of South Florida." Science of The Total Environment. 566 (2016): 1552-1567.

\section{References}

1. Carpenter, S.; Caraco, N.; Correll, D. .; Howarth, R. W.; Sharpley, A. N.; Smith, V. H. Nonpoint pollution of surface waters with phosphorus and nitrogen. Ecol. Appl. 1998, 8, 559-568.

2. Jarvie, H. P.; Whitton, B. A.; Neal, C. Nitrogen and phosphorus in east coast British rivers: Speciation, sources and biological significance. Sci. Total Environ. 1998, 210$211,79-109$.

3. Singh, K. P.; Malik, A.; Mohan, D.; Sinha, S. Multivariate statistical techniques for the evaluation of spatial and temporal variations in water quality of Gomti River (India) - A case study. Water Res. 2004, 38, 3980-3992.

4. Vega, M. Assessment of seasonal and polluting effects on the quality of river water by exploratory data analysis. Water Res. 1998, 32, 3581-3592.

5. Singh, K. P.; Malik, A.; Sinha, S. Water quality assessment and apportionment of pollution sources of Gomti river (India) using multivariate statistical techniques--a case study. Anal. Chim. Acta 2005, 538, 355-374.

6. Duan, W.; Takara, K.; He, B.; Luo, P.; Nover, D.; Yamashiki, Y. Spatial and temporal trends in estimates of nutrient and suspended sediment loads in the Ishikari River, Japan, 1985 to 2010. Sci. Total Environ. 2013, 461-462, 499-508.

7. Mustapha, A.; Aris, A. Z. Spatial aspects of surface water quality in the Jakara Basin, Nigeria using chemometric analysis. J. Environ. Sci. Health. A. Tox. Hazard. Subst. Environ. Eng. 2012, 47, 1455-65.

8. Simeonov, V.; Stratis, J. A.; Samara, C.; Zachariadis, G.; Voutsa, D.; Anthemidis, A.; Sofoniou, M.; Kouimtzis, T. Assessment of the surface water quality in Northern Greece. Water Res. 2003, 37, 4119-4124.

9. Juahir, H.; Zain, S. M.; Yusoff, M. K.; Hanidza, T. I. T.; Armi, A. S. M.; Toriman, M. E.; Mokhtar, M. Spatial water quality assessment of Langat River Basin (Malaysia) using environmetric techniques. Environ. Monit. Assess. 2011, 173, 625-641.

10. Shrestha, S.; Kazama, F. Assessment of surface water quality using multivariate statistical techniques: A case study of the Fuji river basin, Japan. Environ. Model. Softw. 2007, 22, 464-475.

11. Singh, S. P.; Sharma, N. K.; Sharma, B. K. Use of clustering to improve the standard of education system. Int. J. Appl. Inf. Syst. 2012, 1, 16-20. 
12. Kowalkowski, T.; Zbytniewski, R.; Szpejna, J.; Buszewski, B. Application of chemometrics in river water classification. Water Res. 2006, 40, 744-752.

13. Wunderlin, A. D.; Díaz, M. D. P.; Amé, M. V.; Pesce, F. S.; Hued, A. C.; Bistoni, M. D. L. Á. Pattern recognition techniques for the evaluation of spatial and temporal variations in water quality. A case study: Suquía River basin (Córdoba-Argentina). Water Res. 2001, 35, 2881-2894.

14. Kim, J.-H.; Kim, R.-H.; Lee, J.; Cheong, T.-J.; Yum, B.-W.; Chang, H.-W. Multivariate statistical analysis to identify the major factors governing groundwater quality in the coastal area of Kimje, South Korea. Hydrol. Process. 2005, 19, 1261-1276.

15. Schaefer, K.; Einax, J. W. Analytical and chemometric characterization of the Cruces River in South Chile. Environ. Sci. Pollut. Res. 2010, 17, 115-123.

16. Xiao, M.; Bao, F.; Wang, S.; Cui, F. Water quality assessment of the Huaihe River segment of Bengbu (China) using multivariate statistical techniques. Water Resour. 2016, $43,166-176$.

17. Muangthong, S.; Shrestha, S. Assessment of surface water quality using multivariate statistical techniques: case study of the Nampong River and Songkhram River, Thailand. Environ. Monit. Assess. 2015, 187, 1-12.

18. Kumar, A. S.; Reddy, A. M.; Srinivas, L.; Reddy, P. M. Assessment of Surface Water Quality in Hyderabad Lakes by Using Multivariate Statistical Techniques, HyderabadIndia. Environ. Pollut. 2014, 4, 14.

19. Bhat, S. A.; Meraj, G.; Yaseen, S.; Pandit, A. K. Statistical assessment of water quality parameters for pollution source identification in Sukhnag stream: an inflow stream of lake Wular (Ramsar Site), Kashmir Himalaya. J. Ecosyst. 2014, 2014.

20. Duan, W.; He, B.; Nover, D.; Yang, G.; Chen, W.; Meng, H.; Zou, S.; Liu, C. Water Quality Assessment and Pollution Source Identification of the Eastern Poyang Lake Basin Using Multivariate Statistical Methods. Sustainability 2016, 8, 133.

21. Alparslan, E.; Aydöner, C.; Tufekci, V.; Tüfekci, H. Water quality assessment at Ömerli Dam using remote sensing techniques. Environ. Monit. Assess. 2007, 1, 391-398.

22. Anding, D.; Kauth, R. Estimation of sea surface temperature from space. Remote Sens. Environ. 1970, 1, 217-220.

23. Brando, V. E.; Dekker, A. G. Satellite hyperspectral remote sensing for estimating estuarine and coastal water quality. IEEE Trans. Geosci. Remote Sens. 2003, 41, 13781387.

24. El-Din, M.; Gaber, A.; Koch, M. Remote Sensing Application for Water Quality Assessment in Lake Timsah, Suez Canal, Egypt. J. Remote 2013. 
25. Giardino, C.; Bresciani, M.; Cazzaniga, I.; Schenk, K.; Rieger, P.; Braga, F.; Matta, E.; Brando, V. E.; Brando, V. E. Evaluation of multi-resolution satellite sensors for assessing water quality and bottom depth of Lake Garda. Sensors (Switzerland) 2014, 14, $24116-24131$.

26. Hadjimitsis, D.; Clayton, C. Assessment of temporal variations of water quality in inland water bodies using atmospheric corrected satellite remotely sensed image data. Environ. Monit. Assess. 2009.

27. Hellweger, F.; Schlosser, P.; Lall, U. Use of satellite imagery for water quality studies in New York Harbor. Estuarine, Coast. 2004.

28. Kondratyev, K.; Pozdnyakov, D. Water quality remote sensing in the visible spectrum. Int. J. 1998.

29. Koponen, S.; Pulliainen, J.; Kallio, K.; Hallikainen, M. Lake water quality classification with airborne hyperspectral spectrometer and simulated MERIS data. Remote Sens. Environ. 2002, 79, 51-59.

30. Maillard, P.; Pinheiro Santos, N. A. A spatial-statistical approach for modeling the effect of non-point source pollution on different water quality parameters in the Velhas river watershed - Brazil. J. Environ. Manage. 2008, 86, 158-170.

31. Morel, A.; Prieur, L. Analysis of variations in ocean color. Limnol. Oceanogr. 1977, $22,709-722$.

32. Pozdnyakov, D.; Shuchman, R.; Korosov, A.; Hatt, C. Operational algorithm for the retrieval of water quality in the Great Lakes. Remote Sens. Environ. 2005, 97, 352-370.

33. Ritchie, J. C.; Zimba, P. V; Everitt, J. H. Remote Sensing Techniques to Assess Water Quality. Photogramm. Eng. Remote Sens. 2003, 69, 695-704.

34. Seyhan, E.; Dekker, A. Application of remote sensing techniques for water quality monitoring. Hydrobiol. Bull. 1986.

35. Usali, N.; Ismail, M. H. Use of remote sensing and GIS in monitoring water quality. J. Sustain. Dev. 2010, 3, 228-238.

36. Wang, X. J.; Ma, T. Application of Remote Sensing Techniques in Monitoring and Assessing the Water Quality of Taihu Lake. Bull. Environ. Contam. Toxicol. 2001, 6, 863-870.

37. Perry, W. B. Everglades restoration and water quality challenges in south Florida. Ecotoxicology 2008, 17, 569-578.

38. U.S. Army Corps of Engineers, Jacksonville District. Central and Southern Florida Project Water Control Plan for Lake Okeechobee and Everglades Agricultural Area. 2008. 
39. Toxic algae water headed to St. Lucie River, Indian River Lagoon | Video http://archive.tcpalm.com/news/indian-river-lagoon/health/toxic-algae-water-headed-tost-lucie-river-indian-river-lagoon--video-ep-1062569817-332475052.html.

40. Here's what you need to know about Florida's toxic algae infestation - Sun Sentinel http://www.sun-sentinel.com/news/sfl-here-s-what-you-need-to-know-about-florida-stoxic-algae-infestation-20160705-story.html.

41. University of Florida scientist: Beach algae, river algae different types http://archive.tcpalm.com/news/indian-river-lagoon/health/martin-county-beaches-stillclosed-although-algae-ocean-subsiding-36434137-1d0c-5a3e-e053-0100007fa9384567441.html.

42. Phirman, D. The Ecology of Florida Bay- Final http://jrscience.wcp.muohio.edu/FieldCourses00/PapersMarineEcologyArticles/TheEcolo gyofFloridaBay-Fi.html.

43. Dorgelo, J.; Sumich, J. L. An Introduction to the Biology of Marine Life 1999.

44. McPherson, B. F.; Hendrix, G. Y.; Klein, H.; Tyus, H. M. The environment of South Florida; a summary report; 1976.

45. Helena, B.; Pardo, R.; Vega, M.; Barrado, E.; Fernandez, J. M.; Fernandez, L. Temporal evolution of groundwater composition in an alluvial aquifer (Pisuerga River, Spain) by principal component analysis. Water Res. 2000, 34, 807-816.

46. Yang, L.; Mei, K.; Liu, X.; Wu, L.; Zhang, M.; Xu, J.; Wang, F. Spatial distribution and source apportionment of water pollution in different administrative zones of WenRui-Tang (WRT) river watershed, China. Environ. Sci. Pollut. Res. 2013, 20, 5341-5352.

47. Chen, H.; Teng, Y.; Yue, W.; Song, L. Characterization and source apportionment of water pollution in Jinjiang River, China. Environ. Monit. Assess. 2013, 185, 9639-9650.

48. Mustaffa, N. I. H.; Latif, M. T.; Ali, M. M.; Khan, M. F. Source apportionment of surfactants in marine aerosols at different locations along the Malacca Straits. Environ. Sci. Pollut. Res. 2014, 21, 6590-6602.

49. Nasir, M. F. M.; Samsudin, M. S.; Mohamad, I.; Awaluddin, M. R. A.; Mansor, M. A.; Juahir, H.; Ramli, N. River water quality modeling using combined principle component analysis (PCA) and multiple linear regressions (MLR): a case study at Klang River, Malaysia. World Appl. Sci. J. 2011, 14, 73-82.

50. Shrestha, S.; Kazama, F.; Nakamura, T. Use of principal component analysis, factor analysis and discriminant analysis to evaluate spatial and temporal variations in water quality of the Mekong River. J. Hydroinformatics 2008, 10, 43. 
51. Su, S.; Li, D.; Zhang, Q.; Xiao, R.; Huang, F.; Wu, J. Temporal trend and source apportionment of water pollution in different functional zones of Qiantang River, China. Water Res. 2011, 45, 1781-1795.

52. Zhao, J.; Xu, Z.; Liu, X.; Niu, C. Source apportionment in the Liao River Basin. China Environ. Sci. 2013, 5, 13. 
CHAPTER II

A COMPREHENSIVE REVIEW ON WATER QUALITY PARAMETERS

ESTIMATION USING REMOTE SENSING TECHNIQUES 


\section{Abstract}

Remotely sensed data can reinforce the abilities of water resources researchers and decision makers to monitor waterbodies more effectively. Remote sensing techniques have been widely used to measure the qualitative parameters of waterbodies (i.e., suspended sediments, colored dissolved organic matter (CDOM), chlorophyll-a, and pollutants). A large number of different sensors on board various satellites and other platforms, such as airplanes, are currently used to measure the amount of radiation at different wavelengths reflected from the water's surface. In this review paper, various properties (spectral, spatial and temporal, etc.) of the more commonly employed spaceborne and airborne sensors are tabulated to be used as a sensor selection guide. Furthermore, this paper investigates the commonly used approaches and sensors employed in evaluating and quantifying the eleven water quality parameters. The parameters include: chlorophyll-a (chl-a), colored dissolved organic matters (CDOM), Secchi disk depth (SDD), turbidity, total suspended sediments (TSS), water temperature (WT), total phosphorus (TP), sea surface salinity (SSS), dissolved oxygen (DO), biochemical oxygen demand (BOD) and chemical oxygen demand (COD).

Keywords: remote sensing; spaceborne sensors; airborne sensors; water quality indicators. 


\section{Introduction}

Over $40 \%$ of the world's population lives in coastal regions and lake or river shores [1], and this proportion is increasing. The coastal area of rivers and other waterbodies are very sensitive environments that any changes in these fragile ecosystems due to anthropogenic activities can endanger the habitats of fish and other aquatic organisms. Similarly, the need for sustainable urban water supplies requires that the quality of existing available water resources as well as their watersheds need to be under continuous monitoring. Besides, the level of treatment required for human consumption, agriculture, animal husbandry and industry necessitates an understanding of the quality of source waters. In this way, at the beginning of the twentieth century, the importance of water quality has to be considered more than ever, and the concentration of chemicals in wastewater and industrial discharges in waterbodies needs to be taken under more precise control $[2,3]$.

Traditional methods include the determination of different physical, chemical, and biological indicators of water quality field sampling and analysing them in the laboratory Although this in-situ measurement offers high accuracy, it is a labour intensive and time consuming process, and hence it is not feasible to provide a simultaneous water quality database on a regional scale [4,5]. Moreover, conventional point sampling methods are not easily able to identify the spatial or temporal variations in water quality which is vital for comprehensive assessment and management of waterbodies. Therefore, these difficulties of successive and integrated sampling become a significant obstacle to the monitoring and management of water quality. 
With advances in space science and the increasing use of computer applications and increased computing powers over recent decades, remote sensing techniques have become useful tools to achieve this goal. Remote sensing techniques make it possible to monitor and identify large scale regions and waterbodies that suffer from qualitative problems in a more effective and efficient manner. The collection of remotely sensed data occurs in digital form and therefore is easily readable in computer processing. Since the 1970 's, remote sensing application to monitor and evaluate the water quality status of various waterbodies has tremendously increased [6-21].

Different space-borne and airborne sensors measure the amount of radiation at various wavelengths that reflects from the water's surface [17]. These reflections can be used directly or indirectly to detect different water quality indicators, such as total suspended solids (TSS), chlorophyll- $a$ concentration, turbidity, salinity, total phosphorus (TP), Secchi disk depth (SDD), Temperature, pH, Dissolved Organic Carbon (DOC), etc. The spectral characteristics of water and contaminant that depends on the hydrological, biological and chemical characteristics of water, etc. [19], are considered as essential factors to monitor and assess the quality of water. The study thus introduces the widely employed spaceborne and airborne sensors in water quality investigations and discusses the utility of remotely sensed techniques in the qualitative assessment of waterbodies. Various properties (spectral, spatial and temporal, etc.) of spaceborne and airborne sensors are tabulated to be used as a sensor selection guide. Finally, based on the literature survey, the study presents a compilation of the various sensors useful in the study of some measurable water quality parameters, and investigates in more detail 
eleven water quality parameters based on the employed approaches to measuring their concentrations.

\section{An overview of water quality assessment and remote sensing}

In-situ data collections are only able to represent point estimations of the quality of water conditions in time and space, and obtaining spatial and temporal variations of quality indices in large waterbodies is almost impossible [18]. Briefly listed below are the most important limitations associated with conventional methods:

1. In-situ sampling and measurements of water quality parameters are labor intensive, time consuming, and costly.

2. Investigation of the spatial and temporal variations and water quality trends in large waterbodies is almost impossible.

3. Monitoring, forecasting, and management of entire waterbodies might be inaccessible, for example due to the topographic situation.

4. Accuracy and precision of collected in-situ data can be questionable due to both field-sampling error and laboratory error.

To overcome these limitations, the use of remote sensing in water quality assessment can be a useful tool. Remote sensing has shown strong capabilities for the monitoring and evaluation of water quality [30]. Many researchers have used the visible the solar spectrum from blue to near infrared region in their studies to find significant correlations between reflection from water surface and physical and biogeochemical constituents, such as turbidity, chlorophyll concentration, and the organic matters and suspended sediments in different waterbodies $[9,10,18,22-30]$. Although the capabilities of remote sensing to assess water quality has been proved by many studies, the 
application of this technique alone without using the traditional samplings and field observations is not sufficiently precise [29]. In other words, to obtain a better insight, an integrated use of remote sensing, in-situ measurements and computer water quality modelling may lead to an increased knowledge of the water quality of water systems. Collaboration between different governmental, federal and private agencies and data sharing is also helpful to increase the data required for regional studies. Kallio [31] has mentioned five advantages of applying remote sensing in compliance with other water quality monitoring programs as below:

1. Gives a synoptic view of the entire waterbody for more effective monitoring of the spatial and temporal variation,

2. Makes it possible to have a synchronized view of the water quality in a group of lakes over a vast region,

3. Provides a comprehensive historical record of water quality in an area and represents trends over time,

4. Prioritizes sampling locations and field surveying times,

Optically active constituents of water that interact with light and change the energy spectrum of reflected solar radiation from waterbodies can be measured using remote sensing [18]. The components, already enumerated in the first section, constitute the majority of important water quality parameters in surface waters. Other parameters include acidity, chemicals, and pathogens, which do not change the spectral properties of reflected light and have no directly-detectable signals, but which may be interpretable and inferable from those detectable water quality parameters with which strong correlations can be found $[18,31]$. 


\section{Spaceborne and airborne sensors for water quality studies}

Observing sensors are divided into two main categories based on the platforms on which they are situated. Airborne sensors are those that are mounted on a platform within the Earth's atmosphere (i.e. a boat, a balloon, a helicopter, or an aircraft), and spaceborne sensors are carried by a spacecraft or satellite to locations outside of the Earth's atmosphere. Understanding the properties of these sensors is necessary to choose an appropriate sensor for the objectives of the study. Therefore, various remote sensing satellites (Table 2.1) and airborne systems (Table 2.2) commonly used in water quality assessments, along with their spectral properties including spatial resolution, spectral bands, and revisit interval are presented. This tabulated information is helpful when designing water quality assessment studies, and can be used for the selection of appropriate sensors among many other available sensors in the market.

Other categories of sensors that have broad applications in oceanographic remotesensing are microwave radiometers (MWR) and synthetic aperture radar (SAR). Passive microwave radiometers can measure wavelengths from sub-millimeter to centimeter. By understanding the physical processes associated with energy emission at these wavelengths, oceanographers can calculate two important water quality parameters, sea surface temperature (SST) and sea surface salinity (SSS). Table 2.3 shows the characteristics of the more commonly used microwave radiometers in oceanography and water quality studies.

Synthetic aperture radar is used to create two or three-dimensional images of objects [32-34], and can be mounted on either an aircraft or spacecraft. Although SARs are widely used for water pollution detection like oil pollution, ocean topography, wind 
speed at the sea surface, and regional ice monitoring, they are not very often applied in water quality studies and measuring water quality parameters.

\section{Water quality investigations through remote sensing techniques}

Water quality study determines the different physicochemical and biological characteristics of waterbodies and investigates the possible pollution sources [20]. Degradation of the quality of water resources may result from waste discharges, pesticides, heavy metals, nutrients, microorganisms, and sediments. Different water quality standards have been developed to aid in checking the extent of water pollution, and consequently to maintain these quality standards. The most commonly measured qualitative parameters of water are detailed in Table 2.4.

The terminology for Case 1 and Case 2 water classifications were first represented by Morel and Prieur [16] and Gordon and Morel [35]. The definition for Case 1 and case 2 waters was updated by Mobley et al. [36] as follows:

I. Case 1 waters are those waters whose optical properties are determined primarily by phytoplankton and related colored dissolved organic matter (CDOM) and detritus degradation products.

II. Case 2 waters are everything else, namely waters whose optical properties are significantly influenced by other constituents such as mineral particles, CDOM, or microbubbles, whose concentrations do not covary with the phytoplankton concentration. 
Table 2.1. List of the commonly used spaceborne sensors in water quality assessments.

\begin{tabular}{|c|c|c|c|c|}
\hline Category & $\begin{array}{l}\text { Satellite - } \\
\text { sensor }\end{array}$ & $\begin{array}{l}\text { Spectral bands } \\
(\mathrm{nm})\end{array}$ & $\begin{array}{l}\text { Spatial } \\
\text { resolution }(\mathrm{m})\end{array}$ & $\begin{array}{l}\text { Revisit } \\
\text { interval (Day) }\end{array}$ \\
\hline \multirow{9}{*}{$\begin{array}{l}\text { High } \\
\text { resolution }\end{array}$} & $\begin{array}{l}\text { Digital Globe } \\
\text { WorldView-1 }\end{array}$ & Pan & 0.5 & 1.7 \\
\hline & $\begin{array}{l}\text { Digital Globe } \\
\text { WorldView-2 }\end{array}$ & 8 (400-1040)-1 Pan ( 450-800) & $1.85-0.46$ & 1.1 \\
\hline & $\begin{array}{c}\text { NOAA } \\
\text { WorldView-3 }\end{array}$ & $\begin{array}{l}8 \text { (400-1040)-1 Pan( 450-800)- } 8 \text { SWIR (1195 - } \\
2365)\end{array}$ & $1.24-3.7-0.31$ & $1-4.5$ \\
\hline & $\begin{array}{c}\text { Digital Globe } \\
\text { Quickbird }\end{array}$ & 4 (430-918)-1 Pan (450-900) & $2.62-0.65$ & 2.5 \\
\hline & $\begin{array}{l}\text { GeoEye } \\
\text { Geoeye-1 }\end{array}$ & 4 (450-920)-1 Pan (450-800) & $1.65-0.41$ & $<3$ \\
\hline & $\begin{array}{l}\text { GeoEye } \\
\text { IKONOS }\end{array}$ & 4 (445-853)-1 Pan (526-929) & $3.2-0.82$ & $\sim 3$ \\
\hline & $\begin{array}{l}\text { SPOT-5 } \\
\text { HRG }\end{array}$ & $\begin{array}{l}3 \text { (500-890)-1 Pan (480-710) -1 SWIR (1580- } \\
1750)\end{array}$ & 2.5 and $5-10-20$ & $2-3$ \\
\hline & CARTOSAT & Pan (500-850) & 2.5 & 5 \\
\hline & $\begin{array}{c}\text { ALOS } \\
\text { AVNIR-2 } \\
\end{array}$ & $4(420-890)-1$ Pan $(520-770)$ & $2.5-10$ & 2 \\
\hline \multirow{9}{*}{$\begin{array}{l}\text { Moderate } \\
\text { resolution }\end{array}$} & $\begin{array}{l}\text { Landsat-8 } \\
\text { OLI/TIRS }\end{array}$ & $\begin{array}{l}5 \text { (430-880)- 1Pan (500-680)- 2SWIR (1570- } \\
2290)-1 \text { cirrus cloud detection (1360-1380)- } \\
\text { 2TIRS (10600-12510) }\end{array}$ & $30-15-100$ & 16 \\
\hline & $\begin{array}{c}\text { Landsat-7 } \\
\text { ETM+ }\end{array}$ & $\begin{array}{l}6(450-1750)-1 \text { Pan (520-900) -1 (2090-2350)-1 } \\
(1040-1250)\end{array}$ & $30-15-60$ & 16 \\
\hline & $\begin{array}{l}\text { Landsat-5 } \\
\text { TM }\end{array}$ & $5(450-1750)-1(2080-2350)-1(1040-1250)$ & $30-120$ & 16 \\
\hline & $\begin{array}{l}\text { Landsat-5 } \\
\text { MSS }\end{array}$ & 4 (450-1750)-1Pan (1040-1250) & 80 & 18 \\
\hline & $\begin{array}{c}\text { EO-1 } \\
\text { Hyperion }\end{array}$ & $242(350-2570)$ & 30 & 16 \\
\hline & $\begin{array}{r}\text { EO-1 } \\
\text { ALI }\end{array}$ & 9(433-2350)-1 Pan (480-690) & $10-30$ & 16 \\
\hline & $\begin{array}{c}\text { Terra } \\
\text { ASTER } \\
\end{array}$ & $\begin{array}{l}\text { 3VNIR (520-860)-6SWIR(1600-2430)- } \\
\text { 5TIR(8125-11650) }\end{array}$ & $15-30-90$ & 16 \\
\hline & PROBA & 19 in the VNIR range (400 - 1050) & $18-36$ & 7 \\
\hline & $\mathrm{HICO}$ & $128(350-1080)$ & 100 & 10 \\
\hline \multirow{9}{*}{$\begin{array}{l}\text { Regional- } \\
\text { global } \\
\text { resolution }\end{array}$} & $\begin{array}{c}\text { Terra } \\
\text { MODIS }\end{array}$ & $\begin{array}{l}2(620-876)-5 \text { (459-2155) -29 (405-877and } \\
\text { thermal) }\end{array}$ & $250-500-1000$ & $1-2$ \\
\hline & $\begin{array}{l}\text { Envisat-1 } \\
\text { MERIS }\end{array}$ & $15(390-1040)$ & $300-1200$ & daily \\
\hline & $\begin{array}{l}\text { OrbView-2 } \\
\text { SeaWiFS }\end{array}$ & $8(402-885)$ & 1130 & 16 \\
\hline & $\begin{array}{l}\text { NIMBUS-7 } \\
\text { CZCS }\end{array}$ & $6(433-12500)$ & 825 & 6 \\
\hline & $\begin{array}{l}\text { ERS-1 } \\
\text { ATSR-1 }\end{array}$ & $\begin{array}{l}1 \text { SWIR (1600), } 1 \text { MWIR (3700), } 2 \text { TIR (10850 } \\
-12000), \text { Nadir-viewing Microwave } \\
\text { Sounder with channels at } 23.8 \text { and } 35.6 \mathrm{GHz}\end{array}$ & $\begin{array}{l}1000(\mathrm{MW} \\
\text { sounder: } 20 \\
\mathrm{~km})\end{array}$ & $3-6$ \\
\hline & $\begin{array}{c}\text { ERS-2 } \\
\text { ATSR-2 }\end{array}$ & $\begin{array}{l}3 \text { VIS - NIR (555- 865), } 1 \text { SWIR (1600), } 1 \\
\text { MWIR (3700), } 2 \text { TIR (10850 - 12000) }\end{array}$ & 1000 & $3-6$ \\
\hline & $\begin{array}{l}\text { ENVISAT } \\
\text { AATSR }\end{array}$ & $\begin{array}{l}3 \text { VIS - NIR (555- 865), } 1 \text { SWIR (1600), } 1 \\
\text { MWIR (3700), TIR (10850 - 12000) }\end{array}$ & 1000 & $3-6$ \\
\hline & $\begin{array}{l}\text { Suomi NPP } \\
\text { VIIRS }\end{array}$ & $\begin{array}{l}5 \text { I-bands (640-1145), } 16 \text { M-bands (412- } \\
12013) \text {, DNB (500-900) }\end{array}$ & $375-750$ & $\begin{array}{l}\text { 1-2 times a } \\
\text { day }\end{array}$ \\
\hline & $\begin{array}{l}\text { NOAA-16 } \\
\text { AVHRR }\end{array}$ & $6(650-1230)$ & $1100-4000$ & 9 \\
\hline
\end{tabular}


Table 2.2. Specification of the more commonly used airborne sensors in water quality assessments.

\begin{tabular}{|c|c|c|c|c|c|c|c|}
\hline $\begin{array}{l}\text { Types of } \\
\text { sensors }\end{array}$ & Full name & Type & $\begin{array}{c}\text { Scan } \\
\text { system }\end{array}$ & Number of bands & Spectral range $[\mu \mathrm{m}]$ & $\begin{array}{l}\text { Resolution } \\
\text { (m) }\end{array}$ & $\begin{array}{l}\text { Imaging } \\
\text { swath }\end{array}$ \\
\hline AVIRIS & $\begin{array}{l}\text { Airborne Visible } \\
\text { Infrared Imaging } \\
\text { Spectrometer } \\
\end{array}$ & Hyperspectral & Whiskbroom & 224 & $0.40-2.50$ & 17 & $\begin{array}{l}12 \mathrm{~km} \text { and } 614 \\
\text { pixels per } \\
\text { scanline }\end{array}$ \\
\hline HYDICE & $\begin{array}{l}\text { Hyperspectral Digital } \\
\text { Imagery Collection } \\
\text { Experiment }\end{array}$ & Hyperspectral & Pushbroom & 210 & $0.40-2.50$ & 0.8 to 4 & $\begin{array}{l}270 \mathrm{~m} \text { at } \\
\text { the lowest } \\
\text { altitude }\end{array}$ \\
\hline HyMap & $\begin{array}{c}\text { in the U.S. known as } \\
\text { PROBE-1 }\end{array}$ & Hyperspectral & Whiskbroom & 128 & $0.40-2.50$ & 3 to 10 & 512 pixels \\
\hline APEX & $\begin{array}{c}\text { Airborne Prism } \\
\text { Experiment }\end{array}$ & Hyperspectral & Pushbroom & $\begin{array}{c}\text { Up to } 300 \text { VIS/NIR (114), } \\
\text { SWIR (199) }\end{array}$ & $\begin{array}{c}\text { VIS/NIR (0.38-0.97), SWIR1 } \\
(0.97-2.50)\end{array}$ & 2 to 5 & $2.5-5 \mathrm{~km}$ \\
\hline CASI-1500 & $\begin{array}{c}\text { Compact Airborne } \\
\text { Spectrographic Imager }\end{array}$ & Hyperspectral & Pushbroom & Up to 228 & $0.40-1.00$ & 0.5 to 3 & $\begin{array}{l}512 \text { pixels } \\
\text { per scanline }\end{array}$ \\
\hline EPS-H & $\begin{array}{c}\text { Environmental } \\
\text { Protection System }\end{array}$ & Hyperspectral & Whiskbroom & $\begin{array}{l}\text { VIS/NIR (76), SWIR1 (32), } \\
\text { SWIR2 (32), TIR (12) }\end{array}$ & $\begin{array}{c}\text { VIS/NIR (0.43-1.05), SWIR1 } \\
(1.50-1.80), \text { SWIR2 (2.00-2.50), } \\
\text { TIR (8-12.50) }\end{array}$ & $\begin{array}{l}\text { Dependent } \\
\text { upon flight } \\
\text { (minimum } \\
1 \mathrm{~m} \text { ) }\end{array}$ & 89 degrees \\
\hline DAIS 7915 & $\begin{array}{l}\text { Digital Airborne } \\
\text { Imaging Spectrometer }\end{array}$ & Hyperspectral & Whiskbroom & $\begin{array}{l}\text { VIS/NIR (32), SWIR1 (8), } \\
\text { SWIR2 (32), MIR (1), TIR } \\
\text { (12) }\end{array}$ & $\begin{array}{c}\text { VIS/NIR (0.43-1.05), SWIR1 } \\
(1.50-1.80), \text { SWIR2 (2.00-2.50), } \\
\text { MIR (3.00-5.00), TIR (8.70- } \\
12.30)\end{array}$ & $\begin{array}{l}3 \text { to } 20 \\
\text { depending on } \\
\text { altitude }\end{array}$ & $\begin{array}{l}512 \text { pixels } \\
\text { per scanline }\end{array}$ \\
\hline AISA & $\begin{array}{l}\text { Airborne Imaging } \\
\text { Spectrometer }\end{array}$ & Hyperspectral & Pushbroom & Up to 288 & $0.43-0.90$ & 1 & $\begin{array}{c}364 \text { pixels } \\
\text { per scanline }\end{array}$ \\
\hline MIVIS & $\begin{array}{c}\text { Multispectral Infrared } \\
\text { and Visible Imaging } \\
\text { Spectrometer }\end{array}$ & Multispectral & Whiskbroom & $\begin{array}{l}102 \text { VIS/NIR (28), MIR } \\
\text { (64),TIR (10) }\end{array}$ & $\begin{array}{l}\text { VIS (0.43-0.83), NIR (1.15-1.55), } \\
\text { MIR (2.0-2.5) TIR (8.2-12.7) }\end{array}$ & $\begin{array}{c}3 \text { to } 8 \\
\text { depending on } \\
\text { altitude }\end{array}$ & $\begin{array}{l}5.6 \mathrm{~km} \text { at at } \\
4000 \text { meters } \\
\text { altitude }\end{array}$ \\
\hline Daedalus & $\begin{array}{c}\text { Daedalus Multispectral } \\
\text { Scanner (MSS) } \\
\end{array}$ & Multispectral & Pushbroom & $\begin{array}{c}12 \text { VIS/NIR (8), SWIR } \\
(2), \text { TIR (2) }\end{array}$ & $0.42-14.00$ & 25 & $\begin{array}{c}714 \text { pixels } \\
\text { per scanline }\end{array}$ \\
\hline $\begin{array}{c}\text { HySpex } \\
\text { ODIN-1024 }\end{array}$ & $\begin{array}{l}\text { HySpex hyperspectral } \\
\text { cameras }\end{array}$ & Hyperspectral & Pushbroom & $\begin{array}{c}\text { VIS/NIR1 (128), } \\
\text { VIS/NIR2 (160),SWIR1 }\end{array}$ & $0.40-2.50$ & $\begin{array}{l}0.5 \mathrm{~m} \mathrm{at} \\
2000 \mathrm{~m}\end{array}$ & $500 \mathrm{~m}$ \\
\hline
\end{tabular}


Table 2.3. Characteristics of the more commonly used microwave radiometers in oceanography and water quality studies.

\begin{tabular}{|c|c|c|c|c|c|}
\hline satellite & sensor & Frequency (GHz) & $\begin{array}{l}\text { Spatial resolution } \\
\qquad(\mathbf{k m})\end{array}$ & $\begin{array}{c}\text { Swath } \\
\text { width }(\mathrm{km})\end{array}$ & Purpose \\
\hline Nimbus-5 & ESMR & 19.4 & 25 for all Channels & 3000 & SST \\
\hline Nimbus-7 & SMMR & $\begin{array}{c}6.6,10.7,18.0,21.0, \\
\text { and } 37.0\end{array}$ & 25 for all Channels & 800 & SST \\
\hline SEASAT & SMMR & $\begin{array}{c}6.6,10.7,18.0,21.0, \\
\text { and } 37.1\end{array}$ & $\begin{array}{c}22 \text { at } 37.1 \mathrm{GHz} \text { to } \\
100 \text { at } 6.6 \mathrm{GHz}\end{array}$ & 600 & SST \\
\hline $\begin{array}{l}\text { Priroda- } \\
\text { MIR }\end{array}$ & IKAR-P & $5.0,13.3$ & 75 for all Channels & 750 & SST \\
\hline POEM-1 & MIMR & $\begin{array}{c}6.8,10.7,18.7,23.8, \\
36.5, \text { and } 90.0 \\
\end{array}$ & $\begin{array}{c}4.8 \times 3.1 \text { at } 90 \mathrm{GHz} \text { to } \\
60 \times 40 \text { at } 6.8 \mathrm{GHz}\end{array}$ & 1400 & SST \\
\hline EOS PM-1 & MIMR & $\begin{array}{c}6.8,10.7,18.7,23.8 \\
36.5, \text { and } 90.0\end{array}$ & $\begin{array}{c}4.8 \times 3.1 \text { at } 90 \mathrm{GHz} \text { to } \\
60 \times 40 \text { at } 6.8 \mathrm{GHz}\end{array}$ & 1400 & SST \\
\hline TRMM & TMI & $\begin{array}{c}10.7,19.4,21.3,37.0 \\
\text { and } 85.5\end{array}$ & $\begin{array}{l}8 \times 6 \text { at } 85.5 \mathrm{GHz} \text { to } \\
72 \times 43 \text { at } 10.7 \mathrm{GHz}\end{array}$ & 760 & SST \\
\hline ADEOS-2 & AMSR & $\begin{array}{l}6.9,10.7,18.7,23.8 \\
36.5,50.2,53.8,89.0\end{array}$ & $\begin{array}{l}6 \times 3 \text { at } 89 \mathrm{GHz} \text { to } \\
70 \times 40 \text { at } 6.9 \mathrm{GHz}\end{array}$ & 1600 & SST \\
\hline AQUA & AMSR-E & $\begin{array}{c}6.9,10.7,18.7,23.8, \\
36.5, \text { and } 89.0 \\
\end{array}$ & $\begin{array}{c}6 \times 4 \text { at } 89.0 \mathrm{GHz} \text { to } \\
75 \times 43 \text { at } 6.9 \mathrm{GHz}\end{array}$ & 1450 & SST \\
\hline GCOM-W1 & AMSR-2 & $\begin{array}{c}6.9,7.3,10.7,18.7, \\
23.8,36.5, \text { and } 89.0\end{array}$ & $\begin{array}{c}5 \times 3 \text { at } 89.0 \mathrm{GHz} \text { to } \\
62 \times 35 \text { at } 6.9 \mathrm{GHz}\end{array}$ & 1450 & SST \\
\hline GPM & GMI & $\begin{array}{c}10.7,18.7,23.8,36.5 \\
89.0,166.0, \text { and } 183.3\end{array}$ & $\begin{array}{c}7.2 \times 4.4 \text { at } 183.3 \\
\mathrm{GHz} \text { to } 32 \times 19 \text { at } \\
10.7 \mathrm{GHz}\end{array}$ & 850 & SST \\
\hline Coriolis & WindSat & $\begin{array}{c}6.8,10.7,18.7,23.8, \\
\text { and } 37.0\end{array}$ & $\begin{array}{l}13 \times 8 \text { at } 6.8 \mathrm{GHz} \text { to } \\
71 \times 39 \text { at } 37.0 \mathrm{GHz}\end{array}$ & 1000 & SST \\
\hline SAC-D & Aquarius & 1.413 & 100 for all Channels & 390 & SSS-SST \\
\hline SMOS & MIRAS & 1.413 & 50 for all Channels & 1000 & SSS \\
\hline Airborne & ESTAR & 1.413 & 100 for all Channels & 600 & SSS \\
\hline Airborne & PALS & 1.413 & $0.350-1$ & 16 & SSS-SST \\
\hline Airborne & $\begin{array}{l}\text { 2D- } \\
\text { STAR }\end{array}$ & 1.413 & $\begin{array}{c}0.800 \text { for all } \\
\text { Channels }\end{array}$ & 10 & SSS \\
\hline Airborne & SLFMR & 1.413 & $0.5-1$ & $\begin{array}{l}\text { Twice the } \\
\text { altitude }\end{array}$ & SSS \\
\hline Airborne & STARRS & $\begin{array}{c}\text { L-Band: } 1.413, \\
\text { C-Band: } 5.2,5.6,5.9, \\
6.2,6.6 \text { and } 7.1, \\
\text { IR radiometer: } 8-14 \\
\text { and } 9.6-11.5 \text { micron. }\end{array}$ & 1 for all Channels & 5.2 & SSS-SST \\
\hline
\end{tabular}


Table 2.4. The most commonly measured qualitative parameters of water by means of remote sensing.

\begin{tabular}{ccccc}
\hline Water Quality Parameter & Abbreviation & Units & Optical Activity & References \\
\hline chlorophyll- $a$ & CHL- $a$ & $\mathrm{mg} / \mathrm{L}$ & Active & {$[10,37-39]$} \\
Secchi Disk Depth & $\mathrm{SDD}$ & $\mathrm{m}$ & Active & {$[40-43]$} \\
Temperature & $\mathrm{T}$ & ${ }^{\circ} \mathrm{C}$ & Active & {$[44-47]$} \\
Colored Dissolved Organic Matters & $\mathrm{CDOM}$ & $\mathrm{mg} / \mathrm{L}$ & Active & {$[10,48-50]$} \\
Total Organic Carbon & $\mathrm{TOC}$ & $\mathrm{mg} / \mathrm{L}$ & Active & {$[51-53]$} \\
Dissolved Organic Carbon & $\mathrm{DOC}$ & $\mathrm{mg} / \mathrm{L}$ & Inactive & {$[54-56]$} \\
Total Suspended Matters & $\mathrm{TSM}$ & $\mathrm{mg} / \mathrm{L}$ & Active & {$[57-60]$} \\
Turbidity & $\mathrm{TUR}$ & $\mathrm{NTU}$ & Active & {$[61-63]$} \\
Sea Surface Salinity & $\mathrm{SSS}$ & $\mathrm{PSU}$ & Active & {$[64-67]$} \\
Total Phosphorus & $\mathrm{TP}$ & $\mathrm{mg} / \mathrm{L}$ & Inactive & {$[29,37,68-70]$} \\
Ortho-Phosphate & $\mathrm{PO} 4$ & $\mathrm{mg} / \mathrm{L}$ & Inactive & {$[71]$} \\
Chemical Oxygen Demand (COD) & $\mathrm{COD}$ & $\mathrm{mg} / \mathrm{L}$ & Inactive & {$[72-75]$} \\
Biochemical Oxygen Demand & $\mathrm{BOD}$ & $\mathrm{mg} / \mathrm{L}$ & Inactive & {$[63,76-78]$} \\
Electrical Conductivity & $\mathrm{EC}$ & $\mu \mathrm{c} / \mathrm{cm}$ & Active & {$[79-81]$} \\
Ammonia Nitrogen & $\mathrm{NH}-\mathrm{N}$ & $\mathrm{mg} / \mathrm{L}$ & Inactive & {$[74,82,83]$} \\
\hline
\end{tabular}

Remote sensing techniques make it possible to have spatiotemporal view of surface water quality and more effectively monitor the waterbodies, and quantify water quality issues. Most of the studies have focused on optically active variables, such as chlorophyll- $a$ (chl- $a$ ), total suspended solids (TSS), and turbidity. There are several other important water quality variables such as $\mathrm{pH}$, total nitrogen (TN), ammonia nitrogen $(\mathrm{NH} 3-\mathrm{N})$, nitrate nitrogen (NO3--N), and dissolved phosphorus (DP), which existing literature omit. The main reason is due to their weak optical characteristics and low signal noise ratio. However, these parameters are an important part of water quality indices and are a challenging aspect of research in the field of water quality assessment using remote sensing, which should stimulate and motivate scientists in further efforts. In continuing, the study precisely surveys the more commonly employed approaches in estimating the concentration of the eleven water quality parameters. These water quality indicators 
include chlorophyll- $a$ (chl- $a$ ), colored dissolved organic matters (CDOM), Secchi disk depth (SDD), turbidity, total suspended sediments (TSS), water temperature (WT), total phosphorus (TP), sea surface salinity (SSS), dissolved oxygen (DO), biochemical oxygen demand (BOD) and chemical oxygen demand (COD).

\subsection{Chlorophyll-a}

Chl- $a$ is used in oxygenic photosynthesis and is found in plants, algae and cyanobacteria. Chl- $a$ is the major indicator of trophic state because it acts as a link between nutrient concentration, particularly phosphorus, and algal production. Chl$a$ while mainly reflecting green, absorbs most energy from wavelengths of violet-blue and orange-red light, whose reflectance causes chlorophyll to appear green. The addition of chl-b besides chl- $a$ extends the absorption of spectrum. Low light conditions increases the photosynthetic yield as it tends to favor the production of chl-b to chl- $a$ molecules [84]. Figure 2.1 shows the absorption spectrum of both chl- $a$ and chl-b pigments. Many researchers have demonstrated that increasing chl- $a$ concentration causes a decrease in the spectral response at short wavelengths, particularly in the blue band [85-90]. A large number of studies have focused on chl- $a$ concentration measurement using remote sensing, some of which are cited in this review paper.

Narrow bands of imagery are required for the measurement of chl- $a$ concentration and its spatiotemporal variations within a waterbody [91]. Several studies showed that the discrimination of chlorophyll in waterbodies with high concentration of suspended sediments is difficult using broad wavelength spectral data available on current satellites (i.e., Landsat, SPOT) [85] due to the dominance of the spectral signal from the suspended sediments [92,93]. 


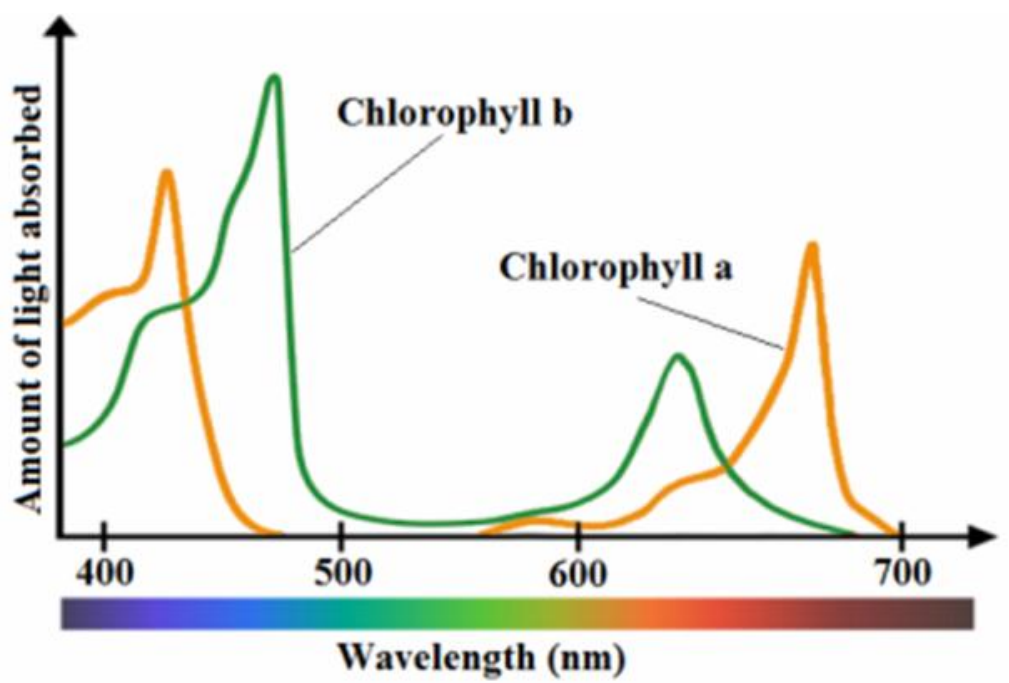

Figure 2.1. The Absorption Spectrum of chl- $a$ and the Chl-b.

Since the late 1970's, bio-optical algorithms have been developed by many researchers for the determination of water quality parameters in oceans [94]. In case 1 waters, by employing an empirical model and interpreting the received radiance at different wavelengths, the concentrations of chl- $a$ can be adequately estimated with satellite images [35]. In Case 1 waters spectral bands in the blue to green region are appropriate to identify chl- $a$ concentrations with acceptable precisions. However, in case 2 waters due to the complexity of the constituents in water, the detection of chl- $a$ is a sophisticated task and requires advanced approaches and techniques. Additionally, the simple fact that Gelbstoff absorption often masks the blue-green region in Case 2 waters implies chl- $a$ algorithms developed for Case 1 waters are not applicable to Case 2 waters [94].

Various visual spectral bands and their ratios are widely used to quantify chl- $a$. Spectral band ratios can assist to reduce irradiance, atmospheric and air-water surface influences and enhance the potential of target detection [85,95]. Strong absorption 
between $450-475 \mathrm{~nm}$ (blue) and at $670 \mathrm{~nm}$ (red) was reported for chl- $a$, which the peak reflectance reaches to around $550 \mathrm{~nm}$ (green) and also near $700 \mathrm{~nm}$ (NIR). Also, various algorithms are developed using the reflectance peak near $700 \mathrm{~nm}$ and its ratio to the reflectance at $670 \mathrm{~nm}$ to retrieve chl- $a$ in turbid waters [23]. Gitelson [96] studied the behavior of the reflectance peak near $700 \mathrm{~nm}$ and found it useful for chl-detection in inland and coastal waters. Han [97] pointed out that the spectral regions at $630-645 \mathrm{~nm}$, $660-670 \mathrm{~nm}, 680-687 \mathrm{~nm}$ and $700-735 \mathrm{~nm}$ are sensitive wavelength ranges to estimate the concentration of chlorophyll. Dekker et al. [98] suggested to use more than one band to estimate chl- $a$ concentrations in order to better understanding the scattering and absorption characteristics of chl- $a$. Hoogenboom et al. [99] used AVIRIS sensor and utilized a band ratio located near $713 \mathrm{~nm}$ along and $667 \mathrm{~nm}$ for chlorophyll estimations in inland waters. Thiemann and Kaufmann [100] used also a similar ratio (R674/R705 for inland lakes and rivers. Table 2.5 shows some of the more commonly used techniques for the measurement of chl- $a$ concentration. 
Table 2.5. Remotely measurements of chl- $a$ using various spectral bands and their ratios.

\begin{tabular}{|c|c|c|c|}
\hline \multicolumn{2}{|c|}{ Band Combination } & Sensor & Reference \\
\hline \multirow{5}{*}{\multicolumn{2}{|c|}{$\begin{array}{l}\text { Ratio between green }(0.50-0.60 \mu \mathrm{m}) \text { and red } \\
\qquad(0.60-0.70 \mu \mathrm{m})\end{array}$}} & Landsat 5-TM & {$[3,12,26,43,101-105]$} \\
\hline & & Landsat 5-MSS & {$[24]$} \\
\hline & & Landsat 7- ETM+ & [106] \\
\hline & & SPOT & [107] \\
\hline & & IRS-LISS-III & {$[72]$} \\
\hline \multirow{6}{*}{\multicolumn{2}{|c|}{ Ratio between near infrared (NIR) and red }} & Landsat 5-TM & [108] \\
\hline & & $\mathrm{HICO}$ & {$[109-111]$} \\
\hline & & PROBA-CHRIS & [112] \\
\hline & & MODIS & {$[22,113,114]$} \\
\hline & & MERIS & [114-116] \\
\hline & & AISA & {$[114,117]$} \\
\hline \multirow{5}{*}{\multicolumn{2}{|c|}{ Ratio between green and blue (B2/B1) }} & Landsat 5-TM & [59] \\
\hline & & Landsat 7- ETM+ & [118] \\
\hline & & MERIS & [119] \\
\hline & & PROBA-CHRIS & [120] \\
\hline & & EO-1 Hyperion & [121] \\
\hline \multirow{2}{*}{\multicolumn{2}{|c|}{$\begin{array}{l}\text { Ratio between blue }(0.40-0.50 \mu \mathrm{m}) \text { and red } \\
\qquad(0.60-0.70 \mu \mathrm{m})\end{array}$}} & Landsat 5-TM & [26] \\
\hline & & Landsat 7- ETM+ & [97] \\
\hline \multirow{6}{*}{ Using a single band } & Blue $(0.40-0.50 \mu \mathrm{m})$ & Landsat 5-TM & {$[11,87,122,123]$} \\
\hline & \multirow{3}{*}{$\operatorname{Red}(0.60-0.70 \mu \mathrm{m})$} & PROBA-CHRIS & [124] \\
\hline & & Landsat 5-TM & {$[85]$} \\
\hline & & CASI & [125] \\
\hline & \multirow{2}{*}{$\begin{array}{c}\text { Green }(0.50-0.60 \\
\mu \mathrm{m})\end{array}$} & Landsat 5-TM & [126] \\
\hline & & $\begin{array}{c}\text { Daedalus Airborne } \\
\text { Thematic Mapper (ATM) }\end{array}$ & [86] \\
\hline
\end{tabular}

Other significant literature that applied other approaches to the measurement of chl- $a$ are considered hereafter. Alparslan et al. [62] measured the concentration of chl- $a$ using all bands of Landsat-5 TM. Ekercin [127] used Band1 (445-530nm), Band2 (520610nm), Band3 (640-720nm), and Band4 (770-880nm) of IKONOS data to estimate chl$a$ concentration in Istanbul, Turkey. Also, Nas et al. [68] used the visible near-infrared (VNIR) and the shortwave infrared (SWIR) (first four bands $0.52-1.70 \mu \mathrm{m}$ ) of Terra/ASTER and developed a multiple regression model to measure chl- $a$ 
concentrations using the spectral reflectance in the Beysehir Lake, Turkey. Shafique et al. [29], using Compact Airborne Spectrographic Imager (CASI) studied the chl-a concentration in the Great Miami River and 80 miles of the Ohio River. They concluded that linear models using the ratio of wavelengths $705 / 675 \mathrm{~nm}$ can be used to measure chl$a$ concentration. Bhatti et al. [41], using Airborne Imaging Spectroradiometer for Applications (AISA) sensor in the Apalachicola Bay in Florida, USA, found that two bands reflectance ratio R70 Other significant literature that applied other approaches to the measurement of chl- $a$ are considered in following. Alparslan et al. [62] measured the concentration of chl- $a$ using all bands of Landsat-5 TM. Ekercin [127] used Band1 (445530nm), Band2 (520-610nm), Band3 (640-720nm), and Band4 (770-880nm) of IKONOS data to estimate chl- $a$ concentration in Istanbul, Turkey. Also, Nas et al. [68] used the visible near-infrared (VNIR) and the shortwave infrared (SWIR) (first four bands 0.52$1.70 \mu \mathrm{m})$ of Terra/ASTER and developed a multiple regression model to measure the concentration of chl- $a$ in the Beysehir Lake, Turkey. Shafique et al. [29], using Compact Airborne Spectrographic Imager (CASI) studied the chl- $a$ concentration in the Great Miami River and 80 miles of the Ohio River. They concluded that linear models using the ratio of wavelengths 705/675 $\mathrm{nm}$ can describe chl- $a$ concentration. Bhatti et al. [41], using Airborne Imaging Spectroradiometer for Applications (AISA) sensor in the Apalachicola Bay in Florida, USA, found a significant correlation between the two bands reflectance ratio R700/R670 and chl- $a$ concentration. Also, the three band model $\mathrm{R} 750 *\left(\mathrm{R} 670^{-1}-\mathrm{R} 700^{-1}\right)$ was found to be a predictor of chl- $a$ concentration in case 2 waters. In addition, the logarithmic ratio of ALOS/AVNIR-2 (band3/band1) was related with chl- $a$ concentration in his study area. Lim and Choi [37] using Landsat-8/OLI 
showed that chl- $a$ presented a good correlation with both OLI bands and band ratio, with calculated $\mathrm{R}$ values for bands $2,3,4$ and band ratio (band 5/band 3) as $-0.66,-0.70$, -0.64 , and -0.64 , respectively, at a significance level of $p<0.01$. Zhang and Han [128] found that OLI bands 1 to 4 and their combinations had good correlation with chl- $a$ concentration. Kim et al. [129] using Landsat-8/OLI employed Band2, Band5, and a ratio of Band2/Band4 to measure chl- $a$ concentration. Mannheim et al. [130] used the spectral bands 8-12 of CHRIS and found the reflectance curve and the baseline from 672 to 742 $\mathrm{nm}$ to be more sensitive for the variations of chl- $a$ concentration. Choe et al. [131] used MODIS, SeaWiFS, MERIS, and RapidEye data for the estimation of chl- $a$ concentration in turbid waters using Two-band and Three-band.

Furthermore, Qi et al. [132] developed an approach based on Empirical Orthogonal Function (EOF) analysis to estimate chl-a concentration in surface waters of Taihu Lake, China. They used the EOF approach and MODIS to analyze the spectral variance of normalized Rayleigh-corrected reflectance $(\mathrm{Rrc})$ data at various wavelengths of $469,555,645$, and $859 \mathrm{~nm}$, and also used field measurements to measure chl- $a$ concentrations. Feng et al. [133] using a normalized green-red difference index (NGRDI) and MERIS data developed an empirical algorithm for the measurement of chl- $a$ in Poyang Lake, China.

Reviewing the literature showed that the majority of the algorithms that have been developed to determine the chl- $a$ are based on the wavelength near $675 \mathrm{~nm}$ and near 700 nm [94]. As mentioned, several satellite and airborne imageries can be used for chl- $a$ estimation. Nonetheless, it revealed that the Landsat TM seems to be more appropriate 
and widely used for chl- $a$ assessment. Temporal coverage and spatial resolution of TM and its easy accessibility can be the main reasons for the selection of this sensor.

\subsection{Colored dissolved organic matters (CDOM)}

Colored Dissolved Organic Matters, which are also called gelbstoff and gilvin, consists of heterogeneous organic substances that their color varies from yellow to brown based on their concentrations. CDOM exists in both fresh and saline waters. These compounds can color the water in a range from brown to yellowish brown based on their concentrations (yellowish brown in high concentrations) [134]. Therefore, they are referred to as yellow matter or colored dissolved organic matter (CDOM), and usually with chl- $a$ and TSS dominate the water color [41].

CDOM absorbance spectrum accounts for the majority of the total absorption at $443 \mathrm{~nm}$, which is usually used to measure chlorophyll concentrations, and can be several times and overlaps the chlorophyll absorption [135]. The increase in the CDOM concentration mainly affects the reflectance values in the blue and green region of the spectrum (especially below $\sim 500 \mathrm{~nm}$ ) and its absorbance increases exponentially with decreasing wavelength [113]. This effect makes the retrieval algorithms for chl- $a$ and phytoplankton production to be more complicated [136]. Nonetheless, it is reported by Strömbeck and Pierson [137] that at high CDOM concentrations, absorbance of red light spectrum can be significant.

Remote sensing of CDOM is important in studying aquatic ecology and carbon dynamics $[18,138]$. Existence of CDOM in any water body affects the water color as seen by many instruments, such as MODIS and SeaWiFS [139]. CDOM also affects the 
underwater light field and water's inherent optical properties (IOP). This characteristic determines the water reflectance received by remote sensors. Inversion of remote sensing data can be an effective way for the estimation of CDOM concentrations and to investigate its spatiotemporal variation in a large scale $[140,141]$. In ocean color studies, the absorption properties of CDOM like its absorption coefficients at $440 \mathrm{~nm}$, are usually considered as CDOM concentration [142]. Some researchers have empirically inverted the chl- $a$ concentrations in the algorithms derived from sensors like CZCS, and based on that CDOM can be measured with the assumption that it co-varies with chlorophyll $[16,35,143]$. Hyperspectral measurements with newly developed remote sensing reflectance models [145-146] have also been used to estimate CDOM as one of ocean color components, such as EO-1 Hyperion with MIM (Matrix Inversion Method) [8]. Kutser et al. [145] also used band ratio of EO-1/ALI band 2 and band 3 to estimate CDOM content in lakes of Southern Finland.

A combination of hyperspectral remote sensing data, new factors like the bottom effects, and semi-analytical models have enhanced the accuracy of CDOM estimations [50]. Traditionally, in most water quality monitoring programs, PCU color (PlatinumCobalt Units) is used to characterize the CDOM inversions and its absorption [50]. Semianalytical models have been developed and applied to SeaWiFS and, in which CDOM's absorption coefficients are directly and independently inverted from remote sensing reflectance (Rrs) [50]. The radiative transfer equations and the simplification of radiance and underwater light field are the major basis of semi-analytical models [141]. As spectral signals of CDOM usually interfere with chlorophyll and suspended sediments, 
remote sensing of $\mathrm{CDOM}$ in rivers and coastal waters compared to oceanic waters is challenging and subject to large errors $[55,146]$.

In coastal waters high spectral resolution at $10 \mathrm{~nm}$ or better can improve the estimation of IOP $[8,148,149]$. However, as mentioned, due to the spectral signal interference from chlorophyll, suspended sediments as well as spatial and temporal heterogeneity of riverine and coastal waters, the applicable bands for CDOM measurement are not always at the same wavelengths [147]. Therefore, identification of significant wavelengths out of hundreds of narrow bands of hyperspectral reflectance is a challenging task [56]. As a solution, first, the dimensionality of hyperspectral data should be reduced through techniques such as band selection, derivative analysis, spectral indices, or hyperspectral transformation [121,150-152]. Calibration and validation of the remotely-sensed CDOM is required using the field measurement data. Additionally, CDOM is reported to be responsible for the dynamics of dissolved organic carbon (DOC) in different waterbodies [147] and many observations have provided evidence that CDOM is correlated to DOC [55,153-157]. Reviewing the literature revealed that most of the studies are based on four sections: underwater CDOM measurements, in situ hyperspectral measurements, water-surface reflected radiance by means of remote sensor on a satellite or an airborne platform, and functional data analysis $[50,147]$. The literature showed that CDOM could be quantified using visual spectral bands and their ratios, which is as summarized in table 2.6. 
Table 2.6. Remotely measurements of CDOM using various spectral bands and their ratios

\begin{tabular}{lll}
\hline Spectral bands & Sensor & Reference \\
\hline \multirow{4}{*}{$\begin{array}{l}\text { Single blue band }(0.40-0.50 \\
\mu \mathrm{m})\end{array}$} & Landsat 5-TM & {$[43]$} \\
\cline { 2 - 3 } & EO-1 Hyperion & {$[121]$} \\
\cline { 2 - 3 } & SeaWIFS+MODIS-Aqua & {$[158]$} \\
\cline { 2 - 3 } & MODIS & {$[159,160]$} \\
\cline { 2 - 3 } & SeaWIFS & {$[49,161,162]$} \\
\cline { 2 - 3 } & HICO & {$[48]$} \\
\cline { 2 - 3 } & CZCS & {$[163]$} \\
\hline Ratio between blue $(0.40-0.50$ & ALOS-AVNIR-2 & {$[57]$} \\
\cline { 2 - 3 }$)$ and green $(0.50-0.60 \mu \mathrm{m})$ & MODIS & {$[164]$} \\
\cline { 2 - 3 } & SeaWiFS & {$[165-168]$} \\
\cline { 2 - 3 } $\begin{array}{l}\text { Ratio between green }(0.50-0.60 \\
\mu \mathrm{m}) \text { and red }(0.60-0.70 \mu \mathrm{m})\end{array}$ & HICO & {$[111]$} \\
\cline { 2 - 3 } & EO-1 ALI & {$[145,169,170]$} \\
\cline { 2 - 3 } & EO-1 Hyperion & {$[171]$} \\
\cline { 2 - 3 } & SeaWiFS & {$[172]$} \\
\hline
\end{tabular}

Furthermore, Taheri Shahraiyni et al. [173] by using reflectance values at 490, 510, 560, 620, and $885 \mathrm{~nm}$ of MERIS data and applying a fuzzy modeling technique, Active Learning Method (ALM), mapped the spatial distribution of CDOM over the southern parts of the Caspian Sea, Iran. A proxy algorithm was reported for remote sensing of CDOM by an absorption coefficient of ocean water, which is a multi-band quasi-analytical algorithm (QAA) developed by Lee et al. [140]. Further, alternative algorithms such as computer-based discrete modelling methods are developed to estimate the concentrations of CDOM [147]. However, Kishino et al. [174] expressed that results can be questionable when a neural network model is implemented to measure the CDOM concentration using ASTER data. Johannessen et al. [175] using SeaWiFS images found out a relationship between ultraviolet (UV) attenuation coefficient (Kd) at $323 \mathrm{~nm}, 338$ $\mathrm{nm}$, and $380 \mathrm{~nm}$ and the $\operatorname{Rrs}(412) / \operatorname{Rrs}(555)$ band ratio. 
Researchers use many sensors to assess CDOM, but SeaWIFS and MODIS, because of their coarse spatial resolution, were widely applied in deep waters. Due to the need for high accuracy for large-scale applications, SeaWiFS data are of little use in shallow waters and hyperspectral imagery like EO-1/Hyperion, EO-1/ALI, and ALOS/AVNIR-2 were preferable for these areas. In addition, a majority of researchers have used a high-resolution spectroradiometer in their in situ hyperspectral measurements to validate their quantified results. These data are useful in identifying concentrations of components within the water column and can be collected above and below the water surface [22]. They are also useful for calibration and validation of remotely sensed estimations of water quality parameters.

\subsection{Secchi disk depth}

Secchi disk depth is considered as an important optical property of water, which is strongly related to a number of water constituents [57]. The Secchi depth exhibits an inverse correlation with the amount of total suspended solids (TSS) present in the waterbodies. For example, it can be used to investigate the nutrient concentrations and solids loading situations [176]. The most commonly attempted method for the measurement of water transparency is based on light attenuation principles [141]. The best-known operational estimation of water transparency is the Secchi disk, created by Pietro Angelo Secchi SJ in 1865, and is a circular disk used for clarity measurements in oceans and lakes. The disc mounts on a line and lowers slowly down in the water until the pattern on the disk is no longer visible. It is known as the Secchi disk depth (SDD) and is also considered in the water quality studies as a measure of water turbidity. Figure 2.2 shows two different types of Secchi disks. 
SDD is a reasonable indicator to evaluate the trophic conditions except in lakes that are highly colored with low chl- $a$ and non-algal turbidity (clay, calcium carbonate) [43]. It is inversely correlated with the amount of TSS [57]. Therefore, remote sensing can be an ideal tool for monitoring water transparency and estimating the SDD. Recently, Lee et al. [177] introduced a model to estimate the SDD, which unlike the classical model that strongly relies on the beam attenuation coefficient, relies only on the diffuse attenuation coefficient at a wavelength corresponding to the maximum transparency. Many researchers have applied remote sensing for this purpose and have shown in their studies that remote sensing data is well correlated with SDD values [178$181]$.

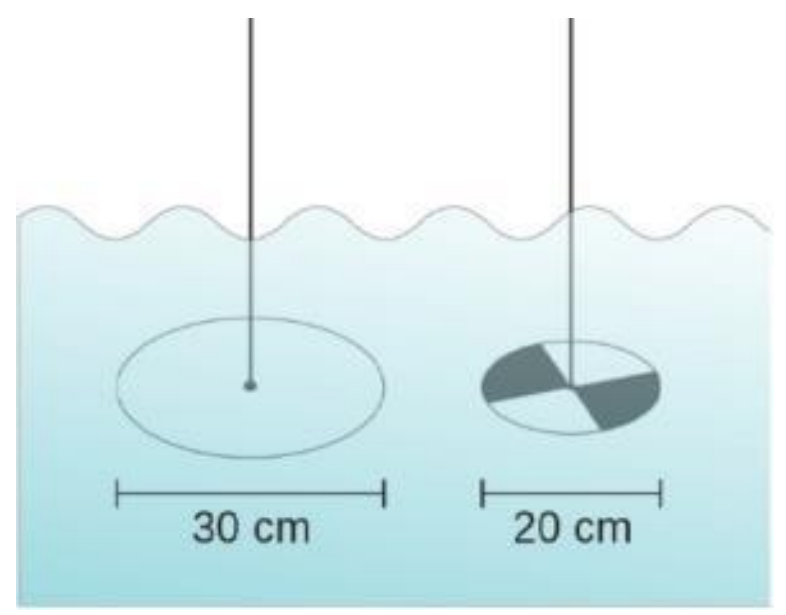

Figure 2.2. Two different types of Secchi disks [182].

SDD has a significant correlation with atmospherically corrected satellite radiance [183-185]. Significant algorithms have been developed for SDD using various remote sensing data, like TM $[27,40,101,186,187]$, MSS [24,25,188-190], IKONOS [28,61,127] and even video data [191]. Landsat-TM is one of the most frequently used sensors to estimate SDD. Braga et al. [192] reported that during high tide conditions a significant 
relationship was found between TM data and SDD. Furthermore, TM1 and TM3 satellite radiance were used to develop suitable models for the estimation of SDD [185]. However, there was an exception research conducted by Lopez-Garcia and Caselles [123]. They used TM data and reported that SDD did not show significant correlation with any TM bands. SDD can also be quantified from reflected radiance received by the IRS satellite [183].

There are many established relationships in the literature between Secchi depth and total phosphorus, chl- $a$, TSS, and CDOM. The existing literature showed that SDD can be quantified using visual spectral bands and various band ratios. Bhatti et al. [41] used ALOS-AVNIR-2 data and found that the Secchi depth was well correlated with reflectance ratio of R750/R560 (NIR/Green). Thiemann and Kaufmann [100] used HyMap and CASI data for Secchi disk transparency and chlorophyll- $a$ determination in the Mecklenburg Lake District, Germany. They used the area between a base line and the spectrum from 400 to $750 \mathrm{~nm}$ and found a good correlation with the in situ measured Secchi disk transparency (SDT). Ekercin [127] using Band1 (445-530nm), Band2 (520610nm), and Band3 (640-720nm) of IKONOS data and developed an algorithm for SDD measurements. Mancino et al. [26] developed an equation using TM1 and the TM3/TM2, TM1/TM2, TM2/TM1 ratios, and Powell et al. [193] suggested a regression equation related to in-situ Secchi disk transparency measurements by using the Blue, Green, and Red bands of TM. In addition, Kloiber et al. (2002) using TM and MSS imagery analysis suggested a Landsat-based procedure to evaluate the clarity of water. Literature also showed that Secchi disk depth can be quantified using visual spectral bands and various band ratios, which are summarized in table 2.7. 
Table 2.7. Remotely measurements of SDD using various spectral bands and their ratios

\begin{tabular}{|c|c|c|c|}
\hline \multicolumn{2}{|c|}{ Band Combination } & Sensor & Reference \\
\hline \multirow{4}{*}{\multicolumn{2}{|c|}{$\begin{array}{l}\text { Ratio between blue }(0.40-0.50 \mu \mathrm{m}) \text { and } \\
\text { green }(0.50-0.60 \mu \mathrm{m})\end{array}$}} & Landsat 5-TM & {$[27,187]$} \\
\hline & & Landsat 5- MSS & [189] \\
\hline & & Landsat 7- ETM+ & [106] \\
\hline & & ASTER and ETM+ & [194] \\
\hline \multirow{4}{*}{\multicolumn{2}{|c|}{$\begin{array}{l}\text { Ratio between blue }(0.40-0.50 \mu \mathrm{m}) \text { and } \\
\text { red }(0.60-0.70 \mu \mathrm{m})\end{array}$}} & Landsat 5-TM & {$[40,43,61,101,178,185,195-197]$} \\
\hline & & Landsat 5- MSS & {$[24]$} \\
\hline & & PROBA-CHRIS & {$[120]$} \\
\hline & & IKONOS & {$[28,61]$} \\
\hline \multirow{3}{*}{\multicolumn{2}{|c|}{$\begin{array}{l}\text { Ratio between green }(0.50-0.60 \mu \mathrm{m}) \text { and } \\
\text { red }(0.60-0.70 \mu \mathrm{m})\end{array}$}} & Landsat 5-TM & {$[30,191]$} \\
\hline & & ALOS-AVNIR-2 & [57] \\
\hline & & SPOT & {$[107,198]$} \\
\hline \multirow{5}{*}{$\begin{array}{l}\text { Using a single } \\
\text { band }\end{array}$} & \multirow[t]{2}{*}{ Blue $(0.40-0.50 \mu \mathrm{m})$} & Landsat 5-TM & [70] \\
\hline & & MODIS & {$[42]$} \\
\hline & $\operatorname{Red}(0.60-0.70 \mu \mathrm{m})$ & Landsat 5-TM & {$[12,30]$} \\
\hline & \multirow{2}{*}{$\begin{array}{l}\text { Green }(0.50-0.60 \\
\mu \mathrm{m})\end{array}$} & Landsat 5- MSS & [188] \\
\hline & & MODIS & [113] \\
\hline
\end{tabular}

SDD and chl- $a$ concentrations have been successfully predicted from satellite image data by developing the relationship between in-situ measurements of SDD and chl$a$, and the spectral response of the blue, green, red, and near-infrared bands. This approach has been successfully implemented in Minnesota [199], Wisconsin [200], and Michigan [201] to estimate water clarity for inland lakes, where in-situ data is limited.

\subsection{Turbidity and total suspended sediments}

Water turbidity is an optical property of water, which causes the scattering and absorption the light more than its transmitting. Suspended sediments are responsible for most of the scattering, whereas the absorption is controlled by chl- $a$ and colored dissolved or particulate matter [202]. The level of turbidity or murkiness is entirely dependent on the amount of suspended particles. The more suspended particles, the more difficult for light to travel through the water and therefore, the higher the water's turbidity. The complex nature of suspended substances in water changes the reflectance 
of the waterbody and therefore causes variation in color. To this end, interpretation of remotely sensed data just based on the color of water is not adequate and accurate. Turbidity and total suspended matters are considered as important variables in many studies due to their linkage with incoming sunlight that in turn affects photosynthesis for growth of algae and plankton. These parameters are also directly associated with Secchi disk depth.

Remote sensing techniques are widely used to estimate and map the turbidity and concentrations of suspended particles, and to provide their spatiotemporal variations. Based on theory, applying a single band can provide a robust and TSM-sensitive algorithm to estimate the turbidity and concentrations of suspended particles, in condition that the band is chosen appropriately [204]. Curran et al. [205] and Novo et al. [206] showed that single band algorithms may be adopted where TSM increases when the reflectance values increase. However, the complex substances in water change the reflectance of the water body and therefore cause variation in colors, and thus, different spectral bands can be used for TSS retrievals [204,207,208]. The advantage of using signal band or band ratios can be employed to obtain more accurate results in different concentrations in waterbodies. In the Near-IR and Mid-IR regions, based on water depth and wavelength the absorption of light increases and makes the water to look darker. Several studies have found that the first four bands of Landsat are well correlated with total suspended matters $[43,195,209,210]$. However, Ritchie et al. [211] by in situ studies showed that the range of spectrum between 700 and $800 \mathrm{~nm}$ is very useful for the measurement of suspended particles in surface waters. The literature showed that 
turbidity and/or Suspended Sediments can be measured using visual spectral bands and various band ratios, which are as summarized in table 2.8 .

Table 2.8. Remotely measurements of Turbidity and Total Suspended Sediments using various spectral bands and their ratios.

\begin{tabular}{|c|c|c|c|}
\hline \multicolumn{2}{|c|}{ Band Combination } & Sensor & Reference \\
\hline \multirow{3}{*}{\multicolumn{2}{|c|}{$\begin{array}{l}\text { Ratio between green }(0.50-0.60 \\
\mu \mathrm{m}) \text { and red }(0.60-0.70 \mu \mathrm{m})\end{array}$}} & Landsat 5-TM & {$[30,210]$} \\
\hline & & PROBA-CHRIS & {$[120]$} \\
\hline & & IRS-LISS-III & {$[72]$} \\
\hline \multirow{2}{*}{\multicolumn{2}{|c|}{$\begin{array}{l}\text { Ratio between blue }(0.40-0.50 \\
\mu \mathrm{m}) \text { and red }(0.60-0.70 \mu \mathrm{m})\end{array}$}} & Landsat 5-TM & [195] \\
\hline & & AISA & {$[22]$} \\
\hline \multirow{2}{*}{\multicolumn{2}{|c|}{$\begin{array}{l}\text { Ratio between near infrared } \\
(\mathrm{NIR}) \text { and red }(0.60-0.70 \mu \mathrm{m})\end{array}$}} & MODIS & {$[60]$} \\
\hline & & ALOS-AVNIR-2 & [57] \\
\hline \multirow{9}{*}{$\begin{array}{l}\text { Using a } \\
\text { single band }\end{array}$} & \multirow{3}{*}{$\begin{array}{l}\text { Near Infrared } \\
(0.75-0.90 \mu \mathrm{m})\end{array}$} & SPOT & [212] \\
\hline & & Landsat 7- ETM+ & [58] \\
\hline & & CASI & [29] \\
\hline & \multirow{4}{*}{$\begin{array}{l}\text { Red } \\
(0.60-0.70 \mu \mathrm{m})\end{array}$} & Landsat 7- ETM+ & [213] \\
\hline & & Landsat 5-TM & {$[12,43,213]$} \\
\hline & & $\mathrm{HICO}$ & [111] \\
\hline & & PROBA-CHRIS & [213] \\
\hline & \multirow{2}{*}{$\begin{array}{l}\text { Green } \\
(0.50-0.60 \mu \mathrm{m})\end{array}$} & Landsat 5-MSS & [189] \\
\hline & & IRS-LISS-III & [214] \\
\hline
\end{tabular}

Furthermore, Ekercin [127] used Band1 (445-530nm), Band2 (520-610nm), Band3 (640-720nm), and Band4 (770-880nm) of IKONOS data and estimated the concentration of TSS in Istanbul, Turkey. Alparslan et al. [62] obtained the amount of turbidity from Band1, Band2, Band3, Band4, Band5 and Band7 of Landsat-5 TM Satellite Image. He et al. [74] used a combination of Landsat TM bands 2, 3, 6 and 7 to correlate with the in situ turbidity measurements. Also, Sudheer et al. [59] suggested that a combination of TM1, TM2, TM3 and TM4 was very useful to retrieve suspended sediments concentration. Bhatti et al. [41] by using NIR/Green band ratio of ALOSAVNIR-2 developed a relationship to calculate total suspended matters. Lim and Choi 
[37] found that suspended solids was correlated with bands 2, 3, 4 and 5 of Landsat8/OLI, and constructed 3 multiple regression models through single bands of OLI.

Reviewing the literature demonstrated that the Landsat/TM was used much more than other sensors. For rivers and other case studies that need more spectral and spatial resolution, ALOS/AVNIR-2, IKONOS on spaceborne sensors, and CASI and AISA hyperspectral imagery on airborne sensors were used to determine turbidity and suspended matters. The methodology to interpret images and to evaluate the turbidity was also improved from simple linear regression to non-linear multiple regression, principle components analysis (PCA) and neural networks.

\subsection{Total phosphorus}

Total phosphorus (TP) studies consist of the measurement of all inorganic, organic and dissolved forms of phosphorus. Phosphates are essential nutrients required for the plant growth and its increased quantity causes the plants and algae to grow quickly. Total phosphorus can be directly related to chl- $a$ concentration and indirectly related to Secchi depth, turbidity, and TSS concentration [215]. Rivers that flow through various land use activities can include different substances and chemicals like total suspended sediments, nutrients, residential fallout, and others. When a river or a creek passes through an agricultural area, for instance, the phosphorus load may show a higher concentration compared to other parameters present in the surface water. Fertilizer-rich agricultural runoffs and effluents from wastewater treatment plants are the main sources of high phosphorus and nitrogen concentrations in surface waters that threaten many worldwide ecosystems [216]. Total suspended matters usually act as a carrier for TP and also closely related to Secchi disk transparency with an exponential equation [217]. 
The measurement of total phosphorus concentrations in waterbodies is challenging due to the spatial heterogeneity and the labor-intensive collection and testing of required field samples. Remote sensing as a robust tool has already been used successfully to monitor water quality parameters in various scales and areas, although it presents a challenge in estimating phosphorus concentration. Remote sensing of total phosphorus is based on the significance of its relationship with optically active parameters, such as chl- $a$ and suspended matters [70,217-221]. Total phosphorus is not directly measurable by optical instruments, but has a general correlation with other water quality parameters [220]. As mentioned above, TP is closely related to some other parameters like phytoplankton [217,220], turbidity and total suspended matters (TSM), and Secchi disk depth (SDD) [221], which is the basis for remote monitoring of TP dynamics [222]. Multispectral Landsat TM data have been widely used to monitor and map the TP spatial and temporal pattern in different regions [70,218,219]. Hyperspectral airborne or spaceborne remote sensing due to its finer diagnostic spectral band(s) provides more potential to detect TP in rivers and small lakes.

Many studies have shown that increasing the TP concentration in waterbodies results in a general tendency of increase in chl- $a$ concentration [223-226]. Schindler [227] showed that $74 \%$ of the variability in chl- $a$ and phosphorus concentrations among lakes are directly correlated. His result shows that chl- $a$ concentration may play a role as a representative of phosphorus concentration in waterbodies. In another study conducted by Heiskary and Wilson [228], the Secchi disk depth was decreased with increasing TP concentration that proved that a proportion of phosphorus can be attached to suspended particles resulted from soil erosion and transferred through river's downslope. These 
studies suggested that both chl- $a$ concentration and SDD are closely correlated with TP concentration [217] and therefore can be used as the potential theoretical parameters for the indirect prediction of TP concentration.

Table 2.9 shows a number of investigations to measure total phosphorus by applying blue band $(0.45-0.51 \mathrm{~m})$ and green band $(0.50-0.60 \mathrm{~m})$, and integration of red $(0.60-0.70 \mathrm{~m})$ and green $(0.50-0.60 \mathrm{~m})$ ratio from different sensors. Empirical estimations and regression models have been used to find a significant correlation between phosphorus concentration and other optically active parameters, such as chl- $a$ and SDD. In addition, Bistani [229] using EO-1/Hyperion obtained a reflectance determination coefficient of 0.49 from the 467 to $529 \mathrm{~nm}$ bands ratio values, from which he derived a polynomial algorithm used to produce a total phosphorus distribution map. Song et al. [230] studied the correlation between TP and TM1, TM2, TM3, and TM4 from the Landsat 5, and found that each band had a correlation with TP of $0.62,0.59$, 0.55, and 0.51, respectively. Later in another study, Song, Li, Li, Tedesco et al. [69] by using the airborne imaging data (AISA), and applying red band (around $690 \mathrm{~m}$ ) and NIR spectral region (around $710 \mathrm{~m}$ ) estimated the total phosphorus $(\mathrm{TP})$ in three central Indiana water supply reservoirs. Wu et al. [70] used a combination of TM1, TM3/TM2, and TM1/TM3 data to correlate chl- $a$ concentration and SDD measurements with TP concentration. Also, Alparslan et al. [62] using Band1, Band2, Band3, Band4, Band5 and Band7 of Landsat-5 TM Satellite Image obtained the amount of total phosphorus concentration. Lim and Choi [37] used bands 2, 3, 4, and 5 of Landsat-8/OLI, and constructed 3 multiple regression models by selecting both single bands and band ratios, and obtained significant correlation coefficients. 
Table 2.9. Remotely measurements of total phosphorus (TP) using various sensors and blue and green bands, and integration of red and green bands ratio.

\begin{tabular}{llll}
\hline Band Combination & Sensor & Reference \\
\hline Blue $(0.45-0.51 \mu \mathrm{m})$ and green & Landsat 5-TM & {$[70]$} \\
\cline { 2 - 3 }$(0.50-0.60 \mu \mathrm{m}) \quad$ bands, and & MODIS & {$[231]$} \\
\cline { 2 - 3 } $\begin{array}{l}\text { integration of red }(0.60-0.70 \mu \mathrm{m}) \\
\text { and green }(0.50-0.60 \mu \mathrm{m}) \text { bands }\end{array}$ & PROBA-CHRIS & {$[120]$} \\
\cline { 2 - 3 } & & SPOT & {$[29]$} \\
\hline
\end{tabular}

Results from studied articles indicate that there is a potential to estimate total phosphorus concentration at different scales using airborne and satellite images. The Landsat/TM was used much more than other sensors for TP assessment in the reviewed literature. As phosphorus is an optically inactive constituent and does not have a diagnostic signals in spectral range $(400-900 \mathrm{~nm})$, empirical models are mostly used to measure the TP concentrations $[69,70,232]$. The literature review also showed that TP has a similar spatial pattern to chl- $a$ and SD concentration due to a high correlation of TP with these parameters. Total phosphorus was also found to be highly correlated with sediment loadings in waterbodies. However, there is a lag-time for phytoplankton to consume TP and therefore, it complicates the relationship between TP and chl- $a$ or total suspended sediments [69].

Light reflection from the bottom in shallow waters cannot be very reliable, because it may be a result of the above-water remotely sensed reflectance spectra. Therefore, the TP concentration estimated in shallow water may be questionable and needs to be validated using in situ data. Spatiotemporal distribution algorithms for TP concentration produced from satellite-based observations should also be verified by in 
situ measurements. These empirical methods provide site-specific predictions of total phosphorus with reasonable accuracy [233].

\subsection{Water temperature}

Water temperature is an important parameter for the physical and biochemical processes occurring within water as well as in air-water interactions because temperature regulates physical, chemical, and biological processes in water. Water temperature also influences the solubility and availability of various chemical constituents in water. Most importantly, this parameter affects dissolved oxygen concentrations in water; as oxygen solubility decreases with increasing water temperature. It is also very important to analyze the temporal variations due to seasonal changes. On the other hand, distribution, transportation, and interaction of some contaminants, such as nutrients have a significant relation with water column temperature.

Thermal infrared bands are able to measure the amount of infrared radiant heat emitted from land surfaces and the radiant temperature of waterbodies that have environmental and economic import. Due to the solar warming or for example after rainfall the water column stratified and more attention should be paid to the estimation of water temperature [234]. In such cases, no relation can be expected between sea surface temperatures and the temperatures found in the water under the surface. Water temperature in freely flowing rivers is unstable because the characteristics of these rivers like the channel shape, and in-stream objects cause a turbulent flow regime [235].

Remote sensing of water temperature in rivers is more complex than in other waterbodies because of their much smaller dimensions and difficulties of determination at the resolution of TIR data [46]. Stream and river temperature is crucial especially when 
dealing with endangered fish populations, which are sensitive to increased water temperature. Sparse sampling in both space and time restricts traditional assessment of water temperature, which is typically measured using a network of in-stream gauges, and records the temporal change at given locations. These gages, located in main streams and rivers, are limited in terms of spatial distribution of river temperatures. The application of remote sensing techniques can be an attractive alternative to measuring and monitoring stream temperatures with determined accuracies and uncertainties [46]. Remotely sensed TIR images could provide reliable measurements of the spatial distribution of the stream and river temperature.

Currently, different TIR imaging sensors with a broad range of spectral bands are available and suitable for the measurement of water temperature [236]. For the selection of appropriate band or bands, careful consideration on the least amount of instrument noise and atmospheric effects is necessary for accurate calculation of the water temperature. However, an average of multiple bands can provide a better estimate of the actual temperature reducing the noise of images related to atmospheric or sensors differences [236].

Compared to airborne TIR imaging sensors, spaceborne TIR imaging sensors cover greater aerial extents [236]. However, significant differences in their range of pixel sizes, number of bands, revisit times, and sensor sensitivities exist. TIR satellite images are very useful data because of their low cost, capability for regional studies, and their revisit times. Airborne sensors with finer pixel size are necessary for smaller waterbodies like rivers, but these images are limited to use over large areas because of the high expense of calibrating and processing. In rivers and small waterbodies, airborne TIR 
sensors can be more useful to estimate the water temperature [236]. When using airborne data acquisition, it is imperative to consider that these images do not provide a truly synoptic assessment of water temperature at a particular time, if the images are collected consecutively along the river course. In addition, in the case of frame based TIR imaging sensors, the TIR accounting for radiometric distortion must be considered due to variability in individual detector response and lens optics.

Many studies have shown the applicability of remote sensing to temperature estimation for rivers and streams. For example, Torgersen et al. [237] used fine pixel-size (0.2-0.4 m) airborne TIR images to evaluate the accuracy of radiant temperature measurements, and found that the remotely sensed radiant temperature was within $0.5{ }^{\circ} \mathrm{C}$ of in-situ measurements. They identified that reflected TIR radiation, vertical thermal stratification in the stream, and thermal boundary-layer effects at the water surface should receive greater attention in the thermal remote sensing of streams. They also concluded that fine pixel-size measurements of stream temperature can be used to study the finescale spatial variation of stream temperature.

Accurate remote sensing measurement of sea surface temperature (SST) is also vital for weather and climate operational as well as atmosphere studies. Infrared radiometers yield SST estimations to around $0.5{ }^{\circ} \mathrm{C}$ precision, though its use is limited in shady zones due to the presence of clouds or fog. Therefore, standard remote sensing practices should be applied to identify and mask these issues out of the used images before one proceeds with the measurement of the water temperature by TIR radiation [238]. Passive microwave techniques are used in cloudy areas with an accuracy limit of about $1.5-2{ }^{\circ} \mathrm{C}$ by the relatively large variation of microwave emissivity with surface 
conditions, such as wind speed [239]. Addition of active microwave (radar) observations can enhance the precision of passive microwave estimates of SST. Reviewing the literature indicates the use of infrared thermal band for quantifying water temperature, which is as summarized in table 2.10 .

Table 2.10. Infrared thermal band applications to quantify the water temperature.

\begin{tabular}{ll}
\hline Sensor & Reference \\
\hline $\begin{array}{l}\text { TIR band of Landsat sensors (TM, ETM+, and } \\
\text { OLI/TIRS) }\end{array}$ & $\begin{array}{l}\text { TM: [44,195,240-242], ETM+: [44,46,194,238,243-246], } \\
\text { OLI/TIRS: [47,247,248]. }\end{array}$ \\
\hline TIR band of MODIS & {$[22,42,46,249,250]$.} \\
\hline TIR band of ASTER & {$[46,194,238,245,246,251]$.} \\
\hline TIR band of AVHRR & {$[45,252-255]$.} \\
\hline TIR band of airborne MODIS/ASTER (MASTER) & {$[46,238,246,251]$.} \\
\hline Sea Surface Temperature monitoring studies & WindSat: [256,257], AATSR: [258-261], ATSR-1: [262-264], \\
using microwave radiometers (MWRs) & ATSR-2: [258,265-267], AMSR-E: [268,269], TMI: [270-272]. \\
\hline
\end{tabular}

\subsection{Sea surface salinity (SSS)}

Salinity and temperature are important factors to identify the density of seawater, and in turn, density is a critical component driving the currents in the oceans, and therefore, salinity is one of the key variables that should be considered for the investigation of the circulation in oceans [273]. Ocean circulation in moderating the climate and sea surface salinity (SSS) is critical, and also is considered as an important factor for the determination of the global water balance, productivity forecast models, as well as evaporation rates [273]. For example, the mixed layer will be more stable when the salinity is relatively low, and the nutrient can be controlled and lead to reduce the productivity of phytoplankton or at least cause a delay in the spring and autumn onset phytoplankton blooms [274]. Seasonal variations of sea surface salinity represent 
limitations on the hydrologic balance and coupled models of ocean-atmosphere climate [274,275]. Salinity also has important effects in the air-sea exchange of gases.

Precipitation makes the ocean water fresher and less dense, which overlays the salty water below, and this thin layer of sea surface fresh water can spoof the shallow satellite readings. The effect of this phenomenon in the tropical ocean, where heavy rainfalls can create pools of local freshwater, is more sensible. It can increase the stability of the upper layer of the water column and significantly reduce the rates of gas transfer across the pycnocline. As the measurement of surface salinity by passive microwave radiometers requires long wavelengths $(20-30 \mathrm{~cm})$, accurate estimation of SSS from satellite altitudes would require an enormous antenna, which most satellites could not accommodate [273]. New interferometric technology has made it possible to overcome such problems with antenna size [276,277]. For instance, the Moisture and Ocean Salinity satellite (SMOS) has been in use to measure SSS.

Aquarius is another salinity-related sensor that can be used to investigate the salinity variability for climate studies purposes. In addition, airborne microwave radiometers, such as the Scanning Low-Frequency Microwave Radiometer (SLFMR) and the Salinity, Temperature, and Roughness Remote Scanner (STARRS) were found to be widely used to investigate the variability of SSS in various waterbodies [273].

Indirect methods based on satellite-derived temperature profiles, brightness temperature, and CDOM have been also used to determine the variability of sea surface salinity. Different relationships have been established between salinity and major water constituents that have direct color signal. For example, relationship between salinity, temperature, and brightness temperature [65,274,278-285], and relationship between 
salinity and CDOM [55,165,286,287]. Detailed sea surface salinity measurements are performed using the application of space-borne and airborne sensors over large coastal and ocean areas. Some of these experiments are as listed in table 2.11, based on the used sensor.

Other notable experiences are performed using European Remote Sensing satellite (ERS) C-band scatterometer [288]; the first seven bands of MODIS [289]; TOPEX/Poseidon Microwave Radiometer [282,290], and Cooperative Airborne Radiometer for Ocean and Land Studies (CAROLS) L-Band Radiometer [65]. Nonetheless, comparison of the various sensors' characteristics shows that the airborne ESTAR and SLFMR are more appropriate than other instruments to sea surface salinity measurements. That notwithstanding, SMOS and Aquarius are the most widely used sensors for the remote sensing of salinity.

\subsection{Dissolved oxygen (DO), Biochemical oxygen demand (BOD) and chemical oxygen} demand $(C O D)$

Dissolved oxygen (DO) is a crucial water quality parameter that influences the living conditions of all aquatic organisms that require oxygen. The level of DO in waterbodies can be affected by natural and anthropogenic activities in basins. The amount of dissolved oxygen in waterbodies decreases by respiring and decaying organisms, and increases by photosynthesizing plants, stream flow, and aeration. The water temperature highly influences the amount of DO; in other words, less oxygen dissolves in warm water than cold water. 
Table 2.11. Remote sensing of Sea Surface Salinity (SSS) based on the used sensor.

\begin{tabular}{ll}
\hline Sensor & Reference \\
\hline $\begin{array}{l}\text { European Soil Moisture and Ocean } \\
\text { Salinity (SMOS) }\end{array}$ & {$[64,66,275,291-298]$.} \\
\hline $\begin{array}{l}\text { Aquarius L-band radiometer } \\
\text { carried by the SAC-D }\end{array}$ & {$[67,299-301]$.} \\
\hline SLFMR & {$[284,302-305]$.} \\
\hline STARRS & {$[285,304,306]$.} \\
\hline $\begin{array}{l}\text { Other MWRs experiences } \\
\text { predicted indirectly by making } \\
\text { relationship between salinity and } \\
\text { temperature }\end{array}$ & PALS: [307-309], AMSR-E: [310] 2D-STAR and ESTAR: [311-313] \\
\hline $\begin{array}{l}\text { predicted indirectly by making } \\
\text { relationship between salinity and } \\
\text { CDOM }\end{array}$ & {$[55,165,286,287]$.} \\
\hline
\end{tabular}

Biochemical Oxygen Demand (BOD) is a measure of the amount of consumed oxygen by bacteria while decomposing organic matters under aerobic conditions [2]. By exploiting dissolved oxygen, the bacteria decompose these organic materials resulting in a reduction in the level of DO necessary for supporting aquatic life. The biochemical oxygen demand is usually determines using a sealed sample of water incubated for five days, and then measuring the loss of oxygen from the first and fifth day of the test [2]. Noteworthy is that the need to dilute the samples prior to incubation stem from the likelihood of the bacteria depleting all the oxygen available in the bottle before the test is complete.

Chemical oxygen demand (COD) is the quantity of organic matter measured with chemical method that needs to be oxidized in water, and it is used to measure the organic contamination in water. BOD values are always less than COD values, yet measuring the latter take only a few hours while five days need to measure BOD values. 
High BOD levels exist in waterbodies accelerates the bacterial growth and thus reduces the level of dissolved oxygen. However, due to atmospheric mixing and aquatic photosynthesis the waterbody reaerates and the oxygen levels will slowly increase towards the downstream. Routine methods to measure COD are based on points, and have the time-consuming and laborious disadvantages in obtaining the distribution patterns so that it is difficult to reflect the status of whole region synchronously. Although point sampling can be more accurate method of measurement, however it is time-consuming and costly. In addition, routine methods cannot provide the real-time spatial patterns for the possible variations in the concentration of COD that is essential for the regional assessment and monitoring of water quality [89].

A review of the available literature confirmed that no single identified and/or recommended sensors can be used with high confidence to perform an appropriate model to measure the reflectance of water resulting from DO, COD, and BOD. Several water quality models were developed to investigate the relationship between the measured values of $\mathrm{DO}, \mathrm{BOD}$, and $\mathrm{COD}$ in laboratory and remote sensing reflectance, by establishing linear, exponential, and logarithmic regressions. Also, various bands ratios have been studied to obtain the DO, BOD, and COD distribution maps in order to analyze the spatial and temporal changes of these water quality parameters. However, interpretation of the satellite or airborne images and making authentic relationships between spectral characteristics of images and in situ measurements of DO, BOD, and COD in the aquatic ecosystems are still poorly understood. The most notable studies to estimate the amounts of DO, BOD, and COD are as cited in Table 2.12. Although the results of studied articles indicated that the Landsat/TM was used much more than other 
sensors to estimate the amount of $\mathrm{DO}, \mathrm{BOD}$ and $\mathrm{COD}$, this research found relatively low potential and accuracy of current remote sensing techniques for the measurements of DO, BOD and COD values in waterbodies, unless there are enough and adequate ground proofs. In situ measurements of surface water radiation and atmospheric corrections of images are vitally important for both the calibration and validation of remotely sensed data.

Table 2.12. Remote sensing of dissolved oxygen (DO), biochemical oxygen demand (BOD), and chemical oxygen demand (COD) based on the used sensor.

\begin{tabular}{ll}
\hline Sensor & Reference \\
\hline Landsat 5-TM & {$[62,74,75,78]$.} \\
\hline Landsat 5- MSS & {$[76]$.} \\
\hline WorldView-2 & {$[9]$.} \\
\hline IRS-LISS-III & {$[72]$.} \\
\hline MODIS & {$[168]$.} \\
\hline MERIS & {$[168]$.} \\
\hline AVHRR & {$[63]$.} \\
\hline SeaWIFS & {$[233]$.} \\
\hline SPOT & {$[77]$.} \\
\hline
\end{tabular}

Despite the fact that remote sensing can be used to reflect many of water quality parameters, such as Secchi disk depth, chlorophyll concentrations, CDOM, total suspended sediments, and temperature, emphasis should be placed on the fact that this technique cannot substitute the traditional methods. The reason behind this is that some parameters of water quality, like DO, BOD and COD cannot be determined with a high level of confidence by these techniques.

\section{Limitations of remote sensing for the assessment of water quality parameters}

Remote sensing has been widely used to study the spatiotemporal variations of water quality variables in different waterbodies. However, there are a number of 
important constraints that require precise considerations prior to conducting this technique. Developed models from remote sensing data require adequate calibration, and validation using in situ measurements, and can be used only in the absence of clouds. Moreover, the accuracy of extracted water quality parameters might be debatable for some situations; for instance, Kutser [169] pointed out that the densest areas of cyanobacteria blooms in the Baltic Sea are rarely detectable using the routine remote sensing procedure and requires precise atmospheric correction and more considerations on processing errors.

The spatial, temporal, and spectral resolution limitations of many current optical sensors can confine the application of remotely sensed data to assess water quality. Furthermore, certain key parameters that are not easy to measure directly by optical sensors exist, examples of which include water discharge and vertical distribution of water quality parameters in waterbodies. The cost of hyperspectral or airborne data, as well as the required equipment for in situ hyperspectral measurement, is among the main restrictions of using remote sensing methods for water quality assessment. There are also some optical complexities for the measurement of water quality variables in different inland and coastal waters that limits the application of remote sensing [41].

The segregation of spectral signatures for chl- $a$, CDOM, and inorganic suspended matter is not well documented in the literature, which is challenging because of the influence of these parameter on each other. In the clear sea waters, the maximum light penetration depth expected is about $55 \mathrm{~m}$ near $475 \mathrm{~nm}$ [315], and the majority of the incident energy on the water surface is absorbed, and/or transmitted. On the other hand, when the concentrations of suspended sediment extend to $400 \mathrm{mg} / \mathrm{liter}$, the penetration 
depth reduces to only $60 \mathrm{~cm}$. Therefore, a progressively thinner layer of surface water is detectable [41].

Most of the studies have focused on optically active variables, such as chl- $a$, CDOM, TSS, and turbidity. However, a number of important water quality variables such as $\mathrm{PH}$, total nitrogen $(\mathrm{TN})$, ammonia nitrogen $(\mathrm{NH} 3-\mathrm{N})$, nitrate nitrogen $(\mathrm{NO} 3--\mathrm{N})$, and dissolved phosphorus (DP), etc. are not well investigated due to their weak optical characteristics and low signal noise ratio. Despite the mentioned limitations, remote sensing is still a useful tool for water quality monitoring.

\section{Discussion}

Several satellite images could be used for water quality assessments. Nonetheless, Landsat TM (Thematic Mapper) images have been used extensively due to their relatively low cost, temporal coverage and spatial resolution $[3,11,12,26,43,59,62,74,85,87,101,102,104,105,108]$. TM data resided on Landsat-5, a sensor that was operational from 1984 until November 2011, and is considered one of the oldest sensors still used for water quality assessment today [40,62,70,210,213,316]. Results from earlier studies referenced in tables indicate that the resolution of Landsat TM is suitable for water quality studies.

Information from the available literature revealed that the Landsat sensors, TM (Thematic Mapper), MSS (Multi-Spectral Scanner), ETM (Enhanced Thematic Mapper), and OLI (Operational Land Imager) have been used fairly successfully to measure most of the important water quality parameters, such as chlorophyll- $a$, Secchi disk depth, Total phosphorus, Total Suspended matters, Turbidity, Dissolved Oxygen, Biochemical Oxygen Demand, and Chemical Oxygen Demand [10,24,40,43,62,76,129,193]. 
Nonetheless, the use of Landsat data for measuring water quality characteristics has significant limitations. The repeat cycle of 16 days of Landsat could be a major limitation for areas like South Florida with frequent cloud cover and this makes the seasonal monitoring of waterbodies more challenging. The water quality parameter characteristics must be related to an "inherent optical property" (IOP) that can be measured by the satellite sensor [43]. For instance, Kloiber et al. [24] using the Landsat TM and MSS related Secchi disk transparency (SDT) to the radiance in several spectral bands. Some other potential sources of error due to varying atmospheric conditions are mentioned for Landsat. For example, Brezonik et al. [43] noted that the radiance at the TM sensor varies based on the season, latitude, and time of day and needs to be calibrated for the intensity of incoming solar radiation. Atmospheric haze interference, due to scattering the light, can affect the accuracy of measurements, especially when the reflected radiance from the waterbodies with high clarity, high algae, and CDOM decreases [43]. These restrictions may apply to other sensors with similar characteristics to Landsat sensors.

Spaceborne and airborne remote sensing and their characteristics, advantages, and disadvantages were discussed previously in this paper. Different considerations of a project, such as required spatial and spectral resolution, geographic coverage area, and project budget determine the preference of one sensor or another. Table 2.13 represents a summarized comparison of the previously discussed issues related to spaceborne and airborne sensors, where various parameters of these sensors are compared. 


\section{Conclusion and recommendation}

By increasing the anthropogenic activities and industrial development, water quality has dramatically degraded. A combination of remote sensing, GIS, and traditional in-situ sampling can lead to perform a better monitoring program for water quality parameters in various waterbodies. From the available literature, one pertinent deduction is that various space-borne and airborne sensors can measure water quality parameters with reliable precision. Newly developed hyperspectral satellite imageries, which can simultaneously record up to 200 spectral channels, such as the Hyperspectral Imager for the Coastal Ocean (HICO), are much more powerful systems for detecting water quality parameters. Also, hyperspectral airborne sensors have greater potential to detect the optically active parameters of water due to their concurrent collection of narrower and continuous bands that facilitates the measurement and monitoring of various parameters of water quality. Therefore, monitoring and assessing water quality issues through remotely sensed data can result in effective management of water resources.

However, remote sensing-derived water quality evaluations have not been properly considered by the water quality managers. An effective dialogue between scientists, policy makers, and federal and local environmental managers is required to better realize the potential of remote sensing technologies in water quality investigations. Results from an internal US Environmental Protection Agency qualitative survey performed by Schaeffer et al. [317] were used to determine the reasons that satellite-

derived water quality products are not well considered in management decisions. They pointed out that difficulties in clarifying the perceptions of environmental managers, 
which was identified 22 years ago by Specter and Gayle [318], is still a challenge for the remote sensing scientists and researchers.

Table 2.13. Comparison between spaceborne and airborne sensors [3].

\begin{tabular}{|c|c|c|}
\hline Parameter & Spaceborne & Airborne \\
\hline Time of overpass & Mostly fixed & Flexible \\
\hline Spatial resolution & $\begin{array}{l}\text { Ground Sampling Distance (GSD) up to } 0.5 \mathrm{~m} \\
\text { for panchromatic images. For multi-band } \\
\text { images, it ranges from a few meters (low } \\
\text { altitude sensors) up to a few kilometers for } \\
\text { high altitude sensors. }\end{array}$ & $\begin{array}{l}\text { Ground Sampling } \\
\text { Distance }(G S D)<5 m\end{array}$ \\
\hline $\begin{array}{l}\text { Spectral } \\
\text { resolution }\end{array}$ & $\begin{array}{l}\text { Mostly panchromatic (one band) to } \\
\text { multispectral, recently developed sensors like } \\
\text { HyspIRI, CHRIS, and HICO are hyperspectral. }\end{array}$ & $\begin{array}{l}\text { Panchromatic to } \\
\text { hyperspectral }\end{array}$ \\
\hline $\begin{array}{l}\text { Temporal } \\
\text { resolution } \\
\text { (Revisit time) }\end{array}$ & Days & Minutes \\
\hline Calibration & $\begin{array}{l}\text { Precalibration before launch, then on-board } \\
\text { characterization (usually yearly) }\end{array}$ & $\begin{array}{l}\text { Before launch }+ \\
\text { possible on-board }\end{array}$ \\
\hline Cost & $\begin{array}{l}\text { Free (non-commercial), up to about } \$ 50 \text { per sq } \\
\mathrm{km} \text { (commercial). High spatial resolution } \\
\text { imagery can be very expensive ( } \$ 2-10 \mathrm{~K} \text { per } \\
\text { scene) }\end{array}$ & $\begin{array}{l}\text { Average costs of } \$ 350 \\
\text { per square mile } \\
\text { (Chipman et al. 2009) }\end{array}$ \\
\hline Stability & High & Low, due to turbulence \\
\hline Swath width & $\begin{array}{l}\text { High (up to } 2500 \mathrm{~km} \text { for low altitude sensors, a } \\
\text { full hemisphere for high altitude sensors) }\end{array}$ & $\begin{array}{l}\text { Small (up to } 10 \mathrm{~km} \text { per } \\
\text { flight line) }\end{array}$ \\
\hline $\begin{array}{l}\text { Interpretation } \\
\text { approaches }\end{array}$ & $\begin{array}{l}\text { Mostly empirical-and semi-empirical-based } \\
\text { approaches }\end{array}$ & $\begin{array}{l}\text { Both empirical and } \\
\text { analytical approaches }\end{array}$ \\
\hline $\begin{array}{l}\text { Complexity of } \\
\text { image processing }\end{array}$ & $\begin{array}{l}\text { Less complex compared to hyperspectral } \\
\text { sensors }\end{array}$ & $\begin{array}{l}\text { Processing of } \\
\text { hyperspectral images is } \\
\text { more complex and } \\
\text { requires specific skills }\end{array}$ \\
\hline Constraints & $\begin{array}{l}\text { Limited to the coverage schedule of the } \\
\text { satellite, including weather/cloud constraints; } \\
\text { this can be challenging when trying to conduct } \\
\text { water quality monitoring at a certain time of } \\
\text { the year or dealing with project schedules. }\end{array}$ & $\begin{array}{l}\text { Coverage schedule is } \\
\text { flexible. }\end{array}$ \\
\hline $\begin{array}{l}\text { Geographic } \\
\text { coverage areas }\end{array}$ & Local, regional, and global & Local and regional \\
\hline
\end{tabular}


As illustrated in this paper, both satellite and airborne remote sensing are useful in assessing the quality of inland waters. Airborne sensors are more flexible tools than spaceborne sensors because of their higher spatial and spectral resolution coupled with their greater number of spectral bands that makes it possible to retrieve the water quality parameters with more accuracy. Airborne sensors are more suitable to monitor smaller waterbodies, such as rivers and their tributaries, ponds, and estuaries, while satellite sensors are more suitable for the evaluation of larger waterbodies and regional studies. In this paper, various properties (spectral, spatial and temporal, etc.) of spaceborne and airborne sensors are tabulated to be used as a sensor selection guide in related studies. Furthermore, based on the literature surveyed, this paper compiled a list of sensors that have been used by researchers to measure various water quality parameters, and compares various parameters of spaceborne and airborne sensors.

Due to the need for high accuracy in local-scale and riverine studies, some of the above mentioned sensors, such as SeaWiFS data are of little use. For these cases, the high resolution and/or hyperspectral remote sensing on spaceborne platforms such as EO1/Hyperion, ALOS AVNOR-2, IKONOS, HICO, and Landsat-8 and airborne platforms CASI, AISA, AVIRIS, HyMap are recommended for use in water quality measurements.

In addition, the recent advances in computer sciences have had a profound influence on the water quality monitoring, resulting in a broader development of the remote sensing technology. Computers can store and analyze the large sets of data generated by most of the Remote Sensing projects. Also, the use of decision support systems (DSS) and Geographical Information Systems (GIS) provide efficient tools for storing, manipulating and analyzing remote sensing data. GIS can enhance the 
contributions of water quality modelling for practical water quality forecasting, which is essential for sustainable water resources management and development. Therefore, the excellent practicality and interoperability of the RS and GIS techniques will lead the future water quality models towards integration of RS and GIS techniques and the increased use of these technologies in qualitative studies of water resources. Regardless of numerous endeavors reported in the literature, remote sensing techniques utilized to quantify water quality are yet to be adopted on a routine framework. Based on author's prior knowledge and experience, and the gained information from this literature review, a schematic flowchart of the supposed framework for water quality monitoring and assessment using remote sensing techniques is presented in figure 2.3. Despite the recent development of analytical approaches, empirical and semi-empirical algorithms are still in extensive use due to the complexity of analytical approaches in terms of their theory and calculation difficulties. Improvement of the methodology to interpret images from simple linear regression to multivariate statistical analysis approaches like principle components analysis (PCA) and neural networks will help to make the procedures more accurate and easier to manipulate. 


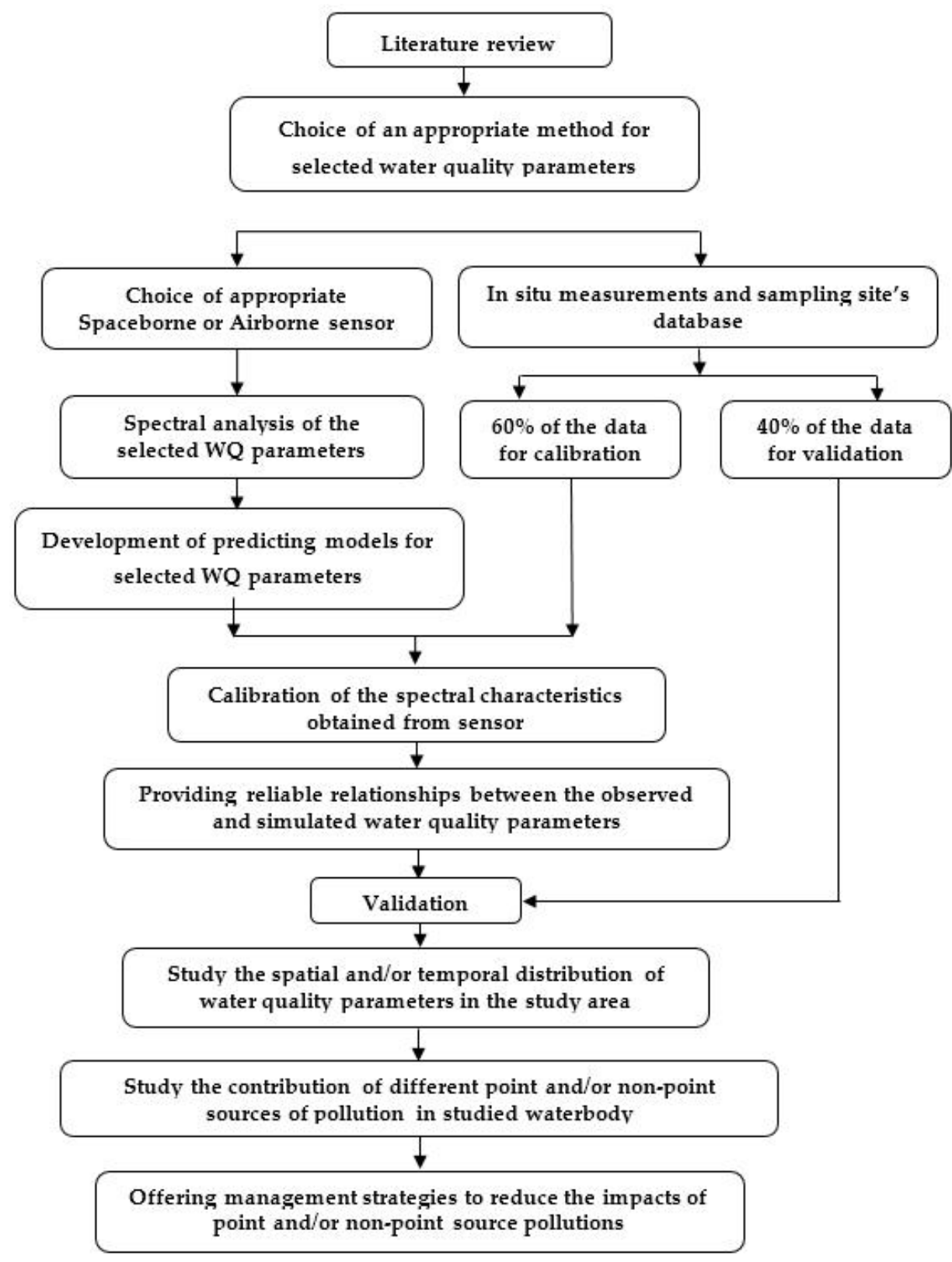

Figure 2.3. A suggested remote sensing based framework to predict and assessment of water quality variables.

\section{Acknowledgements}

This research was made possible by financial support that was provided by the Department of Civil and Environmental Engineering of Florida International University, 
Miami, U.S.A., through a Presidential Fellowship and a Graduate Assistantship to the

main author.

\section{References}

1. Sloggett, D.; Srokosz, M.; Aiken, J.; Boxall, S. Operational uses of ocean colour data-perspectives for the octopus programme. Balkema publishers, Rotterdam: 1995.

2. Engman, E.T.; Gurney, R.J. Remote sensing in hydrology. Chapman and Hall Ltd: 1991.

3. Dekker, A.; Zamurović-Nenad, Ž.; Hoogenboom, H.; Peters, S. Remote sensing, ecological water quality modelling and in situ measurements: A case study in shallow lakes. Hydrological sciences journal 1996, 41, 531-547.

4. Duan, W.; Takara, K.; He, B.; Luo, P.; Nover, D.; Yamashiki, Y. Spatial and temporal trends in estimates of nutrient and suspended sediment loads in the ishikari river, japan, 1985 to 2010. Science of the Total Environment 2013, 461, 499-508.

5. Duan, W.; He, B.; Takara, K.; Luo, P.; Nover, D.; Sahu, N.; Yamashiki, Y. Spatiotemporal evaluation of water quality incidents in japan between 1996 and 2007. Chemosphere 2013, 93, 946-953.

6. Alparslan, E.; Aydöner, C.; Tufekci, V.; Tüfekci, H. Water quality assessment at ömerli dam using remote sensing techniques. Environmental monitoring and assessment 2007, 135, 391-398.

7. Anding, D.; Kauth, R. Estimation of sea surface temperature from space. Remote Sensing of Environment 1970, 1, 217-220.

8. Brando, V.E.; Dekker, A.G. Satellite hyperspectral remote sensing for estimating estuarine and coastal water quality. Geoscience and Remote Sensing, IEEE Transactions on 2003, 41, 1378-1387.

9. El-Din, M.S.; Gaber, A.; Koch, M.; Ahmed, R.S.; Bahgat, I. Remote sensing application for water quality assessment in lake timsah, suez canal, egypt. Journal of Remote Sensing Technology 2013.

10. Giardino, C.; Bresciani, M.; Cazzaniga, I.; Schenk, K.; Rieger, P.; Braga, F.; Matta, E.; Brando, V.E. Evaluation of multi-resolution satellite sensors for assessing water quality and bottom depth of lake garda. Sensors 2014, 14, 2411624131. 
11. Hadjimitsis, D.G.; Clayton, C. Assessment of temporal variations of water quality in inland water bodies using atmospheric corrected satellite remotely sensed image data. Environmental monitoring and assessment 2009, 159, 281-292.

12. Hellweger, F.; Schlosser, P.; Lall, U.; Weissel, J. Use of satellite imagery for water quality studies in new york harbor. Estuarine, Coastal and Shelf Science 2004, 61, 437-448.

13. Kondratyev, K.Y.; Pozdnyakov, D.; Pettersson, L. Water quality remote sensing in the visible spectrum. International Journal of Remote Sensing 1998, 19, 957979.

14. Koponen, S.; Pulliainen, J.; Kallio, K.; Hallikainen, M. Lake water quality classification with airborne hyperspectral spectrometer and simulated meris data. Remote Sensing of Environment 2002, 79, 51-59.

15. Maillard, P.; Santos, N.A.P. A spatial-statistical approach for modeling the effect of non-point source pollution on different water quality parameters in the velhas river watershed-brazil. Journal of Environmental Management 2008, 86, 158-170.

16. Morel, A.; Prieur, L. Analysis of variations in ocean color1. Limnology and oceanography 1977, 22, 709-722.

17. Pozdnyakov, D.; Shuchman, R.; Korosov, A.; Hatt, C. Operational algorithm for the retrieval of water quality in the great lakes. Remote Sensing of Environment 2005, 97, 352-370.

18. Ritchie, J.C.; Zimba, P.V.; Everitt, J.H. Remote sensing techniques to assess water quality. Photogrammetric Engineering \& Remote Sensing 2003, 69, 695704.

19. Seyhan, E.; Dekker, A. Application of remote sensing techniques for water quality monitoring. Hydrobiological Bulletin 1986, 20, 41-50.

20. Usali, N.; Ismail, M.H. Use of remote sensing and gis in monitoring water quality. Journal of sustainable development 2010, 3, p228.

21. Wang, X.; Ma, T. Application of remote sensing techniques in monitoring and assessing the water quality of taihu lake. Bulletin of environmental contamination and toxicology 2001, 67, 863-870.

22. Chipman, J.W.; Olmanson, L.G.; Gitelson, A.A. Remote sensing methods for lake management: A guide for resource managers and decision-makers. North American Lake Management Society: 2009.

23. Gitelson, A.A.; Dall'Olmo, G.; Moses, W.; Rundquist, D.C.; Barrow, T.; Fisher, T.R.; Gurlin, D.; Holz, J. A simple semi-analytical model for remote estimation of 
chlorophyll-a in turbid waters: Validation. Remote Sensing of Environment 2008, $112,3582-3593$.

24. Kloiber, S.M.; Brezonik, P.L.; Bauer, M.E. Application of landsat imagery to regional-scale assessments of lake clarity. Water Research 2002, 36, 4330-4340.

25. Kloiber, S.M.; Brezonik, P.L.; Olmanson, L.G.; Bauer, M.E. A procedure for regional lake water clarity assessment using landsat multispectral data. Remote Sensing of Environment 2002, 82, 38-47.

26. Mancino, G.; Nolè, A.; Urbano, V.; Amato, M.; Ferrara, A. Assessing water quality by remote sensing in small lakes: The case study of monticchio lakes in southern italy. iForest-Biogeosciences and Forestry 2009, 2, 154-161.

27. Olmanson, L.G.; Bauer, M.E.; Brezonik, P.L. A 20-year landsat water clarity census of minnesota's 10,000 lakes. Remote Sensing of Environment 2008, 112, 4086-4097.

28. Sawaya, K.E.; Olmanson, L.G.; Heinert, N.J.; Brezonik, P.L.; Bauer, M.E. Extending satellite remote sensing to local scales: Land and water resource monitoring using high-resolution imagery. Remote Sensing of Environment 2003, $88,144-156$.

29. Shafique, N.A.; Fulk, F.; Autrey, B.C.; Flotemersch, J. In Hyperspectral remote sensing of water quality parameters for large rivers in the ohio river basin, Renard, KG, McElroy, SA, Gburek, WJ, Canfield, HE, Scott, RL,(Eds.) First Interagency Conference on Research in the Watersheds, October 27-30, 2003. US Department of Agriculture, Agricultural Research Service, 2003.

30. Wang, F.; Han, L.; Kung, H.T.; Van Arsdale, R. Applications of landsat 5 tm imagery in assessing and mapping water quality in reelfoot lake, tennessee. International Journal of Remote Sensing 2006, 27, 5269-5283.

31. Kallio, K. Remote sensing as a tool for monitoring lake water quality. Hydrological and limnological aspects of lake monitoring 2000, 14, 237.

32. Hupton, J.R. Three-dimensional target modeling with synthetic aperture radar. 2009.

33. She, Z.; Gray, D.; Bogner, R.; Homer, J.; Longstaff, I. Three-dimensional spaceborne synthetic aperture radar (sar) imaging with multiple pass processing. International Journal of Remote Sensing 2002, 23, 4357-4382.

34. Minvielle, P.; Massaloux, P.; Giovannelli, J.-F. Fast 3d synthetic aperture radar imaging from polarization-diverse measurements. arXiv preprint arXiv:1506.074592015. 
35. Gordon, H.R.; Morel, A.Y. Remote assessment of ocean color for interpretation of satellite visible imagery: A review. 1983.

36. Mobley, C.; Stramski, D.; Bissett, W.; Boss, E. Optical modeling of ocean waters: Is the case 1-case 2 classification still useful? OCEANOGRAPHYWASHINGTON DC-OCEANOGRAPHY SOCIETY- 2004, 17, 60-67.

37. Lim, J.; Choi, M. Assessment of water quality based on landsat 8 operational land imager associated with human activities in korea. Environmental Monitoring and Assessment 2015, 187, 1-17.

38. Santini, F.; Alberotanza, L.; Cavalli, R.M.; Pignatti, S. A two-step optimization procedure for assessing water constituent concentrations by hyperspectral remote sensing techniques: An application to the highly turbid venice lagoon waters. Remote Sensing of Environment 2010, 114, 887-898.

39. Tilstone, G.H.; Lotliker, A.A.; Miller, P.I.; Ashraf, P.M.; Kumar, T.S.; Suresh, T.; Ragavan, B.; Menon, H.B. Assessment of modis-aqua chlorophyll-a algorithms in coastal and shelf waters of the eastern arabian sea. Continental Shelf Research 2013, 65, 14-26.

40. Allan, M.G.; Hamilton, D.P.; Hicks, B.J.; Brabyn, L. Landsat remote sensing of chlorophyll a concentrations in central north island lakes of new zealand. International Journal of Remote Sensing 2011, 32, 2037-2055.

41. Bhatti, A.; Rundquist, D.; Schalles, J.; Ramirez, L. In Application of hyperspectral remotely sensed data for water quality monitoring: Accuracy and limitation, Proceedings of the accuracy symposium, Leicester, UK, 2010.

42. Wang, K.; Wan, Z.; Wang, P.; Sparrow, M.; Liu, J.; Zhou, X.; Haginoya, S. Estimation of surface long wave radiation and broadband emissivity using moderate resolution imaging spectroradiometer (modis) land surface temperature/emissivity products. Journal of Geophysical Research: Atmospheres (1984-2012) 2005, 110.

43. Brezonik, P.; Menken, K.D.; Bauer, M. Landsat-based remote sensing of lake water quality characteristics, including chlorophyll and colored dissolved organic matter (cdom). Lake and Reservoir Management 2005, 21, 373-382.

44. Ahn, Y.-H.; Shanmugam, P.; Lee, J.-H.; Kang, Y.Q. Application of satellite infrared data for mapping of thermal plume contamination in coastal ecosystem of korea. Marine environmental research 2006, 61, 186-201.

45. Casey, K.S.; Brandon, T.B.; Cornillon, P.; Evans, R. The past, present, and future of the avhrr pathfinder sst program. In Oceanography from space, Springer: 2010; pp 273-287. 
46. Handcock, R.; Gillespie, A.; Cherkauer, K.; Kay, J.; Burges, S.; Kampf, S. Accuracy and uncertainty of thermal-infrared remote sensing of stream temperatures at multiple spatial scales. Remote Sensing of Environment 2006, $100,427-440$.

47. Syariz, M.; Jaelani, L.; Subehi, L.; Pamungkas, A.; Koenhardono, E.; Sulisetyono, A. Retrieval of sea surface temperature over poteran island water of indonesia with landsat 8 tirs image: A preliminary algorithm. ISPRS-International Archives of the Photogrammetry, Remote Sensing and Spatial Information Sciences 2015, $1,87-90$.

48. Braga, F.; Giardino, C.; Bassani, C.; Matta, E.; Candiani, G.; Strömbeck, N.; Adamo, M.; Bresciani, M. Assessing water quality in the northern adriatic sea from hico ${ }^{\mathrm{TM}}$ data. Remote Sensing Letters 2013, 4, 1028-1037.

49. Fiorani, L.; Fantoni, R.; Lazzara, L.; Nardello, I.; Okladnikov, I.; Palucci, A. Lidar calibration of satellite sensed cdom in the southern ocean. EARSeL eProc 2006, 5, 89-99.

50. Zhu, W.; Yu, Q.; Tian, Y.Q.; Chen, R.F.; Gardner, G.B. Estimation of chromophoric dissolved organic matter in the mississippi and atchafalaya river plume regions using above surface hyperspectral remote sensing. Journal of Geophysical Research: Oceans (1978-2012) 2011, 116.

51. Imen, S.; Chang, N.-B.; Yang, Y.J. Monitoring spatiotemporal total organic carbon concentrations in lake mead with integrated data fusion and mining (idfm) technique. 2014.

52. Chang, N.-B.; Vannah, B.W.; Yang, Y.J.; Elovitz, M. Integrated data fusion and mining techniques for monitoring total organic carbon concentrations in a lake. International Journal of Remote Sensing 2014, 35, 1064-1093.

53. Chang, N.-B.; Vannah, B. In Monitoring the total organic carbon concentrations in a lake with the integrated data fusion and machine-learning (idfm) technique, SPIE Optical Engineering+ Applications, 2012; International Society for Optics and Photonics: pp 851307-851307-851319.

54. Ferrari, G.M.; Dowell, M.D.; Grossi, S.; Targa, C. Relationship between the optical properties of chromophoric dissolved organic matter and total concentration of dissolved organic carbon in the southern baltic sea region. Marine Chemistry 1996, 55, 299-316.

55. Del Castillo, C.E.; Miller, R.L. On the use of ocean color remote sensing to measure the transport of dissolved organic carbon by the mississippi river plume. Remote Sensing of Environment 2008, 112, 836-844. 
56. Karaska, M.A.; Huguenin, R.L.; Beacham, J.L.; Wang, M.-H.; Jensen, J.R.; Kaufmann, R.S. Aviris measurements of chlorophyll, suspended minerals, dissolved organic carbon, and turbidity in the neuse river, north carolina. Photogrammetric Engineering \& Remote Sensing 2004, 70, 125-133.

57. Bhatti, A.M.; Nasu, S.; Takagi, M.; Nojiri, Y. Assessing the potential of remotely sensed data for water quality monitoring of coastal and inland waters. Res. Bulletin of Kochi Univ. of Tech 2008, 5, 201-207.

58. Onderka, M. Remote sensing and identification of places susceptible to sedimentation in the danube river. 2008.

59. Sudheer, K.; Chaubey, I.; Garg, V. Lake water quality assessment from landsat thematic mapper data using neural network: An approach to optimal band combination selection1. Wiley Online Library: 2006.

60. Wu, G. Seasonal change detection of water quality in texas gulf coast using modis remote sensing data. UC GIS Summer Assembly 2003.

61. Brezonik, P.L.; Olmanson, L.G.; Bauer, M.E.; Kloiber, S.M. Measuring water clarity and quality in minnesota lakes and rivers: A census-based approach using remote-sensing techniques. Cura Reporter 2007, 37, 3-313.

62. Alparslan, E.; Coskun, H.G.; Alganci, U. Water quality determination of küçükçekmece lake, turkey by using multispectral satellite data. The Scientific World Journal 2009, 9, 1215-1229.

63. He, B.; Oki, K.; Wang, Y.; Oki, T. Using remotely sensed imagery to estimate potential annual pollutant loads in river basins. 2009.

64. Font, J.; Boutin, J.; Reul, N.; Spurgeon, P.; Ballabrera-Poy, J.; Chuprin, A.; Gabarró, C.; Gourrion, J.; Guimbard, S.; Hénocq, C. Smos first data analysis for sea surface salinity determination. International journal of remote sensing 2013, 34, 3654-3670.

65. Martin, A.; Boutin, J.; Hauser, D.; Reverdin, G.; Pardé, M.; Zribi, M.; Fanise, P.; Chanut, J.; Lazure, P.; Tenerelli, J. Remote sensing of sea surface salinity from carols l-band radiometer in the gulf of biscay. Geoscience and Remote Sensing, IEEE Transactions on 2012, 50, 1703-1715.

66. Reul, N.; Tenerelli, J.; Chapron, B.; Vandemark, D.; Quilfen, Y.; Kerr, Y. Smos satellite 1 band radiometer: A new capability for ocean surface remote sensing in hurricanes. Journal of Geophysical Research: Oceans (1978-2012) 2012, 117.

67. Vinogradova, N.T.; Ponte, R.M. Assessing temporal aliasing in satellite-based surface salinity measurements. Journal of Atmospheric and Oceanic Technology 2012, 29, 1391-1400. 
68. Nas, B.; Karabork, H.; Ekercin, S.; Berktay, A. In Assessing water quality in the beysehir lake (turkey) by the application of gis, geostatistics and remote sensing, Proceedings of Taal2007: The 12th World Lake Conference, 2007; p 646.

69. Song, K.; Li, L.; Li, S.; Tedesco, L.; Hall, B.; Li, L. Hyperspectral remote sensing of total phosphorus (tp) in three central indiana water supply reservoirs. Water, Air, \& Soil Pollution 2012, 223, 1481-1502.

70. Wu, C.; Wu, J.; Qi, J.; Zhang, L.; Huang, H.; Lou, L.; Chen, Y. Empirical estimation of total phosphorus concentration in the mainstream of the qiantang river in china using landsat tm data. International Journal of Remote Sensing 2010, 31, 2309-2324.

71. El Saadi, A.M.; Yousry, M.M.; Jahin, H.S. Statistical estimation of rosetta branch water quality using multi-spectral data. Water Science 2014, 28, 18-30.

72. Somvanshi, S.; Kunwar, P.; Singh, N.; Shukla, S.; Pathak, V. Integrated remote sensing and gis approach for water quality analysis of gomti river, uttar pradesh. International Journal of Environmental Sciences 2012, 3, 62-74.

73. Chen, C.; Tang, S.; Pan, Z.; Zhan, H.; Larson, M.; Jönsson, L. Remotely sensed assessment of water quality levels in the pearl river estuary, china. Marine pollution bulletin 2007, 54, 1267-1272.

74. He, W.; Chen, S.; Liu, X.; Chen, J. Water quality monitoring in a slightly-polluted inland water body through remote sensing - case study of the guanting reservoir in beijing, china. Frontiers of Environmental Science \& Engineering in China 2008, 2, 163-171.

75. Miao-fen, H.; Xu-feng, X.; Xiao-ping, Q.; Wu-yi, Y.; Yi-min, Z. In Identification mode of chemical oxygen demand in water based on remotely sensing technique and its application, Geoscience and Remote Sensing Symposium, 2007. IGARSS 2007. IEEE International, 2007; IEEE: pp 1738-1741.

76. Whistler, J. A phenological approach to land cover characterization using landsat mss data for analysis of nonpoint source pollution. KARS Rep 1996, 96-91.

77. Ramasamy, S.; Venkatasubramanian, V.; Sam, K.; Chandrasekhar, G.; Ramasamy, S. Remote sensing in pollution monitoring in cauvery river. Remote sensing in water resources 2005, 27-29.

78. Qiu, Y.; Zhang, H.-e.; Tong, X.; Zhang, Y.; Zhao, J. In Monitoring the water quality of water resources reservation area in upper region of huangpu river using remote sensing, Geoscience and Remote Sensing Symposium, 2006. IGARSS 2006. IEEE International Conference on, 2006; IEEE: pp 1082-1085. 
79. Choubey, V. Monitoring surface water conductivity with indian remote sensing satellite data: A case study from central india. IAHS Publications-Series of Proceedings and Reports-Intern Assoc Hydrological Sciences 1994, 219, 317-326.

80. Gürsoy, Ö.; Birdal, A.; Özyonar, F.; Kasaka, E. Determining and monitoring the water quality of kizilirmak river of turkey: First results. The International Archives of Photogrammetry, Remote Sensing and Spatial Information Sciences 2015, 40, 1469.

81. Mallick, J.; Hasan, M.A.; Alashker, Y.; Ahmed, M. Bathymetric and geochemical analysis of lake al-saad, abha, kingdom of saudi arabia using geoinformatics technology. Journal of Geographic Information System 2014, 6, 440.

82. Wang, X.; Fu, L.; He, C. Applying support vector regression to water quality modelling by remote sensing data. International journal of remote sensing 2011, $32,8615-8627$.

83. Hamylton, S.; Silverman, J.; Shaw, E. The use of remote sensing to scale up measures of carbonate production on reef systems: A comparison of hydrochemical and census-based estimation methods. International journal of remote sensing 2013, 34, 6451-6465.

84. Schlichter, D.; Kampmann, H.; Conrady, S. Trophic potential and photoecology of endolithic algae living within coral skeletons. Marine Ecology 1997, 18, 299317.

85. Dekker, A.; Peters, S. The use of the thematic mapper for the analysis of eutrophic lakes: A case study in the netherlands. International Journal of Remote Sensing 1993, 14, 799-821.

86. George, D. The airborne remote sensing of phytoplankton chlorophyll in the lakes and tarns of the english lake district. International Journal of Remote Sensing 1997, 18, 1961-1975.

87. Ritchie, J.C.; Cooper, C.M.; Schiebe, F.R. The relationship of mss and tm digital data with suspended sediments, chlorophyll, and temperature in moon lake, mississippi. Remote Sensing of environment 1990, 33, 137-148.

88. Brivio, P.; Giardino, C.; Zilioli, E. Determination of chlorophyll concentration changes in lake garda using an image-based radiative transfer code for landsat tm images. International Journal of Remote Sensing 2001, 22, 487-502.

89. Brivio, P.A.; Giardino, C.; Zilioli, E. Validation of satellite data for quality assurance in lake monitoring applications. Science of the total environment 2001, 268, 3-18. 
90. Bukata, R.P.; Jerome, J.H.; Kondratyev, A.S.; Pozdnyakov, D.V. Optical properties and remote sensing of inland and coastal waters. CRC press: 1995.

91. Liu, Y.; Islam, M.A.; Gao, J. Quantification of shallow water quality parameters by means of remote sensing. Progress in Physical Geography 2003, 27, 24-43.

92. Östlund, C.; Flink, P.; Strömbeck, N.; Pierson, D.; Lindell, T. Mapping of the water quality of lake erken, sweden, from imaging spectrometry and landsat thematic mapper. Science of the Total Environment 2001, 268, 139-154.

93. Härmä, P.; Vepsäläinen, J.; Hannonen, T.; Pyhälahti, T.; Kämäri, J.; Kallio, K.; Eloheimo, K.; Koponen, S. Detection of water quality using simulated satellite data and semi-empirical algorithms in finland. Science of the Total Environment 2001, 268, 107-121.

94. Gemperli, C. Determination of water quality parameters in indian ponds using remote sensing methods. 2004.

95. Lillesand, T.; Kiefer, R.W.; Chipman, J. Remote sensing and image interpretation. John Wiley \& Sons: 2014.

96. Gitelson, A. The peak near $700 \mathrm{~nm}$ on radiance spectra of algae and water: Relationships of its magnitude and position with chlorophyll concentration. International Journal of Remote Sensing 1992, 13, 3367-3373.

97. Han, L.; Jordan, K.J. Estimating and mapping chlorophyll a concentration in pensacola bay, florida using landsat etm+ data. International Journal of Remote Sensing 2005, 26, 5245-5254.

98. Dekker, A.G.; Malthus, T.J.; Seyhan, E. Quantitative modeling of inland water quality for high-resolution mss systems. Geoscience and Remote Sensing, IEEE Transactions on 1991, 29, 89-95.

99. Hoogenboom, H.; Dekker, A.; Althuis, I.A. Simulation of aviris sensitivity for detecting chlorophyll over coastal and inland waters. Remote Sensing of Environment 1998, 65, 333-340.

100. Thiemann, S.; Kaufmann, H. Lake water quality monitoring using hyperspectral airborne data - a semiempirical multisensor and multitemporal approach for the mecklenburg lake district, germany. Remote sensing of Environment 2002, 81, 228-237.

101. Allee, R.; Johnson, J. Use of satellite imagery to estimate surface chlorophyll a and secchi disc depth of bull shoals reservoir, arkansas, USA. International Journal of Remote Sensing 1999, 20, 1057-1072. 
102. Baban, S.M. Detecting water quality parameters in the norfolk broads, uk, using landsat imagery. International Journal of Remote Sensing 1993, 14, 1247-1267.

103. Lillesand, T.M.; Johnson, W.L.; Deuell, R.L.; Lindstrom, O.M.; Meisner, D.E. Use of landsat data to predict the trophic state of minnesota lakes. Photogrammetric Engineering and Remote Sensing 1983, 49, 219-229.

104. Mayo, M.; Gitelson, A.; Yacobi, Y.; Ben-Avraham, Z. Chlorophyll distribution in lake kinneret determined from landsat thematic mapper data. Remote Sensing $1995,16,175-182$.

105. Zilioli, E.; Brivio, P. The satellite derived optical information for the comparative assessment of lacustrine water quality. Science of the Total Environment 1997, $196,229-245$.

106. Allan, M.G.; Hicks, B.J.; Brabyn, L. Remote sensing of water quality in the rotorua lakes. 2007.

107. Yang, M.-D.; Merry, C.J.; Sykes, R.M. Adaptive short-term water quality forecasts using remote sensing and gis. Ohio State University, 1996.

108. Rundquist, D.C.; Han, L.; Schalles, J.F.; Peake, J.S. Remote measurement of algal chlorophyll in surface waters: The case for the first derivative of reflectance near $690 \mathrm{~nm}$. Photogrammetric Engineering and Remote Sensing 1996, 62, 195-200.

109. Moses, W.J.; Bowles, J.H.; Corson, M.R. Expected improvements in the quantitative remote sensing of optically complex waters with the use of an optically fast hyperspectral spectrometer-a modeling study. Sensors 2015, 15, 6152-6173.

110. Ryan, J.P.; Davis, C.O.; Tufillaro, N.B.; Kudela, R.M.; Gao, B.-C. Application of the hyperspectral imager for the coastal ocean to phytoplankton ecology studies in monterey bay, ca, USA. Remote Sensing 2014, 6, 1007-1025.

111. Keith, D.J.; Schaeffer, B.A.; Lunetta, R.S.; Gould Jr, R.W.; Rocha, K.; Cobb, D.J. Remote sensing of selected water-quality indicators with the hyperspectral imager for the coastal ocean (hico) sensor. International Journal of Remote Sensing 2014, $35,2927-2962$.

112. Ruiz-Verdú, A.; Domínguez-Gómez, J.-A.; Peña-Martínez, R. In Use of chris for monitoring water quality in rosarito reservoir, Proceedings of the Third Chris Proba Workshop, ESA-ESRIN, 2005.

113. Menken, K.D.; Brezonik, P.L.; Bauer, M.E. Influence of chlorophyll and colored dissolved organic matter (cdom) on lake reflectance spectra: Implications for measuring lake properties by remote sensing. Lake and Reservoir Management 2006, 22, 179-190. 
114. Hunter, P.D.; Tyler, A.N.; Carvalho, L.; Codd, G.A.; Maberly, S.C. Hyperspectral remote sensing of cyanobacterial pigments as indicators for cell populations and toxins in eutrophic lakes. Remote Sensing of Environment 2010, 114, 2705-2718.

115. Peña-Martínez, R.; Ruiz-Verdú, A.; Domínguez-Gómez, J.A. In Mapping of photosynthetic pigments in spanish inland waters using meris imagery, Proceedings of the 2004 Envisat \& ERS Symposium. Salzburg, Austria, 2004.

116. Le, C.; Hu, C.; Cannizzaro, J.; English, D.; Muller-Karger, F.; Lee, Z. Evaluation of chlorophyll-a remote sensing algorithms for an optically complex estuary. Remote Sensing of Environment 2013, 129, 75-89.

117. Moses, W.J.; Gitelson, A.A.; Perk, R.L.; Gurlin, D.; Rundquist, D.C.; Leavitt, B.C.; Barrow, T.M.; Brakhage, P. Estimation of chlorophyll-a concentration in turbid productive waters using airborne hyperspectral data. Water research 2012, 46, 993-1004.

118. Turner, D. June 2010. Remote Sensing of Chlorophyll a Concentrations to Support the Deschutes Basin Lake and Reservoirs TMDLs. Department of Environmental Quality. Portland, OR 2010.

119. Gómez, J.A.D.; Alonso, C.A.; García, A.A. Remote sensing as a tool for monitoring water quality parameters for mediterranean lakes of european union water framework directive (wfd) and as a system of surveillance of cyanobacterial harmful algae blooms (scyanohabs). Environmental monitoring and assessment 2011, 181, 317-334.

120. Osinska-Skotak, K.; Kruk, M.; Mróz, M. The spatial diversification of lake water quality parameters in mazurian lakes in summertime. 2007.

121. Giardino, C.; Brando, V.E.; Dekker, A.G.; Strömbeck, N.; Candiani, G. Assessment of water quality in lake garda (italy) using hyperion. Remote Sensing of Environment 2007, 109, 183-195.

122. Garcia, M.L.; Caselles, V. Mapping burns and natural reforestation using thematic mapper data. Geocarto International 1991, 6, 31-37.

123. Lopez-Garcia, M.; Caselles, V. Use of thematic mapper data to assess water quality in albufera lagoon of valencia (spain). Advances in digital image processing 1987, 510-519.

124. Osińska-Skotak, K.; Kruk, M.; Mróz, M.; Ciołkowska, M. Chris/proba superspectral data for inland water quality studies. W: Imaging spectrocsopy-new quality in environmental studies, Warsaw 2005, 357-366.

125. Santini, F.; Alberotanza, L.; Cavalli, R.M.; Pignatti, S. A two-step optimization procedure for assessing water constituent concentrations by hyperspectral remote 
sensing techniques: An application to the highly turbid venice lagoon waters. Remote Sensing of Environment 2010, 114, 887-898.

126. Lathrop, R.G. Use of thematic mapper data to assess water quality in green bay and central lake michigan. Photogramm Eng Remote Sens 1986, 52, 671-680.

127. Ekercin, S. Water quality retrievals from high resolution ikonos multispectral imagery: A case study in istanbul, turkey. Water, air, and soil pollution 2007, 183, 239-251.

128. Zhang, C.; Han, M. Mapping chlorophyll-a concentration in laizhou bay using landsat 8 oli data. 2015.

129. Kim, S.-i.; Kim, H.-c.; Hyun, C.-U. High resolution ocean color products estimation in fjord of svalbard, arctic sea using landsat-8 oli. Korean Journal of Remote Sensing 2014, 30.

130. Mannheim, S.; Segl, K.; Heim, B.; Kaufmann, H. In Monitoring of lake water quality using hyperspectral chris-proba data, Proc. of the 2nd CHRIS/PROBA workshop, ESA/ESRIN, Frascati, Italy, 2004; pp 28-30.

131. Choe, E.-Y.; Lee, J.-W.; Lee, J.-K. Estimation of chlorophyll-a concentrations in the nakdong river using high-resolution satellite image. Korean Journal of Remote Sensing 2011, 27, 613-623.

132. Qi, L.; Hu, C.; Duan, H.; Barnes, B.B.; Ma, R. An eof-based algorithm to estimate chlorophyll a concentrations in taihu lake from modis land-band measurements: Implications for near real-time applications and forecasting models. Remote Sensing 2014, 6, 10694-10715.

133. Feng, L.; Hu, C.; Han, X.; Chen, X.; Qi, L. Long-term distribution patterns of chlorophyll-a concentration in china's largest freshwater lake: Meris fullresolution observations with a practical approach. Remote Sensing 2014, 7, 275 299.

134. Aiken, G.R.; McKnight, D.M.; Wershaw, R.L.; MacCarthy, P. Humic substances in soil, sediment, and water: Geochemistry, isolation and characterization. John Wiley \& Sons: 1985.

135. Corbett, C.A. Colored dissolved organic matter (cdom) workshop summary. 2007.

136. Miller, R.L.; DelCastillo, C.E.; Powell, R.T.; DSa, E.; Spiering, B. Mapping cdom concentration in waters influenced by the mississippi river plume. 2002.

137. Strömbeck, N.; Pierson, D.C. The effects of variability in the inherent optical properties on estimations of chlorophyll a by remote sensing in swedish freshwaters. Science of the total environment 2001, 268, 123-137. 
138. Mannino, A.; Russ, M.E.; Hooker, S.B. Algorithm development and validation for satellite derived distributions of doc and cdom in the us middle atlantic bight. Journal of Geophysical Research: Oceans (1978-2012) 2008, 113.

139. Antoine, D.; d'Ortenzio, F.; Hooker, S.B.; Bécu, G.; Gentili, B.; Tailliez, D.; Scott, A.J. Assessment of uncertainty in the ocean reflectance determined by three satellite ocean color sensors (meris, seawifs and modis a) at an offshore site in the mediterranean sea (boussole project). Journal of Geophysical Research: Oceans (1978-2012) 2008, 113.

140. Lee, Z.; Carder, K.L.; Arnone, R.A. Deriving inherent optical properties from water color: A multiband quasi-analytical algorithm for optically deep waters. Applied optics 2002, 41, 5755-5772.

141. Mobley, C.D. Light and water: Radiative transfer in natural waters. Academic press: 1994.

142. Nelson, N.B.; Siegel, D.A. Chromophoric dom in the open ocean. Biogeochemistry of marine dissolved organic matter 2002, 547-578.

143. Hoge, F.E.; Williams, M.E.; Swift, R.N.; Yungel, J.K.; Vodacek, A. Satellite retrieval of the absorption coefficient of chromophoric dissolved organic matter in continental margins. Journal of Geophysical Research: Oceans (1978-2012) 1995, $100,24847-24854$.

144. Lee, Z.; Carder, K.L.; Mobley, C.D.; Steward, R.G.; Patch, J.S. Hyperspectral remote sensing for shallow waters: 2. Deriving bottom depths and water properties by optimization. Applied Optics 1999, 38, 3831-3843.

145. Kutser, T.; Pierson, D.C.; Kallio, K.Y.; Reinart, A.; Sobek, S. Mapping lake cdom by satellite remote sensing. Remote Sensing of Environment 2005, 94, 535-540.

146. Pan, X.; Mannino, A.; Russ, M.E.; Hooker, S.B. Remote sensing of the absorption coefficients and chlorophyll a concentration in the united states southern middle atlantic bight from seawifs and modis aqua. Journal of Geophysical Research: Oceans (1978-2012) 2008, 113.

147. Yu, Q.; Tian, Y.Q.; Chen, R.F.; Liu, A.; Gardner, G.B.; Zhu, W. Functional linear analysis of in situ hyperspectral data for assessing cdom in rivers. Photogrammetric Engineering \& Remote Sensing 2010, 76, 1147-1158.

148. Ammenberg, P.; Flink, P.; Lindell, T.; Pierson, D.; Strombeck, N. Bio-optical modelling combined with remote sensing to assess water quality. International Journal of Remote Sensing 2002, 23, 1621-1638. 
149. Doxaran, D.; Cherukuru, N.; Lavender, S.J. Apparent and inherent optical properties of turbid estuarine waters: Measurements, empirical quantification relationships, and modeling. Applied Optics 2006, 45, 2310-2324.

150. Gong, P.; Pu, R.; Biging, G.S.; Larrieu, M.R. Estimation of forest leaf area index using vegetation indices derived from hyperion hyperspectral data. Geoscience and Remote Sensing, IEEE Transactions on 2003, 41, 1355-1362.

151. Pu, R.; Yu, Q.; Gong, P.; Biging, G. Eo 1 hyperion, ali and landsat 7 etm+ data comparison for estimating forest crown closure and leaf area index. International Journal of Remote Sensing 2005, 26, 457-474.

152. $\mathrm{Xu}, \mathrm{B}$; Gong, P. Land-use/land-cover classification with multispectral and hyperspectral eo-1 data. Photogrammetric Engineering \& Remote Sensing 2007, 73, 955-965.

153. Ferrari, G.M.; Hoepffner, N.; Mingazzini, M. Optical properties of the water in a deltaic environment: Prospective tool to analyze satellite data in turbid waters. Remote sensing of environment 1996, 58, 69-80.

154. Del Castillo, C.E.; Gilbes, F.; Coble, P.G.; Müller Karger, F.E. On the dispersal of riverine colored dissolved organic matter over the west florida shelf. Limnology and Oceanography 2000, 45, 1425-1432.

155. Stedmon, C.A.; Markager, S.; Søndergaard, M.; Vang, T.; Laubel, A.; Borch, N.H.; Windelin, A. Dissolved organic matter (dom) export to a temperate estuary: Seasonal variations and implications of land use. Estuaries and Coasts 2006, 29, 388-400.

156. Spencer, R.G.; Ahad, J.M.; Baker, A.; Cowie, G.L.; Ganeshram, R.; UpstillGoddard, R.C.; Uher, G. The estuarine mixing behaviour of peatland derived dissolved organic carbon and its relationship to chromophoric dissolved organic matter in two north sea estuaries (uk). Estuarine, Coastal and Shelf Science 2007, $74,131-144$.

157. Vignudelli, S.; Santinelli, C.; Murru, E.; Nannicini, L.; Seritti, A. Distributions of dissolved organic carbon (doc) and chromophoric dissolved organic matter (cdom) in coastal waters of the northern tyrrhenian sea (italy). Estuarine, Coastal and Shelf Science 2004, 60, 133-149.

158. Ortega-Retuerta, E.; Siegel, D.; Nelson, N.; Duarte, C.M.; Reche, I. Observations of chromophoric dissolved and detrital organic matter distribution using remote sensing in the southern ocean: Validation, dynamics and regulation. Journal of Marine Systems 2010, 82, 295-303. 
159. Paavel, B.; Arst, H.; Metsamaa, L.; Toming, K.; Reinart, A. Optical investigations of cdom-rich coastal waters in pärnu bay. Estonian Journal of Earth Sciences 2011, 60, 102 .

160. Palacios, S.L.; Peterson, T.D.; Kudela, R.M. Development of synthetic salinity from remote sensing for the columbia river plume. Journal of Geophysical Research: Oceans (1978-2012) 2009, 114.

161. D'Alimonte, D.; Zibordi, G.; Berthon, J.-F. Determination of cdom and nppm absorption coefficient spectra from coastal water remote sensing reflectance. Geoscience and Remote Sensing, IEEE Transactions on 2004, 42, 1770-1777.

162. Georgas, N.; Li, W.; Blumberg, A.F. Investigation of coastal cdom distributions using in-situ and remote sensing observations and a predictive cdom fate and transport model; DTIC Document: 2009.

163. Alvarez-Borrego, S. Satellite derived photosynthetic pigment surveys: A review of marine phytoplankton biomass and productivity. Oceanographic Literature Review 1996, 11, 1174-1175.

164. Schroeder, T.; Brando, V.; Cherukuru, N.; Clementson, L.; Blondeau-Patissier, D.; Dekker, A.; Schaale, M.; Fischer, J. In Remote sensing of apparent and inherent optical properties of tasmanian coastal waters: Application to modis data, Proceedings of The XIX Ocean Optics Conference, Barga, Italy, 2008.

165. Ahn, Y.; Shanmugam, P.; Moon, J.; Ryu, J.-H. In Satellite remote sensing of a low-salinity water plume in the east china sea, Annales Geophysicae, 2008; Copernicus GmbH: pp 2019-2035.

166. D'Sa, E. Colored dissolved organic matter in coastal waters influenced by the atchafalaya river, USA: Effects of an algal bloom. Journal of Applied Remote Sensing 2008, 2, 023502-023502-023511.

167. D'Sa, E.J.; Miller, R.L. Bio-optical properties in waters influenced by the mississippi river during low flow conditions. Remote sensing of environment 2003, 84, 538-549.

168. Tehrani, N.C.; D'Sa, E.J.; Osburn, C.L.; Bianchi, T.S.; Schaeffer, B.A. Chromophoric dissolved organic matter and dissolved organic carbon from seaviewing wide field-of-view sensor (seawifs), moderate resolution imaging spectroradiometer (modis) and meris sensors: Case study for the northern gulf of mexico. Remote Sensing 2013, 5, 1439-1464.

169. Kutser, T. Passive optical remote sensing of cyanobacteria and other intense phytoplankton blooms in coastal and inland waters. International Journal of Remote Sensing 2009, 30, 4401-4425. 
170. Kutser, T.; Pierson, D.; Tranvik, L.; Reinart, A.; Sobek, S.; Kallio, K. Estimating the colored dissolved organic matter absorption coefficient in lakes using satellite remote sensing. Ecosystems 2005, 8, 709-720.

171. Tiwari, S.; Shanmugam, P. An optical model for the remote sensing of coloured dissolved organic matter in coastal/ocean waters. Estuarine, Coastal and Shelf Science 2011, 93, 396-402.

172. Kutser, T.; Paavel, B.; Verpoorter, C.; Kauer, T.; Vahtmäe, E. In Remote sensing of water quality in optically complex lakes, Proceedings of the XXII Congress of the International Society for Photogrammetry and Remote Sensing, Melbourne, Australia, 2012.

173. Shahraiyni, T.H.; Schaale, M.; Fell, F.; Fischer, J.; Preusker, R.; Vatandoust, M.; Shouraki, B.S.; Tajrishy, M.; Khodaparast, H.; Tavakoli, A. Application of the active learning method for the estimation of geophysical variables in the caspian sea from satellite ocean colour observations. International Journal of Remote Sensing 2007, 28, 4677-4683.

174. Kishino, M.; Tanaka, A.; Ishizaka, J. Retrieval of chlorophyll a, suspended solids, and colored dissolved organic matter in tokyo bay using aster data. Remote Sensing of Environment 2005, 99, 66-74.

175. Johannessen, S.; Miller, W.; Cullen, J. Calculation of uv attenuation and colored dissolved organic matter absorption spectra from measurements of ocean color. Journal of Geophysical Research: Oceans (1978-2012) 2003, 108.

176. Lindell, L.; Steinvall, O.; Jonsson, M.; Claesson, T. Mapping of coastal-water turbidity using landsat imagery. International Journal of Remote Sensing 1985, 6, 629-642.

177. Lee, Z.; Shang, S.; Hu, C.; Du, K.; Weidemann, A.; Hou, W.; Lin, J.; Lin, G. Secchi disk depth: A new theory and mechanistic model for underwater visibility. Remote Sensing of Environment 2015, 169, 139-149.

178. Lathrop, R. Landsat thematic mapper monitoring of turbid inland water quality. Photogrammetric Engineering and Remote Sensing;(United States) 1992, 58.

179. Kloiber, S.M.; Anderle, T.H.; Brezonik, P.L.; Olmanson, L.; Bauer, M.E.; Brown, D.A. Trophic state assessment of lakes in the twin cities(minnesota, USA) region by satellite imagery. Advances in limnology. Stuttgart 2000, 137-151.

180. Dewidar, K.; Khedr, A. Water quality assessment with simultaneous landsat-5 tm at manzala lagoon, egypt. Hydrobiologia 2001, 457, 49-58.

181. Hadjimitsis, D.; Toulios, L.; Clayton, C.; Spanos, K. In Dam trophic state evaluation using satellite remote sensing techniques: A case study of 
asprokremmos dam in paphos, cyprus, Proceedings of the International Conference on Protection and Restoration VI, 2004.

182. contributors, W. Secchi disk. https://en.wikipedia.org/w/index.php?title=Secchi_disk\&oldid=710966414 (28 July 2016),

183. Choubey, V. Laboratory experiment, field and remotely sensed data analysis for the assessment of suspended solids concentration and secchi depth of the reservoir surface water. International Journal of Remote Sensing 1998, 19, 3349-3360.

184. Hurley, P.; Payzant, L.; Topliss, J. In Monitoring offshore water quality from space, IGARSS' 88. Remote Sensing: Moving Towards the 21 st Century. Proceedings of the 1988 International Geoscience and Remote Sensing Symposium, 12-16 September 1988, Edinburgh, Scotland., 1988.

185. Pattiaratchi, C.; Lavery, P.; Wyllie, A.; Hick, P. Estimates of water quality in coastal waters using multi-date landsat thematic mapper data. International Journal of Remote Sensing 1994, 15, 1571-1584.

186. Lavery, P.; Pattiaratchi, C.; Wyllie, A.; Hick, P. Water quality monitoring in estuarine waters using the landsat thematic mapper. Remote Sensing of Environment 1993, 46, 268-280.

187. Álvarez-Robles, J.A.; Zarazaga-Soria, F.J.; Ángel, M.; Latre, R.B.; MuroMedrano, P.R. In Water quality monitoring based on sediment distribution using satellite imagery, 9th AGILE Conference on Geographic Information Science, Visegrad, Hungary, 2006; pp 144-150.

188. Garrison, V.; Bryant, N. Lake classification in vermont. 1981.

189. Khorram, S.; Cheshire, H.; Geraci, A.L.; ROSA, G.L. Water quality mapping of augusta bay, italy from landsat-tm data. International Journal of Remote Sensing 1991, 12, 803-808.

190. Verdin, J.P. Monitoring water quality conditions in a large western reservoir with landsat imagery. Photogrammetric engineering and remote sensing 1985, 51, 343353.

191. Mausel, P.; Karaska, M.; Mao, C.; Escobar, D.; Everitt, J. Insights into secchi transparency through computer analysis of aerial multispectral video data. TitleREMOTE SENSING 1991, 12, 2485-2492.

192. Braga, C.Z.F.; Setzer, A.W.; de Lacerda, L.D. Water quality assessment with simultaneous landsat-5 tm data at guanabara bay, rio de janeiro, brazil. Remote Sensing of Environment 1993, 45, 95-106. 
193. Powell, R.; Brooks, C.; French, N.; Shuchman, R. Remote sensing of lake clarity. Michigan Tech Research Institute (MTRI) 2008.

194. Stefouli, M.; Dimitrakopoulos, D.; Papadimitrakis, J.; Charou, E. In Monitoring and assessing internal waters (lakes) using operational space borne data and field measurements, European Water Resources Association on Water Resources management-EWRA Symposium, 2004; pp 2-4.

195. Cox Jr, R.M.; Forsythe, R.D.; Vaughan, G.E.; Olmsted, L.L. Assessing water quality in catawba river reservoirs using landsat thematic mapper satellite data. Lake and Reservoir Management 1998, 14, 405-416.

196. Kratzer, S.; Håkansson, B.; Sahlin, C. Assessing secchi and photic zone depth in the baltic sea from satellite data. AMBIO: A Journal of the Human Environment 2003, 32, 577-585.

197. Sriwongsitanon, N.; Surakit, K.; Thianpopirug, S. Influence of atmospheric correction and number of sampling points on the accuracy of water clarity assessment using remote sensing application. Journal of Hydrology 2011, 401, 203-220.

198. Lathrop, R.; Lillesand, T.M. Monitoring water quality and river plume transport in green bay, lake michigan with spot-1 imagery. Photogrammetric Engineering and Remote Sensing 1989, 55, 349-354.

199. Olmanson, L.G.; Kloiber, S.M.; Bauer, M.E.; Brezonik, P.L. Image processing protocol for regional assessments of lake water quality. Water Resources Center Technical Report 2001, 14.

200. Batzli, S. Mapping lake clarity: About the map. http://www.lakesat.org/maptext1.php (2003),

201. Fuller, L.M.; Aichele, S.S.; Minnerick, R.J. Predicting water quality by relating secchi-disk transparency and chlorophyll a measurements to satellite imagery for michigan inland lakes, august 2002. US Department of the Interior, US Geological Survey: 2004.

202. Myint, S.; Walker, N. Quantification of surface suspended sediments along a river dominated coast with noaa avhrr and seawifs measurements: Louisiana, USA. International Journal of Remote Sensing 2002, 23, 3229-3249.

203. Wass, P.; Marks, S.; Finch, J.; Leeks, G.J.L.; Ingram, J. Monitoring and preliminary interpretation of in-river turbidity and remote sensed imagery for suspended sediment transport studies in the humber catchment. Science of the Total Environment 1997, 194, 263-283. 
204. Nechad, B.; Ruddick, K.; Park, Y. Calibration and validation of a generic multisensor algorithm for mapping of total suspended matter in turbid waters. Remote Sensing of Environment 2010, 114, 854-866.

205. Curran, P.; Hansom, J.; Plummer, S.; Pedley, M. Multispectral remote sensing of nearshore suspended sediments: A pilot study. International Journal of Remote Sensing 1987, 8, 103-112.

206. Novo, E.; Hansom, J.; Curran, P. The effect of viewing geometry and wavelength on the relationship between reflectance and suspended sediment concentration. International Journal of Remote Sensing 1989, 10, 1357-1372.

207. Feng, L.; Hu, C.; Chen, X.; Song, Q. Influence of the three gorges dam on total suspended matters in the yangtze estuary and its adjacent coastal waters: Observations from modis. Remote Sensing of Environment 2014, 140, 779-788.

208. Doxaran, D.; Froidefond, J.-M.; Lavender, S.; Castaing, P. Spectral signature of highly turbid waters: Application with spot data to quantify suspended particulate matter concentrations. Remote sensing of Environment 2002, 81, 149-161.

209. Dekker, A.G.; Vos, R.; Peters, S. Analytical algorithms for lake water tsm estimation for retrospective analyses of tm and spot sensor data. International Journal of Remote Sensing 2002, 23, 15-35.

210. Akbar, T.; Hassan, Q.; Achari, G. A remote sensing based framework for predicting water quality of different source waters. The International Archives of Photogrammetry, Remote Sensing and Spatial Information Sciences 2010.

211. Ritchie, J.C.; Schiebe, F.R.; McHENRY, J. Remote sensing of suspended sediments in surface waters. American Society of Photogrammetry, Journal of 1976, 42.

212. Mohd Hasmadi, I.; Norsaliza, U. Analysis of spot-5 data for mapping turbidity level of river klang, peninsular malaysia. Applied Remote Sensing Journal 2010, $1,14-18$.

213. Papoutsa, C.; Retalis, A.; Toulios, L.; Hadjimitsis, D.G. Defining the landsat $\mathrm{tm} / \mathrm{etm}+$ and chris/proba spectral regions in which turbidity can be retrieved in inland waterbodies using field spectroscopy. International Journal of Remote Sensing 2014, 35, 1674-1692.

214. Mahato, L.L.; Pathak, A.K.; Kapoor, D.; Patel, N.; Murthy, M. Surface water monitoring and evaluation of indravati reservoir using the application of principal component analysis using satellite remote sensing technology. 2004.

215. Swanson, H., Zurawell, R., . Steele lake water quality 
monitoring report; Monitoring and Evaluation Branch, Environmental Assurance Division, Alberta Environment, Edmonton, Alberta. , 2006.

216. Reed-Andersen, T.; Carpenter, S.R.; Lathrop, R.C. Phosphorus flow in a watershed-lake ecosystem. Ecosystems 2000, 3, 561-573.

217. Carlson, R.E. A trophic state index for lakes1. Limnology and oceanography 1977, 22, 361-369.

218. Kutser, T.; Arst, H.; Miller, T.; Käärmann, L.; Milius, A. Telespectrometrical estimation of water transparency, chlorophyll-a and total phosphorus concentration of lake peipsi. International Journal of Remote Sensing 1995, 16, 3069-3085.

219. Wang, Y.; Xia, H.; Fu, J.; Sheng, G. Water quality change in reservoirs of shenzhen, china: Detection using landsat/tm data. Science of the Total Environment 2004, 328, 195-206.

220. Busse, L.B.; Simpson, J.C.; Cooper, S.D. Relationships among nutrients, algae, and land use in urbanized southern california streams. Canadian Journal of Fisheries and Aquatic Sciences 2006, 63, 2621-2638.

221. Uusitalo, R.; Yli-Halla, M.; Turtola, E. Suspended soil as a source of potentially bioavailable phosphorus in surface runoff waters from clay soils. Water Research 2000, 34, 2477-2482.

222. Hoyer, M.V.; Frazer, T.K.; Notestein, S.K.; Canfield, J., Daniel E. Nutrient, chlorophyll, and water clarity relationships in florida's nearshore coastal waters with comparisons to freshwater lakes. Canadian Journal of Fisheries and Aquatic Sciences 2002, 59, 1024-1031.

223. Vollenweider, R.A. Advances in defining critical loading levels for phosphorus in lake eutrophication. Memorie dell'Istituto Italiano di Idrobiologia, Dott. Marco de Marchi Verbania Pallanza 1976.

224. McQueen, D.J.; Post, J.R.; Mills, E.L. Trophic relationships in freshwater pelagic ecosystems. Canadian Journal of Fisheries and Aquatic Sciences 1986, 43, 15711581 .

225. Chen, Y.; Fan, C.; Teubner, K.; Dokulil, M. Changes of nutrients and phytoplankton chlorophyll-a in a large shallow lake, taihu, china: An 8-year investigation. Hydrobiologia 2003, 506, 273-279.

226. Müller-Navarra, D.C.; Brett, M.T.; Park, S.; Chandra, S.; Ballantyne, A.P.; Zorita, E.; Goldman, C.R. Unsaturated fatty acid content in seston and tropho-dynamic coupling in lakes. Nature 2004, 427, 69-72. 
227. Schindler, D. Evolution of phosphorus limitation in lakes. Science 1977, 195, 260-262.

228. Heiskary, S.; Wilson, B. Minnesota lake water quality: Developing nutrient criteria, 3rd edn (st paul, mn: Minnesota pollution control agency). 2005.

229. Bistani, L.F.C. Identifying total phosphorus spectral signal in a tropical estuary lagoon using an hyperspectral sensor and its applicaton to water quality modeling. UNIVERSITY OF PUERTO RICO MAYAGÜEZ CAMPUS, 2009.

230. Song, K.; Wang, Z.; Blackwell, J.; Zhang, B.; Li, F.; Zhang, Y.; Jiang, G. Water quality monitoring using landsat themate mapper data with empirical algorithms in chagan lake, china. Journal of Applied Remote Sensing 2011, 5, 053506053506-053516.

231. Wu, M.; Zhang, W.; Wang, X.; Luo, D. Application of modis satellite data in monitoring water quality parameters of chaohu lake in china. Environmental monitoring and assessment 2009, 148, 255-264.

232. Tripathi, N.K.; Patil, A.A. Spectral characterization of aquatic nutrients and water quality parameters in marine environment. 2004, 15, 25-31.

233. Chen, Q.; Zhang, Y.; Hallikainen, M. Water quality monitoring using remote sensing in support of the eu water framework directive (wfd): A case study in the gulf of finland. Environmental monitoring and assessment 2007, 124, 157-166.

234. Haakstad, M.; Kogeler, J.; Dahle, S. Studies of sea surface temperatures in selected northern norwegian fjords using landsat tm data. Polar research 1994, 13, 95-10.

235. River, S.; Sub-Basins, S.R. Aerial surveys using thermal infrared and color videography. 2004.

236. Carbonneau, P.; Piégay, H. Fluvial remote sensing for science and management. John Wiley \& Sons: 2012.

237. Torgersen, C.E.; Faux, R.N.; McIntosh, B.A.; Poage, N.J.; Norton, D.J. Airborne thermal remote sensing for water temperature assessment in rivers and streams. Remote Sensing of Environment 2001, 76, 386-398.

238. Handcock, R.N.; Torgersen, C.E.; Cherkauer, K.A.; Gillespie, A.R.; Tockner, K.; Faux, R.; Tan, J.; Carbonneau, P.E. Thermal infrared remote sensing of water temperature in riverine landscapes. Fluvial Remote Sensing for Science and Management 2012, 85-113.

239. Vesecky, J.; Onstott, R.; Wang, N.-Y.; Lettvin, E.; Slawski, J.; Shuchman, R. In Water surface temperature estimates using active and passive microwave remote 
sensing: Preliminary results from an outdoor wind-wave tank, Geoscience and Remote Sensing Symposium, 1994. IGARSS'94. Surface and Atmospheric Remote Sensing: Technologies, Data Analysis and Interpretation., International, 1994; IEEE: pp 1021-1023.

240. Giardino, C.; Pepe, M.; Brivio, P.A.; Ghezzi, P.; Zilioli, E. Detecting chlorophyll, secchi disk depth and surface temperature in a sub-alpine lake using landsat imagery. Science of the Total Environment 2001, 268, 19-29.

241. Thomas, A.; Byrne, D.; Weatherbee, R. Coastal sea surface temperature variability from landsat infrared data. Remote Sensing of Environment 2002, 81, 262-272.

242. Fisher, J.I.; Mustard, J.F. High spatial resolution sea surface climatology from landsat thermal infrared data. Remote Sensing of Environment 2004, 90, 293-307.

243. Wloczyk, C.; Richter, R.; Borg, E.; Neubert, W. Sea and lake surface temperature retrieval from landsat thermal data in northern germany. International Journal of Remote Sensing 2006, 27, 2489-2502.

244. Trisakti, B.; Sulma, S.; Budhiman, S. In Study of sea surface temperature (sst) using landsat-7/etm (in comparison with sea surface temperature of noaa-12 avhrr), Proceedings The Thirteenth Workshop of OMISAR (WOM-13) on Validation and Application of Satellite Data for Marine Resources Conservation. Denpasar, 2004.

245. Tarantino, E. Monitoring spatial and temporal distribution of sea surface temperature with tir sensor data. Italian Journal of Remote Sensing 2012, 44, 97 107.

246. Kay, J.E.; Kampf, S.K.; Handcock, R.N.; Cherkauer, K.A.; Gillespie, A.R.; Burges, S.J. Accuracy of lake and stream temperatures estimated from thermal infrared images1. Wiley Online Library: 2005.

247. Kang, K.-m.; Kim, S.H.; Kim, D.-j.; Cho, Y.-K.; Lee, S.-H. In Comparison of coastal sea surface temperature derived from ship-, air-, and space-borne thermal infrared systems, Geoscience and Remote Sensing Symposium (IGARSS), 2014 IEEE International, 2014; IEEE: pp 4419-4422.

248. Brando, V.; Braga, F.; Zaggia, L.; Giardino, C.; Bresciani, M.; Matta, E.; Bellafiore, D.; Ferrarin, C.; Maicu, F.; Benetazzo, A. High-resolution satellite turbidity and sea surface temperature observations of river plume interactions during a significant flood event. Ocean Science 2015, 11, 909-920.

249. Morozov, E.; Kondrik, D.; Fedorova, A.; Pozdnyakov, D.; Tang, D.; Pettersson, L. A spaceborne assessment of cyclone impacts on barents sea surface 
temperature and chlorophyll. International Journal of Remote Sensing 2015, 36, 1921-1941.

250. Bierman, P.E. Remote sensing to monitor interactions between aquaculture and the environment of spencer gulf, south australia. 2010.

251. Cherkauer, K.A.; Burges, S.J.; Handcock, R.N.; Kay, J.E.; Kampf, S.K.; Gillespie, A.R. Assessing satellite-based and aircraft-based thermal infrared remote sensing for monitoring pacific northwest river temperature. Journal of the American Water Resources Association 2005, 41, 1149-1159.

252. McMillin, L.; Crosby, D. Theory and validation of the multiple window sea surface temperature technique. Journal of Geophysical Research: Oceans (19782012) $1984,89,3655-3661$.

253. Walton, C.C. Nonlinear multichannel algorithms for estimating sea surface temperature with avhrr satellite data. Journal of Applied Meteorology 1988, 27, 115-124.

254. Irbe, J.; Cross, R.; Saulesleja, A. Remote sensing of surface water temperature of the great lakes and off the canadian east coast. Northwest Atlantic Fisheries Organization Scientific Council Studies 1982, 31-39.

255. McClain, E.P.; Pichel, W.G.; Walton, C.C. Comparative performance of avhrr based multichannel sea surface temperatures. Journal of Geophysical Research: Oceans (1978-2012) 1985, 90, 11587-11601.

256. Gaiser, P.W.; St Germain, K.M.; Twarog, E.M.; Poe, G.; Purdy, W.; Richardson, D.; Grossman, W.; Jones, W.L.; Spencer, D.; Golba, G. The windsat spaceborne polarimetric microwave radiometer: Sensor description and early orbit performance. Geoscience and Remote Sensing, IEEE Transactions on 2004, 42, 2347-2361.

257. Meissner, T.; Wentz, F. In High quality sea surface temperature from the windsat radiometer: Algorithm and validation, 2007 IEEE International Geoscience and Remote Sensing Symposium, 2007.

258. Llewellyn-Jones, D.; Edwards, M.; Mutlow, C.; Birks, A.; Barton, I.; Tait, H. Aatsr: Global-change and surface-temperature measurements from envisat. ESA bulletin 2001, 105, 11-21.

259. Corlett, G.; Barton, I.; Donlon, C.; Edwards, M.; Good, S.; Horrocks, L.; Llewellyn-Jones, D.; Merchant, C.; Minnett, P.; Nightingale, T. The accuracy of sst retrievals from aatsr: An initial assessment through geophysical validation against in situ radiometers, buoys and other sst data sets. Advances in Space Research 2006, 37, 764-769. 
260. O'Carroll, A.; Watts, J.; Horrocks, L.; Saunders, R.; Rayner, N. Validation of the aatsr meteo product sea surface temperature. Journal of Atmospheric and Oceanic Technology 2006, 23, 711-726.

261. Kong, X.; Noyes, E.; Corlett, G.; Remedios, J.; Llewellyn-Jones, D.; Merchant, C.J.; Embury, O. In Saharan dust corrections for the envisat aatsr sst product, ENVISAT Symposium, Montreux 2007, 2007.

262. Donlon, C.J.; Robinson, I.S. Radiometric validation of ers-1 along-track scanning radiometer average sea surface temperature in the atlantic ocean. Journal of Atmospheric and Oceanic Technology 1998, 15, 647-660.

263. Merchant, C.; Harris, A. Toward the elimination of bias in satellite retrievals of sea surface temperature, 2, comparison with in situ measurements. JOURNAL OF GEOPHYSICAL RESEARCH-ALL SERIES- 1999, 104, 23,579-523,590.

264. Murray, M.; Allen, M.; Merchant, C.; Harris, A.; Donlon, C. Direct observations of skin bulk sst variability. Geophysical Research Letters 2000, 27, 1171-1174.

265. Horrocks, L.A.; Candy, B.; Nightingale, T.J.; Saunders, R.W.; O'Carroll, A.; Harris, A.R. Parameterizations of the ocean skin effect and implications for satellite based measurement of sea surface temperature. Journal of Geophysical Research: Oceans (1978-2012) 2003, 108.

266. Merchant, C.; Llewellyn-Jones, D.; Saunders, R.; Rayner, N.; Kent, E.; Old, C.; Berry, D.; Birks, A.; Blackmore, T.; Corlett, G. Deriving a sea surface temperature record suitable for climate change research from the along-track scanning radiometers. Advances in Space Research 2008, 41, 1-11.

267. Vázquez-Cuervo, J.; Armstrong, E.M.; Harris, A. The effect of aerosols and clouds on the retrieval of infrared sea surface temperatures. Journal of Climate 2004, 17, 3921-3933.

268. Gentemann, C.L.; Meissner, T.; Wentz, F.J. Accuracy of satellite sea surface temperatures at 7 and 11 ghz. Geoscience and Remote Sensing, IEEE Transactions on 2010, 48, 1009-1018.

269. Shibata, A. In Calibration of amsr-e sst toward a monitoring of global warming, Geoscience and Remote Sensing Symposium, 2005. IGARSS'05. Proceedings. 2005 IEEE International, 2005; IEEE: pp 3448-3449.

270. Wentz, F.J.; Gentemann, C.; Smith, D.; Chelton, D. Satellite measurements of sea surface temperature through clouds. Science 2000, 288, 847-850.

271. Gentemann, C.L.; Donlon, C.J.; Stuart Menteth, A.; Wentz, F.J. Diurnal signals in satellite sea surface temperature measurements. Geophysical Research Letters 2003, 30 . 
272. Gentemann, C.L.; Wentz, F.J.; Mears, C.A.; Smith, D.K. In situ validation of tropical rainfall measuring mission microwave sea surface temperatures. Journal of Geophysical Research: Oceans (1978-2012) 2004, 109.

273. Klemas, V. Remote sensing of sea surface salinity: An overview with case studies. Journal of Coastal Research 2011, 27, 830-838.

274. Topliss, B.; Helbig, J. Sea surface salinity from space: A canadian perspective. Fisheries and Oceans: 2002.

275. Srokosz, M. In Ocean surface salinity-the why, what and whether, Proceedings of the Consultative Meeting on Soil Moisture and Ocean Salinity Measurement Requirements and Radiometer Techniques (SMOS), 1995; pp 49-56.

276. ESA (European Space Agency). Esa's water mission smos. http://www.esa.int/esaLP/ESAMBA2VMOC_LPsmos_0.html (accessed April 6, 2011),

277. Martin, S. An introduction to remote sensing. Cambridge, UK: Cambridge University Press: 2004.

278. Elachi, C.; Van Zyl, J.J. Introduction to the physics and techniques of remote sensing. John Wiley \& Sons: 2006; Vol. 28.

279. Ikeda, M. Oceanographic applications of remote sensing. CRC press: 1995.

280. Klein, L.; Swift, C.T. An improved model for the dielectric constant of sea water at microwave frequencies. Antennas and Propagation, IEEE Transactions on 1977, 25, 104-111.

281. Lagerloef, G.S.; Swift, C.T.; LeVine, D.M. Sea surface salinity: The next remote sensing challenge. 1995.

282. Maes, C.; Behringer, D. Using satellite derived sea level and temperature profiles for determining the salinity variability: A new approach. Journal of Geophysical Research: Oceans (1978-2012) 2000, 105, 8537-8547.

283. Swift, C. Passive microwave remote sensing of the ocean-a review. BoundaryLayer Meteorology 1980, 18, 25-54.

284. Miller, J.L.; Goodberlet, M.A.; Zaitzeff, J.B. Airborne salinity mapper makes debut in coastal zone. Eos, Transactions American Geophysical Union 1998, 79, 173-177.

285. Miller*, J.L.; Goodberlet, M. Development and applications of starrs: A next generation airborne salinity imager. International Journal of Remote Sensing 2004, 25, 1319-1324. 
286. Bai, Y.; Pan, D.; Cai, W.J.; He, X.; Wang, D.; Tao, B.; Zhu, Q. Remote sensing of salinity from satellite derived cdom in the changjiang river dominated east china sea. Journal of Geophysical Research: Oceans 2013, 118, 227-243.

287. Hu, C.; Chen, Z.; Clayton, T.D.; Swarzenski, P.; Brock, J.C.; Muller-Karger, F.E. Assessment of estuarine water-quality indicators using modis medium-resolution bands: Initial results from tampa bay, fl. Remote Sensing of Environment 2004, 93, 423-441.

288. Yueh, S.H. In Microwave remote sensing modeling of ocean surface salinity and winds using an empirical sea surface spectrum, Geoscience and Remote Sensing Symposium, 2004. IGARSS'04. Proceedings. 2004 IEEE International, 2004; IEEE: pp 1358-1361.

289. Wong, M.S.; Kwan, S.; Young, J.; Nichol, J.; Zhangging, L.; Emerson, N. Modeling of suspended solids and sea surface salinity in hong kong using aqua/modis satellite images. Korean Journal of Remote Sensing 2007, 23, 161169.

290. Vossepoel, F.C.; Reynolds, R.W.; Miller, L. Use of sea level observations to estimate salinity variability in the tropical pacific. Journal of Atmospheric and Oceanic Technology 1999, 16, 1401-1415.

291. Barre, H.M.; Duesmann, B.; Kerr, Y.H. Smos: The mission and the system. Geoscience and Remote Sensing, IEEE Transactions on 2008, 46, 587-593.

292. Boutin, J.; Martin, N. Argo upper salinity measurements: Perspectives for 1-band radiometers calibration and retrieved sea surface salinity validation. Geoscience and Remote Sensing Letters, IEEE 2006, 3, 202-206.

293. Brown, M.A.; Torres, F.; Corbella, I.; Colliander, A. Smos calibration. Geoscience and Remote Sensing, IEEE Transactions on 2008, 46, 646-658.

294. Cracknell, A.P. Introduction to remote sensing. CRC press: 2007.

295. Font, J.; Camps, A.; Borges, A.; Martín-Neira, M.; Boutin, J.; Reul, N.; Kerr, Y.H.; Hahne, A.; Mecklenburg, S. Smos: The challenging sea surface salinity measurement from space. Proceedings of the IEEE 2010, 98, 649-665.

296. Font, J.; Lagerloef, G.S.; Le Vine, D.M.; Camps, A.; Zanife, O.-Z. The determination of surface salinity with the european smos space mission. Geoscience and Remote Sensing, IEEE Transactions on 2004, 42, 2196-2205.

297. Lagerloef, G.; Font, J. Smos and aquarius/sac-d missions: The era of spaceborne salinity measurements is about to begin. In Oceanography from space, Springer: 2010; pp 35-58. 
298. Zine, S.; Boutin, J.; Font, J.; Reul, N.; Waldteufel, P.; Gabarró, C.; Tenerelli, J.; Petitcolin, F.; Vergely, J.-L.; Talone, M. Overview of the smos sea surface salinity prototype processor. Geoscience and Remote Sensing, IEEE Transactions on 2008, 46, 621-645.

299. Lagerloef, G.; Colomb, R.; Le Vine, D.; Wetz, F.; Yueh, S.; Ruf, C.; Lilly, J.; Gunn, J.; Chao, Y.; Decharon, A. The aquarius/sac-d mission: Special issue on salinity. Oceanography 2008, 21, 69-81.

300. Le Vine, D.M.; Lagerloef, G.S.; Torrusio, S.E. Aquarius and remote sensing of sea surface salinity from space. Proceedings of the IEEE 2010, 98, 688-703.

301. Le Vine, D.M.; Lang, R.; Utku, C.; Tarkocin, Y. In Remote sensing of salinity: The dielectric constant of sea water, General Assembly and Scientific Symposium, 2011 XXXth URSI, 2011; IEEE: pp 1-3.

302. Burrage, D.; Heron, M.; Hacker, J.; Miller, J.; Stieglitz, T.; Steinberg, C.; Prytz, A. Structure and influence of tropical river plumes in the great barrier reef: Application and performance of an airborne sea surface salinity mapping system. Remote Sensing of Environment 2003, 85, 204-220.

303. Heron, M.; Prytz, A.; Stieglitz, T.; Burrage, D. Remote sensing of sea surface salinity: A case study in the burdekin river, north-eastern australia. Gayana (Concepción) 2004, 68, 278-283.

304. Perez, T.; Wesson, J.C.; Burrage, D. Airborne remote sensing of the plata plume using starrs; DTIC Document: 2006.

305. Wang, Y.; Heron, M.L.; Prytz, A.; Ridd, P.V.; Steinberg, C.R.; Hacker, J.M. Evaluation of a new airborne microwave remote sensing radiometer by measuring the salinity gradients across the shelf of the great barrier reef lagoon. Geoscience and Remote Sensing, IEEE Transactions on 2007, 45, 3701-3709.

306. Burrage, D.; Wesson, J.; Martinez, C.; Pérez, T.; Möller, O.; Piola, A. Patos lagoon outflow within the río de la plata plume using an airborne salinity mapper: Observing an embedded plume. Continental Shelf Research 2008, 28, 1625-1638.

307. Wilson, W.J.; Yueh, S.H.; Dinardo, S.J.; Chazanoff, S.L.; Kitiyakara, A.; Li, F.K.; Rahmat-Samii, Y. Passive active l-and s-band (pals) microwave sensor for ocean salinity and soil moisture measurements. Geoscience and Remote Sensing, IEEE Transactions on 2001, 39, 1039-1048.

308. Li, F.K.; Wilson, W.J.; Yueh, S.H.; Dinardo, S.J.; Howden, S. In Passive active 1/s-band microwave aircraft sensor for ocean salinity measurements, Geoscience and Remote Sensing Symposium, 2000. Proceedings. IGARSS 2000. IEEE 2000 International, 2000; IEEE: pp 2540-2542. 
309. Wilson, W.J.; Yueh, S.H.; Li, F.K.; Dinardo, S.; Chao, Y.; Koblinsky, C.; Lagerloef, G.; Howden, S. In Ocean surface salinity remote sensing with the jpl passive/active 1-/s-band (pals) microwave instrument, Geoscience and Remote Sensing Symposium, 2001. IGARSS'01. IEEE 2001 International, 2001; IEEE: pp 937-939.

310. Reul, N.; Saux Picart, S.; Chapron, B.; Vandemark, D.; Tournadre, J.; Salisbury, J. Demonstration of ocean surface salinity microwave measurements from space using amsr e data over the amazon plume. Geophysical Research Letters 2009, 36.

311. Le Vine, D.M.; Haken, M. In Rfi at l-band in synthetic aperture radiometers, Geoscience and Remote Sensing Symposium, 2003. IGARSS'03. Proceedings. 2003 IEEE International, 2003; IEEE: pp 1742-1744.

312. Le Vine, D.; Kao, M.; Garvine, R.; Sanders, T. Remote sensing of ocean salinity: Results from the delaware coastal current experiment. Journal of Atmospheric and Oceanic Technology 1998, 15, 1478-1484.

313. Lagerloef, G.; Swift, C.; Levine, D. In Remote sensing of sea surface salinity: Airborne and satellite concepts, Abstract, EOS Supplement, AGU 1992 Ocean sciences meeting, New Orleans, 1991; p 29.

314. Robinson, I.S. Discovering the ocean from space: The unique applications of satellite oceanography. Springer Science \& Business Media: 2010; Vol. 4110.

315. Gordon, H.R.; McCluney, W. Estimation of the depth of sunlight penetration in the sea for remote sensing. Applied optics 1975, 14, 413-416.

316. Markogianni, V.; Dimitriou, E.; Tzortziou, M. In Monitoring of chlorophyll-a and turbidity in evros river (greece) using landsat imagery, First International Conference on Remote Sensing and Geoinformation of Environment, 2013; International Society for Optics and Photonics: pp 87950R-87950R-87913.

317. Schaeffer, B.A.; Schaeffer, K.G.; Keith, D.; Lunetta, R.S.; Conmy, R.; Gould, R.W. Barriers to adopting satellite remote sensing for water quality management. International journal of remote sensing 2013, 34, 7534-7544.

318. Specter, C.; Gayle, D. Managing technology transfer for coastal zone development: Caribbean experts identify major issues. REMOTE SENSING 1990, 11, 1729-1740. 


\section{CHAPTER III}

REGIONAL LAKE WATER QUALITY ASSESSMENT USING REMOTE SENSING: THE CASE STUDY OF LAKE OKEECHOBEE, FLORIDA, USA 


\section{Abstract}

In this study, the bio-physical parameters of Lake Okeechobee were investigated based on atmospherically corrected data. The principal objective of this study is to monitor and assess the spatial and temporal changes of four water quality parameters: total suspended solids (TSS), chlorophyll- $a$ (chl- $a$ ), total phosphate, and total kjeldahl nitrogen (TKN) using the application of integrated remote sensing, GIS data, and statistical techniques. For this purpose, two dates of Landsat Thematic Mapper (TM) data in 2000 (February 29); 2007 (January 31), and one date of Landsat Operational Land Imager (OLI) in 2015 (February 6) in the dry season, and three dates of TM data in 2000 (July 6); 2007 (August 11), and one date of OLI data in 2015 (September 15) in the wet season of the subtropical climate of South Florida, were used to assess temporal and spatial patterns and dimensions of studied parameters in Lake Okeechobee, Florida. The simultaneous observed data of four studied parameters were obtained from 26 monitoring stations and were used for the development and validation of the models. The optical bands in the region from blue to near infrared and all the possible band ratios were used to explore the relation between the reflectance of waterbody and observed data. The predictive models to estimate chl- $a$ and TSS concentrations were developed through the use of stepwise multiple linear regression (MLR) and gave high coefficients of determination in dry season $\left(\mathrm{R}^{2}=0.84\right.$ for chl- $a$ and $\mathrm{R}^{2}=0.67$ for TSS) and moderate coefficients of determination in wet season $\left(\mathrm{R}^{2}=0.48\right.$ for chl- $a$ and $\mathrm{R}^{2}=0.60$ for TSS $)$. Values for total phosphate and TKN were strongly correlated with chl- $a$ and TSS concentration and some bands and their ratios. Total phosphate and TKN were estimated using best-fit multiple linear regression models as a function of Landsat TM and OLI, 
and ground data and showed a high coefficient of determination in dry season $\left(\mathrm{R}^{2}=0.85\right.$ for total phosphate and $\mathrm{R}^{2}=0.88$ for $\left.\mathrm{TKN}\right)$ and in wet season $\left(\mathrm{R}^{2}=0.80\right.$ for total phosphate and $\mathrm{R}^{2}=0.86$ for $\mathrm{TKN}$ ). The MLR models showed a good trustiness to monitor and predict the spatiotemporal variations of the studied water quality parameters in Lake Okeechobee.

Keywords: Water quality, Spatiotemporal modelling, Remote Sensing, Landsat, chlorophyll, Total suspended solids, Nutrients, Lake Okeechobee.

\section{Introduction}

Remote sensing techniques make it possible to have spatial and temporal view of surface water quality parameters (WQPs) and more effectively and efficiently monitor the waterbodies, and quantify water quality issues. Most of the studies have focused on optically active variables, such as chlorophyll-a (chl-a), total suspended solids (TSS), and turbidity. There are several other important water quality variables such as $\mathrm{pH}$, total nitrogen $(\mathrm{TN})$, ammonia nitrogen $(\mathrm{NH} 3-\mathrm{N})$, nitrate nitrogen $(\mathrm{NO} 3-\mathrm{N})$, and dissolved phosphorus (DP), which existing literatures omit. The main reason is due to their weak optical characteristics and low signal noise ratio. However, these parameters are an important part of water quality indices and are a challenging aspect of research in the field of water quality assessment using remote sensing.

Chl- $a$ is the major indicator of trophic state because it acts as a link between nutrient concentration, particularly phosphorus, and algal production. Chl- $a$ while mainly reflecting green, absorbs most energy from wavelengths of violet-blue and orange-red light, whose reflectance causes chlorophyll to appear green. Various visual spectral bands 
and their ratios are widely used to quantify chl- $a$. Spectral band ratios can reduce some important characteristics of the remotely sensed signal, such as irradiance, atmospheric and air-water surface influences [19,20]. Alparslan, et al. [21] measured the concentration of chl-a using all bands of Landsat-5 TM. Lim and Choi [18] using Landsat-8/OLI showed that chl-a presented a good correlation with both OLI bands and band ratio, with calculated $\mathrm{R}$ values for bands $2,3,4$ and band ratio (band 5/band 3) as $-0.66,-0.70$, -0.64 , and -0.64 , respectively. Zhang and Han [22] found that OLI bands 1 to 4 and their combinations had good correlation with chl-a concentration. Kim, et al. [23] using Landsat-8/OLI employed Band2, Band5, and a ratio of Band2/Band4 to measure chl-a concentration. Therefore, the Landsat visible bands are appropriate for detecting chlorophyll- $a$ concentration in lake water.

Suspended sediments are responsible for most of the scattering, whereas the absorption is controlled by chl- $a$ and colored dissolved or particulate matter [24]. The more suspended particles, the more difficult for light to travel through the water and therefore, the higher the water's turbidity. Based on theory, applying a single band can provide a robust and TSM-sensitive algorithm to estimate the turbidity and concentrations of suspended particles, in condition that the band is chosen appropriately [25] . Curran, et al. [26] and Novo, et al. [27] showed that single band algorithms can be applied where TSM increases coincides with the reflectance values increase. However, the complex substances in water change the reflectance of the water body and hence, cause variation in colors, and thus, different spectral bands can be used for TSS retrievals $[25,28,29]$. Therefore, the advantage of using signal band or band ratios can be employed to obtain more accurate results in different concentrations in waterbodies. However, 
Ritchie, et al. [30] by in situ studies showed that the spectrum between 700 and $800 \mathrm{~nm}$ is the most useful range for the measurement of suspended particles. In the Near-IR and Mid-IR regions, based on water depth and wavelength the absorption of light increases and makes the water to look darker.

Total phosphorus (TP) studies consist of the measurement of all inorganic, organic and dissolved forms of phosphorus. Phosphorus (P) occurs mostly as Phosphates (PO4). Inorganic phosphates are considered as phosphorus compounds that contain some salts ions and/or metals, such as sodium, potassium, and calcium in various structures and chains [31]. Phosphates are plant nutrients whose increased quantity helps plants and algae to grow quickly. The measurement of total phosphorus and total phosphate concentrations in waterbodies is challenging due to the spatial heterogeneity and the labor-intensive collection and testing of required field samples. Total phosphorus is not directly measurable by optical instruments, but has a general correlation with other water quality parameters [32].

TKN is a measure of the amount of ammonia-N and organic nitrogen in the water [33]. High nitrogen concentrations, especially in freshwaters, can cause the increased amounts of algae and therefore, the concentrations of chl- $a$. However phosphorus should be paid more attention in fresh waters compared to nitrogen as they can stimulate the growth of algae [34]. Among the numerous sources of Ammonia-N found in the water body, the nitrogen released by the decomposition of organic matter and fertilizer released from agricultural applications are the major contributors [35]. Different types of agricultural areas in South Florida generate non-point sources of pollution that have a high percentage of ammonia from pesticides and fertilizers [36]. The main source of 
suspended solids is inorganic materials, although some other constituents in water such as bacteria, organic particles from decomposing materials, and algae can also influence the concentration of total suspended solids [37].

Lake Okeechobee is a dynamic and biologically productive water system that is fed mainly by the Kissimmee River from its north, and during wet season, there is an inverse flow from a system of pumping stations in its south part that pumps excess water from the north part of the Everglades agricultural area into the Lake Okeechobee is surrounded by different types of agricultural productions that load significant amounts of phosphorus and nitrogen to the Everglades during dry season [38]. Recent studies has shown that these high concentrations of nutrient and other chemical loadings that enter the Lake Okeechobee from different land uses such as agricultural area, livestock farms, and cattle lands have impaired the quality of lake's water. This water eventually discharges into the freshwater Everglades or its coastal estuaries and affects its water quality and important aquatic lives [38]. Therefore, monitoring and control of nutrient loading to Lake Okeechobee is an essential issue and hence, more attention should be paid to this region. In this study, the spatial and temporal changes of four water quality parameters including total suspended solids (TSS) and chlorophyll- $a$ (chl- $a$ ), total phosphate, and total kjeldahl nitrogen (TKN), were investigated by using the application of integrated remote sensing, GIS data, and statistical techniques. The simultaneous observed data of four studied parameters were obtained from 26 monitoring stations and were used for the development and validation of the models. The optical bands in the region from blue to near infrared and all the possible band ratios were used to explore the relation between the reflectance of waterbody and observed data. 


\section{Materials and methods}

\subsection{Study area}

South Florida is one of the unique parts of the United States with a subtropical climate. It contains two important vast waterbodies of Lake Okeechobee and the Everglades, which the first one is the Florida's largest freshwater lake and the second one is the largest subtropical wilderness in the United States. In this study, Lake Okeechobee, which is the largest and the most important lake in South Florida, is selected to be investigated for its bio-physical parameters associated with water quality using remote sensing. The major land uses in its watersheds include agricultural area, wetlands, cattle ranch and dairy farming, and urban areas [39]. Figure 3.1 shows the location of the study area and the selected water quality monitoring sites. The average annual temperature ranges from $19.2^{\circ} \mathrm{C}$ to $28.7^{\circ} \mathrm{C}$ and the annual rainfall in the entire area of South Florida is generally about 55 inches $(1,400 \mathrm{~mm})$. Considering the subtropical climate of South Florida, the average rainfall is still considerable in the dry season. In addition, during El Niño phenomenon, greater amounts of rainfall in dry season are observed in South Florida.

\subsection{Limnological data}

The monitoring stations, downloaded from the South Florida Water Management District's (SFWMD) geographic information systems data catalog, were overlaid with the Lake Okeechobee map in ArcGIS to design a network of sampling stations that include sufficient historical data to construct a robust statistical database of studied parameters, considering a suitable spatial distribution on the Lake. 

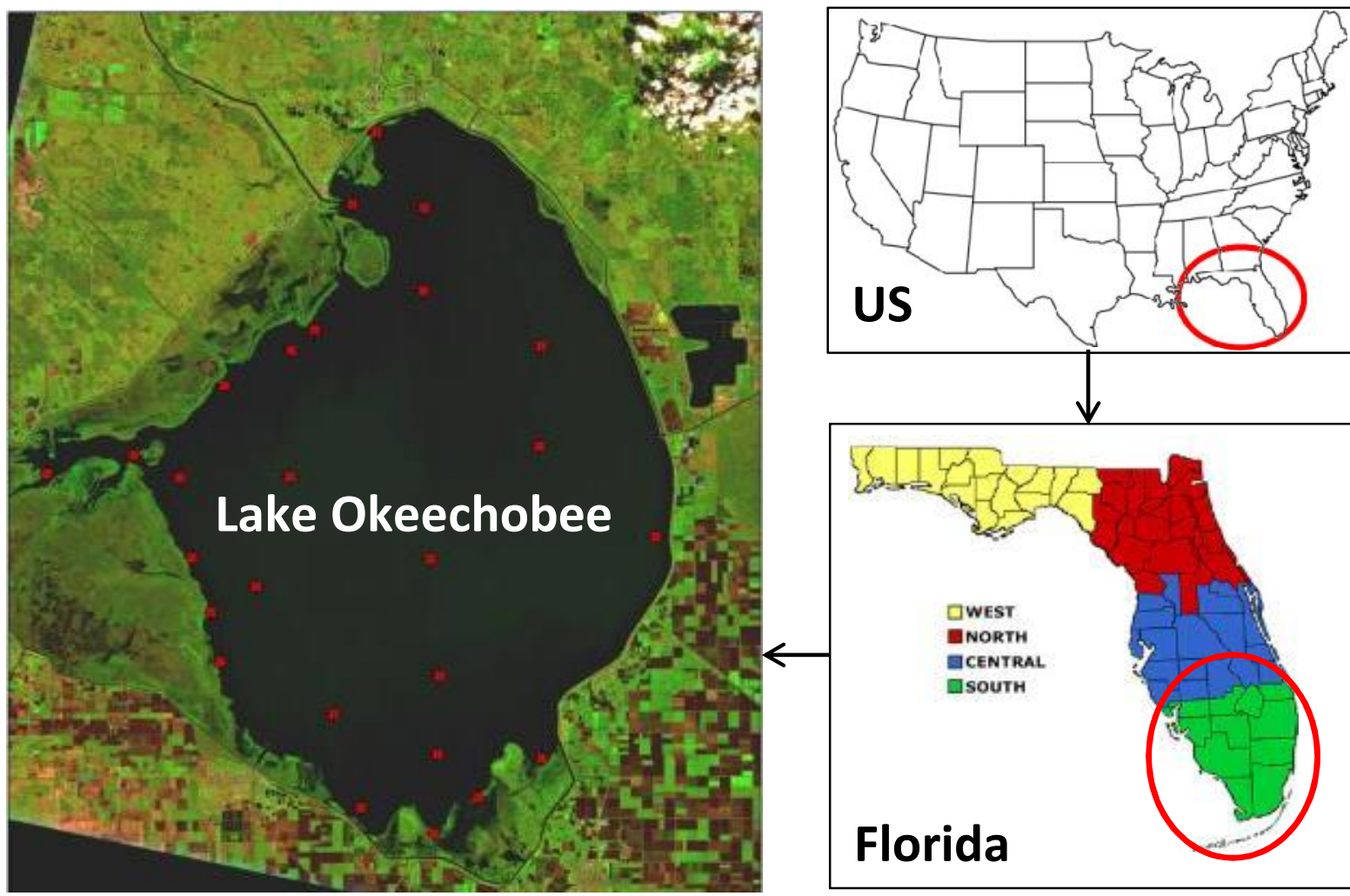

Figure 3.1. The location of the study area and the water quality monitoring sites.

The limnological data on chl- $a$, TSS, total phosphate, and TKN used in this study were obtained from the DBHYDRO (environmental database of SFWMD), United States Geological Survey (USGS), the Environmental Protection Agency (EPA), and the National Water Quality Monitoring Council (NWQMC) from 26 selected monitoring stations. Then, a database was developed for the observed data of four studied parameters simultaneous or in the closest day of the month as the satellite image are obtained in wet (May $15^{\text {th }}$ through October $15^{\text {th }}$ ) and dry seasons (October $16^{\text {th }}$ through May $14^{\text {th }}$ ), and was used for the development and validation of the models. The SPSS 16.0 software package was employed for data treatment. The descriptive statistics of the four limnological parameters are shown in Table 3.1. 
Due to differences in units of the studied water quality parameters in the dataset, pre-treatment of data is required. in order to the homogenization [40]. Outliers are one of the statistical issues that affect most of the parametric calculations, such as means, standard deviations, and correlations and every statistical analysis is significantly sensitive to them. Also, outliers can really mess up any statistical procedure that their assumptions are based on these statistics. However, the outlier affects both results and assumptions and therefore it is not acceptable to simply drop the outlier if it is not due to incorrectly entered or measured the observations. The nature of the outliers should be clearly considered before excluding an observation from the analysis. Transformation of data to for example, log transformations, was considered to make a better decision dealing with and declaring the outliers. In this study, data pre-treatment methods, such as the elimination of non-informative variables, the treatment of missing data values, and the detection and treatment of outliers were performed before the statistical analyses.

\subsection{Satellite data}

The remotely sensed data were acquired from the Landsat Thematic Mapper (TM) and Landsat OLI sensors onboard Landsat 5 and 8, respectively, in 2000, 2007, and 2015. Pre-processing of the Landsat data including the radiometric calibration and atmospheric correction is essential for quantitative studies [41,42], especially for lake waters that the reflected light is small [43].The radiance of small lakes in average is usually less than $10 \%$, and even in many cases values less than $1 \%$, of total radiance are also reported [44]. For this purpose, in order to remove the effects of high local variability, the digital number values should be first converted to unitless planetary reflectance before the process of atmospheric correction. As two types of imagery were used in this study, two 
different methods were used for the radiometric calibration and Atmospheric correction of TM and OLI data. ERDAS IMAGINE 2014 and ESRI ArcGIS 10.0 platforms were used for image processing.

Table 3.1. Descriptive statistics of chl- $a$, TSS, total phosphate, and TKN in the Lake Okeechobee

\begin{tabular}{|c|c|c|c|c|c|c|}
\hline \multicolumn{3}{|c|}{ Indices } & $\begin{array}{c}\text { Chl- } a \\
\left(\mathrm{mg} / \mathrm{m}^{3}\right)\end{array}$ & $\begin{array}{c}\text { TSS } \\
(\mathrm{mg} / \mathrm{L})\end{array}$ & $\begin{array}{c}\text { total phosphate } \\
(\mathrm{mg} / \mathrm{L})\end{array}$ & $\begin{array}{c}\text { TKN } \\
(\mathrm{mg} / \mathrm{L})\end{array}$ \\
\hline \multirow{12}{*}{ 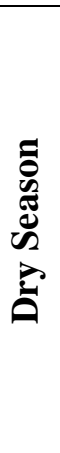 } & \multirow{4}{*}{ 2000, February 29} & Minimum & 3.30 & 8.0 & 0.107 & 1.03 \\
\hline & & Maximum & 67.7 & 53.0 & 0.192 & 1.96 \\
\hline & & Average & 17.8 & 29.5 & 0.156 & 1.31 \\
\hline & & St. Dev. & 14.8 & 13.0 & 0.021 & 0.21 \\
\hline & \multirow{4}{*}{ 2007, January 31} & Minimum & 1.0 & 8.0 & 0.085 & 0.88 \\
\hline & & Maximum & 27.5 & 162.0 & 0.299 & 2.04 \\
\hline & & Average & 12.9 & 41.2 & 0.158 & 1.22 \\
\hline & & St. Dev. & 7.1 & 36.0 & 0.050 & 0.30 \\
\hline & \multirow{4}{*}{ 2015, February 6} & Minimum & 1.86 & 5.0 & 0.0821 & 0.821 \\
\hline & & Maximum & 43.2 & 92.0 & 0.203 & 1.85 \\
\hline & & Average & 14.08 & 31.04 & 0.143 & 1.09 \\
\hline & & St. Dev. & 11.50 & 21.54 & 0.033 & 0.22 \\
\hline \multirow{12}{*}{ 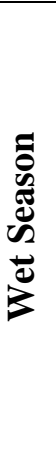 } & \multirow{4}{*}{ 2000, July 6} & Minimum & 6.20 & 3.0 & 0.036 & 0.95 \\
\hline & & Maximum & 106.5 & 70.0 & 0.238 & 2.89 \\
\hline & & Average & 27.7 & 20.6 & 0.101 & 1.38 \\
\hline & & St. Dev. & 23.4 & 15.3 & 0.044 & 0.48 \\
\hline & \multirow{4}{*}{ 2007, August 11} & Minimum & 3.50 & 4.0 & 0.016 & 0.87 \\
\hline & & Maximum & 76.5 & 22.0 & 0.280 & 2.61 \\
\hline & & Average & 16.1 & 11.3 & 0.092 & 1.35 \\
\hline & & St. Dev. & 16.0 & 7.0 & 0.064 & 0.37 \\
\hline & \multirow{4}{*}{ 2015, September 15} & Minimum & 4.8 & 3.0 & 0.023 & 0.77 \\
\hline & & Maximum & 76.0 & 39.0 & 0.295 & 2.93 \\
\hline & & Average & 18.4 & 13.7 & 0.084 & 1.57 \\
\hline & & St. Dev. & 18.87 & 9.3 & 0.070 & 0.75 \\
\hline
\end{tabular}

\section{Preprocessing of Landsat-5/TM data}

The digital number (DN) values of each band were converted to radiance values to remove the voltage bias and gains from the satellite sensor as follows:

$$
L_{\lambda}=\frac{\left(\operatorname{Lmax}_{\lambda}-\operatorname{Lmin}_{\lambda}\right)}{(Q C A L \max -Q C A L \min )} *(Q C A L-Q C A L \min )+\operatorname{Lmin}_{\lambda}
$$

Where, $L_{\lambda}$ is the spectral radiance at the sensor's aperture in watts/(meter squared $\times$ ster $\times \mu \mathrm{m}), \operatorname{Lmin}_{\lambda}$ is the spectral radiance that is scaled to QCALmin in 
watts/(meter squared $\times$ ster $\times \mu \mathrm{m}), \operatorname{Lmax}_{\lambda}$ is the spectral radiance that is scaled to QCALmax in watts/(meter squared $\times$ ster $\times \mu \mathrm{m}), Q C A L \min$ is the minimum quantized calibrated pixel value (corresponding to $\operatorname{Lmin}_{\lambda}$ ) in DN, QCALmax is and the maximum quantized calibrated pixel value (corresponding to $\operatorname{Lmax}_{\lambda}$ ) in DN.

As the process of atmospheric correction, the radiance values are converted to atsatellite reflectance values that consider the variation of sun angle in different latitude, time of day, season, and the distance between the earth and sun. The simplified model of the effects of the atmosphere is [45]:

$\rho_{p}=\frac{\pi \times L_{\lambda} \times d^{2}}{E S U N_{\lambda} \times \cos \theta_{S}}$

Where, $\rho_{p}$ is the unitless planetary reflectance, $L_{\lambda}$ is the spectral radiance at the sensor's aperture, $d$ is the Earth-Sun distance in astronomical units, $E S U N_{\lambda}$ is the mean solar exo-atmospheric irradiance, and $\theta_{s}$ is the solar zenith angle in degrees.

\section{Preprocessing of Landsat-8/OLI data}

COST-DOS was used as the radiometric correction method for mitigating atmospheric effects recorded by Landsat-8/OLI data. It accounts for absorption, scattering, and refraction of atmospheric particles such as particulate matter and water vapor [46]. The improved cosine of the solar zenith angle (COST) method presented by Chavez [47] was used to convert the DN values of each band of Landsat-8/OLI to reflectance values as follows:

$$
P_{\lambda}=\frac{\pi\left(L_{\lambda \text { sensor }}-L_{\lambda \text { haze }}\right) d^{2}}{\operatorname{ESUN}_{\lambda} \cos \left(\frac{\pi}{180 \theta_{S}}\right)}
$$


Where, $P_{\lambda}$ is the dimensionless spectral reflectance value of surface water, $\pi$ is a constant (3.14159265), $L_{\lambda \text { sensor }}$ is the spectral radiance value, and $L_{\lambda h a z e}$ is the path radiance or upwelling atmospheric spectral radiance. $d$ is the distance between the earth and the sun in astronomical units, and $\theta_{s}$ is the solar zenith angle $\left({ }^{\circ}\right) . E S U N_{\lambda}$ is the solar spectral irradiance at to the top of atmosphere (TOA). The spectral radiance value $\left(\mathrm{L}_{\text {ssensor }}\right)$ at the satellite sensor's aperture $\left(\mathrm{Wm}^{-2} \mathrm{sr}^{-1} \mathrm{~m}^{-1}\right)$ is calculated as follows:

$L_{\lambda s e n s o r}=\left(M_{\lambda} \times Q_{\text {cal }}\right)+A_{\lambda}$

Where, $M_{\lambda}$ is the band-specific multiplicative rescaling factor, $A_{\lambda}$ is the bandspecific additive rescaling factor, and $Q_{c a l}$ is the minimum quantized and calibrated standard product pixel value. Both $M_{\lambda}$ and $A_{\lambda}$ are provided in the Landsat 8 metadata file (MTL file).

$L_{\lambda h a z e}=L_{\lambda \min }-L_{\lambda, 1 \%}$

Where, $L_{\text {ihaze }}$ is the path radiance or upwelling atmospheric spectral radiance scattered in the direction of the sensor entrance pupil and within the sensor's field of view, $L_{\lambda \min }$ is the minimum spectral radiance, and $L_{\lambda, 1 \%}$ is the spectral radiance value of the darkest object on each band of the Landsat 8 and can be calculated as follows:

$L_{\lambda, 1 \%}=\frac{0.01 \times E \operatorname{SUN}_{\lambda} \times \cos (\theta)^{2}}{\pi \times d^{2}}$

The theoretical radiance of a dark object is then computed, under the assumption that dark objects have $1 \%$ or smaller reflectance $[47,48]$. 


\subsection{Statistical methods}

In this study, Pearson's correlation analysis was utilized to determine the linear relationship and calculate the correlation between two variables in order to characterize the relationship between various TM and OLI bands and each of the 4 water quality parameters (chl- $a$, TSS, total phosphate and TKN) for the 26 selected stations. The Pearson's correlation basic equation is defined as follows:

$$
R=\frac{\sum\left(X_{\text {band }}-\overline{X_{\text {band }}}\right)\left(Y_{W Q P}-\overline{Y_{W Q P}}\right)}{\sqrt{\left(X_{\text {band }}-\overline{X_{\text {band }}}\right)^{2}+\left(Y_{W Q P}-\overline{Y_{W Q P}}\right)^{2}}}
$$

Where, $X_{\text {band }}$ is the corrected reflectance value, $\overline{X_{\text {band }}}$ is the mean of the corrected reflectance value, $Y_{W Q P}$ is the in-situ WQPs data, and $\overline{Y_{W Q P}}$ is the mean of the in situ WQP data. Then, a linear multiple regression analysis was conducted for all WQPs. The general formula for multiple regressions is as follows:

$W Q P=a+\left(b \times X_{k, 1}\right)+\left(c \times X_{k, 2}\right)+\left(d \times X_{k, 3}\right)+\left(e \times X_{k, 4}\right)$

Where, $W Q P$ is the dependent variable and represents measured (or known) water quality parameters (chl- $a$, TSS, total phosphate and TKN) at study site $k$ and $X$ is the independent reflectance variable acquired from the Landsat-5/TM or Landsat-8/OLI images at study site $k$. The numbers represent the band number and $a, b, c, d$, and $e$ are the model coefficients using both the measured water quality parameter value at a particular station and the known pixel reflectance values there, according to the least squares algorithm. 


\section{Results and discussion}

In this study, statistical techniques were also applied to find the most significant relationships between water quality parameters and reflectance values of visible band of TM and OLI data and their combinations [2,18,49-52]. First, Pearson's correlation was carried out between Landsat bands, and chlorophyll and TSS concentrations to find the most significant relationships. Previous studies [50,52-56] indicated significant correlations between chlorophyll concentration and water transparency and the visible bands. As regards to chlorophyll, the prominent scattering-absorption features of chl-a include strong absorption between 450-475 $\mathrm{nm}$ (blue) and at $670 \mathrm{~nm}$ (red), and reflectance reaches to peak at $550 \mathrm{~nm}$ (green) and near $700 \mathrm{~nm}$ (NIR). The applicability of reflectance peak near $700 \mathrm{~nm}$ and its ratio to the reflectance at $670 \mathrm{~nm}$ to retrieve chl-a in turbid waters was tested by Gitelson [57] . Several studies have also found that the first four bands of Landsat are well correlated with total suspended matters [55,58-60] and the analyses carried out with Pearson's correlation (Table 3.2) are in agreement with their results. By increasing the amounts of dissolved inorganic materials, the peak of visible reflectance relocates from green band to red band [61]. In this study, the stepwise multiple linear regression analysis was applied on all the visible bands and their combinations to select significant variables. Visible band and their ratios constructed the independent variables and $\mathrm{p}$ values greater than 0.1 were considered as a limit for factor removal. 
Table 3.2. Pearson's $R$ correlation between limnological data and Landsat bands and ratios $(* *)$ : significant correlation for $\mathrm{p}<0.05$.

\begin{tabular}{lccccc}
\hline \multirow{2}{*}{ Bands } & \multicolumn{2}{c}{ Dry Season } & & \multicolumn{2}{c}{ Wet Season } \\
\cline { 2 - 3 } \cline { 5 - 6 } & $\begin{array}{c}\text { Chlorophyll- } \boldsymbol{a} \\
\left(\mathbf{m g} / \mathbf{m}^{\mathbf{3}}\right)\end{array}$ & $\begin{array}{c}\text { TSS } \\
(\mathbf{m g} / \mathbf{L})\end{array}$ & & $\begin{array}{c}\text { Chlorophyll-a } \\
\left(\mathbf{m g} / \mathbf{m}^{\mathbf{3}}\right)\end{array}$ & $\begin{array}{c}\text { TSS } \\
(\mathbf{m g} / \mathbf{L})\end{array}$ \\
\hline Blue & $-0.70^{* *}$ & -0.29 & & $-0.45^{* *}$ & $-0.55^{* *}$ \\
Green & $-0.60^{* *}$ & -0.27 & & $-0.31^{* *}$ & $-0.35^{* *}$ \\
Red & $-0.80^{* *}$ & -0.07 & & $-0.42^{* *}$ & $-0.41^{* *}$ \\
Near Infrared (NIR) & $-0.63^{* *}$ & 0.20 & & -0.24 & $-0.32^{* *}$ \\
Blue/Green & $0.26^{* *}$ & -0.27 & & -0.23 & -0.15 \\
Blue/Red & $0.78^{* *}$ & $-0.36^{* *}$ & & 0.20 & 0.05 \\
Blue/Near Infrared (NIR) & 0.60 & $-0.47^{* *}$ & & $-0.30^{* *}$ & $-0.36^{* *}$ \\
Green/Blue & -0.25 & 0.25 & & 0.14 & 0.06 \\
Green/Red & $0.82^{* *}$ & -0.22 & & $0.76^{* *}$ & $0.64^{* *}$ \\
Green/Near Infrared (NIR) & 0.54 & $-0.46^{* *}$ & & -0.12 & $0.49^{* *}$ \\
Red/Blue & $-0.76^{* *}$ & 0.32 & & -0.28 & -0.29 \\
Red/Green & $-0.81^{* *}$ & 0.22 & & $-0.76^{* *}$ & $-0.68^{* *}$ \\
Red/Near Infrared (NIR) & -0.06 & $-0.49^{* *}$ & & $-0.43^{* *}$ & $-0.62^{* *}$ \\
Near Infrared (NIR)/Blue & -0.56 & $0.43^{* *}$ & & -0.01 & -0.06 \\
Near Infrared (NIR)/Green & -0.51 & $0.46^{* *}$ & & -0.01 & -0.01 \\
Near Infrared (NIR)/Red & 0.08 & $0.50^{* *}$ & & 0.29 & 0.08 \\
\hline
\end{tabular}

As for chl-a, in dry season the selected band by the statistical analysis were Blue,

Blue/Red, Green/Red, Red/Blue, and Red/Green ratios, and in wet season were Red, Green/Red, Red/Green, and Red/NIR ratios . Therefore, the functional model is:

Dry season: $C h l-a=a+(b \times B l u e)+\left(c \times \frac{\text { Blue }}{\text { Red }}\right)+\left(d \times \frac{\text { Green }}{\text { Red }}\right)+\left(e \times \frac{\text { Red }}{\text { Blue }}\right)+\left(f \times \frac{\text { Red }}{\text { Green }}\right)$

Wet season: $C h l-a=a+(b \times \operatorname{Red})+\left(c \times \frac{\text { Green }}{\text { Red }}\right)+\left(d \times \frac{\text { Red }}{\text { Green }}\right)+\left(e \times \frac{\text { Red }}{\text { NIR }}\right)$

The variability of TSS concentration was also investigated using the same procedure, incorporating visible bands and their ratios as independent variables in the stepwise multiple linear regression analysis. The following functional model was selected from the stepwise variable selection procedure for dry and wet season:

Dry season: $T S S=a+\left(b \times \frac{B l u e}{N I R}\right)+\left(c \times \frac{\text { Green }}{N I R}\right)+\left(d \times \frac{\text { Red }}{N I R}\right)+\left(e \times \frac{N I R}{\text { Blue }}\right)+\left(f \times \frac{N I R}{\text { Green }}\right)$ $+\left(g \times \frac{N I R}{R e d}\right)$ 
Wet season: $T S S=a+(b \times B l u e)+(c \times$ Red $)+\left(d \times \frac{\text { Green }}{\text { Red }}\right)+\left(\right.$ ex $\left.\frac{\text { Red }}{\text { Green }}\right)+\left(f \times \frac{\text { Red }}{\text { NIR }}\right)$

The statistical values given in Table 3.3 were obtained, as a result of the regression analysis computation. The $\mathrm{R}^{2}$ values, which show the correlation between the measured values and the estimated values from the satellite image, prove that the first four bands and their ratios of Landsat satellite image are well capable of being used in the measurement of chl- $a$ and TSS concentrations. The model coefficients are given in Table 3.4 to compute chl- $a$ and TSS at anywhere on the lake surface, based on the pixel reflectance values. Maps given in Figure 3.2 were made using directly the satellite data of the Lake Okeechobee's entire surface, based on the equalities in Table 3.4.

Table 3.3. Statistical values obtained from regression analyses for chl- $a$ and TSS

\begin{tabular}{lcccc}
\hline \multirow{2}{*}{ Regression analysis statistics } & \multicolumn{2}{c}{ Dry Season } & \multicolumn{2}{c}{ Wet Season } \\
& Chl- $\boldsymbol{a}$ & TSS & Chl- $\boldsymbol{a}$ & TSS \\
\hline R Square & 0.84 & 0.67 & 0.48 & 0.60 \\
Standard error & 8.84 & 6.07 & 20.88 & 12.77 \\
p-value & 0.000 & 0.000 & 0.005 & 0.002 \\
Durbin-Watson & 1.797 & 2.249 & 2.103 & 1.650 \\
Observations & 48 & 48 & 38 & 38 \\
\hline
\end{tabular}

Table 3.4. Extracted equations based on regression analysis between limnological parameters and Landsat bands

\begin{tabular}{|c|c|c|}
\hline Season & $\begin{array}{l}\text { Water quality } \\
\text { parameters }\end{array}$ & Formulae derived \\
\hline \multirow{3}{*}{ Dry Season } & Chlorophyll-a (mg/m3) & $\begin{array}{l}=525.5-1167 \times(\text { Blue })+881.1 \times(\text { Blue } / \text { Red })- \\
1784.7 \times(\text { Green } / \text { Red })+5331.5 \times(\text { Red } / \text { Blue })- \\
3096.2 \times(\text { Red } / \text { Green })\end{array}$ \\
\hline & TSS (mg/L) & $\begin{array}{l}=-1037.79-74.63 \times(\text { Blue } / \text { NIR })-8.86 \times(\text { Green/NIR }) \\
+517.91 \times(\text { Red/NIR })-799.23 \times(\text { NIR/Blue })+\end{array}$ \\
\hline & & $127.76 \times($ NIR/Green $)+1100.92 \times($ NIR/Red $)$ \\
\hline \multirow{3}{*}{ Wet Season } & Chlorophyll-a (mg/m3) & $\begin{array}{l}=3095.6+297.75 \times(\text { Red })-1067.77 \times(\text { Green } / \text { Red })- \\
2144.45 \times(\text { Red } / \text { Green })-35.04 \times(\operatorname{Red} / \text { NIR })\end{array}$ \\
\hline & TSS (mg/L) & $\begin{array}{l}=2855.76-182.90 \times(\text { Blue })+361.89 \times(\text { Red })- \\
1018.25 \times(\text { Green } / \text { Red })-1919.21 \times(\text { Red } / \text { Green })-\end{array}$ \\
\hline & & $26.15 \times(\operatorname{Red} / \mathrm{NIR})$ \\
\hline
\end{tabular}




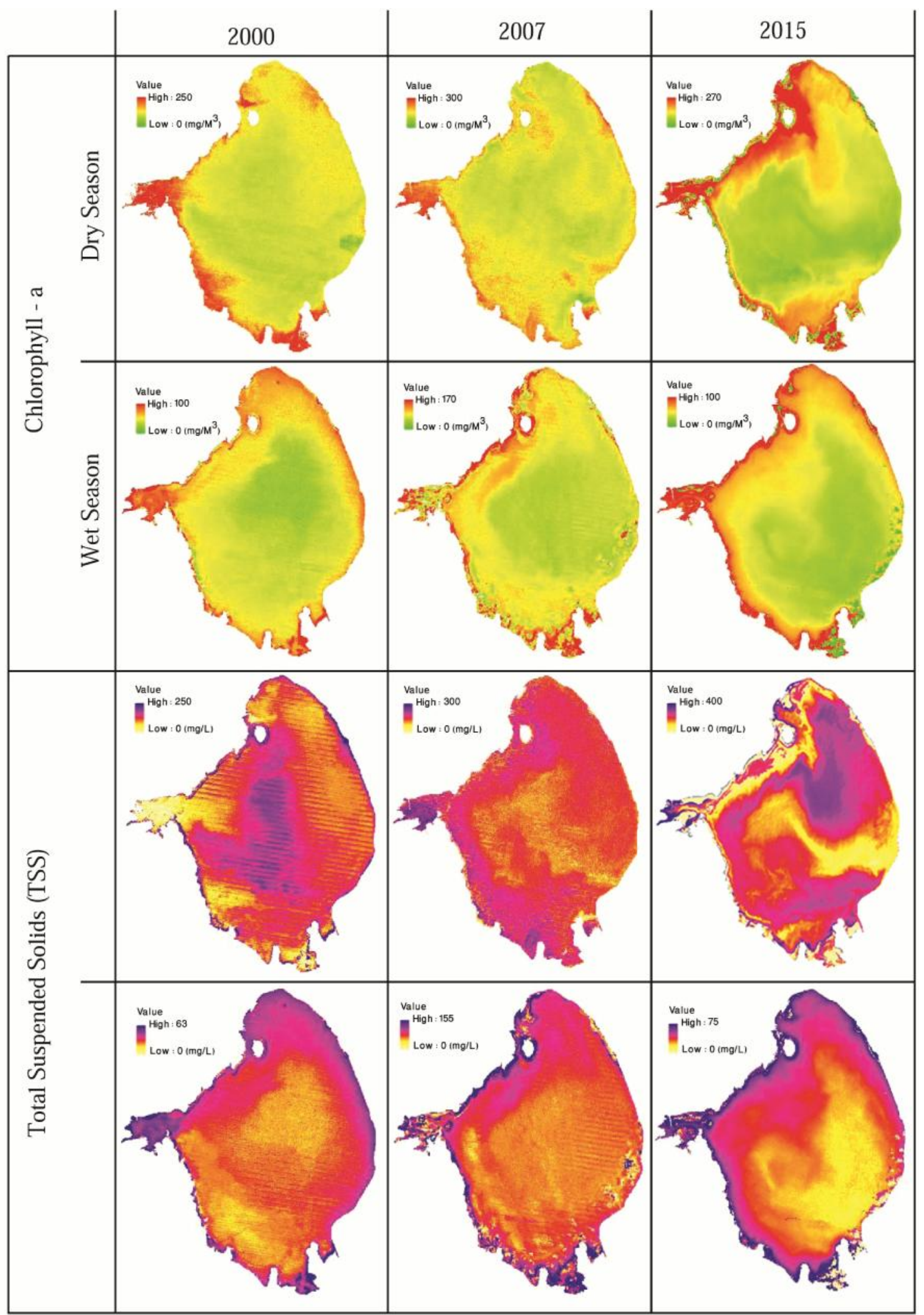

Figure 3.2. Spatial and temporal patterns of chl- $a$ and TSS concentrations in Lake Okeechobee 


\section{Chlorophyll-a}

The results of correlation analysis between landsat bands and chl- $a$ concentration varied from -0.81 (Red/Green band ratio) to 0.82 (Green/Red band ratio) in dry season, and from -0.76 (Red/Green band ratio) to 0.76 (Green/Red band ratio) in wet season (Table 3.2). Also, significant relationships $\left(\mathrm{R}^{2}=0.82\right.$ and 0.76 in dry and wet seasons, respectively) were observed with the Green/Red band ratio at a significance level of $\mathrm{p}<0.05$ (Table 3.2). Extracted equations based on regression analysis between chl- $a$ and Landsat bands showed correlation coefficients of 0.84 and 0.48 for dry and wet seasons, respectively. Due to the existance of missing values in the monitoring sites dataset, 48 data points in dry season and 38 data points in wet season were used in the statistical analysis. Table 3.4 presents the multiple regression models constructed through equations 3.9 and 3.10. Among the different combinations of bands and band ratios, this research selected a multiple regression model and revealed the best significant relationships in order to compare the estimated chl- $a$ through the Landsat TM and OLI data with in situ measurement data. The Durbin-Watson values should be greater than 1.5 and less than 2.5 to indicate that multiple linear regression data is free of first order linear autocorrelation. For chl- $a$, the Durbin-Watson values were 1.797 and 2.103 in dry and wet seasons, respectively, which lay in the accepted range.

\section{Total suspended solids}

As shown in Table 3.2, the correlation between the Landsat bands and TSS from -0.49 (Red/NIR band ratio) to 0.50 (NIR/Red band ratio) in dry season, and from -0.68 (Red/Green band ratio) to 0.64 (Green/Red band ratio) in wet season. The correlation 
results with single bands ratios, not band ratios, indicated the strongest correlation $\left(\mathrm{R}^{2}=\right.$ $-0.55)$ at a significance level of $\mathrm{p}<0.05$ with the blue band in wet season. Particularly in dry season, the NIR band was closely related to TSS as seen by the high numerical value of Blue/NIR, Green/NIR, Red/NIR, NIR/Blue, NIR/Green, and NIR/ Red (Table 3.2). To construct multiple regression models, the bands and band ratios that indicated a good correlation with TSS were selected. In dry season, the six above mentioned band ratios showed significant relationships $\left(\mathrm{R}^{2}=0.67\right)$, and in wet season, five band combinations containing blue band, red band, green/red, red/green, and red/NIR revealed significant relationships $\left(\mathrm{R}^{2}=0.60\right)$ with TSS. The Durbin-Watson values were 2.249 and 1.650 in dry and wet seasons, respectively, which lay in the accepted range. The normal probability-probability (P-P) plots were generated based on the standardized residuals. If the residuals are Normally Distributed the values should fall on the diagonal line of identity. Straight lines in Figure 3.3 indicated the normal distribution for the studied variables in both dry and wet seasons. 

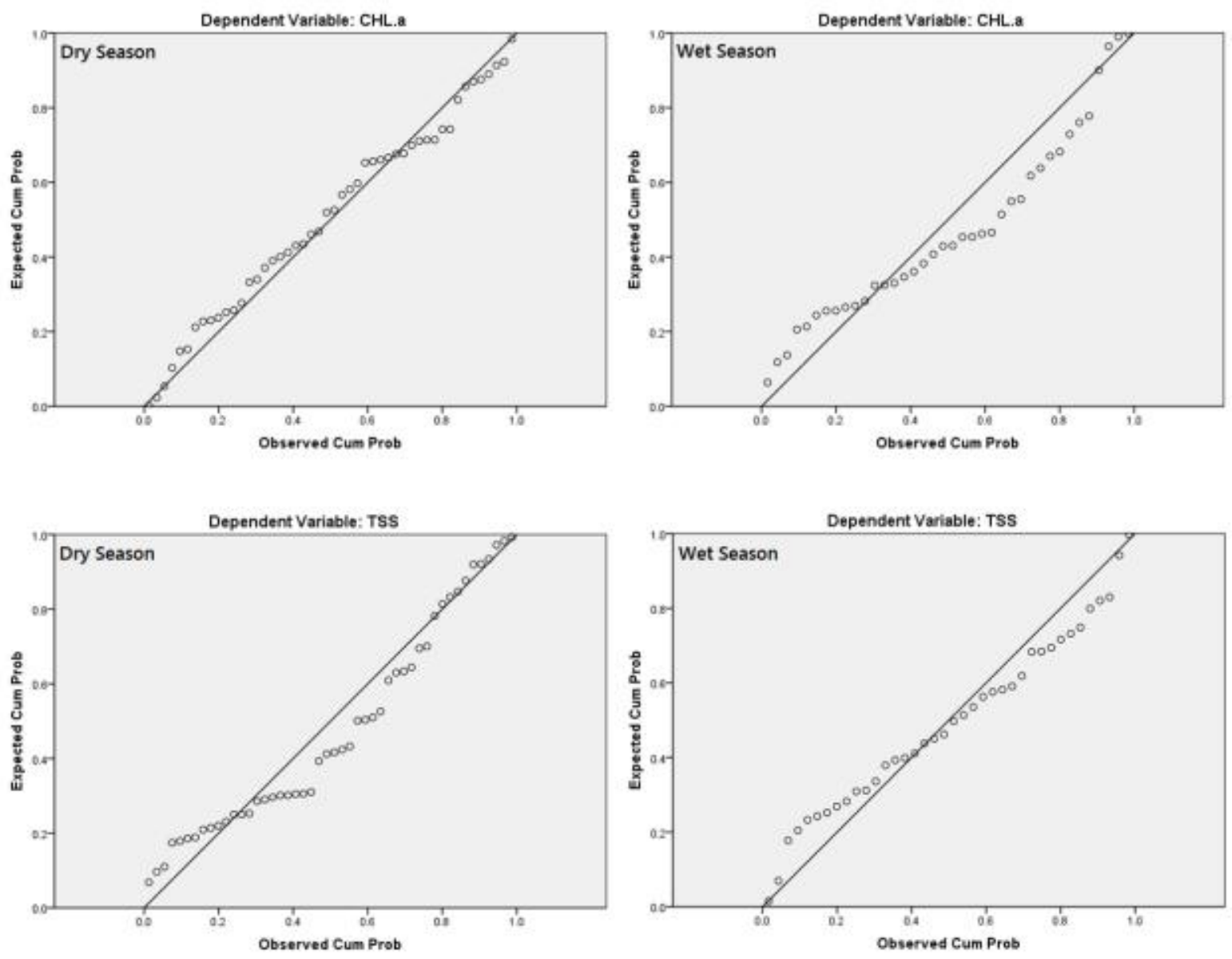

Figure 3.3. The normal probability-probability (P-P) plots of regression standardized residuals for chl-a and TSS in dry and wet seasons.

\section{Nutrients (total phosphate and TKN)}

Phosphorus and phosphate are closely related to some other parameters like phytoplankton $[32,62]$, turbidity and total suspended matters (TSM), and Secchi disk transparency (SDT) [63], which is the basis for remote monitoring of TP dynamics [64]. Carlson [62] found that $\mathrm{TP}$ is also closely related to secchi disk with an exponential equation. Remote estimation of total phosphorus (TP) and total phosphate has been investigated based on its high correlation with optically active constituents $[2,62,65]$. Although there is a possibility that TP may be indirectly correlated to remote sensing 
measurements, few studies have been conducted to estimate TP concentration using remotely sensed imagery and can be quantified using visual spectral bands.

Multispectral Landsat TM data have been widely used to monitor and map the TP spatiotemporal pattern in different regions [65-67]. Empirical statistical regression models were used to study the relationship between the concentration of phosphorus with other water quality indicators, such as secchi depth and chl- $a$ concentration [65]. Song, et al. [48] studied the correlation between TP and TM1, TM2, TM3, and TM4 from the Landsat 5, and found that each band had a correlation with TP of $0.62,0.59,0.55$, and 0.51, respectively. Wu, et al. [65] used a combination of TM1, TM3/TM2, and TM1/TM3 data to correlate chl- $a$ concentration and SD measurements with TP concentration. Also, Alparslan et al. [2] used the first four bands of Landsat 7-ETM satellite data to map total phosphate in Ömerli Dam, Turkey. Later, Alparslan, et al. [21] using Band1, Band2, Band3, Band4, Band5 and Band7 of Landsat-5 TM Satellite Image obtained the amount of total phosphorus concentration. Lim and Choi [18] used bands 2, 3, 4, and 5 of Landsat-8/OLI, and constructed 3 multiple regression models by selecting both single bands and band ratios, and obtained significant correlation coefficients.

Also, there is still little literature with regard to estimate nitrogen concentration in waterbodies from remote sensing. Hood, et al. [68] studied two unique optical characteristics of chlorophyll- $a$ (chl- $a$ ), absorption and fluorescence, are strongly related with the nitrogen concentration. Also, Hanson, et al. [69] proved the points regarding that the fluorescence of chl- $a$ would be influenced by nitrogen and phosphorous concentrations. Additionally, Edwards, et al. [70] showed that suspended sediment concentration (SSC), chl- $a$ and colored dissolved organic matters (CDOM) are important 
substance sources of nutrients elements. Gong, et al. [71] measured different concentrations of nitrogen and phosphorus using the reflectance spectra in the laboratory and found their special features by hyperspectral remote sensing technique. Their result showed the reflectance peaks at 404 and $477 \mathrm{~nm}$, and phosphorus at $350 \mathrm{~nm}$, for nitrogen and phosphorous, respectively, and developed a quantitative retrieval model for these two parameters. Karakaya and Evrendilek [72] applied Landsat 7 Enhanced Thematic Mapper Plus $(\mathrm{ETM}+)$ data to measure the concentration of nitrite nitrogen $\left(\mathrm{NO}_{2}-\mathrm{N}\right)$ and nitrate nitrogen $\left(\mathrm{NO}_{3}-\mathrm{N}\right)$ using best-fit multiple linear regression (MLR) models as a function of Landsat 7 ETM+ and ground data in Mersin Bay, Turkey. Based on the Pearson's correlation between limnological data and Landsat bands and ratios, and also the relationship between these nutrients, and TSS and chl- $a$ (Table 3.5), different models for total phosphate and TKN were developed in two wet and dry seasons.

Table 3.5. Pearson's R correlation between observed water quality parameters and Landsat bands and ratios $(* *)$ : significant correlation for $\mathrm{p}<0.05$.

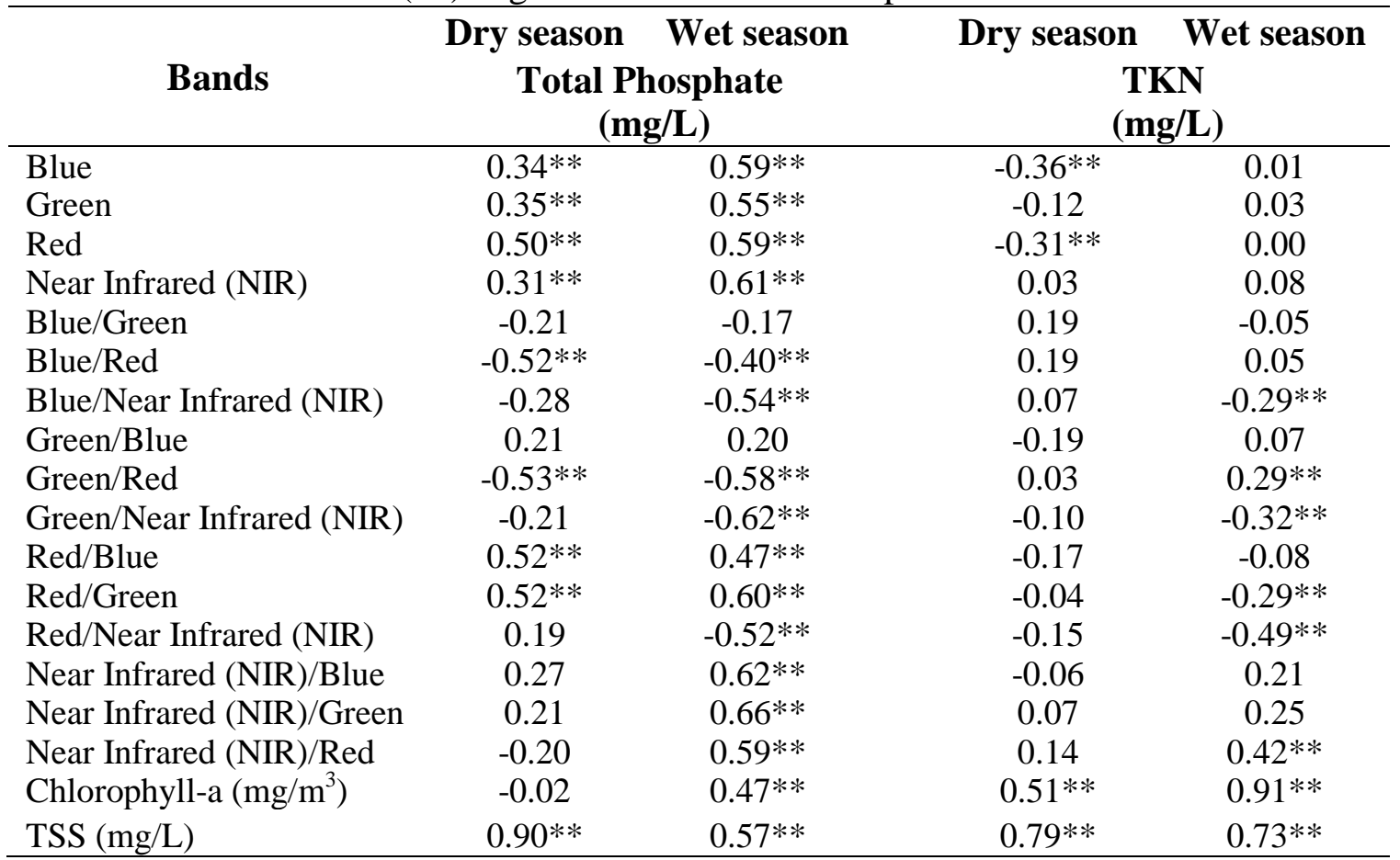


The selected bands by the statistical analysis for the estimation of total phosphate in dry season were correlated with TSS, NIR, and Green/Red ratio, and TSS, Blue/Red, NIR/Green, and NIR/Red in wet season. Therefore, the functional model is:

Dry season: Total Phosphate $=a+(b \times T S S)+\left(c \times \frac{\text { Green }}{\text { Red }}\right)+(d \times N I R)$

Wet season: Total Phosphate $=a+(b \times T S S)+\left(c \times \frac{B l u e}{\text { Red }}\right)+\left(d \times \frac{N I R}{\text { Green }}\right)+\left(e \times \frac{N I R}{\text { Red }}\right)$

The variability of TKN concentration was also investigated using the same procedure, incorporating visible bands and their ratios as independent variables in the regression analysis, and the following functional model was selected for dry and wet season:

Dry season: $T K N=a+(b \times C h l-a)+(c \times T S S)+(d \times B l u e)+(e \times R e d)$

Wet season: $T K N=a+(b \times C h l-a)+(c \times T S S)+\left(d \times \frac{\text { Blue }}{N I R}\right)+\left(e \times \frac{\text { Green }}{N I R}\right)+\left(f \times \frac{R e d}{N I R}\right)+\left(g \times \frac{N I R}{R e d}\right)$

The statistical values given in Table 3.6 were obtained, as a result of the regression analysis computation. The $\mathrm{R}^{2}$ values, which show the correlation between the measured values and the estimated values from the satellite image, prove that the first four bands and their ratios of Landsat satellite image plus the concentrations of chl- $a$ and TSS are well capable of being used in the measurement of total phosphate and TKN. The model coefficients are given in Table 3.7 to compute total phosphate and TKN at anywhere on the lake surface, based on both the pixel reflectance values and chl- $a$ and TSS concentrations. Maps given in Figure 3.4 were made using directly the satellite data of the Lake Okeechobee's entire surface, based on the equalities in Table 3.7. 
Table 3.6. Statistical values obtained as a result of regression analyses for total phosphate and TKN

\begin{tabular}{lcccc}
\hline $\begin{array}{l}\text { Regression analysis } \\
\text { Statistics }\end{array}$ & \multicolumn{2}{c}{ Dry Season } & \multicolumn{2}{c}{ Wet Season } \\
Total Phosphate & TKN & Total Phosphate & TKN \\
\hline R Square & 0.85 & 0.88 & 0.80 & 0.86 \\
Standard error & 0.015 & 0.097 & 0.025 & 0.166 \\
p-value & 0.000 & 0.000 & 0.000 & 0.000 \\
Durbin-Watson & 1.974 & 2.027 & 2.488 & 1.627 \\
Observations & 50 & 50 & 38 & 48 \\
\hline
\end{tabular}

Table 3.7. Extracted equations based on regression analysis between Total Phosphate and TKN, and Landsat bands and other water quality parameters

\begin{tabular}{|c|c|c|}
\hline Season & Water quality parameters & Formulae derived \\
\hline Dry & Total Phosphate (mg/L) & $=0.468+0.001(\mathrm{TSS})-0.202(\mathrm{Green} / \mathrm{Red})-2.56(\mathrm{NIR})$ \\
\hline Season & $\mathrm{TKN}(\mathrm{mg} / \mathrm{L})$ & $\begin{array}{l}=0.641+0.009(\text { Chl-a })+0.008(\text { TSS })+3.91(\text { Blue })- \\
4.35(\text { Red })\end{array}$ \\
\hline \multirow{2}{*}{$\begin{array}{c}\text { Wet } \\
\text { Season }\end{array}$} & Total Phosphate (mg/L) & $\begin{array}{l}=-0.232+0.002(\mathrm{TSS})+0.154(\text { Blue } / \text { Red })+ \\
1.66(\text { NIR/Green })-1.23(\text { NIR/Red })\end{array}$ \\
\hline & $\mathrm{TKN}(\mathrm{mg} / \mathrm{L})$ & $\begin{array}{l}=2.21+0.017(\mathrm{Chl}-\mathrm{a})+0.001(\mathrm{TSS})-0.057(\mathrm{Blue} / \mathrm{NIR}) \\
+0.345(\mathrm{Green} / \mathrm{NIR})-1.09(\mathrm{Red} / \mathrm{NIR})-0.249(\mathrm{NIR} / \mathrm{Red})\end{array}$ \\
\hline
\end{tabular}




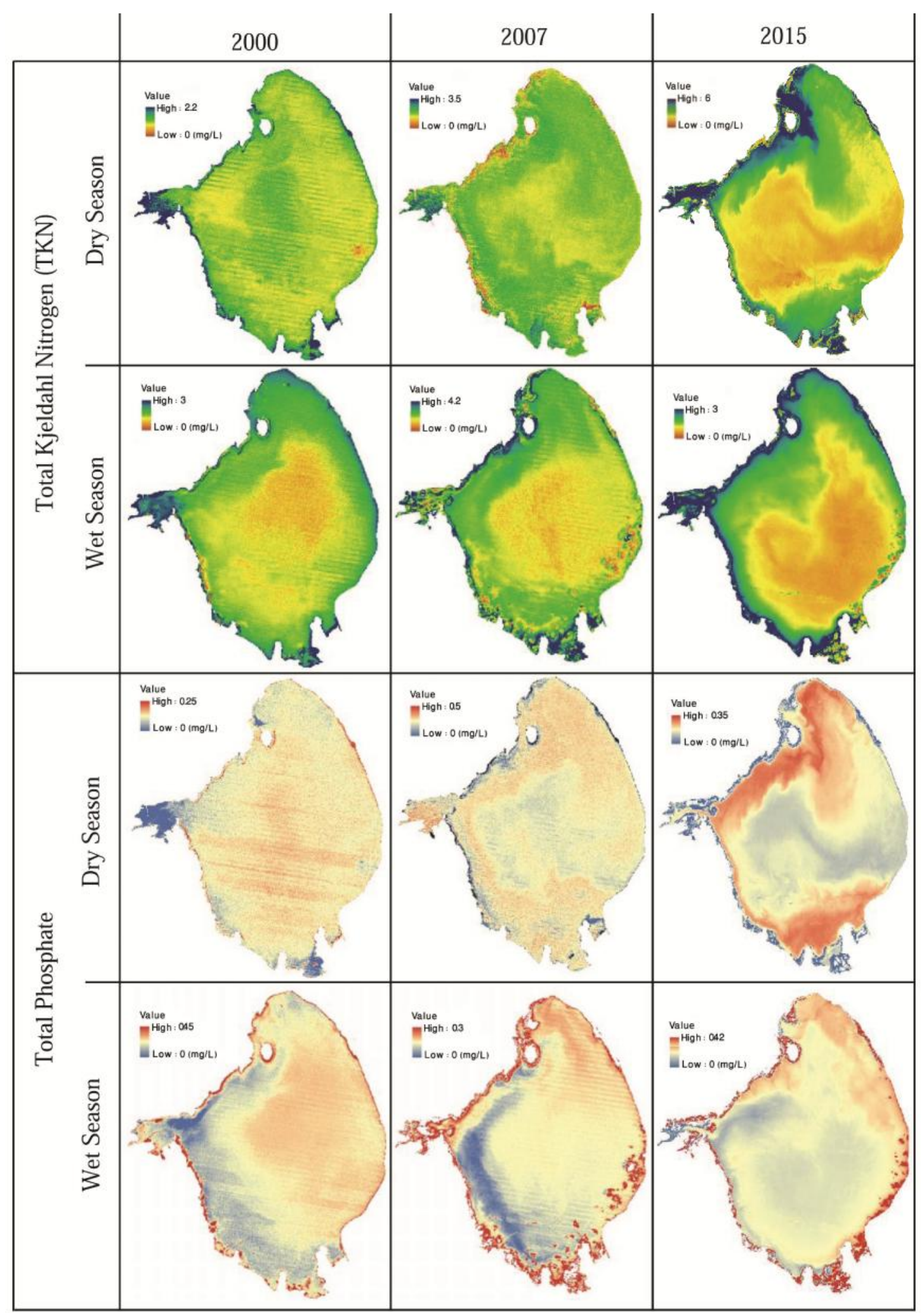

Figure 3.4. Spatial and temporal patterns of total phosphate and TKN in Lake Okeechobee 


\section{Total phosphate}

The correlation of Landsat bands with total phosphate concentration ranged from -0.53 (Green/Red band ratio) to 0.90 (TSS) in dry season, and from -0.62 (Green/NIR band ratio) to 0.66 (NIR/Green band ratio) in wet season. In particular, total phosphate concentration displayed a significant relationship $(\mathrm{R}=0.90$ and 0.66 in dry and wet seasons, respectively) with TSS and NIR/Green band ratio at a significance level of $\mathrm{p}<0.05$ (Table 3.5). Multiple linear regression models constructed for total phosphate estimation through band combination by selecting both correlataed water quality parameters from ground data and imagery showing high correlation coefficients of 0.85 and 0.80 in dry and wet seasons, respectively. A total of 50 data points in dry season seasons and 38 data points in wet season were used due to missing values in the in situ

measurements. Table 3.8 presents the MLR models constructed through equations 3.13 and 3.14. Among the different combinations of bands and band ratios, this research selected a multiple regression model and revealed the best significant relationships in order to compare the estimated total phosphate through the Landsat TM and OLI data with in situ measurement data. The Durbin-Watson values were 1.947 and 2.488 in dry and wet seasons, respectively, which lay in the accepted range.

\section{TKN}

The correlation between the landsat bands and TKN from -0.36 (Blue band) to 0.79 (TSS) in dry season, and from -0.49 (Red/NIR band ratio) to 0.91 (chl- $a$ ) in wet season. In particular, TKN concentration displayed a significant relationship $(\mathrm{R}=0.79$ and 0.91 in dry and wet seasons, respectively) with TSS and chl- $a$ at a significance level 
of $\mathrm{p}<0.05$ (Table 3.5). In dry season, the blue and red bands showed the highest correlation, and in wet season Red/NIR and NIR/Red band ratios were closely related to TKN (Table 3.5). To construct multiple regression models, the highly correlated chl- $a$ and TSS, and the bands and band ratios that indicated a good correlation with TKN were selected. In dry season, chl- $a$ and TSS, and Blue and Red bands showed significant relationships ( $\mathrm{R}=0.94)$, and in wet season, chl- $a$ and TSS, and four band combinations containing Blue/NIR, Green/NIR, Red/NIR, and NIR/Red band ratios revealed significant relationships $(\mathrm{R}=0.60)$ with $\mathrm{TKN}$. The Durbin-Watson values were 2.027 and 1.627 in dry and wet seasons, respectively, which lay in the accepted range. The normal probability-probability (P-P) plots for the studied variables in both dry and wet seasons indicated the normal distribution for the total phosphate and TKN in both dry and wet seasons (Figure 3.5).

After identifiying the regression functions for the four studied water quality parameters, and considering their spatial distribution that were mapped for the whole lake surface in two seasons (Figures 3.2 and 3.3), different spatial and temporal variations were observe. The generated maps were reclassified taking into account the ranges in order to define the trophic conditions of Lake Okeechobee in two seasons and in three years of 2000, 2007, and 2015, which is summarized in Table 3.8. 

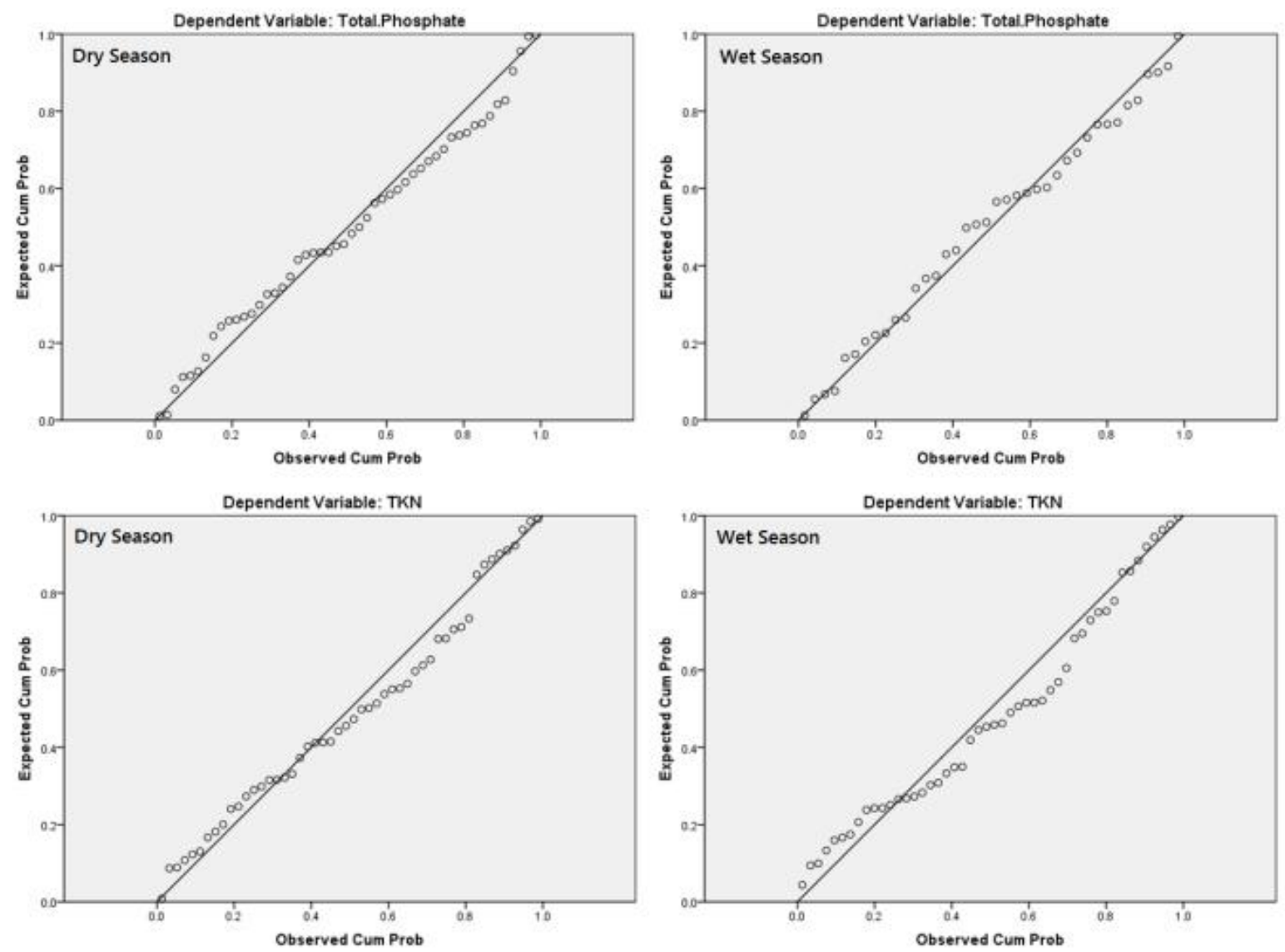

Figure 3.5. The normal probability-probability (P-P) plots of regression standardized residuals for total phosphate and TKN in dry and wet seasons. 
Table 3.8. The area based condition of water quality parameters in Lake Okeechobee in dry and wet seasons, and in three years of 2000, 2007, and $2015\left(\mathrm{Km}^{2}\right)$

\begin{tabular}{|c|c|c|c|c|c|c|c|c|c|c|c|c|}
\hline & & \multicolumn{5}{|c|}{ Dry Season } & \multicolumn{5}{|c|}{ Wet Season } & \multirow[b]{2}{*}{$>100$} \\
\hline & & $0-50$ & $50-100$ & $100-150$ & $150-200$ & $>200$ & $0-20$ & $20-40$ & $40-60$ & $60-80$ & $80-100$ & \\
\hline \multirow{4}{*}{$\begin{array}{c}\text { Chl-a } \\
\left(\mathbf{m g} / \mathbf{M}^{3}\right)\end{array}$} & 2000 & 51.6 & 287.3 & 722.9 & 175.2 & 93.1 & 514.7 & 842.9 & 50.5 & 7 & 0.1 & 0 \\
\hline & 2007 & 96.2 & 334.1 & 451 & 317.9 & 170.2 & 616.7 & 687.8 & 63.8 & 37.9 & 3.6 & 5.4 \\
\hline & 2015 & 117.4 & 226.6 & 767.3 & 247.9 & 8 & 913.5 & 346.2 & 80.6 & 66.1 & 8.8 & 0 \\
\hline & & $0-40$ & $40-80$ & 80-120 & $120-160$ & $>160$ & $0-15$ & $15-30$ & $30-45$ & $45-60$ & $60-75$ & $>75$ \\
\hline \multirow{3}{*}{$\begin{array}{c}\text { TSS } \\
(\mathrm{mg} / \mathrm{L})\end{array}$} & 2000 & 31.9 & 17.9 & 543.9 & 735.8 & 85.4 & 605.4 & 772.2 & 31.5 & 6 & 0.1 & 0 \\
\hline & 2007 & 46.9 & 74.2 & 389.9 & 845.2 & 58.5 & 555.8 & 739.8 & 67.1 & 42.4 & 3.5 & 6.3 \\
\hline & 2015 & 149.8 & 154.2 & 222.2 & 253.3 & 637 & 932.7 & 359.2 & 75.8 & 45.4 & 2.4 & 0 \\
\hline
\end{tabular}

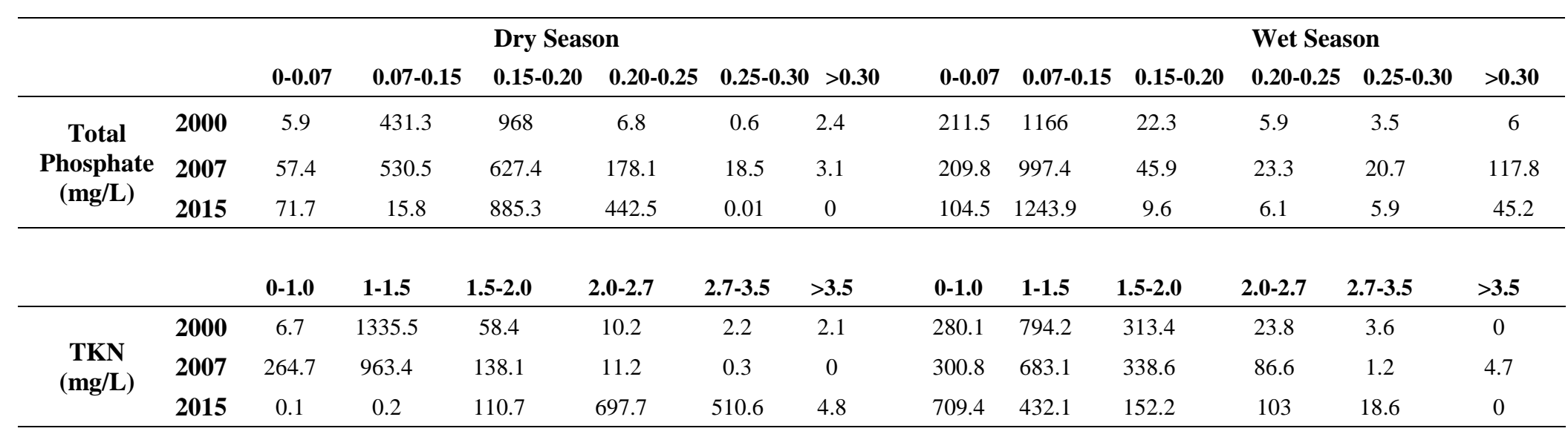




\section{Conclusion}

The water supplies for domestic and industrial use, irrigated agriculture, and livestock and mining activities require continuous monitoring to make sure that the required standards and criteria are met. However, due to anthropogenic activities and industrial development, water quality has dramatically degraded. A combination of remote sensing, GIS, and traditional in-situ sampling can lead to perform a better monitoring program for water quality parameters in various waterbodies.

In this study, bio-physical parameters associated with water quality in Lake Okeechobee were investigated based on atmospherically corrected data. The principal objective of this study was to monitor and assess the spatial and temporal changes of four water quality parameters including total suspended solids (TSS), chlorophyll-a (chl-a), total phosphate, and total kjeldahl nitrogen (TKN), by using the application of integrated remote sensing, GIS data, and statistical techniques. For this purpose, two dates of Landsat Thematic Mapper (TM) data in 2000 (February 29); 2007 (January 31), and one date of Landsat Operational Land Imager (OLI) in 2015 (February 6) in the dry season, and three dates of TM data in 2000 (July 6); 2007 (August 11), and one date of OLI data in 2015 (September 15) in the wet season of the subtropical climate of South Florida, were used to assess temporal and spatial patterns and dimensions of studied parameters in Lake Okeechobee, Florida. The simultaneous observed data of four studied parameters were obtained from 26 monitoring stations and were used for the development and validation of the models. The optical bands in the region from blue to near infrared and

all the possible band ratios were used to explore the relation between the reflectance of waterbody and observed data. 
The predictive models to estimate chl-a and TSS concentrations were developed through the use of stepwise multiple linear regression (MLR) and gave high coefficients of determination in dry season $\left(\mathrm{R}^{2}=0.84\right.$ for chl-a and $\mathrm{R}^{2}=0.67$ for TSS $)$ and moderate coefficients of determination in wet season $\left(R^{2}=0.48\right.$ for chl-a and $R^{2}=0.60$ for TSS $)$. Values for total phosphate and TKN were strongly correlated with chl-a and TSS concentration and some bands and their ratios, therefore, total phosphate and TKN were estimated using best-fit multiple linear regression models as a function of Landsat TM and OLI, and ground data and showed a high coefficient of determination in dry season $\left(\mathrm{R}^{2}=0.85\right.$ for total phosphate and $\mathrm{R}^{2}=0.88$ for $\left.\mathrm{TKN}\right)$ and in wet season $\left(\mathrm{R}^{2}=0.80\right.$ for total phosphate and $\mathrm{R}^{2}=0.86$ for $\mathrm{TKN}$ ). The multiple linear regression (MLR) models showed a good trustiness to monitor and predict the spatiotemporal variations of the studied water quality parameters in Lake Okeechobee.

This study showed that Landsat TM and OLI data and water quality parameters at various locations of Lake Okeechobee can be related through a regression analysis and constitute a model that can be used to measure water quality parameters over the entire lake surface. The four studied parameters mapped by identifying the best set of band combinations and also their interreltionship to describe the linkage between the spectral response to limnological data. The same method can be applied to the trophic conditions for landsat images in different years.

\section{Acknowledgements}

This research was made possible by financial support that was provided by the Department of Civil and Environmental Engineering of Florida International University, 
Miami, U.S.A., through a Presidential Fellowship and a Graduate Assistantship to the main author. The observational data were obtained from South Florida Water Management District (SFWMD). Also, the satellite images were downloaded from USGS Earth Explorer website.

\section{References}

1. Duan, W.; He, B.; Nover, D.; Yang, G.; Chen, W.; Meng, H.; Zou, S.; Liu, C. Water Quality Assessment and Pollution Source Identification of the Eastern Poyang Lake Basin Using Multivariate Statistical Methods. Sustainability 2016, 8, 133.

2. Alparslan, E.; Aydöner, C.; Tufekci, V.; Tüfekci, H. Water quality assessment at Ömerli Dam using remote sensing techniques. Environ. Monit. Assess. 2007, 1, 391-398.

3. Anding, D.; Kauth, R. Estimation of sea surface temperature from space. Remote Sens. Environ. 1970, 1, 217-220.

4. Brando, V. E.; Dekker, A. G. Satellite hyperspectral remote sensing for estimating estuarine and coastal water quality. IEEE Trans. Geosci. Remote Sens. 2003, 41, 13781387.

5. El-Din, M.; Gaber, A.; Koch, M. Remote Sensing Application for Water Quality Assessment in Lake Timsah, Suez Canal, Egypt. J. Remote 2013.

6. Giardino, C.; Bresciani, M.; Cazzaniga, I.; Schenk, K.; Rieger, P.; Braga, F.; Matta, E.; Brando, V. E.; Brando, V. E. Evaluation of multi-resolution satellite sensors for assessing water quality and bottom depth of Lake Garda. Sensors (Switzerland) 2014, 14, 2411624131.

7. Hadjimitsis, D.; Clayton, C. Assessment of temporal variations of water quality in inland water bodies using atmospheric corrected satellite remotely sensed image data. Environ. Monit. Assess. 2009.

8. Hellweger, F.; Schlosser, P.; Lall, U. Use of satellite imagery for water quality studies in New York Harbor. Estuarine, Coast. 2004.

9. Kondratyev, K.; Pozdnyakov, D. Water quality remote sensing in the visible spectrum. Int. J. 1998.

10. Koponen, S.; Pulliainen, J.; Kallio, K.; Hallikainen, M. Lake water quality classification with airborne hyperspectral spectrometer and simulated MERIS data. Remote Sens. Environ. 2002, 79, 51-59.

11. Maillard, P.; Pinheiro Santos, N. A. A spatial-statistical approach for modeling the effect of non-point source pollution on different water quality parameters in the Velhas river watershed - Brazil. J. Environ. Manage. 2008, 86, 158-170.

12. Morel, A.; Prieur, L. Analysis of variations in ocean color. Limnol. Oceanogr. 1977, $22,709-722$. 
13. Pozdnyakov, D.; Shuchman, R.; Korosov, A.; Hatt, C. Operational algorithm for the retrieval of water quality in the Great Lakes. Remote Sens. Environ. 2005, 97, 352-370.

14. Ritchie, J. C.; Zimba, P. V; Everitt, J. H. Remote Sensing Techniques to Assess Water Quality. Photogramm. Eng. Remote Sens. 2003, 69, 695-704.

15. Seyhan, E.; Dekker, A. Application of remote sensing techniques for water quality monitoring. Hydrobiol. Bull. 1986.

16. Usali, N.; Ismail, M. H. Use of remote sensing and GIS in monitoring water quality. J. Sustain. Dev. 2010, 3, 228-238.

17. Wang, X. J.; Ma, T. Application of Remote Sensing Techniques in Monitoring and Assessing the Water Quality of Taihu Lake. Bull. Environ. Contam. Toxicol. 2001, 6, $863-870$.

18. Lim, J.; Choi, M. Assessment of water quality based on Landsat 8 operational land imager associated with human activities in Korea. Environ. Monit. Assess. 2015.

19. Lillesand, T.; Kiefer, R.; Chipman, J. Remote sensing and image interpretation; 2014.

20. Dekker, A.; Peters, S. The use of the Thematic Mapper for the analysis of eutrophic lakes: a case study in the Netherlands. Int. J. Remote Sens. 1993.

21. Alparslan, E.; Coskun, G.; Alganci, U. Water quality determination of Küçükçekmece Lake, Turkey by using multispectral satellite data. ScientificWorldJournal. 2009, 9, $1215-29$.

22. ZHANG, C.; HAN, M. Mapping Chlorophyll-a Concentration in Laizhou Bay Using Landsat 8 OLI data. 89.31.100.18.

23. Kim, S.; Kim, H.; Hyun, C. High Resolution Ocean Color Products Estimation in Fjord of Svalbard, Arctic Sea using Landsat-8 OLI. Korean J. Remote Sens. 2014.

24. Myint, S. W.; Walker, N. D. Quantification of surface suspended sediments along a river dominated coast with NOAA AVHRR and SeaWiFS measurements: Louisiana, USA. Int. J. Remote Sens. 2002, 23, 3229-3249.

25. Nechad, B.; Ruddick, K. G.; Park, Y. Calibration and validation of a generic multisensor algorithm for mapping of total suspended matter in turbid waters. Remote Sens. Environ. 2010, 114, 854-866.

26. Curran, P. J.; Hansom, J. D.; Plummer, S. E.; Pedley, M. I. Multispectral remote sensing of nearshore suspended sediments: a pilot study. Int. J. Remote Sens. 1987, 8, $103-112$.

27. NOVO, E. M. M.; HANSOM, J. D.; CURRAN, P. J. The effect of viewing geometry and wavelength on the relationship between reflectance and suspended sediment concentration. Int. J. Remote Sens. 1989, 10, 1357-1372.

28. Feng, L.; Hu, C.; Chen, X.; Song, Q. Influence of the Three Gorges Dam on total suspended matters in the Yangtze Estuary and its adjacent coastal waters: Observations from MODIS. Remote Sens. Environ. 2014. 
29. Doxaran, D.; Froidefond, J. M.; Lavender, S.; Castaing, P. Spectral signature of highly turbid waters: Application with SPOT data to quantify suspended particulate matter concentrations. Remote Sens. Environ. 2002, 81, 149-161.

30. Ritchie, J.; Schiebe, F.; McHENRY, J. Remote sensing of suspended sediments in surface waters. Am. Soc. 1976.

31. Soltis-Muth, C. TP- It Stands for Total Phosphorus. Northeast Ohio Reg. Sewer Dist.

32. Busse, L.; Simpson, J. Relationships among nutrients, algae, and land use in urbanized southern California streams. Can. J. 2006.

33. Patton, C. J.; Kryskalla, J. R. Methods of analysis by the US Geological Survey National Water Quality Laboratory: evaluation of alkaline persulfate digestion as an alternative to Kjeldahl digestion for determination of total and dissolved nitrogen and phosphorus in water; 2003.

34. Description of River Water Quality Parameters.

35. Mikkelsen, R. Ammonia emissions from agricultural operations: fertilizer. Better Crop. 2009, 93, 9-11.

36. Gholizadeh, M. H.; Melesse, A. M.; Reddi, L. A Comprehensive Review on Water Quality Parameters Estimation Using Remote Sensing Techniques. Sensors (Basel). 2016, 16, 1298.

37. Turbidity, Total Suspended Solids \&amp; Water Clarity - Environmental Measurement Systems http://www.fondriest.com/environmentalmeasurements/parameters/water-quality/turbidity-total-suspended-solids-water-clarity/.

38. Perry, W. B. Everglades restoration and water quality challenges in south Florida. Ecotoxicology 2008, 17, 569-578.

39. Havens, K.; Brady, M.; Colborn, E.; Gornak, S.; Gray, S.; James, R. T.; Jin, K.-R.; Mo, C.; O 'dell, K.; Patino, J.; Ritter, G.; Whalen, B.; Zhang, J. 2005 South Florida Environmental Report Chapter 10: Lake Okeechobee Protection Program - State of the Lake and Watershed.

40. Praveena, S. M.; Kwan, O. W.; Aris, A. Z. Effect of data pre-treatment procedures on principal component analysis: a case study for mangrove surface sediment datasets. Environ. Monit. Assess. 2012, 184, 6855-6868.

41. Gordon, H. R. Calibration requirements and methodology for remote sensors viewing the ocean in the visible. Remote Sens. Environ. 1987, 22, 103-126.

42. Teillet, P. M.; Horler, D. N. H.; O'Neill, N. T. Calibration, validation, and quality assurance in remote sensing: A new paradigm. Can. J. Remote Sens. 1997, 23, 401-414.

43. Maul, G. Introduction to satellite oceanography; 2012.

44. Brivio, P. a.; Giardino, C.; Zilioli, E. Determination of chlorophyll concentration changes in Lake Garda using an image-based radiative transfer code for Landsat TM images. Int. J. Remote Sens. 2001, 22, 487-502. 
45. Moran, M. S.; Jackson, R. D.; Slater, P. N.; Teillet, P. M. Evaluation of simplified procedures for retrieval of land surface reflectance factors from satellite sensor output. Remote Sens. Environ. 1992, 41, 169-184.

46. Visibility and Light Scattering in the Atmosphere http://mtweb.mtsu.edu/nchong/pmatm3.htm.

47. Chávez, P. S. J. Image-Based Atmospheric Corrections - Revisited and Improved. Photogramm. Eng. Remote Sensing 1996, 62, 1025-1036.

48. Song, K.; Wang, Z.; Blackwell, J.; Zhang, B.; Li, F.; Zhang, Y.; Jiang, G. Water quality monitoring using Landsat Themate Mapper data with empirical algorithms in Chagan Lake, China. J. Appl. Remote Sens. 2011, 5, 53506-53516.

49. Kloiber, S. M.; Brezonik, P. L.; Bauer, M. E. Application of Landsat imagery to regional-scale assessments of lake clarity. Water Res. 2002, 36, 4330-4340.

50. Kloiber, S. M.; Brezonik, P. L.; Olmanson, L. G.; Bauer, M. E. A procedure for regional lake water clarity assessment using Landsat multispectral data. Remote Sens. Environ. 2002, 82, 38-47.

51. Mayo, M.; Gitelson, A.; Yacobi, Y.; Ben-Avraham, Z. Chlorophyll distribution in Lake Kinneret determined from Landsat Thematic Mapper data. Int. J. Remote Sens. 1995, 16, 175-182.

52. Mancino, G.; Nolè, A.; Urbano, V.; Amato, M.; Ferrara, A. Assessing water quality by remote sensing in small lakes: The case study of Monticchio lakes in southern Italy. IForest 2009, 2, 154-161.

53. Lathrop, R. G.; Lillesand, T. M. Use of Thematic Mapper data to assess water quality in Green Bay and central Lake Michigan. Photogramm. Eng. Remote Sens. 1986, 52, 671-680.

54. Lavery, P.; Pattiaratchi, C.; Wyllie, A.; Hick, P. Water quality monitoring in estuarine waters using the landsat thematic mapper. Remote Sens. Environ. 1993, 46, 268-280.

55. Jr, R. C.; Forsythe, R.; Vaughan, G. Assessing water quality in Catawba River reservoirs using Landsat thematic mapper satellite data. Lake Reserv. 1998.

56. Giardino, C.; Pepe, M.; Brivio, P.; Ghezzi, P. Detecting chlorophyll, Secchi disk depth and surface temperature in a sub-alpine lake using Landsat imagery. Sci. Total 2001.

57. Gitelson, A. A.; Dall'Olmo, G.; Moses, W.; Rundquist, D. C.; Barrow, T.; Fisher, T. R.; Gurlin, D.; Holz, J. A simple semi-analytical model for remote estimation of chlorophyll-a in turbid waters: Validation. Remote Sens. Environ. 2008, 112, 3582-3593.

58. Dekker, a. G.; Vos, R. J.; Peters, S. W. M. Analytical algorithms for lake water TSM estimation for retrospective analyses of TM and SPOT sensor data. Int. J. Remote Sens. 2002, 23, 15-35. 
59. Akbar, T. A.; Hassan, Q. K.; Achari, G. A remote sensing based framework for predicting water quality of different source waters. Int. Arch. Photogramm. Remote Sens. Spat. Inf. Sci. - ISPRS Arch. 2010, 38, 1-4.

60. Brezonik, P.; Menken, K. D.; Bauer, M. Landsat-based remote Sensing of Lake Water Quality Characteristics, Including Chlorophyll and Colored Dissolved OrganiC Matter (CDOM). Lake Reserv. Manag. 2005, 21, 373-382.

61. Band Combinations http://web.pdx.edu/ emch/ip1/bandcombinations.html.

62. Carlson, R. E. A trophic state index for lakes1. Limnol. Oceanogr. 1977, 22, 361369.

63. Uusitalo, R.; Aura, E. A rainfall simulation study on the relationships between soil test $\mathrm{P}$ versus dissolved and potentially bioavailable particulate phosphorus forms in runoff. Agric. Food Sci. 2005, 14, 335-345.

64. Hoyer, M. V; Frazer, T. K.; Notestein, S. K.; Canfield, Jr., D. E. Nutrient, chlorophyll, and water clarity relationships in Florida's nearshore coastal waters with comparisons to freshwater lakes. Can. J. Fish. Aquat. Sci. 2002, 59, 1024-1031.

65. Wu, C.; Wu, J.; Qi, J.; Zhang, L.; Huang, H.; Lou, L.; Chen, Y. Empirical estimation of total phosphorus concentration in the mainstream of the Qiantang River in China using Landsat TM data. Int. J. Remote Sens. 2010, 31, 2309-2324.

66. Kutser, T.; Arst, H.; Miller, T.; Kaarmann, L.; Milius, A. Telespectrometrical Estimation of Water Transparency, Chlorophyll-a and Total Phosphorus Concentration of Lake Peipsi. Int. J. Remote Sens. 1995, 16, 3069-3085.

67. Wang, Y.; Xia, H.; Fu, J.; Sheng, G. Water quality change in reservoirs of Shenzhen, China: Detection using LANDSAT/TM data. Sci. Total Environ. 2004, 328, 195-206.

68. Hood, R. R.; Subramaniam, A.; May, L. R.; Carpenter, E. J.; Capone, D. G. Remote estimation of nitrogen fixation by Trichodesmium. Deep. Res. Part II Top. Stud. Oceanogr. 2002, 49, 123-147.

69. Hanson, C. E.; Waite, A. M.; Thompson, P. A.; Pattiaratchi, C. B. Phytoplankton community structure and nitrogen nutrition in Leeuwin Current and coastal waters off the Gascoyne region of Western Australia. Deep. Res. Part II Top. Stud. Oceanogr. 2007, 54, 902-924.

70. Edwards, V.; Icely, J.; Newton, A.; Webster, R. The yield of chlorophyll from nitrogen: a comparison between the shallow Ria Formosa lagoon and the deep oceanic conditions at Sagres along the southern coast of. Estuarine, Coast. Shelf 2005.

71. Gong, S. Q.; Huang, J. Z.; Li, Y. M.; Lu, W. N.; Wang, H. J.; Wang, G. X. [Preliminary exploring of hyperspectral remote sensing experiment for nitrogen and phosphorus in water]. Guang Pu Xue Yu Guang Pu Fen Xi 2008, 28, 839-842.

72. Karakaya, N.; Evrendilek, F. Monitoring and validating spatio-temporal dynamics of biogeochemical properties in Mersin Bay (Turkey) using Landsat ETM+. Environ. Monit. Assess. 2011, 181, 457-464. 


\section{CHAPTER IV}

STUDY ON SPATIOTEMPORAL VARIABILITY OF WATER QUALITY

PARAMETERS IN FLORIDA BAY USING REMOTE SENSING 


\section{Abstract}

In this study, the bio-physical parameters associated with water quality of Florida Bay were investigated based on atmospherically corrected data. The principal objective of this study was to monitor and assess the spatial and temporal changes of four water quality parameters: turbidity, chlorophyll- $a$ (chl- $a$ ), total phosphate, and total nitrogen (TN), using the application of integrated remote sensing, GIS data, and statistical techniques. For this purpose, three dates of Landsat Thematic Mapper (TM) data in 2000 (February 13), 2007 (January 31), and one date of Landsat Operational Land Imager (OLI) in 2015 (January 5) in the dry season, and three dates of TM data in 2000 (August 7), 2007 (September 28), and one date of OLI data in 2015 (September 2) in the wet season of the subtropical climate of South Florida, were used to assess temporal and spatial patterns and dimensions of studied parameters in Florida Bay, USA. The simultaneous observed data of four studied parameters were obtained from 20 monitoring stations and were used for the development and validation of the models. The optical bands in the region from blue to near infrared and all the possible band ratios were used to explore the relation between the reflectance of waterbody and observed data. The predictive models to estimate chl- $a$ and turbidity concentrations were developed through the use of stepwise multiple linear regression (MLR) and gave high coefficients of determination in dry season $\left(\mathrm{R}^{2}=0.86\right.$ for chl- $a$ and $\mathrm{R}^{2}=0.84$ for turbidity) and moderate coefficients of determination in wet season $\left(\mathrm{R}^{2}=0.66\right.$ for chl- $a$ and $\mathrm{R}^{2}=0.63$ for turbidity). Values for total phosphate and $\mathrm{TN}$ were correlated with chl- $a$ and turbidity concentration and some bands and their ratios. Total phosphate and TN were estimated using best-fit multiple linear regression models as a function of Landsat TM and OLI, 
and ground data and showed a high coefficient of determination in dry season $\left(R^{2}=0.74\right.$ for total phosphate and $\mathrm{R}^{2}=0.82$ for $\left.\mathrm{TN}\right)$ and in wet season $\left(\mathrm{R}^{2}=0.69\right.$ for total phosphate and $\mathrm{R}^{2}=0.82$ for $\left.\mathrm{TN}\right)$. The MLR models showed a good trustiness to monitor and predict the spatiotemporal variations of the studied water quality parameters in Florida Bay.

Keywords: Water quality, Spatiotemporal modelling, Remote Sensing, Landsat, chlorophyll, Turbidity, Nutrients, Florida Bay.

\section{Introduction}

Florida Bay is the other important waterbody of South Florida that is a dynamic and biologically productive system, which provides unique habitats. Based on the volume of freshwater flow coming from the Everglades, the salinity of the Florida Bay is varies in different wet and dry seasons. Therefore, in this area, the flow of freshwater from the Everglades determines the conditions in Florida Bay. The regular inflow from the everglades also contain significant amounts of nutrients, which provide the required energy for aquatic organisms, and the constant variation of inflow and sediments discharged into the region make the Florida Bay and its surrounded estuaries one of the most biologically productive systems on earth [18].

The majority of the water quality studies using the application of remote sensing have focused on optically active variables, such as chlorophyll-a (chl- $a$ ), total suspended solids (TSS), and turbidity, while other important water quality variables such as total phosphorous (TP) and total nitrogen (TN) which existing literatures omit due to their weak optical characteristics and low signal noise ratio. In chapter III, the applicability of 
remotely-sensed data to measure the concentrations of chl-a, TP, total phosphate, and TN were discussed. Turbidity and total suspended matters are considered as important variables in many studies due to their linkage with incoming sunlight that in turn affects photosynthesis for growth of algae and plankton. Water turbidity is an optical property of water, which causes the scattering and absorption the light more than its transmitting. As water turbidity is mainly a result of the presence of suspended matter, it is used to measure the concentration of fluvial suspended sediment and is commonly regarded as the opposite of clarity. The complex nature of suspended substances in water changes the reflectance of the waterbody and therefore causes variation in color. To this end, interpretation of remotely sensed data just based on the color of water is not adequate and accurate. In this study, the spatial and temporal changes of four water quality parameters including turbidity, chlorophyll- $a(\operatorname{chl}-a)$, total phosphate, and total nitrogen (TN), were investigated by using the application of integrated remote sensing, GIS data, and statistical techniques. The simultaneous observed data of four studied parameters were obtained from 20 monitoring stations and were used for the development and validation of the models. The optical bands in the region from blue to near infrared and all the

possible band ratios were used to explore the relation between the reflectance of waterbody and observed data.

\section{Materials and methods}

\subsection{Study area}

South Florida is one of the unique parts of the United States with a subtropical climate. It contains two important vast waterbodies of Lake Okeechobee and the Everglades, which the first one is the Florida's largest freshwater lake and the second one 
is the largest subtropical wilderness in the United States. In this study, Lake Okeechobee, which is the largest and the most important lake in South Florida, is selected to be investigated for its bio-physical parameters associated with water quality using remote sensing. Florida Bay is located at the southern part of Florida and on the southeast is bordered by the Florida Keys and is open to the Gulf of Mexico along its western margin. Runoff from the Everglades enters this area and a number of its northern creeks, which in its way flows through different saw-grass areas, sloughs and wetlands. Figure 4.1 shows the location of the study area and the selected water quality monitoring sites. The average annual temperature ranges from $19.2{ }^{\circ} \mathrm{C}$ to $28.7^{\circ} \mathrm{C}$ and the annual rainfall in the entire area of South Florida is generally about 55 inches $(1,400 \mathrm{~mm})$. Considering the subtropical climate of South Florida, the average rainfall is still considerable in the dry season. In addition, during El Niño phenomenon, greater amounts of rainfall in dry season are observed in South Florida.
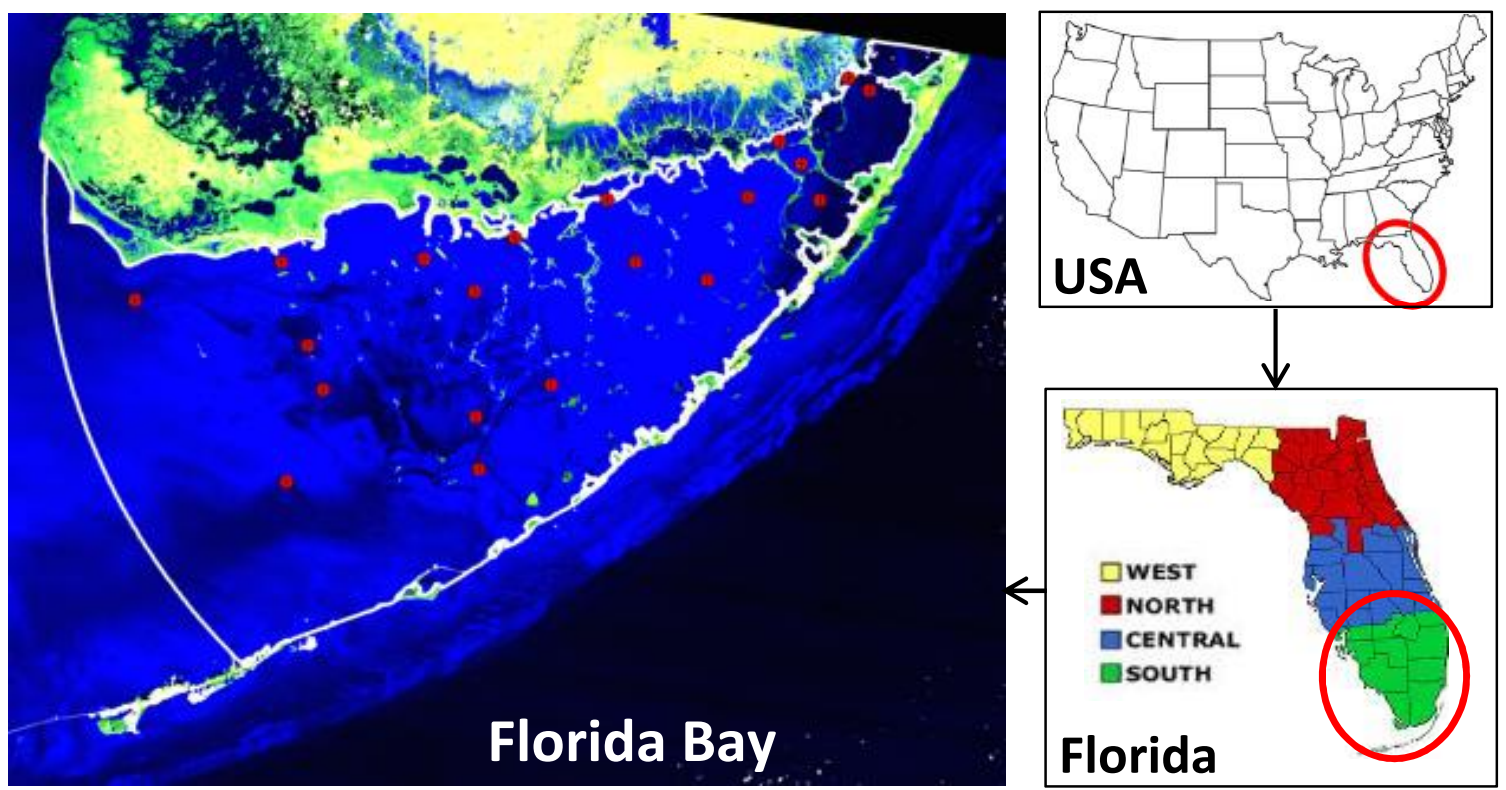

Figure 4.1. The location of the study area and the water quality monitoring sites. 


\subsection{Limnological data}

The monitoring stations, downloaded from the South Florida Water Management District's (SFWMD) geographic information systems data catalog, were overlaid with the Florida bay map in ArcGIS to design a network of sampling stations that include sufficient historical data to construct a robust statistical database of studied parameters, considering a suitable spatial distribution on the Lake. The limnological data on chl- $a$, turbidity, total phosphate, and TN used in this study were obtained from the DBHYDRO (environmental database of SFWMD), United States Geological Survey (USGS), the Environmental Protection Agency (EPA), and the National Water Quality Monitoring Council (NWQMC) from 20 selected monitoring stations. Then, a database was developed for the observed data of four studied parameters simultaneous or in the closest day of the month as the satellite image are obtained in wet (May $15^{\text {th }}$ through October $15^{\text {th }}$ ) and dry seasons (October $16^{\text {th }}$ through May $14^{\text {th }}$ ), and was used for the development and validation of the models. The SPSS 16.0 software package was employed for data treatment. The descriptive statistics of the four studied parameters are shown in Table 4.1.

Due to differences in units of the studied water quality parameters in the dataset, pre-treatment of data is required. in order to the homogenization [36]. In this study, data pre-treatment methods, such as the elimination of non-informative variables, the treatment of missing data values, and the detection and treatment of outliers were performed before the statistical analyses. 
Table 4.1. Descriptive statistics of chl- $a$, turbidity, total phosphate, and TN in the Florida Bay

\begin{tabular}{|c|c|c|c|c|c|c|}
\hline \multicolumn{3}{|c|}{ Indices } & $\begin{array}{c}\text { Chl- } a \\
\left(\mathrm{mg} / \mathrm{m}^{3}\right)\end{array}$ & $\begin{array}{c}\text { Turbidity } \\
\text { (NTU) }\end{array}$ & $\begin{array}{c}\text { total phosphate } \\
\text { (mg/L) }\end{array}$ & $\begin{array}{c}\mathrm{TN} \\
(\mathrm{mg} / \mathrm{L})\end{array}$ \\
\hline \multirow{12}{*}{ 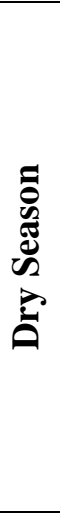 } & \multirow{4}{*}{ 2000, February 13} & Minimum & 0.80 & 0.70 & 0.001 & 0.186 \\
\hline & & Maximum & 8.30 & 17.70 & 0.022 & 0.928 \\
\hline & & Average & 2.24 & 5.04 & 0.008 & 0.522 \\
\hline & & St. Dev. & 2.09 & 4.91 & 0.006 & 0.263 \\
\hline & \multirow{4}{*}{ 2007, January 31} & Minimum & 0.11 & 0.330 & 0.005 & 0.145 \\
\hline & & Maximum & 5.97 & 14.69 & 0.042 & 0.866 \\
\hline & & Average & 1.54 & 4.91 & 0.013 & 0.446 \\
\hline & & St. Dev. & 1.61 & 3.47 & 0.008 & 0.191 \\
\hline & \multirow{4}{*}{ 2015, January 5} & Minimum & 0.47 & 0.40 & 0.002 & 0.262 \\
\hline & & Maximum & 4.20 & 11.4 & 0.024 & 1.110 \\
\hline & & Average & 1.69 & 2.84 & 0.007 & 0.617 \\
\hline & & St. Dev. & 1.45 & 2.57 & 0.005 & 0.235 \\
\hline \multirow{12}{*}{ 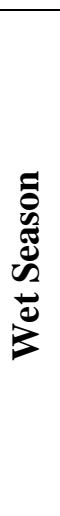 } & \multirow{4}{*}{ 2000, August 7} & Minimum & 1.30 & 7.40 & 0.019 & 0.204 \\
\hline & & Maximum & 0.59 & 2.49 & 0.012 & 1.551 \\
\hline & & Average & 0.36 & 1.63 & 0.004 & 0.940 \\
\hline & & St. Dev. & 1.3 & 7.4 & 0.019 & 0.435 \\
\hline & \multirow{4}{*}{ 2007, September 28} & Minimum & 0.30 & 0.80 & 0.005 & 0.249 \\
\hline & & Maximum & 5.90 & 8.60 & 0.023 & 1.142 \\
\hline & & Average & 2.18 & 3.37 & 0.012 & 0.567 \\
\hline & & St. Dev. & 1.78 & 1.93 & 0.005 & 0.253 \\
\hline & \multirow{4}{*}{2015, September 2} & Minimum & 0.90 & 2.50 & 0.005 & 0.299 \\
\hline & & Maximum & 3.40 & 6.90 & 0.021 & 1.920 \\
\hline & & Average & 1.26 & 4.16 & 0.014 & 1.354 \\
\hline & & St. Dev. & 1.34 & 1.80 & 0.004 & 0.644 \\
\hline
\end{tabular}

\subsection{Satellite data}

The remotely sensed data were acquired from the Landsat Thematic Mapper (TM) and Landsat OLI sensors onboard Landsat 5 and 8, respectively, in 2000, 2007, and 2015. Pre-processing of the Landsat data including the radiometric calibration and atmospheric correction is essential for quantitative studies [37,38], especially for lake waters that the reflected light is small [39]. The radiance of small lakes in average is usually less than $10 \%$, and even in many cases values less than $1 \%$ of total radiance are also reported [40]. For this purpose, in order to remove the effects of high local variability, the digital 
number values should be first converted to unitless planetary reflectance before the process of atmospheric correction. As two types of imagery were used in this study, two different methods were used for the radiometric calibration and Atmospheric correction of TM and OLI data. ERDAS IMAGINE 2014 and ESRI ArcGIS 10.0 platforms were used for image processing.

\section{Preprocessing of Landsat-5/TM data}

The digital number (DN) values of each band were converted to radiance values to remove the voltage bias and gains from the satellite sensor as follows:

$L_{\lambda}=\frac{\left(\operatorname{Lmax}_{\lambda}-\operatorname{Lmin}_{\lambda}\right)}{(Q C A L \max -Q C A L \min )} *(Q C A L-Q C A L \min )+\operatorname{Lmin}_{\lambda}$

Where, $L_{\lambda}$ is the spectral radiance at the sensor's aperture in watts/(meter squared $\times$ ster $\times \mu \mathrm{m}), \quad \operatorname{Lmin}_{\lambda}$ is the spectral radiance that is scaled to QCALmin in watts/(meter squared $\times$ ster $\times \mu \mathrm{m}), \operatorname{Lmax}_{\lambda}$ is the spectral radiance that is scaled to QCALmax in watts/(meter squared $\times$ ster $\times \mu \mathrm{m}), Q C A L \min$ is the minimum quantized calibrated pixel value (corresponding to $\operatorname{Lmin}_{\lambda}$ ) in DN, QCALmax is and the maximum quantized calibrated pixel value (corresponding to $\operatorname{Lmax}_{\lambda}$ ) in DN.

As the process of atmospheric correction, the radiance values are converted to atsatellite reflectance values that consider the variation of sun angle in different latitude, time of day, season, and the distance between the earth and sun. The simplified model of the effects of the atmosphere is [41]:

$$
\rho_{p}=\frac{\pi \times L_{\lambda} \times d^{2}}{E S U N_{\lambda} \times \cos \theta_{S}}
$$


Where, $\rho_{p}$ is the unitless planetary reflectance, $L_{\lambda}$ is the spectral radiance at the sensor's aperture, $d$ is the Earth-Sun distance in astronomical units, $E S U N_{\lambda}$ is the mean solar exo-atmospheric irradiance, and $\theta_{s}$ is the solar zenith angle in degrees.

\section{Preprocessing of Landsat-8/OLI data}

COST-DOS was used as the radiometric correction method for mitigating atmospheric effects recorded by Landsat-8/OLI data. It accounts for absorption, scattering, and refraction of atmospheric particles such as particulate matter and water vapor [42]. The improved cosine of the solar zenith angle (COST) method presented by Chavez [43] was used to convert the DN values of each band of Landsat-8/OLI to reflectance values as follows:

$P_{\lambda}=\frac{\pi\left(L_{\lambda \text { sensor }}-L_{\lambda \text { haze }}\right) d^{2}}{\operatorname{ESUN}_{\lambda} \cos \left(\frac{\pi}{180 \theta_{S}}\right)}$

Where, $P_{\lambda}$ is the dimensionless spectral reflectance value of surface water, $\pi$ is a constant (3.14159265), $L_{\lambda \text { sensor }}$ is the spectral radiance value, and $L_{\lambda h a z e}$ is the path radiance or upwelling atmospheric spectral radiance. $d$ is the distance between the earth and the sun in astronomical units, and $\theta_{s}$ is the solar zenith angle $\left(^{\circ}\right) . E S U N_{\lambda}$ is the solar spectral irradiance at to the top of atmosphere (TOA). The spectral radiance value $\left(\mathrm{L}_{\text {sensor }}\right)$ at the satellite sensor's aperture $\left(\mathrm{Wm}^{-2} \mathrm{sr}^{-1} \mathrm{~m}^{-1}\right)$ is calculated as follows:

$L_{\lambda \text { sensor }}=\left(M_{\lambda} \times Q_{\text {cal }}\right)+A_{\lambda}$

Where, $M_{\lambda}$ is the band-specific multiplicative rescaling factor, $A_{\lambda}$ is the bandspecific additive rescaling factor, and $Q_{c a l}$ is the minimum quantized and calibrated 
standard product pixel value. Both $M_{\lambda}$ and $A_{\lambda}$ are provided in the Landsat 8 metadata file (MTL file).

$L_{\lambda \text { haze }}=L_{\lambda \min }-L_{\lambda, 1 \%}$

Where, $L_{\lambda \text { haze }}$ is the path radiance or upwelling atmospheric spectral radiance scattered in the direction of the sensor entrance pupil and within the sensor's field of view, $L_{\lambda \min }$ is the minimum spectral radiance, and $L_{\lambda, 1 \%}$ is the spectral radiance value of the darkest object on each band of the Landsat 8 and can be calculated as follows:

$L_{\lambda, 1 \%}=\frac{0.01 \times E S U N_{\lambda} \times \cos (\theta)^{2}}{\pi \times d^{2}}$

The theoretical radiance of a dark object is then computed, under the assumption that dark objects have $1 \%$ or smaller reflectance $[43,44]$.

\subsection{Statistical methods}

In this study, Pearson's correlation analysis was utilized to determine the linear relationship and calculate the correlation between two variables in order to characterize the relationship between various TM and OLI bands and each of the 4 water quality parameters (chl- $a$, TSS, total phosphate and TKN) for the 26 selected stations. The Pearson's correlation basic equation is defined as follows:

$$
R=\frac{\sum\left(X_{\text {band }}-\overline{X_{\text {band }}}\right)\left(Y_{W Q P}-\overline{Y_{W Q P}}\right)}{\sqrt{\left(X_{\text {band }}-\overline{X_{\text {band }}}\right)^{2}+\left(Y_{W Q P}-\overline{Y_{W Q P}}\right)^{2}}}
$$

Where, $X_{\text {band }}$ is the corrected reflectance value, $\overline{X_{\text {band }}}$ is the mean of the corrected reflectance value, $Y_{W Q P}$ is the in situ WQPs data, and $\overline{Y_{W Q P}}$ is the mean of the in situ WQP 
data. Then, a linear multiple regression analysis was conducted for all WQPs. The general formula for multiple regressions is as follows:

$W Q P=a+\left(b \times X_{k, 1}\right)+\left(c \times X_{k, 2}\right)+\left(d \times X_{k, 3}\right)+\left(e \times X_{k, 4}\right)$

Where, $W Q P$ is the dependent variable and represents measured (or known) water quality parameters (chl- $a$, TSS, total phosphate and TKN) at study site $k$ and $X$ is the independent reflectance variable acquired from the Landsat-5/TM or Landsat-8/OLI images at study site $k$. The numbers represent the band number and $a, b, c, d$, and $e$ are the model coefficients using both the measured water quality parameter value at a particular station and the known pixel reflectance values there, according to the least squares algorithm.

\section{Results and discussion}

In this study, statistical techniques were also applied to find the most significant relationships between water quality parameters and reflectance values of visible band of TM and OLI data and their combinations [3,19,45-48]. Pearson's correlation was carried out between Landsat bands, and chlorophyll and turbidity concentrations to find the most significant relationships. Previous studies [28,46,48-51] found a very significant correlation between chlorophyll concentration and water transparency and the relationships among the visible bands. As regards to chlorophyll, the prominent scattering-absorption features of chl- $a$ include strong absorption between $450-475 \mathrm{~nm}$ (blue) and at $670 \mathrm{~nm}$ (red), and reflectance reaches to peak at $550 \mathrm{~nm}$ (green) and near $700 \mathrm{~nm}$ (NIR). The applicability of reflectance peak near $700 \mathrm{~nm}$ and its ratio to the reflectance at $670 \mathrm{~nm}$ to retrieve chl-a in turbid waters was tested by Gitelson [52]. By 
increasing the amounts of dissolved inorganic materials, the peak of visible reflectance relocates from green band to red band [53]. Alparslan, et al. [54] obtained the amount of turbidity from Band1, Band2, Band3, Band4, Band5 and Band7 of Landsat-5 TM Satellite Image. He, et al. [55] used a combination of Landsat TM bands 2, 3, 6 and 7 to correlate with the in situ turbidity measurements. In this study, the stepwise multiple linear regression analysis was applied on all the visible bands and their combinations to select significant variables. Visible band and their ratios constructed the independent variables and $\mathrm{p}$ values greater than 0.1 were considered as a limit for factor removal.

Table 4.2. Pearson's $R$ correlation between limnological data and Landsat bands and ratios $\left({ }^{* *}\right)$ : significant correlation for $\mathrm{p}<0.05$.

\begin{tabular}{|c|c|c|c|c|}
\hline \multirow[b]{2}{*}{ Bands } & \multicolumn{2}{|c|}{ Dry Season } & \multicolumn{2}{|c|}{ Wet Season } \\
\hline & $\begin{array}{c}\text { Chlorophyll- } a \\
\left(\mathbf{m g} / \mathbf{m}^{3}\right)\end{array}$ & $\begin{array}{c}\text { Turbidity } \\
\text { (NTU) }\end{array}$ & $\begin{array}{c}\text { Chlorophyll-a } \\
\left(\mathbf{m g} / \mathbf{m}^{3}\right)\end{array}$ & $\begin{array}{c}\text { Turbidity } \\
\text { (NTU) }\end{array}$ \\
\hline Blue & $-0.38^{* *}$ & $0.74^{\text {** }}$ & $-0.34^{* *}$ & -0.05 \\
\hline Green & -0.28 & $0.80^{* *}$ & $-0.57^{* *}$ & 0.01 \\
\hline Red & -0.23 & $0.73^{* *}$ & -0.09 & -0.01 \\
\hline Near Infrared (NIR) & 0.19 & $0.52^{* *}$ & 0.13 & -0.20 \\
\hline Blue/Green & -0.19 & $-0.53^{* *}$ & $0.65^{* *}$ & $-0.29^{* *}$ \\
\hline Blue/Red & $-0.34^{* *}$ & -0.02 & -0.02 & -0.11 \\
\hline Blue/Near Infrared (NIR) & $-0.52^{* *}$ & $0.52^{* *}$ & $-0.35^{* *}$ & $0.25^{* *}$ \\
\hline Green/Blue & 0.26 & $0.53^{\text {** }}$ & $-0.59^{* *}$ & $0.31^{* *}$ \\
\hline Green/Red & -0.27 & $0.53^{* *}$ & -0.27 & 0.05 \\
\hline Green/Near Infrared (NIR) & $-0.41^{* *}$ & $0.63^{* *}$ & $-0.61^{* *}$ & $0.31^{* *}$ \\
\hline Red/Blue & $0.39^{* *}$ & 0.05 & 0.01 & 0.12 \\
\hline Red/Green & 0.25 & $-0.48^{* *}$ & 0.22 & -0.05 \\
\hline Red/Near Infrared (NIR) & $-0.41^{* *}$ & $0.51^{* *}$ & $-0.64^{* *}$ & $0.46^{* *}$ \\
\hline Near Infrared (NIR)/Blue & $0.60^{* *}$ & -0.35 & 0.20 & $-0.29^{* * *}$ \\
\hline Near Infrared (NIR)/Green & $0.38^{* *}$ & $-0.57^{* *}$ & 0.27 & $-0.35^{* * *}$ \\
\hline Near Infrared (NIR)/Red & $0.35^{\text {** }}$ & $-0.51^{* *}$ & $0.33^{* *}$ & $-0.42^{* *}$ \\
\hline
\end{tabular}

As for chl- $a$, in dry season the selected band by the statistical analysis were Blue/Red, Blue/NIR, Green/Red, Red/Blue, and NIR/Blue ratios, and in wet season were Red, Green/Red, Red/Green, and Red/NIR ratios. Therefore, the functional model is: 
Dry season: $C h l-a=a+\left(b \times \frac{B l u e}{\text { Red }}\right)+\left(c \times \frac{\text { Blue }}{N I R}\right)+\left(d \times \frac{\text { Green }}{\text { Red }}\right)+\left(e \times \frac{\text { Red }}{\text { Blue }}\right)+\left(f \times \frac{\text { NIR }}{\text { Blue }}\right)$

Wet season: $C h l-a=a+(b \times$ Green $)+\left(c \times \frac{\text { Blue }}{\text { Green }}\right)+\left(d \times \frac{\text { Green }}{\text { Blue }}\right)+\left(e \times \frac{\text { Green }}{\text { NIR }}\right)+\left(f \times \frac{\text { Red }}{\text { NIR }}\right)$

The variability of TSS concentration was also investigated using the same procedure, incorporating visible bands and their ratios as independent variables in the stepwise multiple linear regression analysis. The following functional model was selected from the stepwise variable selection procedure for dry and wet season:

Dry season: Turbidity $=a+(b \times$ Blue $)+(c \times$ Red $)+\left(d \times \frac{\text { Green }}{N I R}\right)+\left(e \times \frac{\text { Red }}{\text { Green }}\right)$

Wet season: Turbidity $=a+\left(b \times \frac{\text { Green }}{\text { Blue }}\right)+\left(c \times \frac{\text { Green }}{N I R}\right)+\left(d \times \frac{\text { Red }}{N I R}\right)+\left(e \times \frac{N I R}{B l u e}\right)$

The statistical values given in Table 4.3 were obtained, as a result of the regression analysis computation. The $\mathrm{R}^{2}$ values, which show the correlation between the measured values and the estimated values from the satellite image, prove that the first four bands and their ratios of Landsat satellite image are well capable of being used in the measurement of chl- $a$ and turbidity concentrations. The model coefficients are given in Table 4.4 to compute chl- $a$ and turbidity at anywhere on the lake surface, based on the pixel reflectance values. Maps given in Figure 4.2 were made using directly the satellite data of the Florida Bay's entire surface, based on the equalities in Table 4.4.

Table 4.3. Statistical values obtained from regression analyses for chl- $a$ and turbidity

\begin{tabular}{lcccc}
\hline \multirow{2}{*}{ Regression analysis statistics } & \multicolumn{2}{c}{ Dry Season } & \multicolumn{2}{c}{ Wet Season } \\
& Chl- $\boldsymbol{a}$ & turbidity & Chl- $\boldsymbol{a}$ & turbidity \\
\hline R Square & 0.86 & 0.84 & 0.66 & 0.63 \\
Standard error & 1.186 & 1.499 & 1.174 & 1.496 \\
p-value & 0.000 & 0.000 & 0.002 & 0.001 \\
Durbin-Watson & 1.667 & 1.937 & 1.712 & 2.052 \\
Observations & 40 & 58 & 38 & 40 \\
\hline
\end{tabular}


Table 4.4. Extracted equations based on regression analysis between limnological parameters and Landsat bands

\begin{tabular}{|c|c|c|}
\hline Season & Water quality parameters & Formulae derived \\
\hline \multirow{2}{*}{$\begin{array}{l}\text { Dry } \\
\text { Season }\end{array}$} & Chlorophyll- $a$ (mg/m3) & $\begin{array}{l}=-18.73+5.54 \times(\text { Blue } / \text { Red })-0.82 \times(\text { Blue } / \text { NIR })+ \\
0.80 \times(\text { Green/Red })+30.95 \times(\text { Red/Blue })- \\
17.64 \times(\text { NIR/Blue })\end{array}$ \\
\hline & Turbidity (NTU) & $\begin{array}{l}=-0.24-53.34 \times(\text { Blue })+66.1 \times(\text { Red })+ \\
1.48 \times(\text { Green/NIR })+0.08 \times(\text { Red } / \text { Green })\end{array}$ \\
\hline $\begin{array}{c}\text { Wet } \\
\text { Season }\end{array}$ & Chlorophyll- $a$ (mg/m3) & $\begin{array}{l}=-83.56-11.11 \times(\text { Green })+38.63 \times(\text { Blue } / \text { Green })+ \\
47.13 \times(\text { Green } / \text { Blue }) \\
-0.18 \times(\text { Green } / \text { NIR })+0.52 \times(\text { Red } / \text { NIR })\end{array}$ \\
\hline & Turbidity (NTU) & $\begin{array}{l}=-5.54+6.67 \times(\text { Green } / \text { Blue })-1.2 \times(\text { Green } / \text { NIR })+ \\
3.21 \times(\text { Red/NIR })-1.51 \times(\text { NIR/Blue })\end{array}$ \\
\hline
\end{tabular}

\section{Chlorophyll-a}

The results of correlation analysis between landsat bands and chl- $a$ concentration varied from -0.52 (Blue/NIR band ratio) to 0.60 (NIR/Blue band ratio) in dry season, and from -0.64 (Red/NIR band ratio) to 0.65 (Blue/Green band ratio) in wet season (Table 4.2). Extracted equations based on regression analysis between chl- $a$ and Landsat bands showed correlation coefficients of 0.86 and 0.66 in dry and wet seasons, respectively. Due to the existance of missing values in the monitoring sites dataset, 40 data points in dry season and 58 data points in wet season were used in the statistical analysis. Table 4.4 presents the multiple regression models constructed through equations 4.9 and 4.10 . Among the different combinations of bands and band ratios, this research selected a multiple regression model and revealed the best significant relationships in order to compare the estimated chl- $a$ through the Landsat TM and OLI data with in situ measurement data. The Durbin-Watson values should be greater than 1.5 and less than 2.5 to indicate that multiple linear regression data is free of first order linear auto- 
correlation. For chl- $a$, the Durbin-Watson values were 1.667 and 1.712 in dry and wet seasons, respectively, which lay in the accepted range.

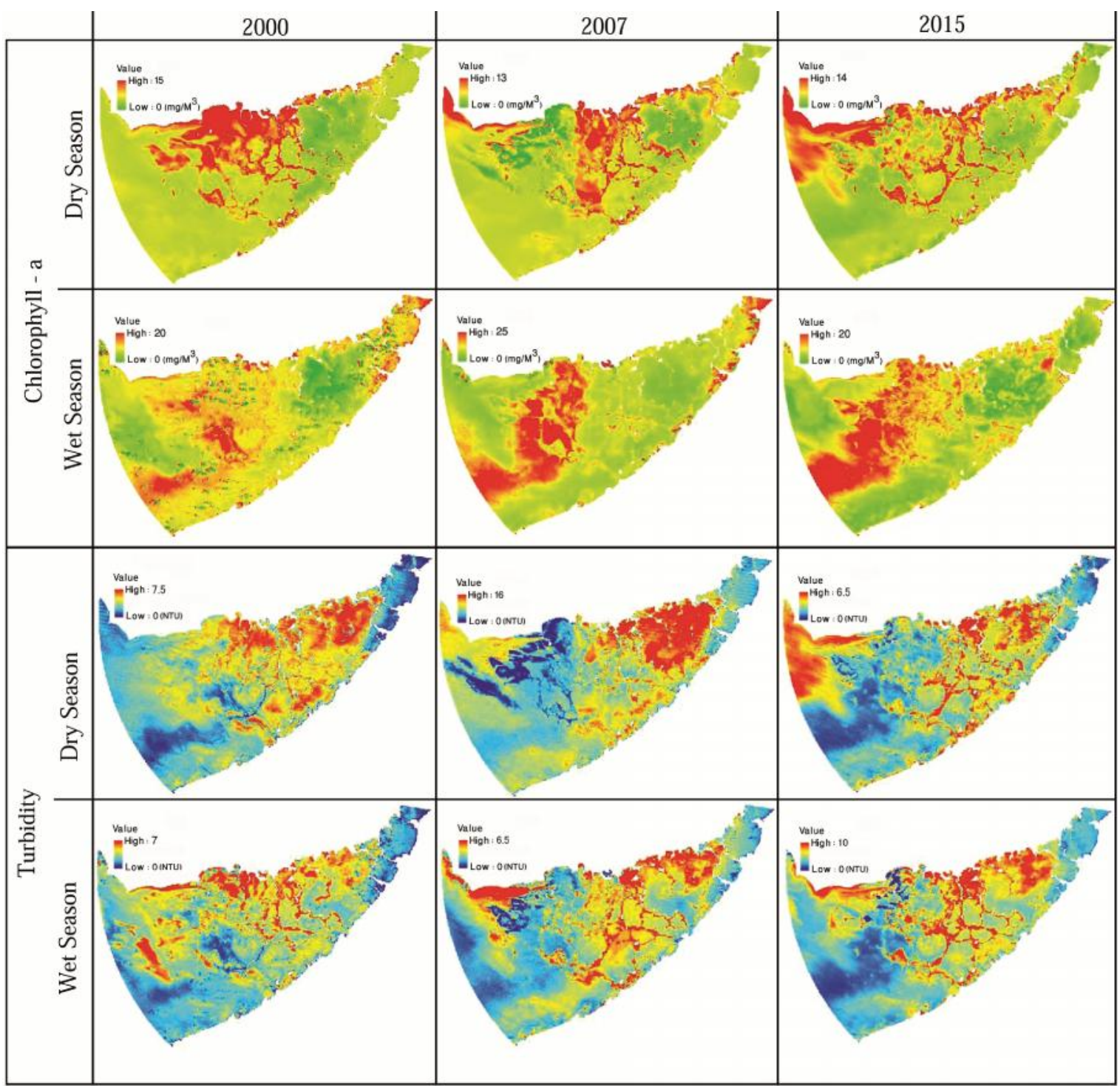

Figure 4.2. Spatial and temporal patterns of chl- $a$ and turbidity concentrations in Florida Bay

\section{Turbidity}

The correlation between the Landsat bands and TSS ranged from -0.57 (NIR/Green band ratio) to 0.80 (Green band) in dry season, and from -0.42 (NIR/Red 
band ratio) to 0.46 (Red/NIR band ratio) in wet season (Table 4.2). The strongest correlations $\left(\mathrm{R}^{2}=0.74\right.$ with blue, 0.80 with green, and 0.73 with red band) at a significance level of $\mathrm{p}<0.05$ were found from the correlation with single bands. Particularly in wet season, the NIR band was closely related to turbidity as seen by the high numerical value of Blue/NIR, Green/NIR, Red/NIR, NIR/Blue, NIR/Green, and NIR/ Red (Table 4.2). To construct multiple regression models, the bands and band ratios that indicated a good correlation with turbidity were selected. In dry season, four band and band ratios of blue, red, green/NIR, and red/green showed significant relationships $\left(\mathrm{R}^{2}=0.84\right)$, and in wet season, four band combinations containing green/blue, green/NIR, red/NIR, and NIR/blue revealed significant relationships $\left(\mathrm{R}^{2}=0.63\right)$ with turbidity. The Durbin-Watson values were 1.937 and 2.052 in dry and wet seasons, respectively, which lay in the accepted range.

The normal probability-probability (P-P) plots were generated based on the standardized residuals. If the residuals are Normally Distributed the values should fall on the diagonal line of identity. Straight lines in Figure 4.3 indicated the normal distribution for the studied variables in both dry and wet seasons. 

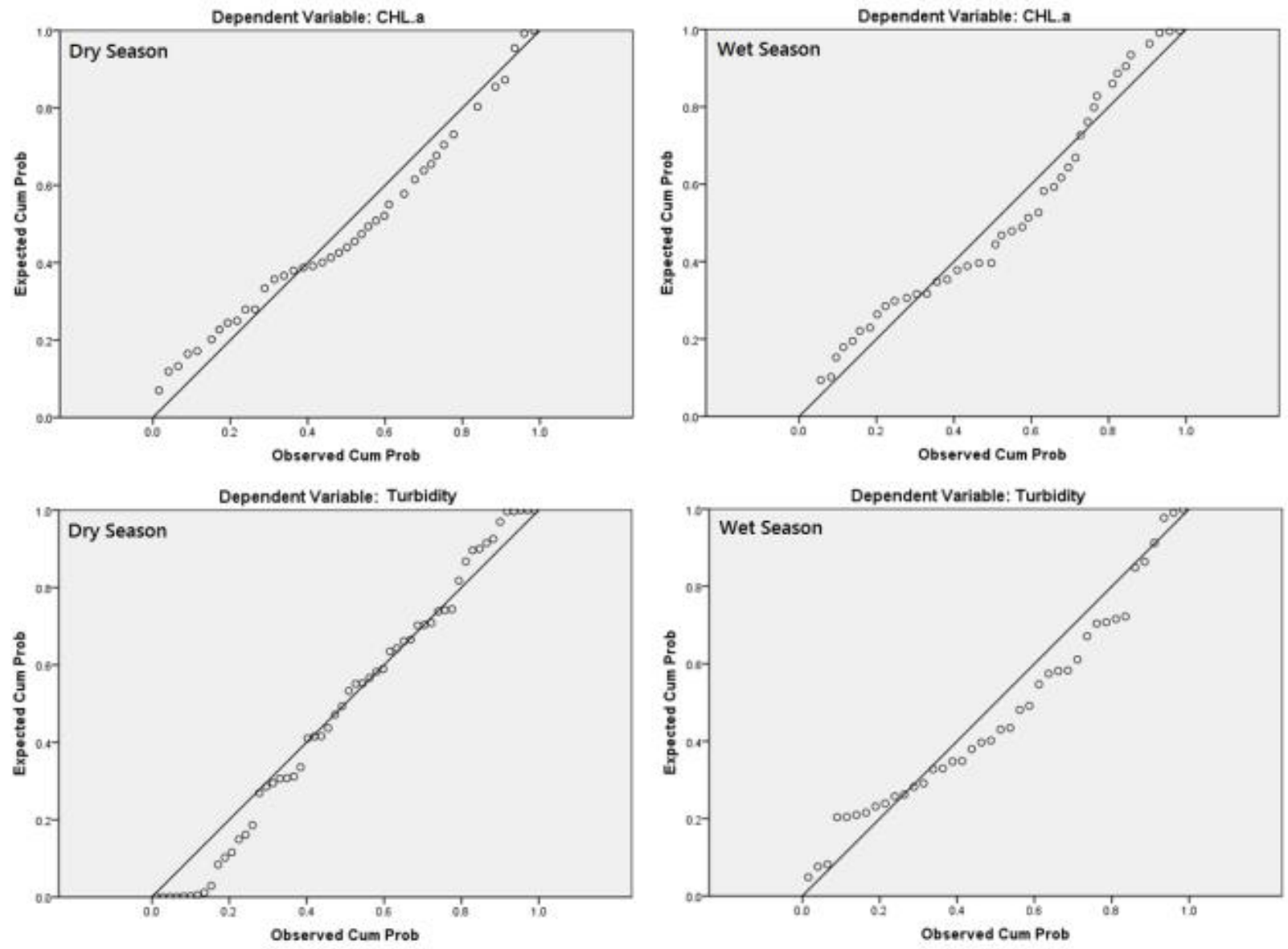

Figure 4.3. The normal probability-probability (P-P) plots of regression standardized residuals for chl- $a$ and turbidity in dry and wet seasons.

\section{Nutrients (total phosphate and total nitrogen)}

Phosphorus and phosphate are closely related to some other parameters like phytoplankton $[31,56]$, turbidity and total suspended matters (TSM), and Secchi disk transparency (SDT) [57], which is the basis for remote monitoring of TP dynamics [58]. TP is closely related to Chl-a concentration, and total suspended matter usually acts as a carrier for TP loading, thus, TP is also closely related to secchi disk with an exponential equation [56]. Remote estimation of total phosphorus (TP) and total phosphate has been investigated based on their high correlation with optically active constituents $[3,56,59]$. 
Although there is a possibility that TP may be indirectly correlated to remote sensing measurements, few studies have been conducted to estimate TP concentration using remotely sensed imagery and can be quantified using visual spectral bands.

Multispectral Landsat TM data have been widely used to monitor and map the TP spatiotemporal pattern in different regions [59-61]. Empirical statistical regression models were used to study the relationship between the concentration of phosphorus with other water quality indicators, such as secchi depth and chl- $a$ concentration [59]. Song, et al. [44] studied the correlation between TP and TM1, TM2, TM3, and TM4 from the Landsat 5, and found that each band had a correlation with TP of $0.62,0.59,0.55$, and 0.51, respectively. Wu, et al. [59] used a combination of TM1, TM3/TM2, and TM1/TM3 data to correlate chl- $a$ concentration and SD measurements with TP concentration. Also, Alparslan et al. [3] used the first four bands of Landsat 7-ETM satellite data to map total phosphate in Ömerli Dam, Turkey. Later, Alparslan, et al. [54] using Band1, Band2, Band3, Band4, Band5 and Band7 of Landsat-5 TM Satellite Image obtained the amount of total phosphorus concentration. Lim and Choi [19] used bands 2, 3, 4, and 5 of Landsat-8/OLI, and constructed 3 multiple regression models by selecting both single bands and band ratios, and obtained significant correlation coefficients.

Also, there is still little literature with regard to estimate nitrogen concentration in waterbodies from remote sensing. Hood, et al. [62] studied two unique optical characteristics of chlorophyll- $a$ (chl- $a$ ), absorption and fluorescence, are strongly related with the nitrogen concentration. Also, Hanson, et al. [63] proved the points regarding that the fluorescence of chl- $a$ would be influenced by nitrogen and phosphorous concentrations. Additionally, Edwards, et al. [64] showed that suspended sediment 
concentration (SSC), chl- $a$ and colored dissolved organic matters (CDOM) are important substance sources of nutrients elements. Gong, et al. [65] measured different concentrations of nitrogen and phosphorus using the reflectance spectra in the laboratory and found their special features by hyperspectral remote sensing technique. Their result showed the reflectance peaks at 404 and $477 \mathrm{~nm}$, and phosphorus at $350 \mathrm{~nm}$, for nitrogen and phosphorous, respectively, and developed a quantitative retrieval model for these two parameters. Karakaya and Evrendilek [66] applied Landsat 7 Enhanced Thematic Mapper Plus $(\mathrm{ETM}+)$ data to measure the concentration of nitrite nitrogen $\left(\mathrm{NO}_{2}-\mathrm{N}\right)$ and nitrate nitrogen $\left(\mathrm{NO}_{3}-\mathrm{N}\right)$ using best-fit multiple linear regression (MLR) models as a function of Landsat 7 ETM+ and ground data in Mersin Bay, Turkey. Based on the pearson correlation between limnological data and Landsat bands and ratios, and also the relationship between these nutrients, and turbidity and chl- $a$ (Table 4.5), different models for total phosphate and TN were developed in two wet and dry seasons.

Table 4.5. Pearson's R correlation between observed water quality parameters and Landsat bands and ratios $\left(^{* *}\right)$ : significant correlation for $\mathrm{p}<0.05$.

\begin{tabular}{|c|c|c|c|c|}
\hline \multirow{2}{*}{ Bands } & Dry season & Wet season & Dry season & Wet season \\
\hline & \multicolumn{2}{|c|}{ Total Phosphate (mg/L) } & \multicolumn{2}{|c|}{ Total Nitrogen $(\mathrm{mg} / \mathrm{L})$} \\
\hline Blue & $0.34 * *$ & $0.59 * *$ & $-0.36 * *$ & 0.01 \\
\hline Green & $0.35 * *$ & $0.55 * *$ & -0.12 & 0.03 \\
\hline Red & $0.50 * *$ & $0.59 * *$ & $-0.31 * *$ & 0.00 \\
\hline Near Infrared (NIR) & $0.31 * *$ & $0.61 * *$ & 0.03 & 0.08 \\
\hline Blue/Green & -0.21 & -0.17 & 0.19 & -0.05 \\
\hline Blue/Red & $-0.52 * *$ & $-0.40 * *$ & 0.19 & 0.05 \\
\hline Blue/Near Infrared (NIR) & -0.28 & $-0.54 * *$ & 0.07 & $-0.29 * *$ \\
\hline Green/Blue & 0.21 & 0.20 & -0.19 & 0.07 \\
\hline Green/Red & $-0.53 * *$ & $-0.58 * *$ & 0.03 & $0.29 * *$ \\
\hline Green/Near Infrared (NIR) & -0.21 & $-0.62 * *$ & -0.10 & $-0.32 * *$ \\
\hline Red/Blue & $0.52 * *$ & $0.47 * *$ & -0.17 & -0.08 \\
\hline Red/Green & $0.52 * *$ & $0.60 * *$ & -0.04 & $-0.29 * *$ \\
\hline Red/Near Infrared (NIR) & 0.19 & $-0.52 * *$ & -0.15 & $-0.49 * *$ \\
\hline Near Infrared (NIR)/Blue & 0.27 & $0.62 * *$ & -0.06 & 0.21 \\
\hline Near Infrared (NIR)/Green & 0.21 & $0.66^{* *}$ & 0.07 & 0.25 \\
\hline Near Infrared (NIR)/Red & -0.20 & $0.59 * *$ & 0.14 & $0.42 * *$ \\
\hline Chlorophyll- $a\left(\mathrm{mg} / \mathrm{m}^{3}\right)$ & -0.02 & $0.47 * *$ & $0.51 * *$ & $0.91 * *$ \\
\hline Turbidity (NTU) & $0.90 * *$ & $0.57 * *$ & $0.79 * *$ & $0.73 * *$ \\
\hline
\end{tabular}


The selected bands by the statistical analysis for the estimation of total phosphate in dry season were correlated with chl- $a$, Blue/Red, Red/Blue, and NIR/Blue ratios, and chl- $a$, Blue/Green, Green/Blue, Green/Red, and Green/NIR ratios in wet season. Therefore, the functional model is:

Dry season: Total Phosphate $=a+(b \times C h l-a)+\left(c \times \frac{\text { Blue }}{R e d}\right)+\left(d \times \frac{\text { Red }}{B l u e}\right)+\left(e \times \frac{N I R}{B l u e}\right)$

Wet season: Total Phosphate $=a+(b \times C h l-a)+\left(c \times \frac{\text { Blue }}{\text { Green }}\right)+\left(d \times \frac{\text { Green }}{\text { Blue }}\right)+\left(\right.$ ex $\left.\frac{\text { Green }}{\text { Red }}\right)$ $+\left(f \times \frac{\text { Green }}{N I R}\right)$

The variability of $\mathrm{TN}$ concentration was also investigated using the same procedure, incorporating visible bands and their ratios as independent variables in the regression analysis, and the following functional model was selected for dry and wet season:

Dry season: $T N=a+(b \times$ Total Phosphate $)+(c \times$ Turbidity $)+\left(d \times \frac{\text { Blue }}{\text { Green }}\right)+\left(e \times \frac{\text { Blue }}{\text { Red }}\right)+$ $\left(d \times \frac{\text { Green }}{\text { Blue }}\right)+\left(e \times \frac{\text { Red }}{\text { Blue }}\right)$

Wet season: $T N=a+(b \times$ Total Phosphate $)+(c \times C h l-a)+(d \times R e d)+(e \times N I R)+$ $\left(f \times \frac{N I R}{R e d}\right)$

The statistical values given in Table 4.6 were obtained, as a result of the regression analysis computation. The $\mathrm{R}^{2}$ values, which show the correlation between the measured values and the estimated values from the satellite image, prove that the first four bands and their ratios of Landsat satellite image plus the values of chl- $a$ and turbidity are well capable of being used in the measurement of total phosphate and TN. The model coefficients are given in Table 4.7 to compute total phosphate and TN at 
anywhere on the bay surface, based on both the pixel reflectance values and chl- $a$ and turbidity concentrations. Maps given in Figure 4.4 were made using directly the satellite data of the Florida Bay's entire surface, based on the equalities in Table 4.7.

Table 4.6. Statistical values obtained as a result of regression analyses for total phosphate and TN

\begin{tabular}{lcccc}
\hline \multirow{2}{*}{ Regression analysis statistics } & $\begin{array}{c}\text { Dry Season } \\
\text { Total Phosphate }\end{array}$ & TN & Total Phosphate & TN \\
\hline R Square & 0.74 & 0.82 & 0.69 & 0.82 \\
Standard error & 0.004 & 0.101 & 0.003 & 0.128 \\
p-value & 0.000 & 0.001 & 0.001 & 0.000 \\
Durbin-Watson & 1.691 & 1.585 & 1.912 & 1.945 \\
Observations & 40 & 36 & 37 & 32 \\
\hline
\end{tabular}

Table 4.7. Extracted equations based on regression analysis between Total Phosphate and $\mathrm{TN}$, and Landsat bands and other water quality parameters

\begin{tabular}{|c|c|c|}
\hline Season & Water quality parameters & Formulae derived \\
\hline \multirow[b]{2}{*}{ Dry Season } & Total Phosphate (mg/L) & $\begin{array}{l}=-0.101+0.002 \times(\text { Chl }-a)+0.022 \times(\text { Blue } / \text { Red })+0.105 \times \\
(\text { Red/Blue })+0.051 \times(\text { NIR/Blue })\end{array}$ \\
\hline & $\mathrm{TN}(\mathrm{mg} / \mathrm{L})$ & $\begin{array}{l}=-4.51-5.18 \times(\text { Total Phosphate })-0.01 \times(\text { Turbidity })+ \\
0.68 \times(\text { Blue } / \text { Green })+0.64 \times(\text { Blue } / \text { Red })+1.67 \times \\
(\text { Green/Blue })+3.02 \times(\text { Red/Blue })\end{array}$ \\
\hline \multirow{3}{*}{ Wet Season } & Total Phosphate $(\mathrm{mg} / \mathrm{L})$ & $\begin{array}{l}=0.163+0.002 \times(\text { Chl }-a)-0.068 \times(\text { Blue } / \text { Green })-0.086 \times \\
(\text { Green/Blue })+0.002 \times(\text { Green/Red })-0.001 \times(\text { Green } / \text { NIR })\end{array}$ \\
\hline & & \\
\hline & $\mathrm{TN}(\mathrm{mg} / \mathrm{L})$ & $\begin{array}{l}=1.35+25.6 \times(\text { Total Phosphate })+0.05 \times(\text { Chl }-a)-12.93 \\
\times(\text { Red })+25.93 \times(\text { NIR })-2.64 \times(\text { NIR } / \text { Red })\end{array}$ \\
\hline
\end{tabular}

\section{Total phosphate}

The correlation of Landsat bands with total phosphate concentration ranged from -0.53 (Blue/Red band ratio) to 0.87 (chl- $a$ ) in dry season, and from -0.40 (Green/NIR band ratio) to $0.57(\operatorname{chl}-a)$ in wet season. In particular, total phosphate concentration displayed a significant relationship $(\mathrm{R}=0.90$ and 0.57 in dry and wet seasons, 
respectively) with chl- $a$ at a significance level of $\mathrm{p}<0.05$ (Table 4.5). Multiple linear regression models constructed for total phosphate estimation through band combination by selecting both correlataed water quality parameters from ground data and imagery showing high correlation coefficients of 0.86 and 0.69 in dry and wet seasons, respectively. Due to the existance of missing values in the monitoring sites dataset, 40 data points in dry season and 37 data points in wet season were used in the statistical analysis. Table 4.8 presents the MLR models constructed through equations 4.13 and 4.14. Among the different combinations of bands and band ratios, this research selected a multiple regression model and revealed the best significant relationships in order to compare the estimated total phosphate through the Landsat TM and OLI data with in situ measurement data. The Durbin-Watson values were 1.691 and 1.912 in dry and wet seasons, respectively, which lay in the accepted range.

\section{Total nitrogen (TN)}

The correlation between the landsat bands and TN from -0.70 (Blue/Red band ratio) to 0.74 (Green/Blue and Red/Blue band ratios) in dry season, and from -0.32 (Red/NIR band ratio) to 0.75 (chl- $a$ ) in wet season. In dry season, the blue and red bands showed the highest correlation, and in wet season NIR and its combinations were closely related to TN (Table 4.5). To construct multiple regression models, the highly correlated chl- $a$ and TSS, and the bands and band ratios that indicated a good correlation with TN were selected. In dry season, chl- $a$ and turbidity, and blue/green, blue/red, green/blue, and red/blue showed significant relationships ( $\mathrm{R}=0.82)$, and in wet season, chl- $a$ and total phosphorous, and three band combinations containing red, NIR, NIR/Red band combinations revealed significant relationships $(\mathrm{R}=0.82)$ with $\mathrm{TN}$. The Durbin-Watson 
values were 1.585 and 1.945 in dry and wet seasons, respectively, which lay in the accepted range. The normal probability-probability (P-P) plots for the studied variables in both dry and wet seasons indicated the normal distribution for the total phosphate and TN in both dry and wet seasons (Figure 4.5).

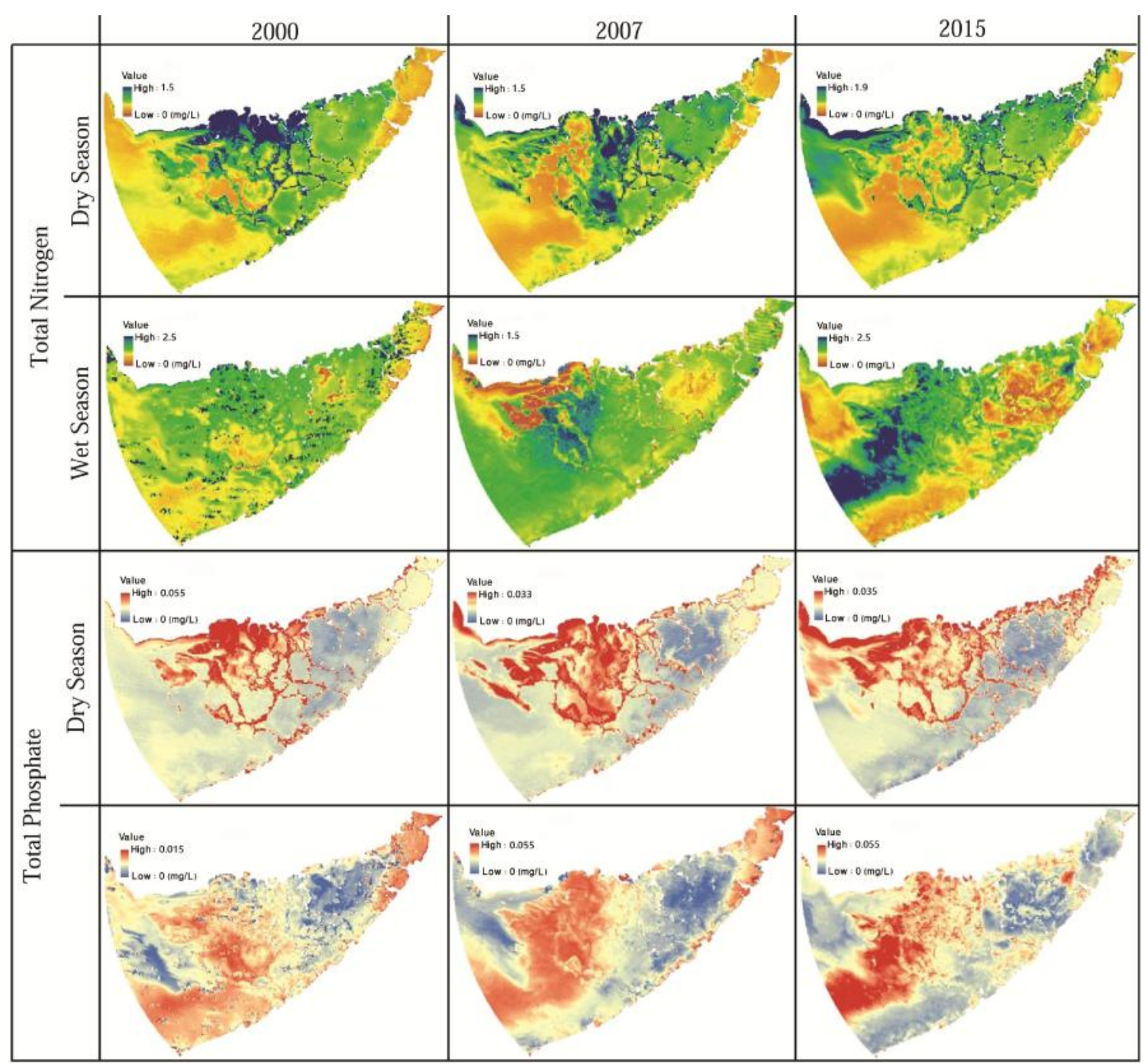

Figure 4.4. Spatial and temporal patterns of total phosphate and TN in Florida Bay 

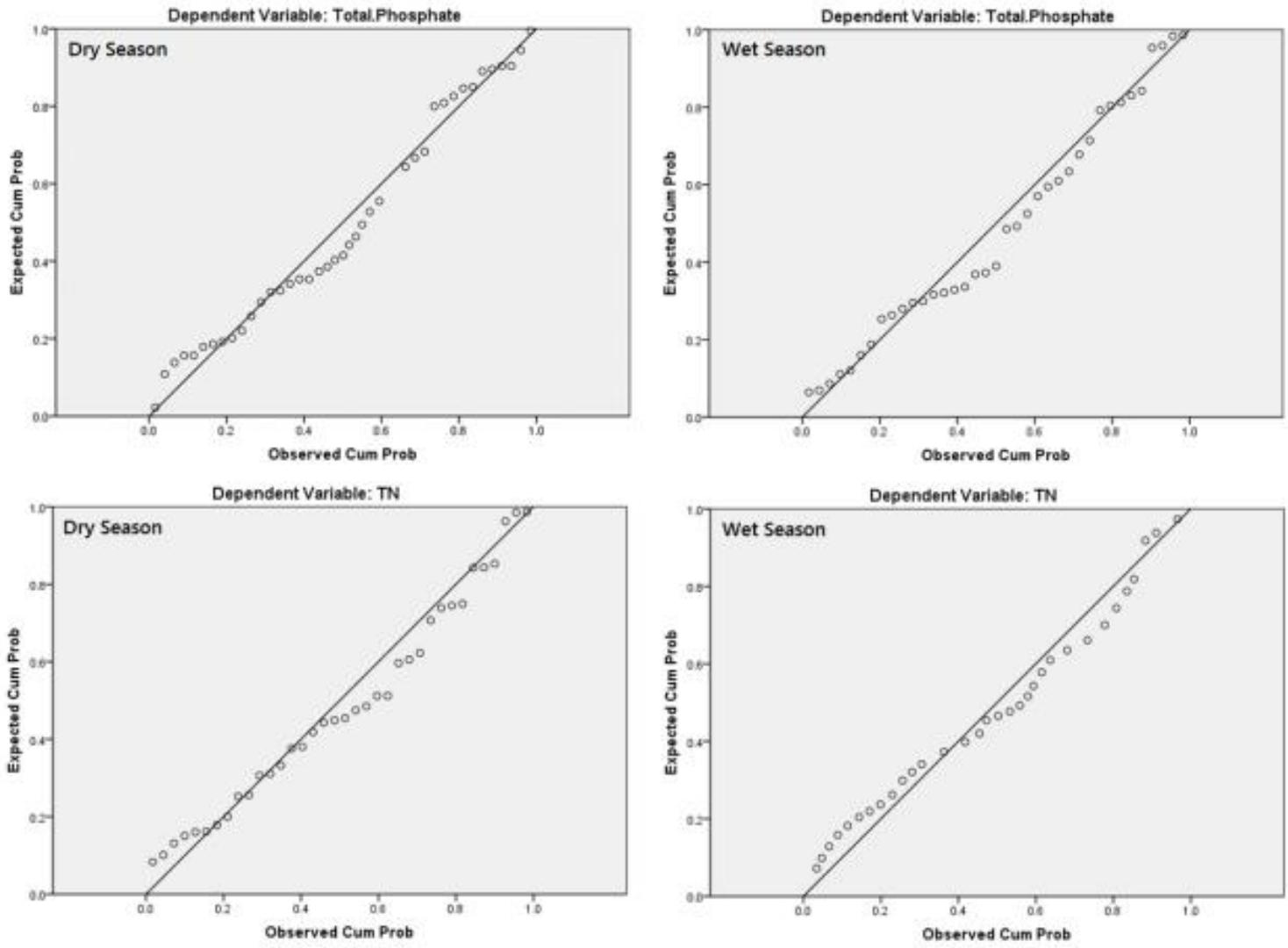

Figure 4.5. The normal probability-probability (P-P) plots of regression standardized residuals for total phosphate and $\mathrm{TN}$ in dry and wet seasons.

After identifiying the regression functions for the four studied water quality parameters, and considering their spatial distribution that were mapped for the whole Florida Bay surface in two seasons (Figures 4.2 and 4.3), different spatial and temporal variations were observe. The generated maps were reclassified taking into account different ranges in order to define the trophic conditions of Florida bay in two seasons and in three years of 2000, 2007, and 2015, which is summarized in Table 4.8. 
Table 4.8. The area based condition of water quality parameters in Florida Bay in dry and wet seasons, and in three years of 2000, 2007, and $2015\left(\mathrm{Km}^{2}\right)$

\begin{tabular}{|c|c|c|c|c|c|c|c|c|c|c|c|c|c|}
\hline & & \multicolumn{6}{|c|}{ Dry Season } & \multicolumn{6}{|c|}{ Wet Season } \\
\hline & & $0-0.5$ & $0.5-1.5$ & $1.5-3.0$ & $3.0-4.5$ & 4.5-6.0 & $>6.0$ & $0-0.5$ & $0.5-1.5$ & $1.5-3.0$ & $3.0-4.5$ & $4.5-6.0$ & $>6.0$ \\
\hline \multirow{4}{*}{$\begin{array}{c}\text { Chl-a } \\
(\mathrm{mg} / \mathrm{M3})\end{array}$} & 2000 & 73.4 & 1251.6 & 677.9 & 196.0 & 95.6 & 54.9 & 440.4 & 1743.7 & 157.1 & 6.3 & 0.9 & 0.9 \\
\hline & 2007 & 181.4 & 1054.2 & 897.3 & 143.5 & 54.3 & 18.6 & 14.8 & 655.4 & 1094.8 & 347.4 & 185.8 & 51.1 \\
\hline & 2015 & 51.8 & 961.1 & 909.1 & 282.0 & 89.2 & 56.1 & 438.8 & 1525.4 & 380.5 & 3.8 & 0.5 & 0.2 \\
\hline & & $0-2$ & $2-5$ & $5-10$ & $10-15$ & $>15$ & & $0-1$ & $1-2.5$ & $2.5-4$ & $4-6$ & $>6$ & \\
\hline \multirow{4}{*}{$\begin{array}{c}\text { Turbidity } \\
\text { (NTU) }\end{array}$} & 2000 & 73.3 & 1494.7 & 779.5 & 1.8 & 0.0 & & 47.5 & 1643.5 & 617.1 & 41.3 & 0.0 & \\
\hline & 2007 & 352.7 & 1591.1 & 405.1 & 0.4 & 0.0 & & 95.9 & 837.5 & 895.9 & 404.1 & 115.9 & \\
\hline & 2015 & 529.6 & 1448.3 & 370.3 & 1.1 & 0.0 & & 155.8 & 1420.2 & 651.7 & 112.6 & 9.0 & \\
\hline & & 0-0.005 & $\begin{array}{c}\text { 0.005- } \\
0.01\end{array}$ & 0.01-0.02 & $0.02-0.03$ & $0.03-0.05$ & $>0.05$ & $\begin{array}{c}0- \\
0.003\end{array}$ & $\begin{array}{c}\text { 0.003- } \\
0.007\end{array}$ & $\begin{array}{c}0.007- \\
0.010 \\
\end{array}$ & $\begin{array}{c}0.010- \\
0.013 \\
\end{array}$ & $\begin{array}{c}\text { 0.013- } \\
0.015 \\
\end{array}$ & $>0.015$ \\
\hline \multirow{4}{*}{$\begin{array}{c}\text { Total } \\
\text { Phosphate } \\
\text { (mg/L) }\end{array}$} & 2000 & 242.1 & 1313.8 & 518.0 & 150.5 & 107.2 & 17.7 & 0.0 & 11.1 & 111.6 & 1850.2 & 375.8 & 0.6 \\
\hline & 2007 & 155.7 & 923.0 & 869.3 & 240.0 & 139.7 & 21.6 & 1.4 & 16.6 & 402.8 & 1130.6 & 726.5 & 71.4 \\
\hline & 2015 & 80.0 & 693.2 & 1157.2 & 248.0 & 139.6 & 31.2 & 0.0 & 0.6 & 134.6 & 1688.6 & 524.4 & 1.0 \\
\hline & & $0-0.5$ & $0.5-0.8$ & $0.8-1.2$ & $1.2-1.5$ & $>1.5$ & & $0-0.5$ & $0.5-0.8$ & 0.8-1.2 & $1.2-1.5$ & $>1.5$ & \\
\hline \multirow{3}{*}{$\begin{array}{c}\text { TN } \\
(\mathrm{mg} / \mathrm{L})\end{array}$} & 2000 & 1628.2 & 630.8 & 87.6 & 2.3 & 0.4 & & 3.6 & 68.1 & 1289.2 & 846.8 & 92.8 & \\
\hline & 2007 & 1445.3 & 840.1 & 60.5 & 2.2 & 1.2 & & 277.7 & 1982.3 & 71.6 & 2.0 & 15.7 & \\
\hline & 2015 & 1341.1 & 938.7 & 68.5 & 1.0 & 0.0 & & 70.8 & 702.5 & 1483.9 & 87.0 & 5.2 & \\
\hline
\end{tabular}




\section{Conclusion}

The water supplies for domestic and industrial use, irrigated agriculture, and livestock and mining activities require continuous monitoring to make sure that the required standards and criteria are met. However, due to anthropogenic activities and industrial development, water quality has dramatically degraded. A combination of remote sensing, GIS, and traditional in-situ sampling can lead to perform a better monitoring program for water quality parameters in various waterbodies.

In this study, bio-physical parameters associated with water quality in Florida Bay were investigated based on atmospherically corrected data. The principal objective of this study was to monitor and assess the spatial and temporal changes of four water quality parameters including turbidity, chlorophyll- $a(\operatorname{chl}-a)$, total phosphate, and total nitrogen (TN), by using the application of integrated remote sensing, GIS data, and statistical techniques. For this purpose, three dates of Landsat Thematic Mapper (TM) data in 2000 (February 13), 2007(January 31), and one date of Landsat Operational Land Imager (OLI) in 2015 (January 5) in the dry season, and three dates of TM data in 2000 (August 7), 2007 (September 28), and one date of OLI data in 2015 (September 2) in the wet season of the subtropical climate of South Florida, were used to assess temporal and spatial patterns and dimensions of studied parameters in Florida Bay, USA. The simultaneous observed data of four studied parameters were obtained from 20 monitoring stations and were used for the development and validation of the models. The optical bands in the region from blue to near infrared and all the possible band ratios were used to explore the relation between the reflectance of waterbody and observed data. The results of Pearson's correlation between limnological data and Landsat bands and ratios, 
and also the relationship between these nutrients, and TSS, turbidity, and chl- $a$ in Lake Okeechobee and Florida bay showed better correlations of totall phosphate and total nitrogen with limnological data and imagery in Lake Okeechobee and Florida bay, respectively. This can also indicate that these two waterbodies are under the influence of which nutrient.

The predictive models to estimate chl- $a$ and turbidity concentrations were developed through the use of stepwise multiple linear regression (MLR) and gave high coefficients of determination in dry season $\left(\mathrm{R}^{2}=0.86\right.$ for chl- $a$ and $\mathrm{R}^{2}=0.84$ for turbidity) and moderate coefficients of determination in wet season $\left(\mathrm{R}^{2}=0.66\right.$ for chl- $a$ and $\mathrm{R}^{2}=0.63$ for turbidity). Values for total phosphate and TN were correlated with chl$a$ and turbidity concentration and some bands and their ratios. Total phosphate and TN were estimated using best-fit multiple linear regression models as a function of Landsat TM and OLI, and ground data and showed a high coefficient of determination in dry season $\left(R^{2}=0.74\right.$ for total phosphate and $R^{2}=0.82$ for $\left.T N\right)$ and in wet season $\left(R^{2}=0.69\right.$ for total phosphate and $\mathrm{R}^{2}=0.82$ for $\mathrm{TN}$ ). The MLR models showed a good trustiness to monitor and predict the spatiotemporal variations of the studied water quality parameters in Florida Bay.

This study showed that Landsat TM and OLI data and water quality parameters at various locations of Florida Bay can be related through a regression analysis and constitute a model that can be used to measure water quality parameters over the entire lake surface. The four studied parameters mapped by identifying the best set of band combinations and also their interreltionship to describe the linkage between the spectral 
response to limnological data. The same method can be applied to the trophic conditions for landsat images in different years.

\section{Acknowledgements}

This research was made possible by financial support that was provided by the Department of Civil and Environmental Engineering of Florida International University, Miami, U.S.A., through a Presidential Fellowship and a Graduate Assistantship to the main author. The observational data were obtained from South Florida Water Management District (SFWMD). Also, the satellite images were downloaded from USGS Earth Explorer website.

\section{References}

1. Percemtage of Total Population Living in Coastal Arears. http://www.un.org/esa/sustdev/natlinfo/indicators/methodology_sheets/oceans_seas_coas ts/pop_coastal_areas.pdf

2. Duan, W.; Takara, K.; He, B.; Luo, P.; Nover, D.; Yamashiki, Y. Spatial and temporal trends in estimates of nutrient and suspended sediment loads in the Ishikari River, Japan, 1985 to 2010. Sci. Total Environ. 2013, 461-462, 499-508.

3. Alparslan, E.; Aydöner, C.; Tufekci, V.; Tüfekci, H. Water quality assessment at Ömerli Dam using remote sensing techniques. Environ. Monit. Assess. 2007, 1, 391-398.

4. Anding, D.; Kauth, R. Estimation of sea surface temperature from space. Remote Sens. Environ. 1970, 1, 217-220.

5. Brando, V. E.; Dekker, A. G. Satellite hyperspectral remote sensing for estimating estuarine and coastal water quality. IEEE Trans. Geosci. Remote Sens. 2003, 41, 13781387.

6. El-Din, M.; Gaber, A.; Koch, M. Remote Sensing Application for Water Quality Assessment in Lake Timsah, Suez Canal, Egypt. J. Remote 2013.

7. Giardino, C.; Bresciani, M.; Cazzaniga, I.; Schenk, K.; Rieger, P.; Braga, F.; Matta, E.; Brando, V. E.; Brando, V. E. Evaluation of multi-resolution satellite sensors for assessing water quality and bottom depth of Lake Garda. Sensors (Switzerland) 2014, 14, 2411624131. 
8. Hadjimitsis, D.; Clayton, C. Assessment of temporal variations of water quality in inland water bodies using atmospheric corrected satellite remotely sensed image data. Environ. Monit. Assess. 2009.

9. Hellweger, F.; Schlosser, P.; Lall, U. Use of satellite imagery for water quality studies in New York Harbor. Estuarine, Coast. 2004.

10. Kondratyev, K.; Pozdnyakov, D. Water quality remote sensing in the visible spectrum. Int. J. 1998.

11. Koponen, S.; Pulliainen, J.; Kallio, K.; Hallikainen, M. Lake water quality classification with airborne hyperspectral spectrometer and simulated MERIS data. Remote Sens. Environ. 2002, 79, 51-59.

12. Maillard, P.; Pinheiro Santos, N. A. A spatial-statistical approach for modeling the effect of non-point source pollution on different water quality parameters in the Velhas river watershed - Brazil. J. Environ. Manage. 2008, 86, 158-170.

13. Morel, A.; Prieur, L. Analysis of variations in ocean color. Limnol. Oceanogr. 1977, $22,709-722$.

14. Pozdnyakov, D.; Shuchman, R.; Korosov, A.; Hatt, C. Operational algorithm for the retrieval of water quality in the Great Lakes. Remote Sens. Environ. 2005, 97, 352-370.

15. Ritchie, J. C.; Zimba, P. V; Everitt, J. H. Remote Sensing Techniques to Assess Water Quality. Photogramm. Eng. Remote Sens. 2003, 69, 695-704.

16. Seyhan, E.; Dekker, A. Application of remote sensing techniques for water quality monitoring. Hydrobiol. Bull. 1986.

17. Usali, N.; Ismail, M. H. Use of remote sensing and GIS in monitoring water quality. J. Sustain. Dev. 2010, 3, 228-238.

18. Wang, X. J.; Ma, T. Application of Remote Sensing Techniques in Monitoring and Assessing the Water Quality of Taihu Lake. Bull. Environ. Contam. Toxicol. 2001, 6, 863-870.

19. Lim, J.; Choi, M. Assessment of water quality based on Landsat 8 operational land imager associated with human activities in Korea. Environ. Monit. Assess. 2015.

20. Lillesand, T.; Kiefer, R.; Chipman, J. Remote sensing and image interpretation; 2014.

21. Dekker, A.; Peters, S. The use of the Thematic Mapper for the analysis of eutrophic lakes: a case study in the Netherlands. Int. J. Remote Sens. 1993.

22. Zhang, C.; Han, M. Mapping Chlorophyll-a Concentration in Laizhou Bay Using Landsat 8 OLI data. 89.31.100.18. 
23. Kim, S.; Kim, H.; Hyun, C. High Resolution Ocean Color Products Estimation in Fjord of Svalbard, Arctic Sea using Landsat-8 OLI. Korean J. Remote Sens. 2014.

24. Wass, P.; Marks, S.; Finch, J.; Leeks, G. Monitoring and preliminary interpretation of in-river turbidity and remote sensed imagery for suspended sediment transport studies in the Humber catchment. Sci. Total 1997.

25. Ritchie, J.; Schiebe, F.; McHENRY, J. Remote sensing of suspended sediments in surface waters. Am. Soc. 1976.

26. Dekker, a. G.; Vos, R. J.; Peters, S. W. M. Analytical algorithms for lake water TSM estimation for retrospective analyses of TM and SPOT sensor data. Int. J. Remote Sens. 2002, 23, 15-35.

27. Akbar, T. A.; Hassan, Q. K.; Achari, G. A remote sensing based framework for predicting water quality of different source waters. Int. Arch. Photogramm. Remote Sens. Spat. Inf. Sci. - ISPRS Arch. 2010, 38, 1-4.

28. Jr, R. C.; Forsythe, R.; Vaughan, G. Assessing water quality in Catawba River reservoirs using Landsat thematic mapper satellite data. Lake Reserv. 1998.

29. Brezonik, P.; Menken, K. D.; Bauer, M. Landsat-based remote Sensing of Lake Water Quality Characteristics, Including Chlorophyll and Colored Dissolved OrganiC Matter (CDOM). Lake Reserv. Manag. 2005, 21, 373-382.

30. McPherson, B. F.; Hendrix, G. Y.; Klein, H.; Tyus, H. M. The environment of South Florida; a summary report; 1976.

31. Busse, L.; Simpson, J. Relationships among nutrients, algae, and land use in urbanized southern California streams. Can. J. 2006.

32. Mikkelsen, R. Ammonia emissions from agricultural operations: fertilizer. Better Crop. 2009, 93, 9-11.

33. Haji Gholizadeh, M.; Melesse, A. M.; Reddi, L. Water quality assessment and apportionment of pollution sources using APCS-MLR and PMF receptor modeling techniques in three major rivers of South Florida. Sci. Total Environ. 2016, 566, 15521567.

34. Kemker, C. Turbidity, Total Suspended Solids and Water Clarity." Fundamentals of Environmental Measurements.

35. Dorgelo, J.; Sumich, J. L. An Introduction to the Biology of Marine Life 1999.

36. Praveena, S. M.; Kwan, O. W.; Aris, A. Z. Effect of data pre-treatment procedures on principal component analysis: a case study for mangrove surface sediment datasets. Environ. Monit. Assess. 2012, 184, 6855-6868. 
37. Gordon, H. R. Calibration requirements and methodology for remote sensors viewing the ocean in the visible. Remote Sens. Environ. 1987, 22, 103-126.

38. Teillet, P. M.; Horler, D. N. H.; O'Neill, N. T. Calibration, validation, and quality assurance in remote sensing: A new paradigm. Can. J. Remote Sens. 1997, 23, 401-414.

39. Maul, G. Introduction to satellite oceanography; 2012.

40. Brivio, P. a.; Giardino, C.; Zilioli, E. Determination of chlorophyll concentration changes in Lake Garda using an image-based radiative transfer code for Landsat TM images. Int. J. Remote Sens. 2001, 22, 487-502.

41. Moran, M. S.; Jackson, R. D.; Slater, P. N.; Teillet, P. M. Evaluation of simplified procedures for retrieval of land surface reflectance factors from satellite sensor output. Remote Sens. Environ. 1992, 41, 169-184.

42. Visibility and Light Scattering in the Atmosphere http://mtweb.mtsu.edu/nchong/pmatm3.htm.

43. Chávez, P. S. J. Image-Based Atmospheric Corrections - Revisited and Improved. Photogramm. Eng. Remote Sensing 1996, 62, 1025-1036.

44. Song, K.; Wang, Z.; Blackwell, J.; Zhang, B.; Li, F.; Zhang, Y.; Jiang, G. Water quality monitoring using Landsat Themate Mapper data with empirical algorithms in Chagan Lake, China. J. Appl. Remote Sens. 2011, 5, 53506-53516.

45. Kloiber, S. M.; Brezonik, P. L.; Bauer, M. E. Application of Landsat imagery to regional-scale assessments of lake clarity. Water Res. 2002, 36, 4330-4340.

46. Kloiber, S. M.; Brezonik, P. L.; Olmanson, L. G.; Bauer, M. E. A procedure for regional lake water clarity assessment using Landsat multispectral data. Remote Sens. Environ. 2002, 82, 38-47.

47. Mayo, M.; Gitelson, A.; Yacobi, Y.; Ben-Avraham, Z. Chlorophyll distribution in Lake Kinneret determined from Landsat Thematic Mapper data. Int. J. Remote Sens. $1995,16,175-182$.

48. Mancino, G.; Nolè, A.; Urbano, V.; Amato, M.; Ferrara, A. Assessing water quality by remote sensing in small lakes: The case study of Monticchio lakes in southern Italy. IForest 2009, 2, 154-161.

49. Lathrop, R. G.; Lillesand, T. M. Use of Thematic Mapper data to assess water quality in Green Bay and central Lake Michigan. Photogramm. Eng. Remote Sens. 1986, 52, 671-680.

50. Lavery, P.; Pattiaratchi, C.; Wyllie, A.; Hick, P. Water quality monitoring in estuarine waters using the landsat thematic mapper. Remote Sens. Environ. 1993, 46, 268-280. 
51. Giardino, C.; Pepe, M.; Brivio, P.; Ghezzi, P. Detecting chlorophyll, Secchi disk depth and surface temperature in a sub-alpine lake using Landsat imagery. Sci. Total 2001.

52. Gitelson, A. A.; Dall'Olmo, G.; Moses, W.; Rundquist, D. C.; Barrow, T.; Fisher, T. R.; Gurlin, D.; Holz, J. A simple semi-analytical model for remote estimation of chlorophyll-a in turbid waters: Validation. Remote Sens. Environ. 2008, 112, 3582-3593.

53. Band Combinations http://web.pdx.edu/ emch/ip1/bandcombinations.html.

54. Alparslan, E.; Coskun, G.; Alganci, U. Water quality determination of Küçükçekmece Lake, Turkey by using multispectral satellite data. ScientificWorldJournal. 2009, 9, 1215-29.

55. He, W.; Chen, S.; Liu, X.; Chen, J. Water quality monitoring in a slightly-polluted inland water body through remote sensing - case study of the Guanting Reservoir in Beijing, China. Environ. Sci. Eng. ... 2008.

56. Carlson, R. E. A trophic state index for lakes1. Limnol. Oceanogr. 1977, 22, 361369.

57. Uusitalo, R.; Aura, E. A rainfall simulation study on the relationships between soil test $\mathrm{P}$ versus dissolved and potentially bioavailable particulate phosphorus forms in runoff. Agric. Food Sci. 2005, 14, 335-345.

58. Hoyer, M. V; Frazer, T. K.; Notestein, S. K.; Canfield, Jr., D. E. Nutrient, chlorophyll, and water clarity relationships in Florida's nearshore coastal waters with comparisons to freshwater lakes. Can. J. Fish. Aquat. Sci. 2002, 59, 1024-1031.

59. Wu, C.; Wu, J.; Qi, J.; Zhang, L.; Huang, H.; Lou, L.; Chen, Y. Empirical estimation of total phosphorus concentration in the mainstream of the Qiantang River in China using Landsat TM data. Int. J. Remote Sens. 2010, 31, 2309-2324.

60. Kutser, T.; Arst, H.; Miller, T.; Kaarmann, L.; Milius, A. Telespectrometrical Estimation of Water Transparency, Chlorophyll-a and Total Phosphorus Concentration of Lake Peipsi. Int. J. Remote Sens. 1995, 16, 3069-3085.

61. Wang, Y.; Xia, H.; Fu, J.; Sheng, G. Water quality change in reservoirs of Shenzhen, China: Detection using LANDSAT/TM data. Sci. Total Environ. 2004, 328, 195-206.

62. Hood, R. R.; Subramaniam, A.; May, L. R.; Carpenter, E. J.; Capone, D. G. Remote estimation of nitrogen fixation by Trichodesmium. Deep. Res. Part II Top. Stud. Oceanogr. 2002, 49, 123-147.

63. Hanson, C. E.; Waite, A. M.; Thompson, P. A.; Pattiaratchi, C. B. Phytoplankton community structure and nitrogen nutrition in Leeuwin Current and coastal waters off the Gascoyne region of Western Australia. Deep. Res. Part II Top. Stud. Oceanogr. 2007, 54, 902-924. 
64. Edwards, V.; Icely, J.; Newton, A.; Webster, R. The yield of chlorophyll from nitrogen: a comparison between the shallow Ria Formosa lagoon and the deep oceanic conditions at Sagres along the southern coast of. Estuarine, Coast. Shelf 2005.

65. Gong, S. Q.; Huang, J. Z.; Li, Y. M.; Lu, W. N.; Wang, H. J.; Wang, G. X.

[Preliminary exploring of hyperspectral remote sensing experiment for nitrogen and phosphorus in water]. Guang Pu Xue Yu Guang Pu Fen Xi 2008, 28, 839-842.

66. Karakaya, N.; Evrendilek, F. Monitoring and validating spatio-temporal dynamics of biogeochemical properties in Mersin Bay (Turkey) using Landsat ETM+. Environ. Monit. Assess. 2011, 181, 457-464. 


\section{CHAPTER V}

ASSORTMENT OF THE SURFACE WATER POLLUTION REGIONS AND STUDY ON SPATIOTEMPORAL VARIABILITY OF POLLUTION USING CLUSTER AND DISCRIMINANT ANALYSES 


\begin{abstract}
In this study, cluster analysis (CA) and discriminant analysis (DA) were used to assess the water quality and evaluate the spatial and temporal variations in surface water quality of South Florida. For this purpose, 15 years (2000-2014) data set of 12 water quality variables covering 16 monitoring stations, and about 35,000 observations were used. Agglomerative hierarchical CA grouped 16 monitoring sites into three groups (low pollution, moderate pollution, and high pollution) based on their similarity of water quality characteristics. Discriminant analysis (DA), as an important data reduction method, and cluster analysis (CA) were used to assess the water pollution status and analysis of its spatiotemporal variation. It was found by the stepwise DA that five variables (chl- $a, \mathrm{DO}, \mathrm{TKN}, \mathrm{TP}$ and water temperature) are the most important discriminating water quality parameters responsible for temporal variations. In spatial DA, the stepwise mode identified seven variables (chl- $a$, DO, TKN, TP, magnesium, chloride, and sodium) and six variables (DO, TKN, TP, turbidity, magnesium, and chloride) as the most important discriminating variables responsible for spatial variations in wet and dry season, respectively. Different patterns associated with spatial variations were identified depending on the variables and considered season, however the overall trend of environment pollution problems was found from the LP region to HP region. It is believed that the results of apportionment could be very useful to the local authorities for the control and management of pollution and better protection of important riverine water quality.
\end{abstract}

Keywords: Water quality; River water; Cluster Analysis; Discriminant Analysis; South Florida. 


\section{Introduction}

To have reliable information about the inherent properties of water quality and also to understand the spatiotemporal variations in hydro-chemical and biological properties of water, continuous and regular monitoring programs are required [5]. Multivariate statistical techniques, such as cluster analysis (CA) and discriminant analysis (DA) are widely used for the evaluation of both temporal and spatial variations and the interpretation of large and complex water quality data sets [3,5-14]. Hierarchical agglomerative cluster analysis (CA) using Ward's method, as an unsupervised pattern recognition technique, was applied to group the monitoring stations (cases) into classes (clusters) based on their similarities within a class and dissimilarities between different classes in three major rivers of South Florida (Kissimmee River, Caloosahatchee River, and Miami Canal). The results of CA help to interpret the data and indicate patterns. Discriminant analysis (DA), as supervised pattern recognition technique, was employed to the data set on water quality of three selected rivers of the study area to construct the discriminant functions on two different modes of standard and stepwise to bring out the most significant variables that result in water quality spatial and temporal variation, and to optimize the monitoring program by decreasing the number of parameters monitored.

Given the above considerations, a large data matrix obtained during fifteen years (2000-2014) monitoring period at sixteen different sites for twelve water quality parameters, and in two wet and dry seasons (about 35,000 observations) were subjected to cluster analysis (CA) and discriminant analysis (DA) to (1) identify the similarities or dissimilarities between sampling sites, (2) confirm the clusters determined by means of CA based on the accuracy rate of discriminant functions, and (3) identify the most 
significant water quality variables responsible for spatial and temporal variations in river water quality. It is believed that the results of the spatial and temporal variations can be used to select the polluted areas and set the priority areas for the river water quality management in the study area.

\section{Methodology}

\subsection{Study area}

South Florida has an extensive network of canals that drain water from various agricultural productions orand urban land areas and carry different concentrations of chemicals, especially high concentrations of nutrients. These are biologically productive waterbodies contain various important aquatic lives include plants, animals, and microorganisms [15]. In this study, three major rivers in South Florida, the Miami Canal, Kissimmee River and Caloosahatchee River, are investigated for their water quality by applying different multivariate analysis techniques. The average annual temperature ranges from $19.2{ }^{\circ} \mathrm{C}$ to $28.7^{\circ} \mathrm{C}$ and the annual rainfall in the entire area of South Florida is generally about 55 inches $(1400 \mathrm{~mm})$. The major land uses in their watersheds include agricultural area, wetlands, cattle ranching and dairy farming, and urban areas. Figure 5.1 shows the location of study area and selected water quality monitoring sites on three major rivers of South Florida. 


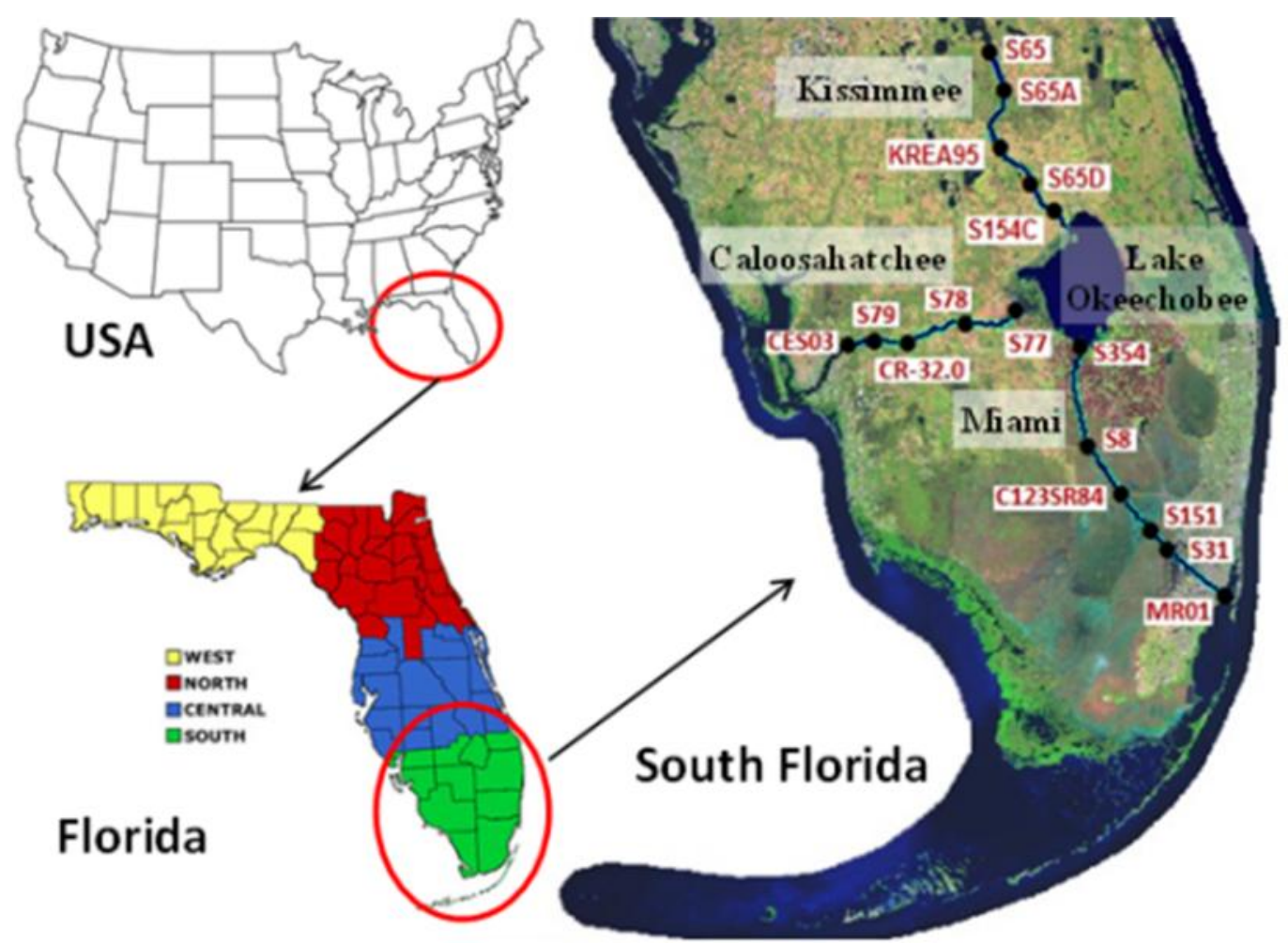

Figure 5.1. The location of study area and water quality monitoring sites.

\subsection{Dataset preparation}

The hydrography network of the study area, generated using the 1:24000 national hydrography dataset (NHD) obtained from the South Florida water management district's (SFWMD) geographic information systems (GIS) data catalog, was used to delineate the flow line of three selected rivers. The most recent (2008-09) land cover/land use (LCLU) map provided by the SFWMD was used in this study. This data then was clipped to fit our study area. The area of each type of land use within each watershed was calculated using an ESRI ArcGIS 10.0 platform. The monitoring stations, downloaded from the same source, were overlaid with rivers' map in ArcGIS to design a network of sampling stations that include sufficient historical data to construct a robust statistical database of studied parameters, considering a suitable spatial distribution on the river. Then, the 
DBHYDRO (environmental database of SFWMD) was used to obtain continuous time series data for 12 selected water quality parameters from 2000 to 2014 . This database then was divided into two dry and wet seasons (wet season from May $15^{\text {th }}$ thru October $15^{\text {th }}$, and the dry season from October $16^{\text {th }}$ thru May $\left.14^{\text {th }}\right)$. The basic statistics of water quality parameters in three major rivers of South Florida, based on 34,560 observations $(15$ years $\times 12$ months $\times 16$ sampling sites $\times 12$ parameters $)$, are summarized in Table 5.1 .

\subsection{Multivariate statistical methods}

Multivariate statistical methods are widely used for the classification, modeling and interpretation of large datasets, and also for the reduction of the dimensionality of the complex dataset with minimum loss of the original information [16]. Cluster analysis is an unsupervised pattern recognition technique that groups the objects (cases) into classes (clusters) based on their similarities within a class and dissimilarities between different classes. The results of CA help to interpret the data and indicate patterns. One of the most commonly used measurements to find the similarity of cases is the Euclidean distance [17] in which the square root of the sum of the squares of the differences between corresponding values is computed to extract the distance from site $\mathrm{i}$ to site $\mathrm{j}$ by:

$D_{i, j}=\sum_{k=1}^{p}\left[\left(Z_{i, k}-Z_{j, k}\right)^{2}\right]^{0.5}$

Where, $p$ is the number of variables, $\mathrm{Z}_{\mathrm{i}, \mathrm{k}}$ and $\mathrm{Z}_{\mathrm{j}, \mathrm{k}}$ are standardized value for variable $\mathrm{k}$ at site $\mathrm{i}$ and $\mathrm{j}$, respectively. However, the squared Euclidean distance is used more often than the simple Euclidean distance. It uses the same equation as the Euclidean distance without taking the square root in order to place progressively greater weight on objects that are further apart and cause a faster clustering in compare with the regular 
Euclidean distance. Hence, we used the squared Euclidean distances as a measure of similarity. Between several clustering algorithms, the most commonly used manner is Ward's method. Willet [18] proved that the hierarchical agglomerative clustering using the Ward's method is an extremely powerful method for the grouping of cases.

The measured variables in this study were in different scales and units, so the data was treated after data scaling by z-transformation in SPSS 16.0 software. The dendrogram resulting by ward's method was used to get an insight about the possible number of clusters, in the way that they merge. Dendrograms provide important information and a visual summary of the clustering that shows the proximity of the groups [9]. In addition, to differentiate and allocate a proper name to the identified clusters by CA, water quality criteria for the Florida State's waters (Approved by EPA and published on 08/01/2013), released and updated by the Florida Department of Environmental Protection (FDEP) was considered and the average concentration of each variable was compared to this document. FDEP's water quality standards include numeric criteria for springs, lakes, streams, and estuaries. In this study, 12 water quality parameters considered for investigation including: chl- $a$, dissolved oxygen (DO), total kjeldahl nitrogen (TKN), total phosphorus (TP), total phosphate, ammonia-N, water temperature (WT), total suspended solids (TSS), turbidity, magnesium, chloride, and sodium.

Discriminant analysis (DA), also called supervised pattern recognition technique, is a multivariate statistical analysis method that uses linear combinations of several variables to construct statistical classification of samples into categorical-dependent values. In DA, membership of objects and spatial or temporal groups are usually pre- 
known. Also, the results of CA can help in spatial DA. This technique generally uses two different modes, i.e., standard and stepwise, to construct the discriminant functions presenting important information about for each group [3,12,19], and Discriminant analysis was used in this study to describe the relationships among two groups of temporal and three pre-specified groups of spatial (clusters resulted from CA). The canonical discriminant functions of the discriminating variables were used to discriminate among groups. The canonical discriminant functions are defined as weighted linear combinations of the original variables, where variables are separately weighted based on their ability to discriminate among different pre-specified groups. The first canonical discriminant function defines the specific linear combination of variables that maximizes the ratio of among group to within group variance in any single dimension. It constructs a discriminant function for each group, as follows:

$f\left(G_{i}\right)=K_{i}+\sum_{j=1}^{n} W_{i j} \times P_{i j}$

Where, $i$ is the number of groups $(G), k_{i}$ is a constant inherent to each group, $n$ is the number of parameters, and $\mathrm{w}_{\mathrm{ij}}$ is the weight coefficient, assigned by DA to a given parameters $\left(\mathrm{P}_{\mathrm{ij}}\right)$. The weight coefficient maximizes the distance between the means of the dependent variable. The classification table, which is also known as confusion, assignment or prediction matrix, is commonly used to evaluate the performance of analysis. In this table the rows present the observed categories of the dependents and the columns show the predicted categories for each dependent.

All cases should lie on the diagonal if the predictions are perfectly performed. The percentage of correct classifications will be identified by the percentage of cases on the 
diagonal. Box and whisker plots can also help to evaluate and interpret different patterns associated to the spatiotemporal variations in water quality. In this study, DA was applied on the raw data matrix using both standard and stepwise modes in order to the construction of discriminant functions to differentiate and classify the water quality. Temporal Da was performed after dividing the whole data set into two groups of temporal (wet season from May $15^{\text {th }}$ through October $15^{\text {th }}$, and dry season from October $16^{\text {th }}$ thru May $\left.14^{\text {th }}\right)$. Furthermore, spatial DA was performed for each season data matrix, based on three groups of LP, MP, and HP as the grouping variables. The monitoring sites (spatial) and the wet and dry seasons (temporal) were considered as the grouping (dependent) variables, whereas all the observed water quality parameters constituted the independent variables. The SPSS 16.0 software package was employed for data treatment. 
Table 5.1. Summary basic statistics of water quality parameters between 2000 and 2014

\begin{tabular}{|c|c|c|c|c|c|c|c|c|c|c|c|c|c|c|}
\hline $\begin{array}{c}\text { River/Canal } \\
\text { Name }\end{array}$ & $\begin{array}{c}\text { Site } \\
\text { Number }\end{array}$ & Statistics & $\begin{array}{c}\text { Chl- } \boldsymbol{a} \\
(\mu \mathrm{g} / \mathrm{L})\end{array}$ & $\begin{array}{c}\text { DO } \\
(\mathrm{mg} / \mathrm{L})\end{array}$ & $\begin{array}{c}\text { TKN } \\
(\mathbf{m g} / \mathbf{L})\end{array}$ & $\underset{(\mathbf{m g} / \mathrm{L})}{\mathbf{T P}}$ & $\begin{array}{c}\text { Total } \\
\text { Phosphate } \\
\text { (mg/L) }\end{array}$ & $\underset{(\mathrm{mg} / \mathrm{L})}{\operatorname{Ammonia}-\mathbf{N}}$ & $\begin{array}{c}\text { WT } \\
\text { (DegC) }\end{array}$ & $\begin{array}{c}\text { TSS } \\
(\mathbf{m g} / \mathbf{L})\end{array}$ & $\begin{array}{c}\text { Turbidity } \\
\text { (NTU) }\end{array}$ & $\underset{(\mathrm{mg} / \mathrm{L})}{\text { Magnesium }}$ & $\begin{array}{c}\text { Chloride } \\
(\mathrm{mg} / \mathrm{L})\end{array}$ & $\begin{array}{l}\text { Sodium } \\
(\mathrm{mg} / \mathrm{L})\end{array}$ \\
\hline \multirow{20}{*}{$\begin{array}{l}\text { Kissimmee } \\
\text { River }\end{array}$} & \multirow{4}{*}{ S65 } & Min & 4.0 & 0.93 & 0.05 & 0.007 & 0.002 & 0.005 & 7.5 & 3.0 & 1.1 & 2.2 & 11.6 & 7.2 \\
\hline & & Mean & 23.7 & 6.93 & 1.13 & 0.070 & 0.056 & 0.016 & 24.1 & 7.8 & 5.2 & 3.7 & 21.5 & 11.9 \\
\hline & & $\operatorname{Max}$ & 63.0 & 12.10 & 2.04 & 0.515 & 0.515 & 0.133 & 33.1 & 71.5 & 26.7 & 5.4 & 34.0 & 18.1 \\
\hline & & SD & 10.8 & 1.71 & 0.24 & 0.045 & 0.046 & 0.015 & 5.1 & 5.7 & 2.5 & 0.8 & 4.6 & 2.5 \\
\hline & \multirow{4}{*}{ S65A } & Min & 1.2 & 0.58 & 0.05 & 0.016 & 0.004 & 0.005 & 12.0 & 1.0 & 1.0 & 1.7 & 3.9 & 5.0 \\
\hline & & Mean & 20.2 & 6.05 & 1.16 & 0.063 & 0.056 & 0.030 & 24.6 & 6.2 & 4.2 & 3.5 & 20.4 & 11.6 \\
\hline & & Max & 88.0 & 12.30 & 3.43 & 0.366 & 0.328 & 0.288 & 34.7 & 43.0 & 37.9 & 5.7 & 40.3 & 17.4 \\
\hline & & SD & 11.4 & 2.14 & 0.25 & 0.033 & 0.033 & 0.040 & 5.0 & 4.2 & 2.7 & 0.9 & 5.0 & 2.7 \\
\hline & \multirow{4}{*}{$\begin{array}{c}\text { KREA } \\
\quad 95\end{array}$} & Min & 1.9 & 0.20 & 0.05 & 0.032 & 0.002 & 0.005 & 12.1 & 3.0 & 1.6 & 2.2 & 6.3 & 6.8 \\
\hline & & Mean & 15.1 & 5.02 & 1.20 & 0.080 & 0.075 & 0.060 & 24.3 & 11.2 & 7.9 & 4.5 & 22.9 & 12.6 \\
\hline & & Max & 65.0 & 10.20 & 3.07 & 0.242 & 0.273 & 0.359 & 32.2 & 59.0 & 37.9 & 15.0 & 71.9 & 30.2 \\
\hline & & SD & 10.9 & 2.66 & 0.31 & 0.038 & 0.043 & 0.059 & 4.8 & 8.4 & 6.0 & 2.4 & 9.5 & 4.6 \\
\hline & \multirow{4}{*}{ S65D } & Min & 1.0 & 0.08 & 0.05 & 0.022 & 0.002 & 0.005 & 12.0 & 1.0 & 0.9 & 2.2 & 10.1 & 6.5 \\
\hline & & Mean & 11.3 & 5.27 & 1.13 & 0.077 & 0.073 & 0.044 & 24.4 & 4.7 & 3.5 & 3.7 & 20.8 & 11.8 \\
\hline & & Max & 223.6 & 10.40 & 3.03 & 0.398 & 0.721 & 0.489 & 33.5 & 45.0 & 19.9 & 5.9 & 34.7 & 17.2 \\
\hline & & SD & 15.1 & 2.39 & 0.28 & 0.044 & 0.045 & 0.054 & 4.6 & 3.7 & 2.0 & 0.8 & 4.1 & 2.2 \\
\hline & \multirow{4}{*}{ S154C } & Min & 1.1 & 0.14 & 0.05 & 0.060 & 0.002 & 0.005 & 11.3 & 1.0 & 0.6 & 14.0 & 63.5 & 95.9 \\
\hline & & Mean & 8.7 & 3.85 & 1.54 & 0.370 & 0.344 & 0.147 & 23.9 & 8.1 & 5.8 & 75.8 & 1125.4 & 417.7 \\
\hline & & Max & 69.3 & 11.70 & 4.29 & 2.290 & 2.290 & 1.279 & 33.5 & 181.0 & 135.0 & 186.4 & 2421.1 & 1017.0 \\
\hline & & SD & 7.5 & 2.55 & 0.75 & 0.296 & 0.292 & 0.227 & 4.9 & 12.6 & 11.2 & 49.5 & 525.6 & 270.6 \\
\hline
\end{tabular}


Table 5.1. (Continued) Summary basic statistics of water quality parameters between 2000 and 2014

\begin{tabular}{|c|c|c|c|c|c|c|c|c|c|c|c|c|c|c|}
\hline $\begin{array}{l}\text { River/Canal } \\
\text { Name }\end{array}$ & $\begin{array}{c}\text { Site } \\
\text { Number }\end{array}$ & Statistics & $\begin{array}{l}\text { Chl- } a \\
(\mu \mathrm{g} / \mathrm{L})\end{array}$ & $\underset{(\mathrm{mg} / \mathrm{L})}{\mathrm{DO}}$ & $\begin{array}{c}\text { TKN } \\
(\mathbf{m g} / \mathbf{L})\end{array}$ & $\underset{(\mathbf{m g} / \mathbf{L})}{\mathbf{T P}}$ & $\begin{array}{c}\text { Total } \\
\text { Phosphate } \\
\text { (mg/L) }\end{array}$ & $\underset{(\mathrm{mg} / \mathrm{L})}{\operatorname{Ammonia-N}}$ & $\begin{array}{c}\text { WT } \\
\text { (DegC) }\end{array}$ & $\begin{array}{c}\text { TSS } \\
(\mathrm{mg} / \mathrm{L})\end{array}$ & $\begin{array}{c}\text { Turbidity } \\
\text { (NTU) }\end{array}$ & $\underset{(\mathrm{mg} / \mathrm{L})}{\text { Magnesium }}$ & $\begin{array}{c}\text { Chloride } \\
(\mathrm{mg} / \mathrm{L})\end{array}$ & $\begin{array}{l}\text { Sodium } \\
(\mathrm{mg} / \mathrm{L})\end{array}$ \\
\hline \multirow{20}{*}{$\begin{array}{l}\text { Caloosahatchee } \\
\text { River }\end{array}$} & \multirow{4}{*}{ S77 } & Min & 1.0 & 0.26 & 0.88 & 0.006 & 0.002 & 0.005 & 9.7 & 1.6 & 1.2 & 2.6 & 5.1 & 7.0 \\
\hline & & Mean & 19.0 & 5.70 & 1.50 & 0.100 & 0.087 & 0.068 & 25.5 & 13.3 & 10.0 & 11.0 & 52.9 & 32.1 \\
\hline & & $\operatorname{Max}$ & 181.0 & 13.10 & 6.39 & 0.838 & 0.838 & 0.304 & 36.3 & 158.0 & 71.4 & 19.1 & 108.2 & 59.0 \\
\hline & & SD & 27.6 & 2.42 & 0.47 & 0.076 & 0.074 & 0.058 & 4.7 & 14.6 & 11.2 & 3.0 & 16.8 & 9.4 \\
\hline & \multirow{4}{*}{ S78 } & Min & 1.0 & 0.63 & 0.88 & 0.010 & 0.043 & 0.005 & 14.3 & 1.0 & 1.1 & 6.1 & 27.0 & 15.5 \\
\hline & & Mean & 5.5 & 5.99 & 1.30 & 0.100 & 0.108 & 0.060 & 25.6 & 6.1 & 4.8 & 10.1 & 52.5 & 29.6 \\
\hline & & Max & 31.0 & 12.50 & 2.72 & 0.561 & 0.840 & 0.304 & 32.9 & 36.0 & 24.9 & 18.2 & 133.3 & 73.4 \\
\hline & & SD & 6.6 & 2.16 & 0.22 & 0.056 & 0.056 & 0.058 & 4.3 & 5.0 & 4.3 & 2.4 & 15.6 & 8.8 \\
\hline & \multirow{4}{*}{ CR-32.0 } & Min & 0.7 & 1.53 & 0.95 & 0.053 & 0.047 & 0.005 & 15.7 & 2.0 & 0.8 & 6.4 & 34.0 & 20.0 \\
\hline & & Mean & 10.8 & 5.29 & 1.41 & 0.140 & 0.113 & 0.052 & 25.7 & 5.9 & 4.0 & 10.9 & 57.2 & 33.1 \\
\hline & & Max & 49.0 & 9.45 & 2.00 & 0.490 & 0.757 & 0.596 & 31.4 & 20.0 & 13.7 & 17.4 & 120.0 & 57.6 \\
\hline & & SD & 11.2 & 2.04 & 0.26 & 0.080 & 0.053 & 0.058 & 4.0 & 4.0 & 3.4 & 2.7 & 17.4 & 8.4 \\
\hline & \multirow{4}{*}{ S79 } & Min & 0.5 & 0.91 & 0.81 & 0.028 & 0.050 & 0.005 & 15.0 & 1.4 & 0.1 & 5.6 & 3.3 & 1.1 \\
\hline & & Mean & 12.9 & 6.65 & 1.18 & 0.113 & 0.118 & 0.045 & 25.8 & 5.0 & 2.0 & 11.8 & 76.8 & 42.9 \\
\hline & & Max & 370.0 & 12.20 & 4.67 & 0.311 & 0.673 & 0.887 & 33.1 & 14.0 & 17.7 & 38.4 & 451.0 & 248.6 \\
\hline & & SD & 21.9 & 2.05 & 0.29 & 0.047 & 0.051 & 0.058 & 4.1 & 2.3 & 2.3 & 4.8 & 61.4 & 34.2 \\
\hline & \multirow{4}{*}{ CES03 } & Min & 1.0 & 0.04 & 0.30 & 0.037 & 0.010 & 0.031 & 14.7 & 1.0 & 0.6 & 4.8 & 4.0 & 11.7 \\
\hline & & Mean & 12.7 & 5.45 & 1.07 & 0.185 & 0.132 & 0.049 & 26.4 & 9.0 & 3.7 & 110.4 & 554.8 & 199.2 \\
\hline & & Max & 133.0 & 13.38 & 2.35 & 0.810 & 0.680 & 0.063 & 34.4 & 66.5 & 17.1 & 793.0 & 12500.0 & 1350.0 \\
\hline & & SD & 15.0 & 2.27 & 0.28 & 0.136 & 0.073 & 0.012 & 3.8 & 9.9 & 3.1 & 149.3 & 1484.3 & 284.2 \\
\hline
\end{tabular}


Table 5.1. (Continued) Summary basic statistics of water quality parameters between 2000 and 2014

\begin{tabular}{|c|c|c|c|c|c|c|c|c|c|c|c|c|c|c|}
\hline $\begin{array}{l}\text { River/Canal } \\
\text { Name }\end{array}$ & $\begin{array}{c}\text { Site } \\
\text { Number }\end{array}$ & Statistics & $\begin{array}{r}\text { Chl-a } \\
(\mu \mathrm{g} / \mathrm{L})\end{array}$ & $\underset{(\mathrm{mg} / \mathrm{L})}{\mathrm{DO}}$ & $\begin{array}{c}\text { TKN } \\
(\mathbf{m g} / \mathrm{L})\end{array}$ & $\begin{array}{c}\text { TP } \\
(\mathbf{m g} / \mathrm{L})\end{array}$ & $\begin{array}{c}\text { Total } \\
\text { Phosphate } \\
(\mathrm{mg} / \mathrm{L})\end{array}$ & $\underset{(\mathrm{mg} / \mathrm{L})}{\text { Ammonia-N }}$ & $\begin{array}{c}\text { WT } \\
\text { (DegC) }\end{array}$ & $\underset{(\mathrm{mg} / \mathrm{L})}{\mathrm{TSS}}$ & $\begin{array}{c}\text { Turbidity } \\
\text { (NTU) }\end{array}$ & $\underset{(\mathrm{mg} / \mathrm{L})}{\text { Magnesium }}$ & $\begin{array}{c}\text { Chloride } \\
\text { (mg/L) }\end{array}$ & $\begin{array}{r}\text { Sodium } \\
(\mathrm{mg} / \mathrm{L})\end{array}$ \\
\hline \multirow{24}{*}{$\begin{array}{l}\text { Miami } \\
\text { Canal }\end{array}$} & \multirow{4}{*}{ S354 } & Min & 1.0 & 0.26 & 0.88 & 0.006 & 0.002 & 0.005 & 9.7 & 1.6 & 1.2 & 2.6 & 5.1 & 7.0 \\
\hline & & Mean & 19.0 & 5.70 & 1.50 & 0.100 & 0.087 & 0.068 & 25.5 & 13.3 & 10.0 & 11.0 & 52.9 & 32.1 \\
\hline & & $\operatorname{Max}$ & 181.0 & 13.10 & 6.39 & 0.838 & 0.838 & 0.304 & 36.3 & 158.0 & 71.4 & 19.1 & 108.2 & 59.0 \\
\hline & & $\mathrm{SD}$ & 27.6 & 2.42 & 0.47 & 0.076 & 0.074 & 0.058 & 4.7 & 14.6 & 11.2 & 3.0 & 16.8 & 9.4 \\
\hline & \multirow{4}{*}{ S8 } & Min & 1.0 & 0.63 & 0.88 & 0.010 & 0.043 & 0.005 & 14.3 & 1.0 & 1.1 & 6.1 & 27.0 & 15.5 \\
\hline & & Mean & 5.5 & 5.99 & 1.30 & 0.100 & 0.108 & 0.060 & 25.6 & 6.1 & 4.8 & 10.1 & 52.5 & 29.6 \\
\hline & & $\operatorname{Max}$ & 31.0 & 12.50 & 2.72 & 0.561 & 0.840 & 0.304 & 32.9 & 36.0 & 24.9 & 18.2 & 133.3 & 73.4 \\
\hline & & SD & 6.6 & 2.16 & 0.22 & 0.056 & 0.056 & 0.058 & 4.3 & 5.0 & 4.3 & 2.4 & 15.6 & 8.8 \\
\hline & \multirow{4}{*}{ C123SR84 } & Min & 0.7 & 1.53 & 0.95 & 0.053 & 0.047 & 0.005 & 15.7 & 2.0 & 0.8 & 6.4 & 34.0 & 20.0 \\
\hline & & Mean & 10.8 & 5.29 & 1.41 & 0.140 & 0.113 & 0.052 & 25.7 & 5.9 & 4.0 & 10.9 & 57.2 & 33.1 \\
\hline & & $\operatorname{Max}$ & 49.0 & 9.45 & 2.00 & 0.490 & 0.757 & 0.596 & 31.4 & 20.0 & 13.7 & 17.4 & 120.0 & 57.6 \\
\hline & & SD & 11.2 & 2.04 & 0.26 & 0.080 & 0.053 & 0.058 & 4.0 & 4.0 & 3.4 & 2.7 & 17.4 & 8.4 \\
\hline & \multirow{4}{*}{ S151 } & Min & 0.5 & 0.91 & 0.81 & 0.028 & 0.050 & 0.005 & 15.0 & 1.4 & 0.1 & 5.6 & 3.3 & 1.1 \\
\hline & & Mean & 12.9 & 6.65 & 1.18 & 0.113 & 0.118 & 0.045 & 25.8 & 5.0 & 2.0 & 11.8 & 76.8 & 42.9 \\
\hline & & $\operatorname{Max}$ & 370.0 & 12.20 & 4.67 & 0.311 & 0.673 & 0.887 & 33.1 & 14.0 & 17.7 & 38.4 & 451.0 & 248.6 \\
\hline & & SD & 21.9 & 2.05 & 0.29 & 0.047 & 0.051 & 0.058 & 4.1 & 2.3 & 2.3 & 4.8 & 61.4 & 34.2 \\
\hline & \multirow{4}{*}{ S31 } & Min & 1.0 & 0.04 & 0.30 & 0.037 & 0.010 & 0.031 & 14.7 & 1.0 & 0.6 & 4.8 & 4.0 & 11.7 \\
\hline & & Mean & 12.7 & 5.45 & 1.07 & 0.185 & 0.132 & 0.049 & 26.4 & 9.0 & 3.7 & 110.4 & 554.8 & 199.2 \\
\hline & & Max & 133.0 & 13.38 & 2.35 & 0.810 & 0.680 & 0.063 & 34.4 & 66.5 & 17.1 & 793.0 & 12500.0 & 1350.0 \\
\hline & & SD & 15.0 & 2.27 & 0.28 & 0.136 & 0.073 & 0.012 & 3.8 & 9.9 & 3.1 & 149.3 & 1484.3 & 284.2 \\
\hline & \multirow{4}{*}{ MR01 } & Min & 0.6 & 0.61 & 0.15 & 0.150 & 0.002 & 0.020 & 12.14 & 0.8 & 0.1 & 7.0 & 38.0 & 26.0 \\
\hline & & Mean & 17.6 & 5.14 & 1.08 & 1.082 & 0.069 & 0.100 & 25.99 & 19.9 & 2.2 & 10.6 & 59.1 & 39.6 \\
\hline & & $\operatorname{Max}$ & 68.0 & 10.71 & 2.40 & 2.400 & 0.160 & 0.230 & 33.14 & 102.0 & 14.0 & 20.4 & 140.0 & 81.0 \\
\hline & & SD & 16.3 & 1.40 & 0.55 & 0.548 & 0.049 & 0.038 & 3.55 & 27.3 & 2.4 & 2.2 & 12.2 & 7.3 \\
\hline
\end{tabular}




\section{Results and discussion}

\subsection{Spatiotemporal similarities and grouping the sampling sites by cluster analysis}

Two dendrograms was rendered after cluster analysis using SPSS 16.0 (Figure 5.2), where all the sixteen monitoring sites were grouped into three statistically significant clusters of low pollution (LP), moderate pollution (MP), and high pollution (HP), reflecting the water quality characteristics of considered sites. The linkage distance $\left(D_{\text {link }} / D_{\max }\right)$ was used to evaluate the spatial variability of water quality in the entire area, which is a quotient between the linkages distance divided by the maximal linkage distance for a case. The quotient also should be then multiplied by 100 in order to standardize the linkage distance that is usually shown on the $y$-axis $[5,7,12]$.

Three groups of sites for each season were generated in a convincing way through the clustering procedure, in which river water quality decreases from top to bottom. These groups or clusters include monitoring sites that have similar characteristics in terms of features and natural background affecting by similar sources of type or strength. Each site has been located in a certain cluster considering the whole 12 studied parameters, and based on the squared Euclidian distance between each site. Figure 5.3 demonstrates the spatial distribution of these three groups in the study area in the wet and dry seasons based on their similarity and the level of impairment. As is shown in maps (Figure 5.3), generally the relatively less polluted sites were located in the middle parts of rivers in both wet and dry seasons, whereas moderate polluted and highly polluted sites were mainly located at the beginning and the end sections of studied rivers. It can be concluded that Lake Kissimmee and Lake Okeechobee as the upstream parts of these rivers, discharge relatively polluted waters into these rivers. Besides, most of the rivers in the 
moderate and high pollution regions are affected by urban areas with more industrial and domestic wastewater. Furthermore, according to the location of Environmental Resource Permits (ERP), issued under the jurisdiction of South Florida Water Management District (SFWMD), it was observed that the moderate and high pollution regions of studied rivers are located in areas with high-density permits.
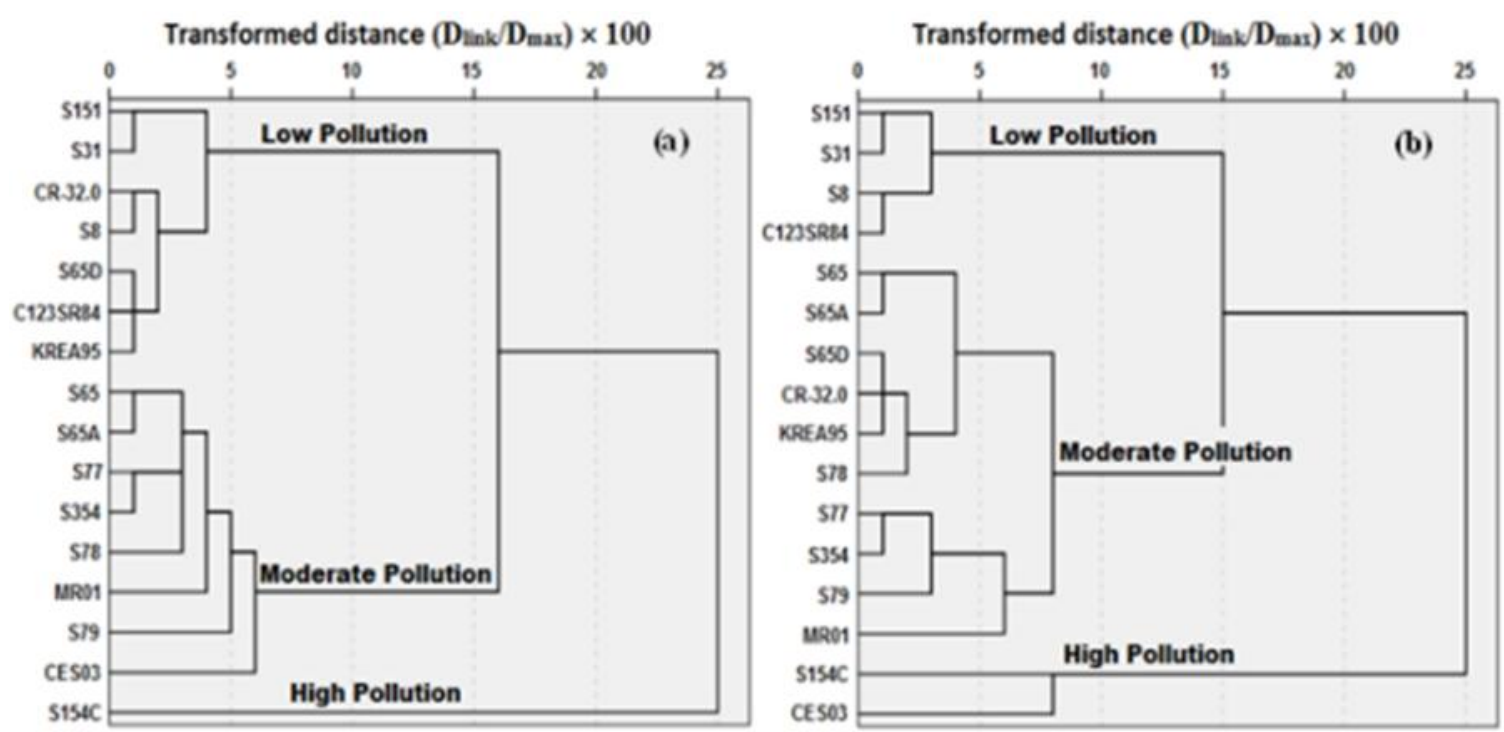

Figure 5.2. Dendrogram showing three clusters of monitoring sites in dry season (a) and wet season (b) using the Ward's linkage distance $\left(\mathrm{D}_{\text {link }} / \mathrm{D}_{\max }\right)$.

Agricultural area with different types of production as the major land use in the studied watersheds plus numerous head of beef and dairy cattle and livestock farms, every year discharge significant amounts of agricultural and animal wastes containing high levels of nitrogen, phosphorus, and pesticides, into the drainage networks and finally into the main stem of rivers. 

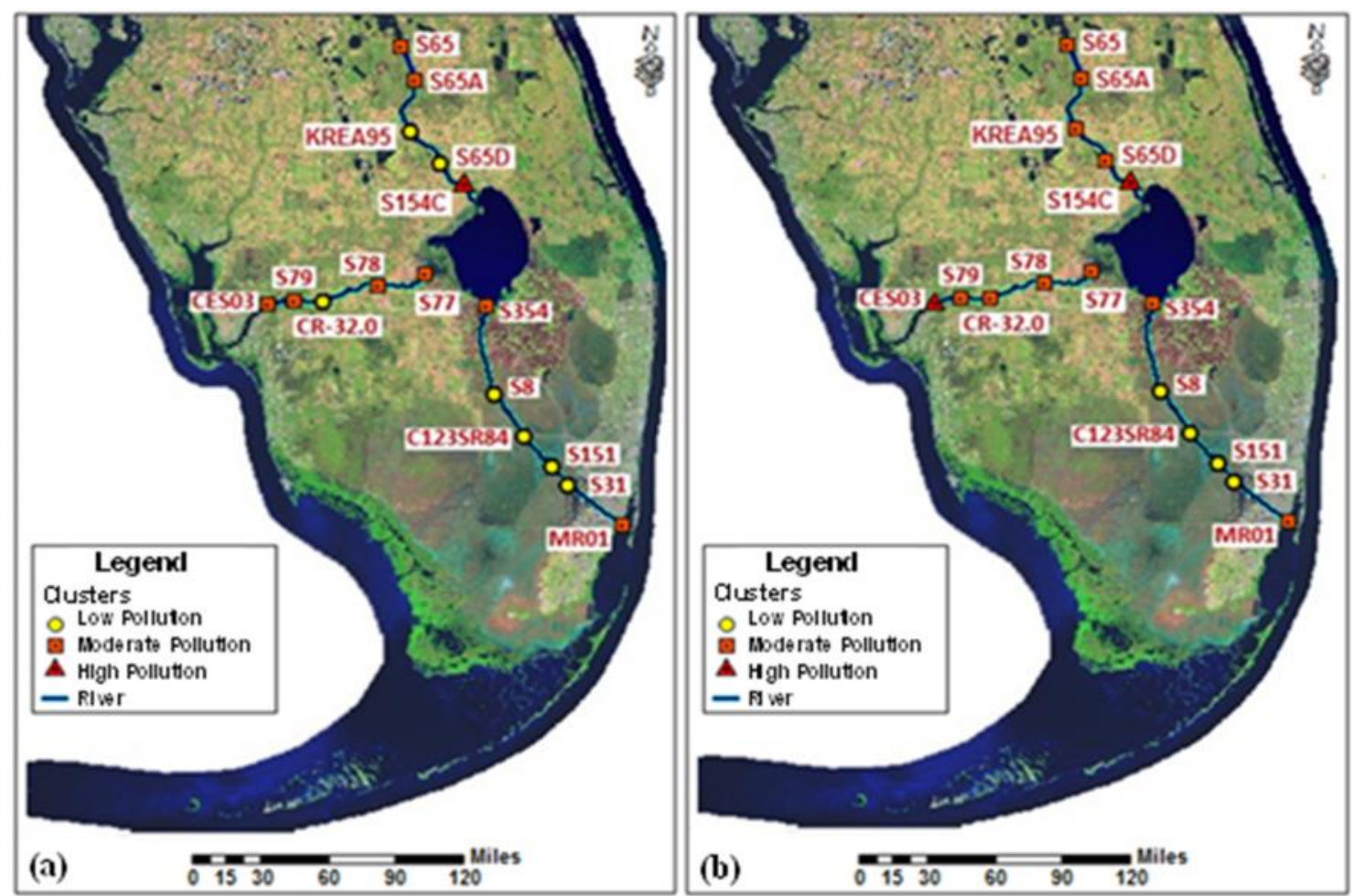

Figure 5.3. Spatial distribution of three groups of sites based on their similarity and the level of impairment in the study area in the dry (a) and wet (b) seasons.

Therefore, the spatial variation of water quality was detected to be under the influence of both point and non-point sources of pollution resulted from anthropogenic activities. Nevertheless, these three river systems with very low slope, and a great volume of flows in their mainstream, have high capacities to mitigate pollution loads and showed self-cleansing characteristics for some parameters. The comparison of average concentrations of water quality parameters in two studied seasons showed significant differences in average amounts of chl- $a$, dissolved oxygen (DO), total kjeldahl nitrogen (TKN), total phosphorus (TP), total phosphate, ammonia-N, and water temperature (WT). The results of $\mathrm{CA}$ revealed that the average concentrations of nutrients in Caloosahatchee River were worse than other two studied rivers. In order to assess and analyze the temporal trends of nutrients in the selected waterbodies of South Florida that the 
agricultural activities were found to be the main source for these chemicals, three monitoring sites in the middle parts of these river, which were surrounded by different types of agriculture, were selected to investigate. The historical and continues sampling observations for total phosphate, which is the measurement of all inorganic, organic and dissolved forms of phosphorus, and TKN from 2000 to 2015 were obtained from DBHYDRO, and their temporal changes were graphed (Figure 5.4).

According to the observed data and the historical trend of nutrients and especially total phosphate in three selected rivers, it was found higher concentrations at the Caloosahatchee River and the Kissimmee River than Miami Canal sites. The percentage of agricultural and urbanized areas in the Miami Canal watershed was measured from the land use/land cover map in GIS and was seen to be even more than the other two rivers. Therefore, this could be related to the effectiveness of eco-restoration projects implemented in its watershed and adjacent linked watersheds to reduce the concentration of TP (the water conservation area-3, WCA-3) in order to decrease the amounts of nutrients, especially, total phosphorous. In addition, two S154 and CES03 sites showed very greater amounts of studied parameters in both wet and dry seasons compared to other sites. One of the possible reasons may be the effluent discharges of industrial and domestic wastewater, generally kept at a relatively steady level throughout the entire year. 

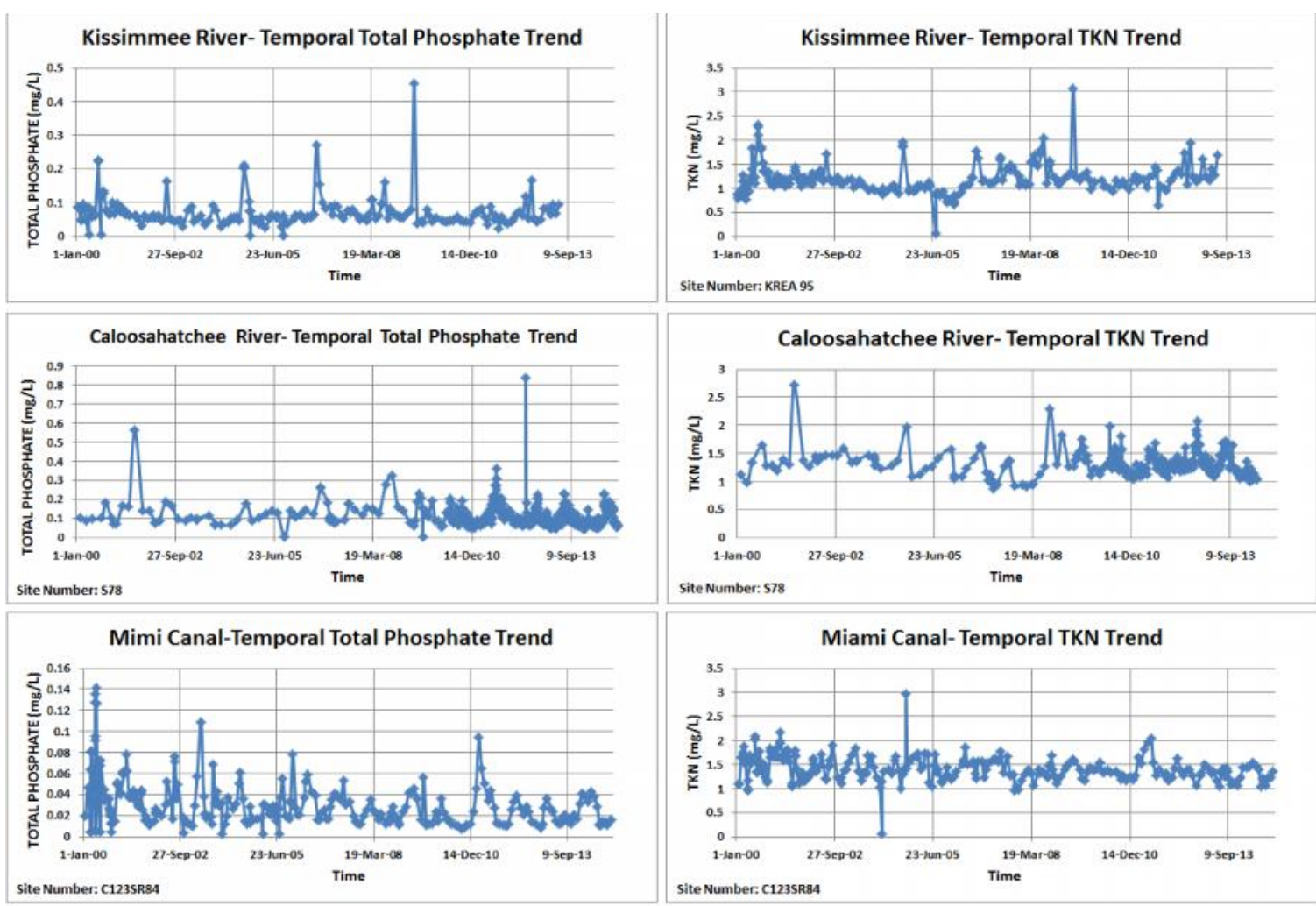

Figure 5.4. Temporal trends of nutrients in the selected waterbodies of South Florida.

\subsection{Spatiotemporal variations in river water quality using discriminant analysis}

\subsubsection{Temporal variations in water quality}

Discriminant analysis (DA) was used to evaluate the temporal variation in water quality. Both standard and stepwise modes were applied on the raw data after dividing the whole data set into two seasonal groups (wet and dry seasons). The standard mode constructs discriminating functions containing all predictive variables, whereas in the stepwise mode, one variable that minimized the overall Wilk's Lambda statistic was entered or removed at each step. Season was the dependent variable and all considered water quality parameters constructed the independent variables. 
The measured values of Wilk's lambda and chi-square statistic of each discriminant function (DFs) obtained from both standard mode and stepwise mode shown in Table 5.2 varied from 0.222 to 0.244 and from 277.3 to 267.5 , respectively. Wilks' lambda shows the discriminatory ability of the function for the separation of cases into groups. The associated chi-square statistic is used to test the hypothesis that the means of the functions listed are equal between the considered groups. The small significance values $(\mathrm{p}$-level $<0.01)$ indicated that the temporal DA was effective. The first function in standard DA explained almost all $(\mathrm{R}=88.2 \%)$ of the total variance in dependent variables. The stepwise DA had similar results, which indicated that $87 \%$ of the total group differences in the data set were explained by its first DF. Therefore, the first DF alone was significant adequate to explain the difference of water quality between two wet and dry seasons.

Five variables (chl-a, DO, TKN, TP and water temperature) were selected using stepwise DA identified as the most important variables that explain the temporal variation of water quality in wet and dry seasons. The first function in the stepwise DA was perfectly correlated with temperature (coefficient $=1.000)$, and then mostly correlated with DO (coefficient $=0.613)$. Classification functions $(\mathrm{CFs})$ and the classification matrices (CMs) for the temporal discriminant analysis of water quality variations in wet and dry seasons are shown in Tables 5.3 and 5.4. All 12 variables were included in the standard mode and correctly classified $95.3 \%$ of the original grouped cases, while in the stepwise mode, $93.2 \%$ of the cases were correctly assigned using only five discriminating variables. Therefore, the temporal DA results of the stepwise mode suggested that chl-a, DO, TKN, $\mathrm{pH}$ and water temperature were the most significant parameters for 
discriminating differences between the wet season and dry season, and could be used to explain most of the expected temporal variations in water quality.

Table 5.2. Wilk's lambda and chi-square test for the temporal discriminant analysis of water quality variations across two wet and dry seasons.

\begin{tabular}{ccccccc}
\hline Mode & $\begin{array}{c}\text { Discriminant } \\
\text { Function } \\
(\mathbf{D F})\end{array}$ & $\begin{array}{c}\text { Canonical } \\
\text { Correlation } \\
(\mathbf{R})\end{array}$ & Eigenvalue & $\begin{array}{c}\text { Wilk's } \\
\text { lambda }\end{array}$ & $\begin{array}{c}\text { Chi- } \\
\text { square }\end{array}$ & $\begin{array}{c}\text { p-level } \\
\text { (Sig.) }\end{array}$ \\
\hline Standard Mode & 1 & 0.882 & 3.513 & 0.222 & 277.271 & 0.000 \\
Stepwise Mode & 1 & 0.870 & 3.102 & 0.244 & 267.490 & 0.000 \\
\hline
\end{tabular}

Table 5.3. Classification functions coefficients (CFs) for the temporal discriminant analysis of water quality variations in wet and dry seasons.

\begin{tabular}{|c|c|c|c|c|}
\hline \multirow{2}{*}{ Parameter } & \multicolumn{2}{|c|}{ Standard mode } & \multicolumn{2}{|c|}{ Stepwise Mode } \\
\hline & Dry coef. $^{a}$ & Wet coef. $^{a}$ & Dry coef. $^{a}$ & Wet coef. $^{\text {a }}$ \\
\hline Chl- $a$ & -0.586 & -0.532 & -0.116 & 0.046 \\
\hline Dissolve Oxygen & 9.121 & 8.514 & 3.338 & 1.985 \\
\hline Total Kjeldahl Nitrogen & 27.702 & 25.936 & 24.694 & 27.791 \\
\hline Total Phosphorus & 41.686 & 78.262 & 5.835 & 11.915 \\
\hline Total Phosphate & -126.870 & -168.289 & & \\
\hline Ammonia-N & 43.744 & 45.375 & & \\
\hline Water Temperature & 7.452 & 9.299 & 5.541 & 7.319 \\
\hline Total Suspended Solids & -0.107 & -0.180 & & \\
\hline Turbidity & 0.307 & 0.568 & & \\
\hline Magnesium & -0.082 & -0.141 & & \\
\hline Chloride & 0.017 & 0.020 & & \\
\hline Sodium & 0.039 & 0.048 & & \\
\hline (Constant) & -123.968 & -165.618 & -60.360 & -104.781 \\
\hline
\end{tabular}

Table 5.4. Classification matrix (CMs) for the temporal discriminant analysis of water quality variations in wet and dry seasons.

\begin{tabular}{cccc}
\hline Monitoring & \multirow{2}{*}{ \% correct } & \multicolumn{2}{c}{ Season assigned by DA } \\
\cline { 3 - 4 } season & & Dry season & Wet season \\
\hline $\begin{array}{c}\text { Standard mode } \\
\text { Dry season }\end{array}$ & 89.6 & 88 & 8 \\
Wet season & 97.9 & 1 & 95 \\
Total & 95.3 & 89 & 103 \\
& & & \\
Stepwise Mode & & & 12 \\
Dry season & 87.5 & 84 & 95 \\
Wet season & 99.0 & 1 & 107 \\
Total & 93.2 & 85 & \\
\hline
\end{tabular}


Box and whisker plots of discriminating parameters were constructed (stepwise mode) to evaluate different patterns associated with temporal variations in river water quality (Figure 5.5). The first pattern showed clear seasonal differences for chl- $a$, DO, and water temperature in which chl- $a$ and water temperature showed a clear inverse relationship with DO. This could be explained that as water temperature increases in the river, biological activity of aquatic organism strengthens and therefore consumption of DO increases. In addition, more oxygen also dissolves in cooler water. The second pattern showed higher average concentrations of TKN and TP in wet season that could be due to erosion of soil containing nutrients while raining. 

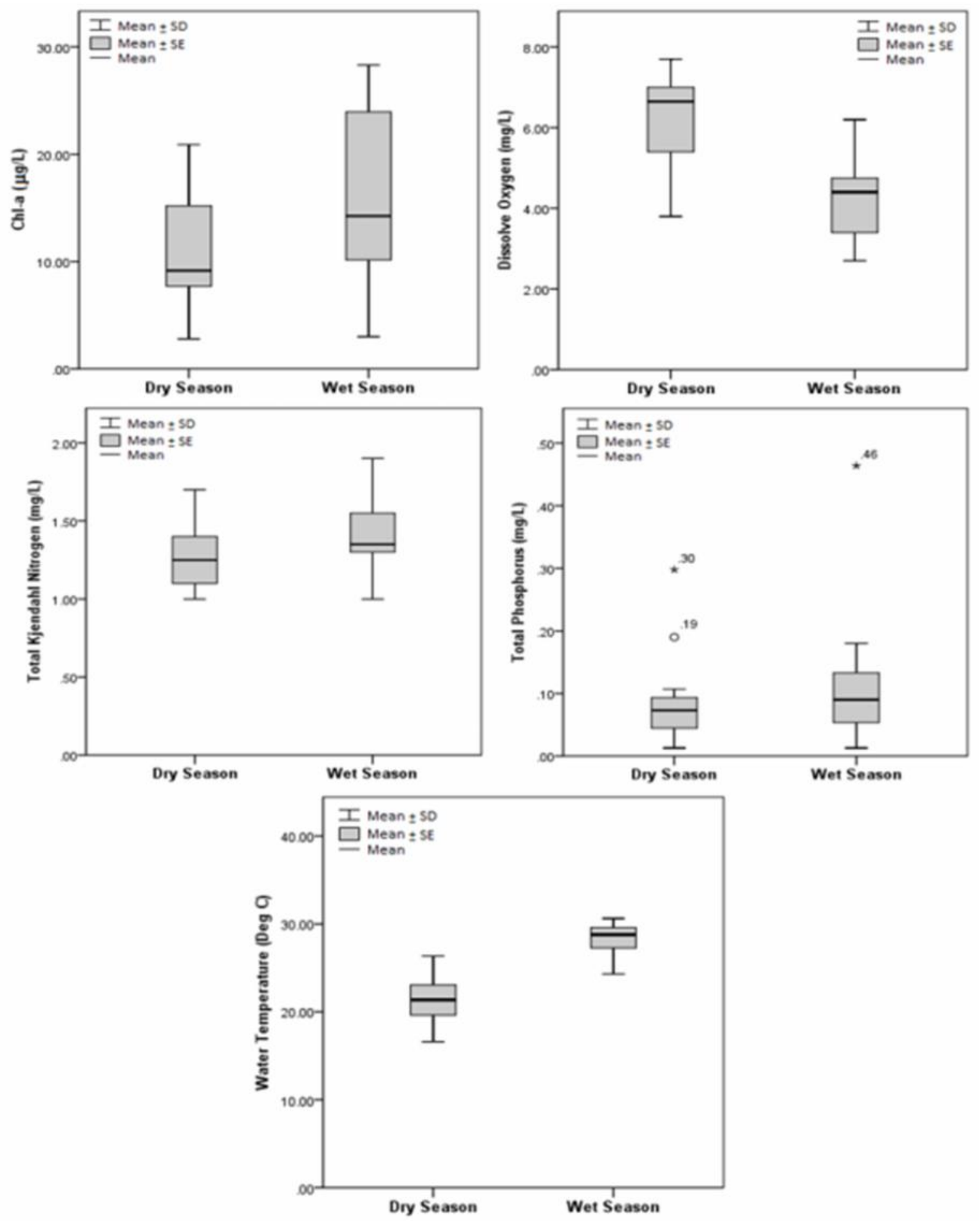

Figure 5.5. Temporal variations in water quality of three major rivers of South Florida: Chl- $a$, Dissolved Oxygen, total kjeldahl nitrogen (TKN), total phosphorus (TP), and water temperature. 


\subsubsection{Spatial variations in water quality}

DA was also used to study the spatial variation in water quality using the preidentified groups from cluster analysis (CA) in both wet and dry seasons. Accordingly, two data matrices were constructed for the investigation of spatial variations in water quality of LP, MP, and HP sites in wet and dry seasons. The main objectives spatial DA were (1) to test and confirm the significance of clusters determined by means of CA based on the accuracy rate of discriminant functions, and (2) to determine the most significant variables associated with differences among the spatial groups. The groups (LP, MP, and HP) were the dependent variables and the studied water quality parameters were considered as the independent variables. In this study, both standard and stepwise modes of DA applied on two data matrices in wet and dry season and the best mode was selected for the interpretation of results.

- Spatial variations in water quality of $L P, M P$, and HP sites in wet season

As shown in Table 5.5, the Wilk's lambda and the chi-square values varied from 0.023 to 0.435 and from 74.864 to 330.242 for each discriminant function. The obtained p-value (all less than 0.01) indicated credibility and effectiveness of spatial DA. Seven variables (chl-a, DO, TKN, TP, magnesium, chloride, and sodium) were selected using stepwise DA as the most important variables that explain the spatial variation of water quality in different pollution regions. Two resulted DFs successfully explained $96.7 \%$ and $75.1 \%$ of the differences between different pollution regions, respectively. The first DF separated HP region from LP and MP sites and was significantly correlated (coefficients > 0.3) with total phosphate, TP, sodium, and chloride. The second DF established some separation between LP and MP regions, and was significantly correlated 
with total phosphate, TP, DO, chl-a, and TKN (Figure 5.6). Spatial distribution patterns of clusters in Figure 5.6 confirm the accuracy of cluster analysis results.

Table 5.5. Wilk's lambda and chi-square test for the spatial discriminant analysis of water quality variations across three groups of sites in wet season.

\begin{tabular}{lcccccc}
\hline Mode & $\begin{array}{c}\text { Discriminant } \\
\text { Function } \\
\text { (DF) }\end{array}$ & $\begin{array}{c}\text { Canonical } \\
\text { Correlation } \\
(\mathbf{R})\end{array}$ & Eigenvalue & $\begin{array}{c}\text { Wilk's } \\
\text { lambda }\end{array}$ & $\begin{array}{c}\text { Chi- } \\
\text { square }\end{array}$ & $\begin{array}{c}\text { p-level } \\
\text { (Sig.) }\end{array}$ \\
\hline Standard & 1 & 0.970 & 16.187 & 0.023 & 330.242 & 0.000 \\
& 2 & 0.778 & 1.535 & 0.395 & 81.380 & 0.000 \\
Stepwise & 1 & 0.967 & 14.467 & 0.028 & 321.347 & 0.000 \\
& 2 & 0.751 & 1.298 & 0.435 & 74.864 & 0.000 \\
\hline
\end{tabular}

Table 5.6. Classification functions coefficients (CFs) for the spatial discriminant analysis of water quality variations across three clusters in wet season.

\begin{tabular}{|c|c|c|c|c|c|c|}
\hline \multirow{2}{*}{ Parameter } & \multicolumn{3}{|c|}{ Standard mode } & \multicolumn{3}{|c|}{ Stepwise Mode } \\
\hline & $\mathbf{L P}$ & MP coef. ${ }^{a}$ & HP coef. $^{a}$ & LP & MP coef. ${ }^{a}$ & HP coef. $^{\text {a }}$ \\
\hline Chl- $a$ & -1.180 & -1.020 & -1.124 & -0.378 & -0.197 & -0.347 \\
\hline Dissolve Oxygen & 8.498 & 9.821 & 6.868 & 2.771 & 3.658 & 1.534 \\
\hline Total Kjeldahl Nitrogen & 35.748 & 28.947 & 34.922 & 48.352 & 40.281 & 48.152 \\
\hline Total Phosphorus & 12.114 & -1.008 & 293.107 & -9.028 & 9.836 & 194.976 \\
\hline Total Phosphate & -150.172 & -112.273 & -224.341 & & & \\
\hline Ammonia-N & 40.179 & 49.687 & 85.854 & & & \\
\hline Water Temperature & 17.927 & 18.078 & 15.806 & & & \\
\hline Total Suspended Solids & -0.430 & -0.423 & -1.109 & & & \\
\hline Turbidity & 1.593 & 1.512 & 3.609 & & & \\
\hline Magnesium & 0.093 & 0.102 & -1.591 & -0.018 & -0.03 & -1.498 \\
\hline Chloride & 0.006 & 0.004 & 0.138 & 0.019 & 0.016 & 0.128 \\
\hline Sodium & -0.049 & -0.047 & 0.371 & -0.056 & -0.039 & 0.344 \\
\hline (Constant) & -286.689 & -292.775 & -383.299 & -37.888 & -35.676 & -173.134 \\
\hline
\end{tabular}

${ }^{a}$ Fisher's linear discriminant functions coefficients for three groups of sites correspond to $\mathrm{w}_{\mathrm{ij}}$ as defined in Eq. (5.2).

Table 5.7. Classification matrix (CMs) for the spatial discriminant analysis in wet season.

\begin{tabular}{|c|c|c|c|c|}
\hline \multirow{2}{*}{$\begin{array}{c}\text { Monitoring } \\
\text { Clusters }\end{array}$} & \multirow{2}{*}{$\begin{array}{c}\% \\
\text { correct }\end{array}$} & \multicolumn{3}{|c|}{ Regions assigned by DA } \\
\hline & & LP & MP & HP \\
\hline Standard mode & & & & \\
\hline LP & 93.3 & 35 & 7 & 0 \\
\hline MP & 91.7 & 3 & 44 & 1 \\
\hline HP & 100.0 & 0 & 0 & 6 \\
\hline Total & 88.5 & 38 & 51 & 7 \\
\hline Stepwise Mode & & & & \\
\hline LP & 83.3 & 35 & 7 & 0 \\
\hline MP & 85.4 & 6 & 41 & 1 \\
\hline HP & 100.0 & 0 & 0 & 6 \\
\hline Total & 85.4 & 41 & 48 & 7 \\
\hline
\end{tabular}

Tables 5.6 and 5.7 demonstrate the values of CFs and CMs for both standard and stepwise modes. All the 12 water quality variables were included in the standard mode 
and the constructed CFs showed an accuracy of $88.5 \%$ for the assignment of cases to different groups. Also, DA presented $85.4 \%$ correct assignment using the stepwise mode and by only selecting seven discriminating variables.

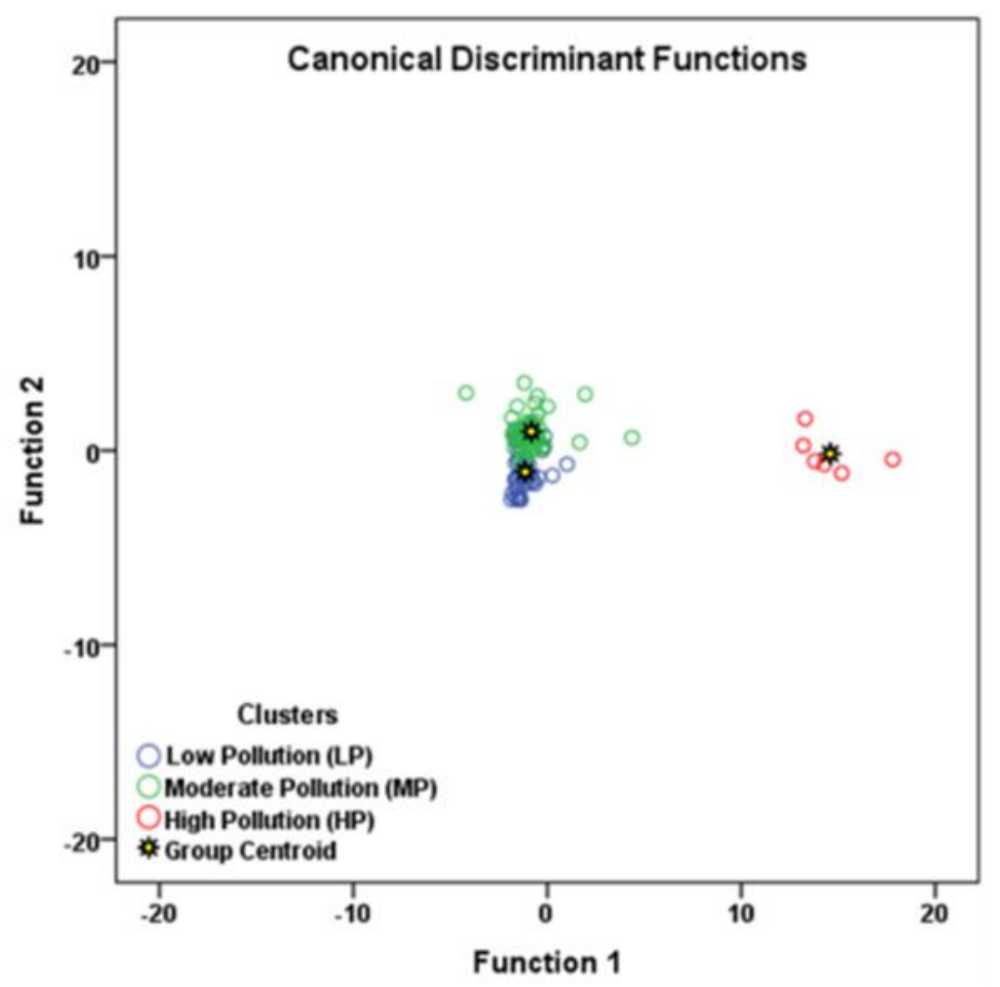

Figure 5.6. Scatter plot for the spatial discriminant analysis of water quality variations across three clusters in wet season (stepwise mode).

Box and whisker plots of identified discriminating water quality parameters from stepwise spatial DA were used to study the patterns of water quality variations between three identified clusters of sampling sites in wet season (Figure 5.7). The points show the outliers and represent the values that are not in the inner fence ranges. The asterisks are extreme outliers that represent the values of cases that are three times larger than the height of the boxes. 
Three patterns recognized from spatial DA in wet season based on identified groups of sites in CA. The first pattern showed clear spatial differences for chl- $a$ and DO, which a strong relationship (0.50) between them was observed from the resultant correlation matrix table of spatial DA in wet season. The higher average concentrations of these two variables, which are a measure of life's vitality and the activity level of the plants and animals living in rivers, were found in MP region that indicates the dynamism and strength of aquatic lives in this region. Besides, the HP region had lower average concentrations of chl- $a$ and DO, which indicated that there was much more serious organic pollution. The second pattern was related to average concentration for TKN that showed higher average concentrations in HP, LP, and MP regions, respectively. Observing the highest level of TKN in HP region was expected due to being located in the area that is under the influence of point source pollution discharges (site S154C). However, LP region is located in the middle parts of river that are attributed to the use of nitrogenous fertilizers in agricultural areas and showed higher average values compared to MP regions located at the beginning and the end parts of studied rivers. The third pattern showed the expected trend of environment pollution problems from the LP region to HP region for total phosphorous (TP), magnesium, chloride, and sodium. The spatial differences of these variables in wet season suggested that water quality problems in the HP region were worse than in the LP and MP regions and hence more attention should be paid to this region. 

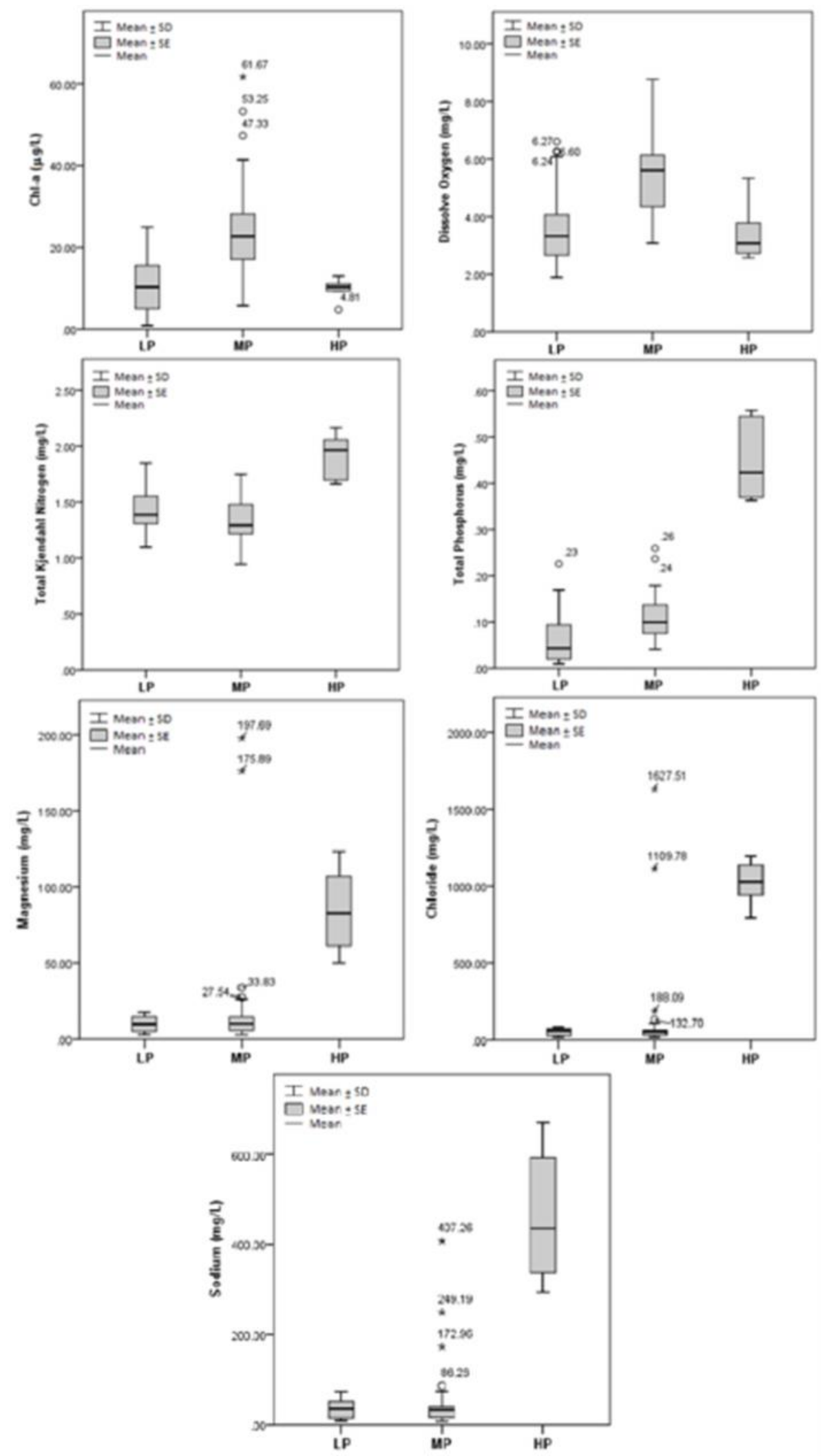

Figure 5.7. Spatial variations in water quality of three clusters of sites in wet season: Chl- $a$; DO, TKN, TP, magnesium, chloride, and sodium. 
- Spatial variations in water quality of $L P, M P$, and HP sites in dry season

Spatial variations of water quality in LP, MP, and HP sites were also performed in dry season. As shown in Table 5.8, the values of Wilk's lambda and the chi-square values varied from 0.007 to 0.135 and from 181.131 to 438.145 for each discriminant function. The obtained p-value (all less than 0.01) indicated credibility and effectiveness of spatial DA in dry season. Six variables (DO, TKN, TP, turbidity, magnesium, and chloride) were selected using stepwise DA as the most important variables that explain the spatial variation of water quality in dry season and in different pollution regions. Two resulted DFs successfully explained $96.8 \%$ and $93 \%$ of the differences between different pollution regions, respectively. Likewise wet season, the first DF separated HP sites from LP and MP sites (Figure 5.8), and was significantly correlated (coefficients $>0.3$ ) with total phosphate, TP, sodium, chloride, and magnesium. The second DF established some separation between LP and MP sites, and was significantly correlated with TP and DO. Spatial distribution patterns of clusters in Figure 5.8 confirm the accuracy of cluster analysis results. Tables 5.9 and 5.10 demonstrate the values of CFs and CMs for both standard and stepwise modes for the dry season discriminant analysis. All the 12 water quality variables were included in the standard mode and the constructed CFs showed an accuracy of $99 \%$ for the assignment of cases to different groups. Also, DA presented $100 \%$ correct assignment using the stepwise mode and by only selecting six discriminating variables. 
Table 5.8. Wilk's lambda and chi-square test for the spatial discriminant analysis of water quality variations across three groups of sites in dry season.

\begin{tabular}{lcccccc}
\hline Mode & $\begin{array}{c}\text { Discriminant } \\
\text { Function } \\
(\mathbf{D F})\end{array}$ & $\begin{array}{c}\text { Canonical } \\
\text { Correlation } \\
(\mathbf{R})\end{array}$ & Eigenvalue & $\begin{array}{c}\text { Wilk's } \\
\text { lambda }\end{array}$ & $\begin{array}{c}\text { Chi- } \\
\text { square }\end{array}$ & $\begin{array}{c}\text { p-level } \\
\text { (Sig.) }\end{array}$ \\
\hline Standard Mode & 1 & 0.972 & 17.208 & 0.007 & 438.145 & 0.000 \\
& 2 & 0.937 & 7.211 & 0.122 & 184.233 & 0.000 \\
Stepwise Mode & 1 & 0.968 & 14.869 & 0.009 & 431.305 & 0.000 \\
& 2 & 0.930 & 6.400 & 0.135 & 181.131 & 0.000 \\
\hline
\end{tabular}

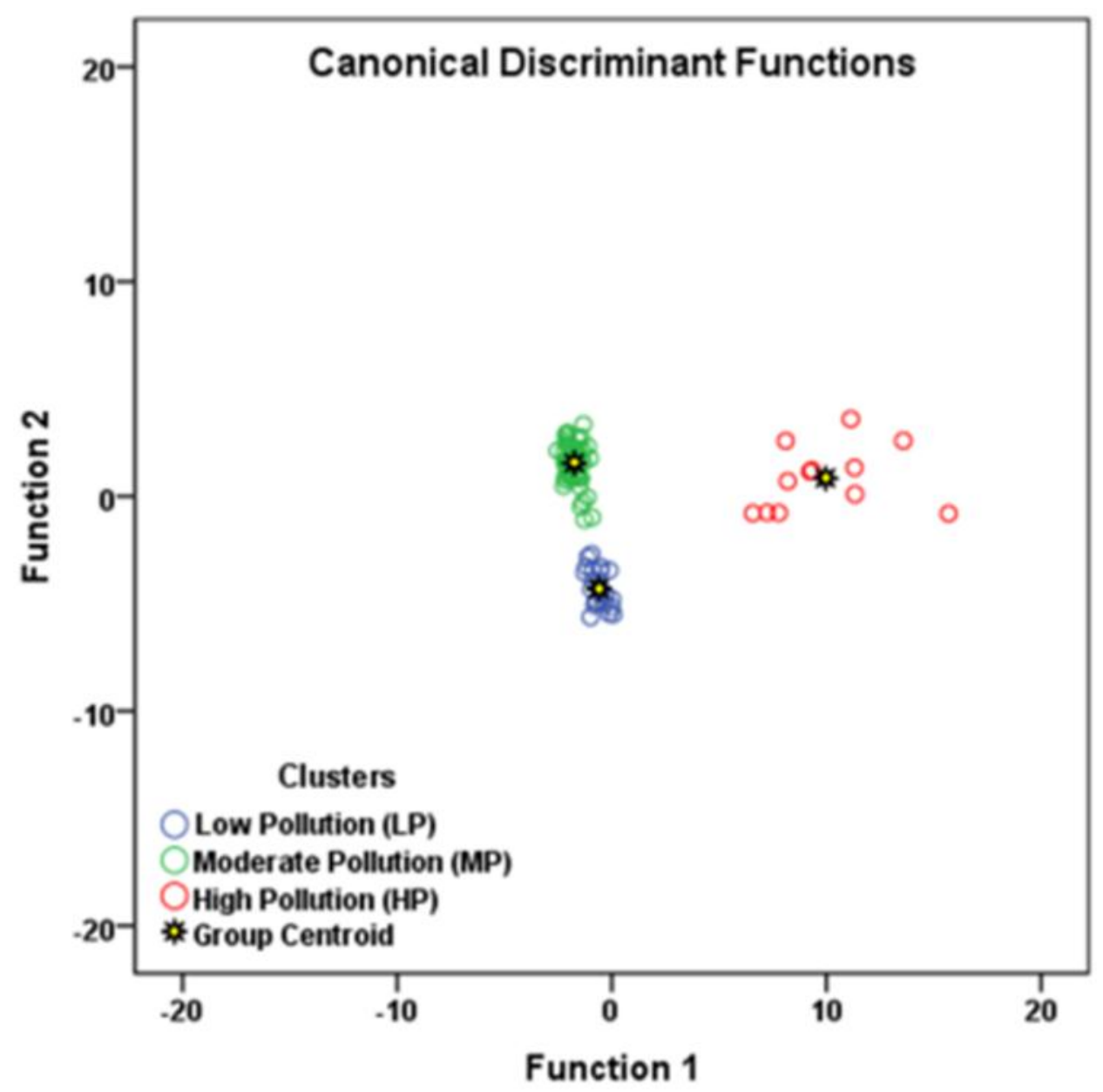

Figure 5.8. Scatter plot for the spatial discriminant analysis of water quality variations across three clusters in dry season (stepwise mode). 
Table 5.9. Classification functions coefficients (CFs) for the spatial discriminant analysis of water quality variations across three clusters in dry season.

\begin{tabular}{|c|c|c|c|c|c|c|}
\hline \multirow{2}{*}{ Parameter } & \multicolumn{3}{|c|}{ Standard mode } & \multicolumn{3}{|c|}{ Stepwise Mode } \\
\hline & LP coef. $^{\text {a }}$ & MP coef. ${ }^{a}$ & HP coef. ${ }^{a}$ & LP coef. ${ }^{a}$ & MP coef. ${ }^{\text {a }}$ & HP coef. ${ }^{a}$ \\
\hline Chl- $a$ & -0.480 & -0.371 & -0.405 & & & \\
\hline Dissolve Oxygen & 12.566 & 16.127 & 12.579 & 4.256 & 7.034 & 4.673 \\
\hline Total Kjeldahl Nitrogen & 80.086 & 33.217 & 31.081 & 102.327 & 59.963 & 56.968 \\
\hline Total Phosphorus & -152.124 & 70.166 & -350.641 & -299.948 & -68.309 & -192.963 \\
\hline Total Phosphate & -281.361 & -260.732 & 143.078 & & & \\
\hline Ammonia-N & 78.060 & 93.864 & 83.885 & & & \\
\hline Water Temperature & 6.297 & 6.773 & 5.608 & & & \\
\hline Total Suspended Solids & 0.046 & 0.142 & 0.151 & & & \\
\hline Turbidity & -0.970 & 0.086 & -0.518 & -2.213 & -1.152 & -1.329 \\
\hline Magnesium & -0.135 & -0.239 & 0.563 & 0.163 & 0.062 & 0.624 \\
\hline Chloride & 0.066 & 0.028 & 0.106 & 0.03 & -0.003 & 0.088 \\
\hline Sodium & 0.015 & 0.027 & 0.003 & & & \\
\hline (Constant) & -158.628 & -143.293 & -175.014 & -83.327 & -55.383 & -104.087 \\
\hline
\end{tabular}

${ }^{\mathrm{a}}$ Fisher's linear discriminant functions coefficients for three groups of sites correspond to $\mathrm{w}_{\mathrm{ij}}$ as defined in Eq. (5.2).

Table 5.10. Classification matrix $(\mathrm{CMs})$ for the spatial discriminant analysis in dry season.

\begin{tabular}{|c|c|c|c|c|}
\hline \multirow{2}{*}{$\begin{array}{l}\text { Monitoring } \\
\text { Clusters }\end{array}$} & \multirow{2}{*}{$\begin{array}{c}\% \\
\text { correct }\end{array}$} & \multicolumn{3}{|c|}{ Regions assigned by DA } \\
\hline & & $\mathbf{L P}$ & MP & HP \\
\hline \multicolumn{5}{|l|}{ Standard mode } \\
\hline $\mathbf{L P}$ & 100.0 & 24 & 0 & 0 \\
\hline MP & 98.3 & 1 & 59 & 0 \\
\hline $\mathbf{H P}$ & 100.0 & 0 & 0 & 12 \\
\hline Total & 99.0 & 2 & 59 & 12 \\
\hline \multicolumn{5}{|l|}{ Stepwise Mode } \\
\hline LP & 100.0 & 24 & 0 & 0 \\
\hline MP & 100.0 & 0 & 60 & 0 \\
\hline HP & 100.0 & 0 & 0 & 12 \\
\hline Total & 100.0 & 24 & 60 & 12 \\
\hline
\end{tabular}

Box and whisker plots of identified discriminating water quality parameters from stepwise spatial DA were used to study the patterns of water quality variations between three identified clusters of sampling sites in dry season (Figure 5.9). Three patterns recognized from spatial DA in dry season based on identified groups of sites in CA. The first pattern showed clear spatial differences for DO and turbidity, which a strong relationship (0.42) between them was observed from the resultant correlation matrix table 
of spatial DA in dry season. The higher average concentrations of these two variables, which are a measure of life's vitality and the water clarity, respectively, were found in MP region. It was also observed that these two variables make strong relationships with chl-a, which indicates the dynamism and strength of aquatic lives in this region. Besides, lower average concentrations of DO in the HP region indicated that there was much more serious organic pollution like the wet season.

The second pattern was related to average concentration of TKN that showed higher average concentrations in LP, MP, and HP regions, respectively, that indicates the significant role of land use for this parameter. As shown in Figure 5.3, the LP and MP regions are located at the upstream parts of rivers that are attributed to the agricultural areas with the significant use of nitrogenous fertilizers. It can come to the conclusion that the main source of TKN in water quality of studied rivers is the discharge of nitrogenous fertilizers coming from agricultural areas. The third pattern showed the expected trend of environment pollution problems from the LP region to HP region for total phosphorous (TP), magnesium, and chloride. Generally, in dry season the water quality of rivers in the HP sites (sites S154C and CES03), which are located in the areas that are under the influence of point source pollution discharges, were worse than other regions and hence more attention should be paid to this region. 

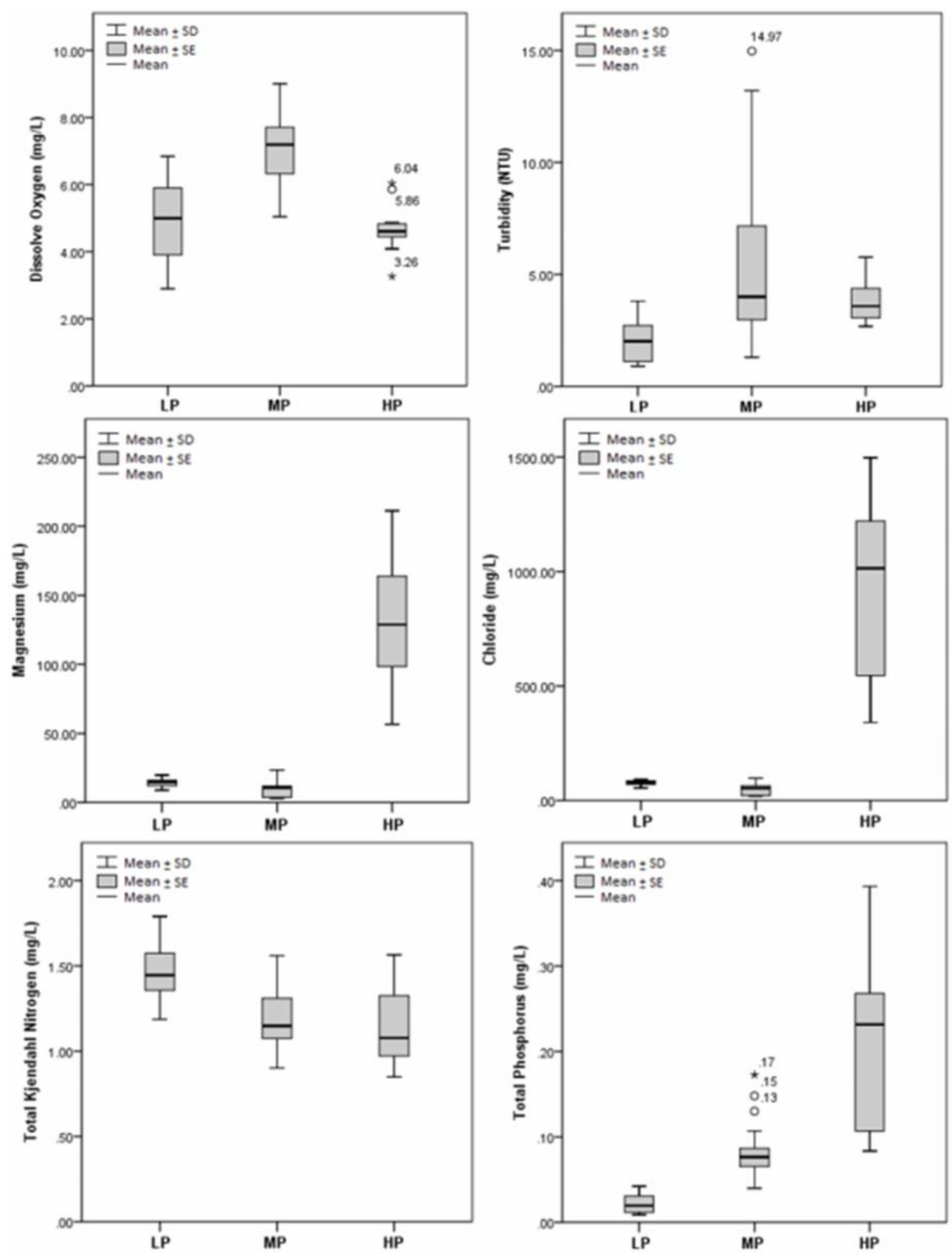

Figure 5.9. Spatial variations in water quality of three clusters of sites in dry season: DO, TKN, TP, turbidity, magnesium, and chloride. 


\section{Conclusion}

In this study, spatiotemporal variations in surface water quality of three major rivers of South Florida were evaluated using multivariate statistical techniques including cluster analysis (CA) and discriminant analysis (DA) using 15 years (2000-2014) datasets of 12 water quality variables covering 16 sampling stations, and about 35,000 observations were used. Agglomerative hierarchical CA grouped 16 monitoring sites into three groups (low pollution, moderate pollution, and high pollution) based on their similarity of water quality characteristics. The results of CA can be used to reduce the need for numerous sampling stations and frequency, and to optimize water quality monitoring program design with lower costs. In other words, in the future studies, the number of monitoring sites can be reduced by selecting only one site from each of the three groups.

Discriminant analysis (DA), as an important data reduction method, and cluster analysis (CA) were used to assess the water pollution status and analysis of its spatiotemporal variation. In temporal DA, 12 months of raw data divided into two seasonal groups (wet and dry season) as the dependent variable, while all observed water quality parameters were independent variables. In spatial DA, sixteen monitoring sites classified by CA to three groups of relatively low pollution (LP), moderate pollution (HP), and high pollution (HP) regions were the grouping (dependent) variables, whereas all the observed parameters constituted the independent variables. It was found by the stepwise DA that five variables (chl- $a, \mathrm{DO}, \mathrm{TKN}, \mathrm{TP}$ and water temperature) are the

most important discriminating water quality parameters responsible for temporal variations. In spatial DA, the stepwise mode identified seven variables (chl- $a$, DO, TKN, 
$\mathrm{TP}$, magnesium, chloride, and sodium) and six variables (DO, TKN, TP, turbidity, magnesium, and chloride) as the most important discriminating variables responsible for spatial variations in wet and dry season, respectively. Different patterns associated with spatial variations were identified depending on the variables and considered season, however the overall trend of environment pollution problems was found from the LP region to HP region. Nonetheless, two highly polluted sites of S154C and CES03 in Kissimmee River and Caloosahatchee River require more attention and considerations. The spatial DA using the identified groups of sites by CA confirmed the accuracy of cluster analysis results.

This study showed the feasibility and reliability of the combined use of these multivariate statistical techniques in river water quality research. It is desirable that both state and local agencies pay more attention and consideration in order to the improvement and protection of vulnerable river quality. Additional studies will be required to assess the variation of other important water quality parameters that were not analyzed in this study. The results also can be useful for water resources managers and decision makers in federal or local water quality protection organizations. The results of the spatial and temporal variations can be used to select the polluted areas and set the priority areas for the river water quality management in the study area.

\section{Acknowledgements}

This research was made possible by financial support that was provided by the Department of Civil and Environmental Engineering of Florida International University, Miami, U.S.A., through a Presidential Fellowship and a Graduate Assistantship to the 
main author. The observational data were obtained from South Florida Water Management District (SFWMD).

\section{References}

1. Carpenter, S.; Caraco, N.; Correll, D. ; Howarth, R. W.; Sharpley, A. N.; Smith, V. H. Nonpoint pollution of surface waters with phosphorus and nitrogen. Ecol. Appl. 1998, 8, 559-568.

2. Jarvie, H. P.; Whitton, B. A.; Neal, C. Nitrogen and phosphorus in east coast British rivers: Speciation, sources and biological significance. Sci. Total Environ. 1998, 210$211,79-109$.

3. Singh, K. P.; Malik, A.; Mohan, D.; Sinha, S. Multivariate statistical techniques for the evaluation of spatial and temporal variations in water quality of Gomti River (India) - A case study. Water Res. 2004, 38, 3980-3992.

4. Vega, M. Assessment of seasonal and polluting effects on the quality of river water by exploratory data analysis. Water Res. 1998, 32, 3581-3592.

5. Singh, K. P.; Malik, A.; Sinha, S. Water quality assessment and apportionment of pollution sources of Gomti river (India) using multivariate statistical techniques--a case study. Anal. Chim. Acta 2005, 538, 355-374.

6. Mustapha, A.; Aris, A. Z. Spatial aspects of surface water quality in the Jakara Basin, Nigeria using chemometric analysis. J. Environ. Sci. Health. A. Tox. Hazard. Subst. Environ. Eng. 2012, 47, 1455-65.

7. Simeonov, V.; Stratis, J. A.; Samara, C.; Zachariadis, G.; Voutsa, D.; Anthemidis, A.; Sofoniou, M.; Kouimtzis, T. Assessment of the surface water quality in Northern Greece. Water Res. 2003, 37, 4119-4124.

8. Juahir, H.; Zain, S. M.; Yusoff, M. K.; Hanidza, T. I. T.; Armi, A. S. M.; Toriman, M. E.; Mokhtar, M. Spatial water quality assessment of Langat River Basin (Malaysia) using environmetric techniques. Environ. Monit. Assess. 2011, 173, 625-641.

9. Shrestha, S.; Kazama, F. Assessment of surface water quality using multivariate statistical techniques: A case study of the Fuji river basin, Japan. Environ. Model. Softw. 2007, 22, 464-475.

10. Singh, S. P.; Sharma, N. K.; Sharma, B. K. Use of clustering to improve the standard of education system. Int. J. Appl. Inf. Syst. 2012, 1, 16-20.

11. Kowalkowski, T.; Zbytniewski, R.; Szpejna, J.; Buszewski, B. Application of chemometrics in river water classification. Water Res. 2006, 40, 744-752.

12. Wunderlin, A. D.; Díaz, M. D. P.; Amé, M. V.; Pesce, F. S.; Hued, A. C.; Bistoni, M. 
D. L. Á. Pattern recognition techniques for the evaluation of spatial and temporal variations in water quality. A case study: Suquía River basin (Córdoba-Argentina). Water Res. 2001, 35, 2881-2894.

13. Kim, J.-H.; Kim, R.-H.; Lee, J.; Cheong, T.-J.; Yum, B.-W.; Chang, H.-W. Multivariate statistical analysis to identify the major factors governing groundwater quality in the coastal area of Kimje, South Korea. Hydrol. Process. 2005, 19, 1261-1276.

14. Schaefer, K.; Einax, J. W. Analytical and chemometric characterization of the Cruces River in South Chile. Environ. Sci. Pollut. Res. 2010, 17, 115-123.

15. McPherson, B. F.; Hendrix, G. Y.; Klein, H.; Tyus, H. M. The environment of South Florida; a summary report; 1976.

16. Massart, D. L.; Kaufman, L. The interpretation of analytical chemical data by the use of cluster analysis; Wiley, 1983.

17. Chapter 4 Measures of distance between samples: Euclidean.

18. Willett, J. Similarity and clustering in chemical information systems; John Wiley \& Sons, Inc., 1987.

19. Johnson, R. A.; Wichern, D. W. Applied multivariate statistical analysis; Prentice hall Englewood Cliffs, NJ, 1992; Vol. 4.

20. ePermitting http://www.swfwmd.state.fl.us/permits/. 
CHAPTER VI

WATER QUALITY ASSESSMENT AND APPORTIONMENT OF POLLUTION SOURCES USING APCS-MLR AND PMF RECEPTOR MODELLING TECHNIQUES IN THREE MAJOR RIVERS OF SOUTH FLORIDA 


\section{Abstract}

In this study, principal component analysis (PCA), factor analysis (FA), the absolute principal component score-multiple linear regression (APCS-MLR) and the positive matrix factorization $(\mathrm{PMF})$ receptor modeling techniques were used to assess the water quality and identify and quantify the potential pollution sources affecting the water quality of three major rivers of South Florida. For this purpose, 15 years (2000-2014) dataset of 12 water quality variables covering 16 monitoring stations, and approximately 35,000 observations were used. The PCA/FA method identified five and four potential pollution sources in wet and dry seasons, respectively, and the effective mechanisms, rules and causes were explained. The APCS-MLR apportioned their contributions to each water quality variable. Results showed that the point source pollution discharges from anthropogenic factors due to the discharge of agriculture waste and domestic and industrial wastewater were the major sources of river water contamination. Also, the studied variables were categorized into three groups of nutrients (total kjeldahl nitrogen, total phosphorus, total phosphate, and ammonia-N), water murkiness conducive parameters (total suspended solids, turbidity, and chlorophyll-a), and salt ions (magnesium, chloride, and sodium), and average contributions of different potential pollution sources to these categories were considered separately. The data matrix was also subjected to PMF receptor model using the EPA PMF-5.0 program and the two-way model described were performed for the PMF analyses. Comparison of the obtained results of PMF and APCS-MLR models showed that there were some significant differences in estimated contribution for each potential pollution source, especially in the wet season. Eventually, it was concluded that the APCS-MLR receptor modeling approach appear to be more physically plausible for the current study. It is believed that 
the results of apportionment could be very useful to the local authorities for the control and management of pollution and better protection of important riverine water quality. Keywords: Water quality; Source apportionments; Pollutants; APCS-MLR; PMF; South Florida.

\section{Introduction}

Multivariate statistical techniques, such as principal component analysis (PCA) and factor analysis (FA), are widely used for the evaluation of spatiotemporal variations of water quality parameters, and also for the interpretation of large and complex datasets [3,5-19]. PCA/FA is a dimension-reduction technique that is generally used for data structure determination and provides further information from the hidden factors. PCA/FA can also provide qualitative information about potential pollution sources. However, PCA/FA alone cannot determine quantitative contributions of the identified pollution sources to each variable. Receptor-based models, such as APCS-MLR, can be used to apportion the contributions of the pre-identified potential pollution sources by PCA/FA. The application of this technique was primarily tested for the identification and apportionment of pollution source in atmospheric environments. In recent years, the application of APCS-MLR has been widely used to study the contribution of different pollution sources to water quality $[5,7,20-27]$.

Given the above considerations, the main purpose of this study is to obtain a deeper understanding of temporal variations and sources of water pollution in three major rivers of South Florida. A large data matrix obtained during a fifteen year (2000-2014) monitoring period at sixteen different sites for twelve water quality parameters, and in 
two wet and dry seasons (about 35,000 observations) were subjected to PCA/FA, APCSMLR and PMF techniques to (1) identify the latent factors explaining the structure of the database, and the influence of possible sources of pollution (natural and anthropogenic) on the water quality parameters, (2) estimate the contribution of possible sources of pollution on the concentration of selected parameters, and (3) comparison of PMF and APCS-MLR models for the Source apportionment in water quality studies. It is believed that the results of apportionment could be very useful to the local authorities for the control and management of pollution and better protection of important riverine water quality.

\section{Study area and methodology}

\subsection{Study area}

South Florida has an extensive network of canals that drain water from various agricultural productions and urban areas and carry different concentrations of chemicals, especially high concentrations of nutrients. These are biologically productive waterbodies contain various important aquatic lives include plants, animals, and microorganisms [28]. In this study, three major rivers in South Florida, the Miami Canal, Kissimmee River and Caloosahatchee River, are investigated for their water quality by applying different multivariate analysis techniques. The average annual temperature ranges from $19.2{ }^{\circ} \mathrm{C}$ to $28.7{ }^{\circ} \mathrm{C}$ and the annual rainfall in the entire area of South Florida is generally about 55 inches $(1,400 \mathrm{~mm})$. Considering the subtropical climate of South Florida, the average rainfall is still considerable in the dry season. In addition, during El Niño phenomenon, greater amounts of rainfall in dry season are observed in South Florida. The monthly flow discharge in the studied rivers was checked and it was found that there was not any 
significant variation between the rivers discharge in the wet and dry seasons. The major land uses in their watersheds include agricultural area, wetlands, cattle ranch and dairy farming, and urban areas. Figure 6.1 shows the location of the study area and the selected water quality monitoring sites on three major rivers of South Florida.
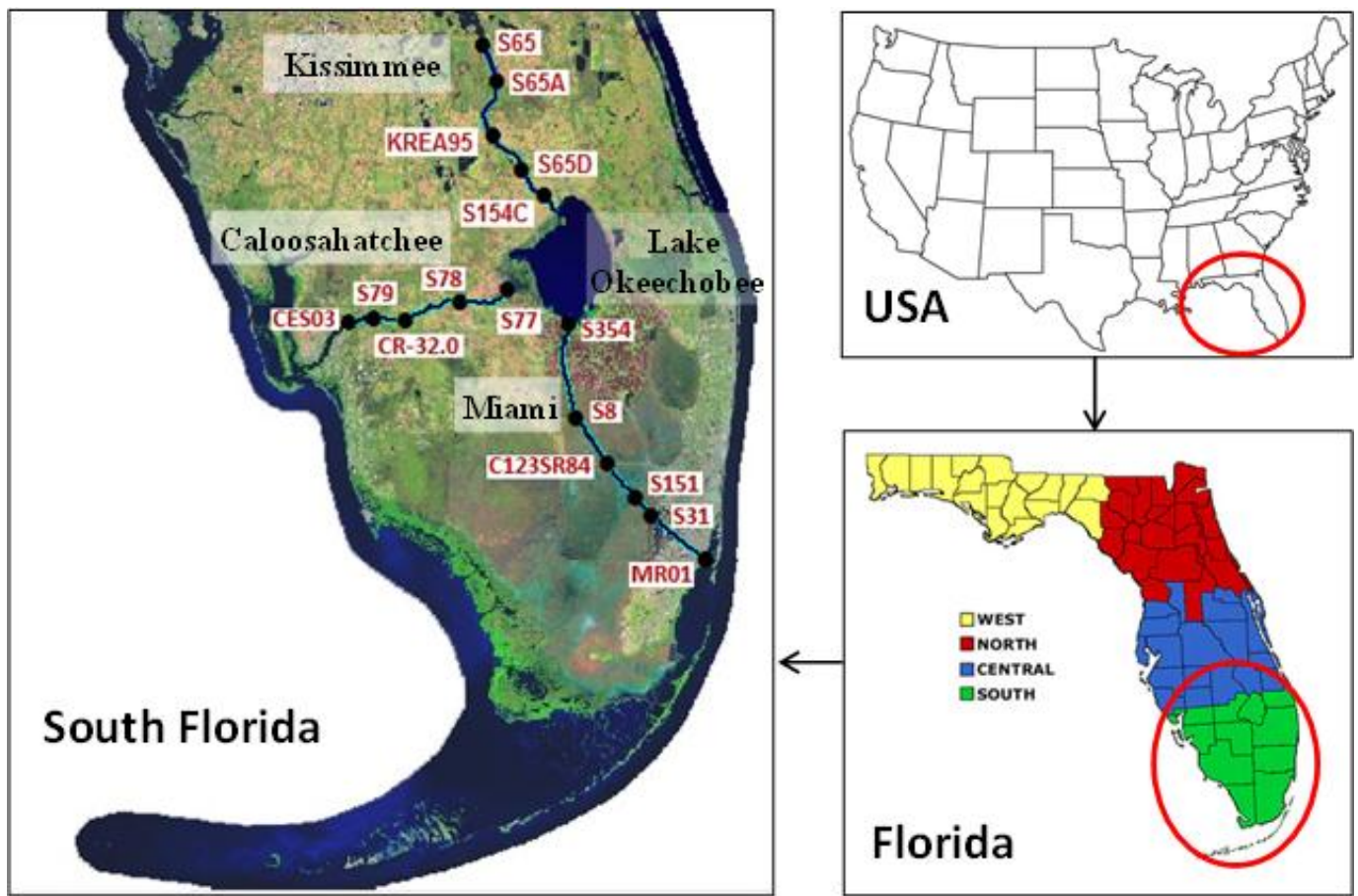

Figure 6.1. The location of the study area and the water quality monitoring sites.

\subsection{Dataset preparation}

The hydrography network of the study area, generated using the 1:24,000 national hydrography dataset (NHD) obtained from the South Florida water management district's (SFWMD) geographic information systems data catalog, was used to delineate the flow line of three selected rivers. The most recent (2008-09) land cover/land use map, provided by the SFWMD, was used in this study. This data was then clipped to fit our study area. The area of each type of land use within each watershed was calculated using an ESRI ArcGIS 10.0 platform. The monitoring stations, downloaded from the same 
source, were overlaid with rivers' map in ArcGIS to design a network of sampling stations that include sufficient historical data to construct a robust statistical database of studied parameters, considering a suitable spatial distribution on the river. Then, the DBHYDRO (environmental database of SFWMD) was used to obtain continuous time series data for 12 selected water quality parameters from 2000 to 2014 . This database was then divided into dry and wet seasons (the wet season lasts from May $15^{\text {th }}$ thru October $15^{\text {th }}$, and the dry season lasts from October $16^{\text {th }}$ thru May $\left.14^{\text {th }}\right)$. The selected water quality parameters for investigation in this study include chlorophyll- $a$ (chl- $a$ ), dissolved oxygen (DO), total kjeldahl nitrogen (TKN), total phosphorus (TP), total phosphate, ammonia-N, water temperature (WT), total suspended solids (TSS), turbidity, magnesium, chloride, and sodium. The basic statistics of water quality parameters in three major rivers of South Florida, based on 34,560 observations $(15$ years $\times 12$ months $\times 16$ sampling sites $\times 12$ parameters), are summarized in Table 6.1.

Successful applications of PCA to environmental datasets depend on the data pretreatment method employed and it is necessary to ensure the suitability of data. Due to differences in units of the studied water quality parameters in the dataset, pre-treatment of data is required. Although studies done by Moreda-Piñeiro et al. [29] and Reid and Spencer [30] have provided appropriate approach to the pre-treatment steps of data, there are other environmental studies [31,32], that provide limited information about data pretreatment steps used in their environmental applications using PCA. In this study, data pre-treatment methods, such as the elimination of non-informative variables, the treatment of missing data values, and the detection and treatment of outliers were performed before the PCA/FA analyses. 


\subsection{Method}

\subsubsection{Principal component analysis and factor analysis}

Principal component analysis is a mathematical tool that uses orthogonal transformation to convert a set of observations that are correlated that are called principal components (PCs) [33]. FA, which is closely related to PCA, is used to describe variability among observed variables that are correlated in order to reduce the number of unobserved variables that are known as factors [34]. PCA reduces the dimensionality of interrelated variables datasets with minimum loss of original information $[35,36]$. The principal component $(\mathrm{PC})$ can be expressed as:

$Z_{i j}=\alpha_{i 1} X_{1 j}+\alpha_{i 2} X_{2 j}+\alpha_{i 3} X_{3 j}+\ldots+\alpha_{i m} X_{m j}$

Where, $Z$ is the component score, $\alpha$ is the component loading, $X$ is the measured value of variable, $i$ is the component number, $j$ is the sample number, and $m$ is the total number of variables. In PCA, the PCs with eigenvalue greater than unity are generally considered and contain most of the variability of the original data set. 
Table 6.1. Summary of basic statistics of water quality parameters between 2000 and 2014

\begin{tabular}{|c|c|c|c|c|c|c|c|c|c|c|c|c|c|c|}
\hline $\begin{array}{l}\text { River/Canal } \\
\text { Name }\end{array}$ & $\begin{array}{c}\text { Site } \\
\text { Number }\end{array}$ & Statistics & $\begin{array}{c}\text { Chl- } \boldsymbol{a} \\
(\mu \mathrm{g} / \mathrm{L})\end{array}$ & $\underset{(\mathrm{mg} / \mathrm{L})}{\mathrm{DO}}$ & $\begin{array}{c}\text { TKN } \\
(\mathbf{m g} / \mathrm{L})\end{array}$ & $\begin{array}{c}\text { TP } \\
(\mathbf{m g} / \mathbf{L})\end{array}$ & $\begin{array}{c}\text { Total } \\
\text { Phosphate } \\
(\mathrm{mg} / \mathrm{L})\end{array}$ & $\underset{(\mathrm{mg} / \mathrm{L})}{\operatorname{Ammonia}-\mathbf{N}}$ & $\begin{array}{c}\text { WT } \\
\text { (DegC) }\end{array}$ & $\begin{array}{c}\text { TSS } \\
(\mathrm{mg} / \mathrm{L})\end{array}$ & $\begin{array}{c}\text { Turbidity } \\
\text { (NTU) }\end{array}$ & $\underset{(\mathrm{mg} / \mathrm{L})}{\text { Magnesium }}$ & $\begin{array}{c}\text { Chloride } \\
(\mathrm{mg} / \mathrm{L})\end{array}$ & $\begin{array}{c}\text { Sodium } \\
(\mathrm{mg} / \mathrm{L})\end{array}$ \\
\hline \multirow{20}{*}{$\begin{array}{l}\text { Kissimmee } \\
\text { River }\end{array}$} & \multirow{4}{*}{ S65 } & Min & 4.0 & 0.93 & 0.05 & 0.007 & 0.002 & 0.005 & 7.5 & 3.0 & 1.1 & 2.2 & 11.6 & 7.2 \\
\hline & & Mean & 23.7 & 6.93 & 1.13 & 0.070 & 0.056 & 0.016 & 24.1 & 7.8 & 5.2 & 3.7 & 21.5 & 11.9 \\
\hline & & $\operatorname{Max}$ & 63.0 & 12.10 & 2.04 & 0.515 & 0.515 & 0.133 & 33.1 & 71.5 & 26.7 & 5.4 & 34.0 & 18.1 \\
\hline & & SD & 10.8 & 1.71 & 0.24 & 0.045 & 0.046 & 0.015 & 5.1 & 5.7 & 2.5 & 0.8 & 4.6 & 2.5 \\
\hline & \multirow{4}{*}{ S65A } & Min & 1.2 & 0.58 & 0.05 & 0.016 & 0.004 & 0.005 & 12.0 & 1.0 & 1.0 & 1.7 & 3.9 & 5.0 \\
\hline & & Mean & 20.2 & 6.05 & 1.16 & 0.063 & 0.056 & 0.030 & 24.6 & 6.2 & 4.2 & 3.5 & 20.4 & 11.6 \\
\hline & & Max & 88.0 & 12.30 & 3.43 & 0.366 & 0.328 & 0.288 & 34.7 & 43.0 & 37.9 & 5.7 & 40.3 & 17.4 \\
\hline & & SD & 11.4 & 2.14 & 0.25 & 0.033 & 0.033 & 0.040 & 5.0 & 4.2 & 2.7 & 0.9 & 5.0 & 2.7 \\
\hline & \multirow{4}{*}{$\begin{array}{c}\text { KREA } \\
95\end{array}$} & Min & 1.9 & 0.20 & 0.05 & 0.032 & 0.002 & 0.005 & 12.1 & 3.0 & 1.6 & 2.2 & 6.3 & 6.8 \\
\hline & & Mean & 15.1 & 5.02 & 1.20 & 0.080 & 0.075 & 0.060 & 24.3 & 11.2 & 7.9 & 4.5 & 22.9 & 12.6 \\
\hline & & Max & 65.0 & 10.20 & 3.07 & 0.242 & 0.273 & 0.359 & 32.2 & 59.0 & 37.9 & 15.0 & 71.9 & 30.2 \\
\hline & & SD & 10.9 & 2.66 & 0.31 & 0.038 & 0.043 & 0.059 & 4.8 & 8.4 & 6.0 & 2.4 & 9.5 & 4.6 \\
\hline & \multirow{4}{*}{ S65D } & Min & 1.0 & 0.08 & 0.05 & 0.022 & 0.002 & 0.005 & 12.0 & 1.0 & 0.9 & 2.2 & 10.1 & 6.5 \\
\hline & & Mean & 11.3 & 5.27 & 1.13 & 0.077 & 0.073 & 0.044 & 24.4 & 4.7 & 3.5 & 3.7 & 20.8 & 11.8 \\
\hline & & Max & 223.6 & 10.40 & 3.03 & 0.398 & 0.721 & 0.489 & 33.5 & 45.0 & 19.9 & 5.9 & 34.7 & 17.2 \\
\hline & & SD & 15.1 & 2.39 & 0.28 & 0.044 & 0.045 & 0.054 & 4.6 & 3.7 & 2.0 & 0.8 & 4.1 & 2.2 \\
\hline & \multirow{4}{*}{ S154C } & Min & 1.1 & 0.14 & 0.05 & 0.060 & 0.002 & 0.005 & 11.3 & 1.0 & 0.6 & 14.0 & 63.5 & 95.9 \\
\hline & & Mean & 8.7 & 3.85 & 1.54 & 0.370 & 0.344 & 0.147 & 23.9 & 8.1 & 5.8 & 75.8 & 1125.4 & 417.7 \\
\hline & & Max & 69.3 & 11.70 & 4.29 & 2.290 & 2.290 & 1.279 & 33.5 & 181.0 & 135.0 & 186.4 & 2421.1 & 1017.0 \\
\hline & & SD & 7.5 & 2.55 & 0.75 & 0.296 & 0.292 & 0.227 & 4.9 & 12.6 & 11.2 & 49.5 & 525.6 & 270.6 \\
\hline
\end{tabular}


Table 6.1. (Continued) Summary of basic statistics of water quality parameters between 2000 and 2014

\begin{tabular}{|c|c|c|c|c|c|c|c|c|c|c|c|c|c|c|}
\hline $\begin{array}{l}\text { River/Canal } \\
\text { Name }\end{array}$ & $\begin{array}{c}\text { Site } \\
\text { Number }\end{array}$ & Statistics & $\begin{array}{l}\text { Chl- } a \\
(\mu \mathrm{g} / \mathrm{L})\end{array}$ & $\begin{array}{c}\text { DO } \\
(\mathbf{m g} / \mathrm{L})\end{array}$ & $\begin{array}{c}\text { TKN } \\
(\mathbf{m g} / \mathbf{L})\end{array}$ & $\begin{array}{c}\text { TP } \\
(\mathbf{m g} / \mathbf{L})\end{array}$ & $\begin{array}{c}\text { Total } \\
\text { Phosphate } \\
(\mathrm{mg} / \mathrm{L})\end{array}$ & $\underset{(\mathrm{mg} / \mathrm{L})}{\operatorname{Ammonia-N}}$ & $\begin{array}{c}\text { WT } \\
\text { (DegC) }\end{array}$ & $\begin{array}{c}\text { TSS } \\
(\mathbf{m g} / \mathrm{L})\end{array}$ & $\begin{array}{c}\text { Turbidity } \\
\text { (NTU) }\end{array}$ & $\begin{array}{c}\text { Magnesium } \\
(\mathrm{mg} / \mathrm{L})\end{array}$ & $\begin{array}{c}\text { Chloride } \\
\text { (mg/L) }\end{array}$ & $\begin{array}{c}\text { Sodium } \\
(\mathrm{mg} / \mathrm{L})\end{array}$ \\
\hline \multirow{20}{*}{$\begin{array}{l}\text { Caloosahatchee } \\
\text { River }\end{array}$} & \multirow{4}{*}{ S77 } & Min & 1.0 & 0.26 & 0.88 & 0.006 & 0.002 & 0.005 & 9.7 & 1.6 & 1.2 & 2.6 & 5.1 & 7.0 \\
\hline & & Mean & 19.0 & 5.70 & 1.50 & 0.100 & 0.087 & 0.068 & 25.5 & 13.3 & 10.0 & 11.0 & 52.9 & 32.1 \\
\hline & & Max & 181.0 & 13.10 & 6.39 & 0.838 & 0.838 & 0.304 & 36.3 & 158.0 & 71.4 & 19.1 & 108.2 & 59.0 \\
\hline & & SD & 27.6 & 2.42 & 0.47 & 0.076 & 0.074 & 0.058 & 4.7 & 14.6 & 11.2 & 3.0 & 16.8 & 9.4 \\
\hline & \multirow{4}{*}{ S78 } & Min & 1.0 & 0.63 & 0.88 & 0.010 & 0.043 & 0.005 & 14.3 & 1.0 & 1.1 & 6.1 & 27.0 & 15.5 \\
\hline & & Mean & 5.5 & 5.99 & 1.30 & 0.100 & 0.108 & 0.060 & 25.6 & 6.1 & 4.8 & 10.1 & 52.5 & 29.6 \\
\hline & & Max & 31.0 & 12.50 & 2.72 & 0.561 & 0.840 & 0.304 & 32.9 & 36.0 & 24.9 & 18.2 & 133.3 & 73.4 \\
\hline & & SD & 6.6 & 2.16 & 0.22 & 0.056 & 0.056 & 0.058 & 4.3 & 5.0 & 4.3 & 2.4 & 15.6 & 8.8 \\
\hline & \multirow{4}{*}{ CR-32.0 } & Min & 0.7 & 1.53 & 0.95 & 0.053 & 0.047 & 0.005 & 15.7 & 2.0 & 0.8 & 6.4 & 34.0 & 20.0 \\
\hline & & Mean & 10.8 & 5.29 & 1.41 & 0.140 & 0.113 & 0.052 & 25.7 & 5.9 & 4.0 & 10.9 & 57.2 & 33.1 \\
\hline & & Max & 49.0 & 9.45 & 2.00 & 0.490 & 0.757 & 0.596 & 31.4 & 20.0 & 13.7 & 17.4 & 120.0 & 57.6 \\
\hline & & SD & 11.2 & 2.04 & 0.26 & 0.080 & 0.053 & 0.058 & 4.0 & 4.0 & 3.4 & 2.7 & 17.4 & 8.4 \\
\hline & \multirow{4}{*}{ S79 } & Min & 0.5 & 0.91 & 0.81 & 0.028 & 0.050 & 0.005 & 15.0 & 1.4 & 0.1 & 5.6 & 3.3 & 1.1 \\
\hline & & Mean & 12.9 & 6.65 & 1.18 & 0.113 & 0.118 & 0.045 & 25.8 & 5.0 & 2.0 & 11.8 & 76.8 & 42.9 \\
\hline & & Max & 370.0 & 12.20 & 4.67 & 0.311 & 0.673 & 0.887 & 33.1 & 14.0 & 17.7 & 38.4 & 451.0 & 248.6 \\
\hline & & SD & 21.9 & 2.05 & 0.29 & 0.047 & 0.051 & 0.058 & 4.1 & 2.3 & 2.3 & 4.8 & 61.4 & 34.2 \\
\hline & \multirow{4}{*}{ CES03 } & Min & 1.0 & 0.04 & 0.30 & 0.037 & 0.010 & 0.031 & 14.7 & 1.0 & 0.6 & 4.8 & 4.0 & 11.7 \\
\hline & & Mean & 12.7 & 5.45 & 1.07 & 0.185 & 0.132 & 0.049 & 26.4 & 9.0 & 3.7 & 110.4 & 554.8 & 199.2 \\
\hline & & Max & 133.0 & 13.38 & 2.35 & 0.810 & 0.680 & 0.063 & 34.4 & 66.5 & 17.1 & 793.0 & 12500.0 & 1350.0 \\
\hline & & SD & 15.0 & 2.27 & 0.28 & 0.136 & 0.073 & 0.012 & 3.8 & 9.9 & 3.1 & 149.3 & 1484.3 & 284.2 \\
\hline
\end{tabular}


Table 6.1. (Continued) Summary of basic statistics of water quality parameters between 2000 and 2014

\begin{tabular}{|c|c|c|c|c|c|c|c|c|c|c|c|c|c|c|}
\hline $\begin{array}{l}\text { River/Canal } \\
\text { Name }\end{array}$ & $\begin{array}{c}\text { Site } \\
\text { Number }\end{array}$ & Statistics & $\begin{array}{c}\text { Chl-a } \\
(\mu \mathrm{g} / \mathrm{L})\end{array}$ & $\underset{(\mathrm{mg} / \mathrm{L})}{\mathrm{DO}}$ & $\begin{array}{c}\text { TKN } \\
(\mathbf{m g} / \mathrm{L})\end{array}$ & $\begin{array}{c}\mathbf{T P} \\
(\mathbf{m g} / \mathbf{L})\end{array}$ & $\begin{array}{c}\text { Total } \\
\text { Phosphate } \\
(\mathrm{mg} / \mathrm{L})\end{array}$ & $\underset{(\mathrm{mg} / \mathrm{L})}{\operatorname{Ammonia}-\mathbf{N}}$ & $\begin{array}{c}\text { WT } \\
\text { (DegC) }\end{array}$ & $\begin{array}{c}\text { TSS } \\
(\mathbf{m g} / \mathrm{L})\end{array}$ & $\begin{array}{c}\text { Turbidity } \\
\text { (NTU) }\end{array}$ & $\underset{(\mathrm{mg} / \mathrm{L})}{\text { Magnesium }}$ & $\begin{array}{c}\text { Chloride } \\
(\mathrm{mg} / \mathrm{L})\end{array}$ & $\begin{array}{c}\text { Sodium } \\
(\mathrm{mg} / \mathrm{L})\end{array}$ \\
\hline \multirow{24}{*}{$\begin{array}{l}\text { Miami } \\
\text { Canal }\end{array}$} & \multirow{4}{*}{ S354 } & Min & 1.0 & 0.26 & 0.88 & 0.006 & 0.002 & 0.005 & 9.7 & 1.6 & 1.2 & 2.6 & 5.1 & 7.0 \\
\hline & & Mean & 19.0 & 5.70 & 1.50 & 0.100 & 0.087 & 0.068 & 25.5 & 13.3 & 10.0 & 11.0 & 52.9 & 32.1 \\
\hline & & $\operatorname{Max}$ & 181.0 & 13.10 & 6.39 & 0.838 & 0.838 & 0.304 & 36.3 & 158.0 & 71.4 & 19.1 & 108.2 & 59.0 \\
\hline & & $\mathrm{SD}$ & 27.6 & 2.42 & 0.47 & 0.076 & 0.074 & 0.058 & 4.7 & 14.6 & 11.2 & 3.0 & 16.8 & 9.4 \\
\hline & \multirow{4}{*}{ S8 } & Min & 1.0 & 0.63 & 0.88 & 0.010 & 0.043 & 0.005 & 14.3 & 1.0 & 1.1 & 6.1 & 27.0 & 15.5 \\
\hline & & Mean & 5.5 & 5.99 & 1.30 & 0.100 & 0.108 & 0.060 & 25.6 & 6.1 & 4.8 & 10.1 & 52.5 & 29.6 \\
\hline & & $\operatorname{Max}$ & 31.0 & 12.50 & 2.72 & 0.561 & 0.840 & 0.304 & 32.9 & 36.0 & 24.9 & 18.2 & 133.3 & 73.4 \\
\hline & & SD & 6.6 & 2.16 & 0.22 & 0.056 & 0.056 & 0.058 & 4.3 & 5.0 & 4.3 & 2.4 & 15.6 & 8.8 \\
\hline & \multirow{4}{*}{ C123SR84 } & Min & 0.7 & 1.53 & 0.95 & 0.053 & 0.047 & 0.005 & 15.7 & 2.0 & 0.8 & 6.4 & 34.0 & 20.0 \\
\hline & & Mean & 10.8 & 5.29 & 1.41 & 0.140 & 0.113 & 0.052 & 25.7 & 5.9 & 4.0 & 10.9 & 57.2 & 33.1 \\
\hline & & $\operatorname{Max}$ & 49.0 & 9.45 & 2.00 & 0.490 & 0.757 & 0.596 & 31.4 & 20.0 & 13.7 & 17.4 & 120.0 & 57.6 \\
\hline & & SD & 11.2 & 2.04 & 0.26 & 0.080 & 0.053 & 0.058 & 4.0 & 4.0 & 3.4 & 2.7 & 17.4 & 8.4 \\
\hline & \multirow{4}{*}{ S151 } & Min & 0.5 & 0.91 & 0.81 & 0.028 & 0.050 & 0.005 & 15.0 & 1.4 & 0.1 & 5.6 & 3.3 & 1.1 \\
\hline & & Mean & 12.9 & 6.65 & 1.18 & 0.113 & 0.118 & 0.045 & 25.8 & 5.0 & 2.0 & 11.8 & 76.8 & 42.9 \\
\hline & & Max & 370.0 & 12.20 & 4.67 & 0.311 & 0.673 & 0.887 & 33.1 & 14.0 & 17.7 & 38.4 & 451.0 & 248.6 \\
\hline & & SD & 21.9 & 2.05 & 0.29 & 0.047 & 0.051 & 0.058 & 4.1 & 2.3 & 2.3 & 4.8 & 61.4 & 34.2 \\
\hline & \multirow{4}{*}{ S31 } & Min & 1.0 & 0.04 & 0.30 & 0.037 & 0.010 & 0.031 & 14.7 & 1.0 & 0.6 & 4.8 & 4.0 & 11.7 \\
\hline & & Mean & 12.7 & 5.45 & 1.07 & 0.185 & 0.132 & 0.049 & 26.4 & 9.0 & 3.7 & 110.4 & 554.8 & 199.2 \\
\hline & & $\operatorname{Max}$ & 133.0 & 13.38 & 2.35 & 0.810 & 0.680 & 0.063 & 34.4 & 66.5 & 17.1 & 793.0 & 12500.0 & 1350.0 \\
\hline & & SD & 15.0 & 2.27 & 0.28 & 0.136 & 0.073 & 0.012 & 3.8 & 9.9 & 3.1 & 149.3 & 1484.3 & 284.2 \\
\hline & \multirow{4}{*}{ MR01 } & Min & 0.6 & 0.61 & 0.15 & 0.150 & 0.002 & 0.020 & 12.14 & 0.8 & 0.1 & 7.0 & 38.0 & 26.0 \\
\hline & & Mean & 17.6 & 5.14 & 1.08 & 1.082 & 0.069 & 0.100 & 25.99 & 19.9 & 2.2 & 10.6 & 59.1 & 39.6 \\
\hline & & Max & 68.0 & 10.71 & 2.40 & 2.400 & 0.160 & 0.230 & 33.14 & 102.0 & 14.0 & 20.4 & 140.0 & 81.0 \\
\hline & & SD & 16.3 & 1.40 & 0.55 & 0.548 & 0.049 & 0.038 & 3.55 & 27.3 & 2.4 & 2.2 & 12.2 & 7.3 \\
\hline
\end{tabular}


Since the factor original loadings may not be readily interpretable and are usually rotated until a "simple structure" is achieved, that means each variable has very high factor loadings (as high as 1) on one of the PCs and very low factor loadings (as low as 0 ) on the other PCs. This process is known as FA, which follows PCA, and constructed new variables are also called varifactors (VFs). In this study, PCA/FA was performed on the normalized variables in the wet and dry seasons. The varimax rotation method is widely used in the literature because it maximizes the sum of the squared loadings for each component, and thus, was also used in this study [7,24,37-39]. The FA can be expressed as:

$Z_{i j}=\alpha_{f 1} f_{1 i}+\alpha_{f 2} f_{2 i}+\alpha_{f 3} f_{3 i}+\ldots+\alpha_{f m} f_{m i}+e_{f i}$

Where, $Z$ is the component score, $\alpha$ is the component loading, $f$ is the factor score, $e$ is the residual term accounting for errors or other source of variation, $i$ is the sample number, and $m$ is the total number of variables. Kaiser-Meyer-Olkin (KMO) and Bartlett's Test were used to test if $k$ samples were from populations with equal variances. They were applied on the dataset to test the null hypothesis, $\mathrm{H}_{0}$ that all $k$ population variances were equal against the alternative that at least two were different. The KMO statistic varies between 0 and 1 . Kaiser (1974) recommends accepting values greater than 0.5 is acceptable. Furthermore, Hutcheson and Sofroniou [41] stated that values between 0.5 and 0.7 are moderate, values between 0.7 and 0.8 are good, values between 0.8 and 0.9 are great, and values above 0.9 are superb. The Kaiser Rule and Scree Plots were used as the sole cut-off criterion for estimating the number of factors. The Kaiser rule drops all components with eigenvalues under 1.0. 


\subsubsection{Source apportionment using APCS-MLR receptor modeling technique}

A combination of the multiple linear regression model (MLR) and the absolute principal component scores (APCS) are the basis of the receptor modeling approach for the apportionment of different sources. In this model all possible pollution sources contribute linearly to the concentration of the studied water quality variable at the receptor site [42]. The APCS is generally used for the estimation of the contribution of possible pollution sources to each water quality parameter [43]. As mentioned, the resultant factor scores from PCA/FA cannot be used directly for the quantitative estimation of source contributions and apportionment, because it is performed on ztransformed normalized variables. These normalized factor scores then should be rescaled and converted to un-normalized APCS values required for the apportionment process. A detailed description of the receptor model and the procedure of calculations is given by Thurston and Spengler [44]. The source contributions to pollutant's concentration $\left(C_{j}\right)$ can be calculated by using a multiple linear regression as:

$C_{j}=\left(r_{0}\right)_{j}+\sum_{L_{k=1}}^{\urcorner^{F}} r_{k j} \times A P C S_{k}$

Where, $\left(r_{0}\right)_{j}$ is constant term of multiple regressions for pollutant $j$ (average contribution of the $j^{\text {th }}$ pollutant from sources not determined by PCA/FA), $r_{k j}$ is coefficient of multiple regression of the source $k$ for pollutant $j, A P C S_{k}$ is scaled value of the rotated factor $\mathrm{k}$ for the considered sample. The combined term $r_{k j} \times$ $A P C S_{k}$ represents the contribution of source $\mathrm{k}$ to $C_{j}$. Moreover, the mean of the product $r_{k j} \times A P C S_{k}$ on all samples represents the average contribution of the sources $(N)$. Quantitative contributions from each each identified source and for each individual water 
quality parameters can be compared with their original measured values to examine the accuracy of calculations. The values for $C_{j},\left(r_{0}\right)_{j}$, and $r_{k j}$ have the dimensions of the original concentration measurements [5].

In APCS-MLR, the source contribution estimates can be negative [45]. Factor loadings from the results of PCA/FA vary from -1 to 1 , which those loadings close to -1 or 1 are the strongest loadings, and loadings close to zero are weak loadings that effect on the variable. The sign and direction of the loading is taken into account to interpret the relationship of a variable to the factor. Negative signs imply an inverse relationship to the factor and vary inversely to other variables that have positive loadings. Similar meanings apply to interpret the contributions of identified potential pollution sources by APCSMLR. However, the existence of these negative contributions, despite being right, might lead to confusion in the interpretation and analysis of the source apportionment results. As an example, in a study performed by Guo et al. [46] negative contributions are obtained for some pollution sources, which has resulted in observed contribution values more than 100 percent for other pollution sources of a variable. In addition, it was observed from literature that in a large number of the studies negative contributions were ignored. This matter may affect the accuracy and precision of source apportionment calculations.

To overcome this issue, a new approach is presented in this study to change the negative percentages to positive quantities, while correctly taking their contributions into account. Consider a hypothetical case with two high contribution loadings of 0.85 and -0.85, which have equal contribution values but in inverse directions, and with a summation equal to zero. An instant error will happen in this case by getting a division 
by zero when calculating the percentage of each factor (i.e. $0.85 \times 100 / 0$ ). The difference between the two numbers can be used as the basis to find the solution. For example, the difference of 0.85 and -0.85 is 1.7 . Therefore, the positive loading ( 0.85$)$ contributes to $50 \%(0.85 \times 100 / 1.7)$. Therefore, the absolute function of negative loading $(-0.85)$ can be used to obtain the same contribution percentage equal to $50 \%$ ([abs $(-0.85) \times 100] / 1.7)$. The difference method also can be used when more than two numbers are considered in the calculations [47]. Therefore, the percentage contributions of $n$ potential pollution sources (S) using the absolute function of all loadings (positive and negative) can be computed as:

$\left(a b s\left(S_{1}\right) \times 100\right) /\left(a b s\left(S_{2}\right)+a b s\left(S_{3}\right)+a b s\left(S_{4}\right)+\ldots+a b s\left(S_{n}\right)\right)$

$\left(a b s\left(S_{2}\right) \times 100\right) /\left(a b s\left(S_{1}\right)+a b s\left(S_{3}\right)+a b s\left(S_{4}\right)+\ldots+a b s\left(S_{n}\right)\right)$

$\left(a b s\left(S_{3}\right) \times 100\right) /\left(a b s\left(S_{1}\right)+a b s\left(S_{2}\right)+a b s\left(S_{4}\right)+\ldots+a b s\left(S_{n}\right)\right)$

$\left(a b s\left(S_{n}\right) \times 100\right) /\left(a b s\left(S_{1}\right)+a b s\left(S_{2}\right)+a b s\left(S_{3}\right)+\ldots+a b s\left(S_{n-1}\right)\right)$

The feasibility of APCS-MLR model in water quality studies compared to its applications in air quality is still a new concept [42]. Researches that utilized its potential in hydrological examinations showed its significant effectiveness in water quality evaluations. Assessment of the contributions of possible pollution sources to the quantities of aquatic pollutants is an essential requirement for the strategic management of precious freshwater resources. Therefore, it is highly recommended that even small contributions of factors be accounted. 


\subsubsection{Source apportionment using PMF model}

The Positive Matrix Factorization (PMF) model, which is considered as a multivariate factor analysis, breaks down a dataset into two matrices of factor contributions and factor profiles, and explicitly addresses the problem of non-optimal scaling [48]. PMF is also one of the models that developed by the US EPA for source apportionment [49-54]. A detailed description of the PMF model is given by Paatero and Tapper [55]. The main idea of these receptor models is to measure the species concentrations and source profiles, as shown in equation 6.5:

$x_{i j}=\sum_{K=1}^{P} g_{i k} f_{k j}+e_{i j}$

Where, $p$ is the number of factors, $f$ is the species profile for each pollution source, $g$ is the amount of mass contributed by each factor to each individual sample, and $e_{i j}$ is the residual for each sample/species. The most critical decision required for the interpretation of the PMF results is choosing the best modeled number of factors for a dataset [56]. There are several qualitative metrics for making the determination of the number of factors. In this study, the number of factors, $p$, in the real dataset was defined based on the results of PCA/FA in order to make the comparison between PMF and APCS-MLR more reasonable. Possible pollution sources of each factor were determined by using relationship among variables and their percentage of contribution in the same group. The advantage of PMF is its capability to weight each data point, individually. In this study, the uncertainty for each variable estimated by the DBHYDRO (environmental database of SFWMD) was used as the input uncertainty data file. In general, the nonnegativity restriction alone is not adequate to produce a unique solution. An infinite 
number of plausible solutions may be generated and cannot be simply disqualified using mathematical algorithms. Rotating a given solution and evaluating how the rotated results fill the solution space is one approach to reduce the number of solutions.

Additional information, such as known source contributions and/or source compositions, can also be used to reduce the number of solutions and to determine whether one solution is more physically realistic than other solutions. Mathematically, the process of rotation include the transformation of a pair of factor matrices $(\mathrm{G}$ and $\mathrm{F})$ to another pair of matrices $\left(\mathrm{G}^{*}\right.$ and $\left.\mathrm{F}^{*}\right)$ with the same Q-value [57]. It is well known that source apportionment results for environmental data were always unpredictable and difficult to judge. Thus, it is essential to perform source apportionment with more than one model, as the validity of a conclusion can be increased after the results from different models are compared. In this study, U.S. EPA PMF-5.0 model was used to compare the results of PMF with the results of APCS-MLR and to enhance the validity of the source apportionment results.

\section{Results and discussion}

\subsection{Data structure determination using PCA and FA}

Before performing PCA and FA, the Kolmogorov-Smirnov (K-S) statistics were used to test the goodness-of-fit of the data to log-normal distribution. According to the $\mathrm{K}-\mathrm{S}$ test, all the variables are log-normally distributed with $95 \%$ or higher confidence. Also, to examine the suitability of the data for PCA/FA, KMO and Bartlett's sphericity, tests were applied on the dataset prepared for wet and dry seasons. KMO values for the wet season and dry season were 0.631 and 0.709 , respectively. Similarly, Bartlett's test of sphericity values were 1,009 and $704(\mathrm{p}<0.05)$, respectively, indicating that there may be 
a statistically significant interrelationship between variables and the appropriateness of the PCA/FA analysis was valid. To reduce the overlap of original variables over each PC, varimax rotation method was conducted.

The normalized data matrices were used for the PCA/FA analysis. Table 6.2 and 6.3 represent the determined initial PCs, their eigenvalues and cumulative $\%$ of variance contributed in each PC for wet and dry seasons, respectively. Based on the Kaiser Rule, the first five and four principal components are obtained with eigenvalue $>1$ for wet and dry seasons, summing $85 \%$ and $74 \%$ of the total variance in the water quality dataset, respectively. Equal numbers of VFs were obtained for two seasons through FA performed on the PCs. Corresponding VFs loadings for 12 selected variables are presented in Table 6.4. According to Liu et al. (2003) and Huang et al. (2010), factor loadings $>0.75,[0.50-0.75]$, and $[0.30-0.50]$ were considered to be strong, moderate, and weak loadings, respectively.

Table 6.2. Total variance explained in wet season.

\begin{tabular}{|c|c|c|c|c|c|c|c|c|c|}
\hline \multirow{2}{*}{ Component } & \multicolumn{3}{|c|}{ Initial Eigenvalues } & \multicolumn{3}{|c|}{$\begin{array}{c}\text { Extraction Sums of Squared } \\
\text { Loadings }\end{array}$} & \multicolumn{3}{|c|}{$\begin{array}{l}\text { Rotation Sums of Squared } \\
\text { Loadings }\end{array}$} \\
\hline & Total & $\begin{array}{c}\% \text { of } \\
\text { Variance }\end{array}$ & $\begin{array}{c}\text { Cumulative } \\
\%\end{array}$ & Total & $\begin{array}{c}\% \text { of } \\
\text { Variance }\end{array}$ & $\begin{array}{c}\text { Cumulative } \\
\%\end{array}$ & Total & $\begin{array}{c}\% \text { of } \\
\text { Variance }\end{array}$ & $\begin{array}{c}\text { Cumulative } \\
\%\end{array}$ \\
\hline 1 & 4.569 & 38.071 & 38.071 & 4.569 & 38.071 & 38.071 & 3.906 & 32.550 & 32.550 \\
\hline 2 & 2.205 & 18.378 & 56.449 & 2.205 & 18.378 & 56.449 & 2.042 & 17.019 & 49.569 \\
\hline 3 & 1.225 & 10.212 & 66.660 & 1.225 & 10.212 & 66.660 & 1.688 & 14.066 & 63.634 \\
\hline 4 & 1.169 & 9.743 & 76.404 & 1.169 & 9.743 & 76.404 & 1.326 & 11.052 & 74.687 \\
\hline 5 & 1.006 & 8.379 & 84.783 & 1.006 & 8.379 & 84.783 & 1.212 & 10.096 & 84.783 \\
\hline 6 & 0.577 & 4.806 & 89.589 & & & & & & \\
\hline 7 & 0.535 & 4.459 & 94.048 & & & & & & \\
\hline 8 & 0.347 & 2.893 & 96.941 & & & & & & \\
\hline 9 & 0.225 & 1.874 & 98.814 & & & & & & \\
\hline 10 & 0.085 & 0.707 & 99.521 & & & & & & \\
\hline 11 & 0.048 & 0.397 & 99.918 & & & & & & \\
\hline 12 & 0.010 & 0.082 & 100.000 & & & & & & \\
\hline
\end{tabular}


Table 6.3. Total variance explained in dry season.

\begin{tabular}{|c|c|c|c|c|c|c|c|c|c|}
\hline \multirow{2}{*}{ Component } & \multicolumn{3}{|c|}{ Initial Eigenvalues } & \multicolumn{3}{|c|}{$\begin{array}{c}\text { Extraction Sums of Squared } \\
\text { Loadings }\end{array}$} & \multicolumn{3}{|c|}{$\begin{array}{c}\text { Rotation Sums of Squared } \\
\text { Loadings }\end{array}$} \\
\hline & Total & $\begin{array}{c}\% \text { of } \\
\text { Variance }\end{array}$ & $\begin{array}{c}\text { Cumulative } \\
\%\end{array}$ & Total & $\begin{array}{c}\% \text { of } \\
\text { Variance }\end{array}$ & $\begin{array}{c}\text { Cumulative } \\
\%\end{array}$ & Total & $\begin{array}{c}\% \text { of } \\
\text { Variance }\end{array}$ & $\begin{array}{c}\text { Cumulative } \\
\%\end{array}$ \\
\hline 1 & 4.347 & 36.221 & 36.221 & 4.347 & 36.221 & 36.221 & 4.19 & 34.965 & 34.965 \\
\hline 2 & 2.207 & 18.392 & 54.613 & 2.207 & 18.392 & 54.613 & 2.03 & 16.968 & 51.933 \\
\hline 3 & 1.341 & 11.179 & 65.791 & 1.341 & 11.179 & 65.791 & 1.54 & 12.902 & 64.835 \\
\hline 4 & 1.016 & 8.466 & 74.257 & 1.016 & 8.466 & 74.257 & 1.13 & 9.422 & 74.257 \\
\hline 5 & 0.919 & 7.655 & 81.912 & & & & & & \\
\hline 6 & 0.684 & 5.704 & 87.616 & & & & & & \\
\hline 7 & 0.468 & 3.900 & 91.515 & & & & & & \\
\hline 8 & 0.424 & 3.532 & 95.047 & & & & & & \\
\hline 9 & 0.242 & 2.016 & 97.063 & & & & & & \\
\hline 10 & 0.188 & 1.565 & 98.628 & & & & & & \\
\hline 11 & 0.119 & 0.988 & 99.616 & & & & & & \\
\hline 12 & 0.046 & 0.384 & 100.000 & & & & & & \\
\hline
\end{tabular}

Table 6.4. Factor loadings of 12 selected variables on varimax rotated factors of different seasons in three major rivers of South Florida.

\begin{tabular}{|c|c|c|c|c|c|c|c|c|c|}
\hline \multirow{2}{*}{ Parameters } & \multicolumn{5}{|c|}{ Wet Season } & \multicolumn{4}{|c|}{ Dry Season } \\
\hline & VF1 & VF2 & VF3 & VF4 & VF5 & VF1 & VF2 & VF3 & VF4 \\
\hline Chl $-a$ & -0.076 & 0.708 & 0.088 & 0.050 & 0.495 & -0.095 & 0.769 & -0.030 & -0.151 \\
\hline Dissolved Oxygen & 0.063 & 0.862 & -0.220 & -0.049 & -0.024 & -0.283 & 0.575 & -0.618 & -0.141 \\
\hline Total Kjeldahl & 0.292 & -0.123 & 0.806 & -0.046 & 0.074 & -0.085 & -0.088 & 0.180 & 0.926 \\
\hline Total Phosphorus & 0.759 & 0.005 & 0.496 & 0.093 & 0.101 & 0.866 & 0.156 & 0.001 & -0.071 \\
\hline Total Phosphate & 0.750 & 0.010 & 0.509 & 0.111 & 0.124 & 0.882 & 0.250 & 0.035 & 0.081 \\
\hline Ammonia-N & 0.234 & -0.439 & -0.151 & 0.749 & 0.140 & 0.302 & -0.080 & 0.609 & -0.025 \\
\hline Water Temperature & -0.051 & 0.042 & 0.043 & 0.005 & 0.936 & -0.158 & 0.018 & 0.670 & 0.191 \\
\hline Total Suspended & 0.037 & 0.416 & 0.190 & 0.796 & -0.085 & 0.120 & 0.611 & 0.458 & -0.198 \\
\hline Turbidity & 0.090 & 0.633 & 0.590 & 0.293 & -0.114 & 0.093 & 0.753 & -0.267 & 0.331 \\
\hline Magnesium & 0.929 & 0.072 & -0.091 & 0.011 & -0.060 & 0.817 & -0.154 & 0.123 & -0.182 \\
\hline Chloride & 0.946 & 0.030 & 0.100 & 0.064 & -0.083 & 0.952 & -0.151 & 0.107 & 0.011 \\
\hline Sodium & $\mathbf{0 . 9 2 0}$ & -0.097 & 0.230 & 0.118 & -0.096 & 0.926 & -0.159 & 0.071 & -0.005 \\
\hline
\end{tabular}

\subsubsection{Identification of potential pollution sources in wet season}

In the wet season, the first varifactor (VF1), accounting for $32.6 \%$ of the total variance, had strong and positive loadings on TP, total phosphate, magnesium, chloride, and sodium. Component loadings for each variable in five selected components after varimax rotation are graphically shown in Figure 6.2. High concentrations of TP, total phosphate in surface waters could come from various sources, including domestic and 
industrial wastewater, fertilizer applications, and animal waste [60]. Sources of salt ions (magnesium, chloride, and sodium) to water resources vary from natural sources (oceans, atmospheric deposition, weathering of common rocks, minerals and soils, and salt deposits and brines) to anthropogenic sources (landfills, wastewater and water treatment, agriculture, and application of deicing salts) [61].

It was observed from the dataset that the average concentrations of these five components are significantly higher in downstream sites, specifically in the Kissimmee River and Caloosahatchee River (sites S154C and CES03), which could be occurred due to both above mentioned natural and anthropogenic sources. At site S154C, the very high concentrations of magnesium, chloride, and sodium could be associated with urban areas with more industrial effluent and domestic wastewater, and in case of site CES03, intrusion of salt water into the river from the Gulf of Mexico could be considered as a natural source for the high concentrations of salt ions. Commonly when fresh water meets seawater and salt water and fresh water mixed together, as in estuaries, brackish water condition occurs. In these area, the interaction of surface waters and groundwater as an important factor in the water quality characteristics and protection of aquifers in South Florida as the main source and supplier for the public water should be precisely considered. The interactions between surface water and groundwater in the studied rivers and canals can enhance and facilitate the spread of nutrients, and pollutants into the aquifer [62]. Seasonal changes in water quality should be considered prior to injection programs. Different issues, such as precipitation of minerals, clogging problems may result from suspended solids, ion-exchange, and etc. could be some of the important 
consequences of the interactions between brackish native waters, aquifer material, and injected fresh water.

In general, the average concentrations of the water quality parameters in the Miami Canal are worse than the other two rivers. The Kissimmee River demonstrated even lower average values. Nonetheless, the outliers in the database were related to the average concentration of the represented variables in two highly polluted sites of S154C and CES03 in the Kissimmee River and the Caloosahatchee River, respectively. Previous analysis by Gholizadeh et al. (2016) indicated that these two highly polluted sites are extremely affected by urbanized areas, and also high-density environmental resource permits (ERP) with more industrial effluent and domestic wastewater. However, TP showed that a different pattern and average concentrations of this variable were much higher in the Caloosahatchee River and the Kissimmee River, respectively, in comparison to the Miami Canal. Besides the two mentioned highly polluted sites, TP was found higher at the Caloosahatchee River and the Kissimmee River than Miami Canal sites. The percentage of agricultural and urbanized areas in the Miami Canal watershed was measured from the landuse/landcover map in GIS and was seen to be even more than the other two rivers. Therefore, this could be related to the effectiveness of eco-restoration projects implemented in its watershed and adjacent linked watersheds (the water conservation area-3, WCA-3) in order to decrease the amounts of nutrients. Therefore, VF1 was identified as "point source pollution discharges".

The second varifactor (VF2), accounting for $17.02 \%$ of the total variance, had strong and positive loadings on DO, moderate positive loading on turbidity and chl- $a$, a weak positive loading (0.42) on TSS, and a weak negative loading (-0.44) on ammonia- 
$\mathrm{N}$. It was seen from the correlation matrix for the wet season dataset that chl- $a$ had strong correlations with DO and turbidity in the wet season. Aquatic components, such as plants and algae that contain chl- $a$ during the chemical process of oxygenic photosynthesis, use carbon dioxide, water and sunlight to produce oxygen [64]. High concentrations of nutrients in surface waters may cause to observe have high chlorophyll conditions, which can come from many sources, such as fertilizers, atmospheric deposition, erosion, and sewage treatment plant discharges. Among all the water quality parameters, DO is the best index for indicating environmental quality because all aquatic life depends on DO to metabolize food for producing energy to maintain life and growth [65]. Hence, the DO level in a water body is of great importance to all aerobic aquatic life; higher levels of DO will maintain the biological diversity. The seasonal and spatial variations of DO, chl$a$, and WT were observed in the dataset, in which chl- $a$ and water temperature showed a clear inverse relationship with DO. By increasing the water temperature the activities of aquatic life increase and more oxygen will be consumed, and causes a decrease in concentration of DO. It is also known that the oxygen can better dissolve as the temperature of water decreases. Turbidity is the most visible indicator of water quality and an optical feature of water clarity. Soil erosion, runoff, stirred bottom sediments, and algal blooms can contribute to the concentration of suspended particles in water [66]. Therefore, high loadings of VF2 on the mentioned parameters and analysis of their possible sources can interpret this factor as "physicochemical and biological non-point sources of pollution".

The third varifactor (VF3), accounting for $14.07 \%$ of the total variance, had strong and positive loadings on TKN, and moderate positive loading on TP, total 
phosphate, and turbidity. TKN is a measure of the amount of ammonia-N and organic nitrogen in the water [67]. High nitrogen can increase the amount of algae and chl- $a$ concentrations in the waterbody, however compared to phosphorus, nitrogen is generally of less concern in fresh water [68]. This "Non-point sources of nutrients" factor represents influences from nonpoint sources, such as fertilizers applied to agricultural fields, deposition of nitrogen from the atmosphere, suburban lawns, and erosion of soil containing nutrients [69].

The fourth varifactor (VF4), accounting for $11.05 \%$ of the total variance, had strong positive loadings on ammonia-N and TSS. Ammonia-N is a toxic chemical that is usually found in landfill leachate [70] and in waste products, such as wastewater, liquid manure and other liquid organic waste products [71]. Among the numerous sources of ammonia-N found in the water body, the nitrogen released by the decomposition of organic matter and fertilizer released from agricultural applications are the major contributors [72]. Different types of agricultural areas in South Florida generate nonpoint sources of pollution that have a high percentage of ammonia from pesticides and fertilizers. The main source of suspended solids is inorganic materials, although some other constituents in water such as bacteria, organic particles from decomposing materials, and algae can also influence the concentration of total suspended solids [73]. Organic particles also can contribute to TSS from decomposing materials. During the decay and decomposition process of algae, plants and animals, small organic particles break away and enter the water column as suspended solids [66]. In addition, clear spatial differences for chl- $a$ and DO, as a measure of life's vitality and the activity level of the aquatic lives, was observed in the studied rivers. The higher average values of these two 
variables were found in the Kissimmee River and the Caloosahatchee River, which indicates the dynamism and strength of aquatic lives in this river. Besides, the Miami Canal had lower average concentrations of chl- $a$ and DO, which indicated that organic pollution may play a significant role in the Miami canal, especially in urbanized areas which are under the influence of more domestic and industrial wastewater. The analysis of the major potential source of these pollutants in the studied rivers could be related to the decomposition of organic matters that mainly originate from discharges from nonpoint sources, so that this factor may be termed as "organic pollutants" [74].

Finally, the fifth varifactor (VF5) accounting for $10.1 \%$ of the total variance in the data sets, was highly correlated with only water temperature. WT significantly influences aquatic life because it can survive only in a narrow temperature range and is very sensitive to WT variations [75]. Therefore, the magnitude of a stream's temperature directly affects its ecology, the survival of aquatic life, and even the concentration of stream DO, so stream temperature can be an important parameter for indexing water quality. The stream temperature in this study is only dependent on season. Therefore, the fifth factor can be regarded as a "seasonal" factor. Regarding the contribution of each factor in the total variance, as the "point source pollution discharges" factor (VF1) has the largest proportion of the total variance (32.6\%) in the wet season, it and be concluded that anthropogenic pollution, mainly due to the agricultural waste, domestic and industrial wastewater disposal, is the major source of river water contamination in the three major rivers of South Florida. 


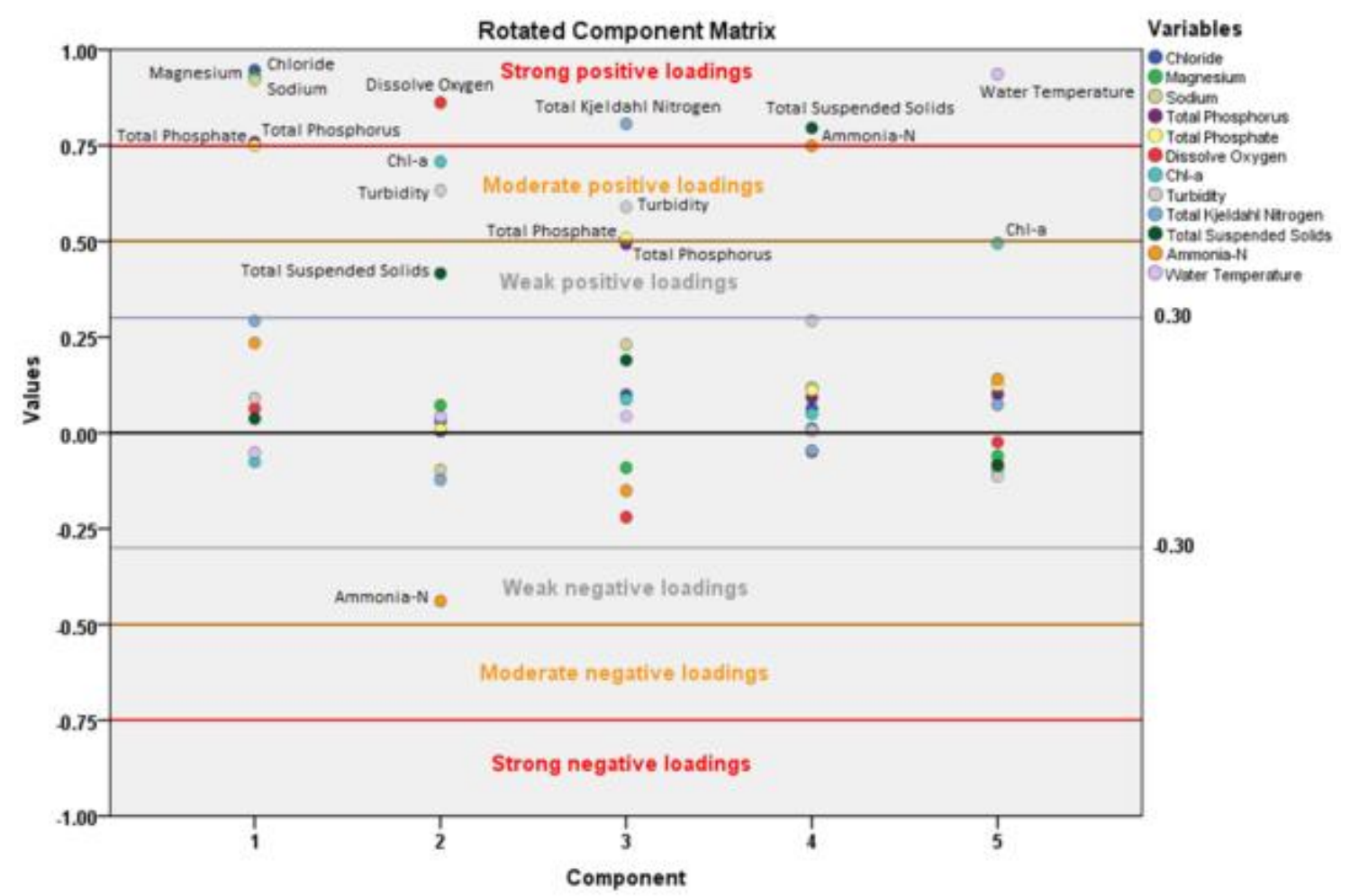

Figure 6.2. Component loadings for twelve variables after varimax rotation in wet season.

\subsubsection{Identification of potential pollution sources in dry season}

The first varifactor (VF1), accounting for 35\% of the total variance, had strong and positive loadings on TP, total phosphate, magnesium, chloride, and sodium. This was analogous to the first factor in the wet season and similar sources of pollution can be accounted for as the first factor in dry season. The identified pattern of variables in the dry season from the database showed that the average concentrations of magnesium and chloride in the Miami Canal are worse than the other two rivers, and the Kissimmee River demonstrated lower average values. Nonetheless, the observed outliers were again related to the average concentration of the represented variables in two highly polluted sites of S154C and CES03 in the Kissimmee River and the Caloosahatchee River, 
respectively. The highest amounts of these components were observed in sites S154C and CES03 that are the most downstream sites of the Kissimmee River and Caloosahatchee River, respectively. These sites are extremely affected by urbanized areas with more industrial effluent and domestic wastewater. Therefore, VF1 in the dry season was also interpreted as "point source pollution discharges". Component loadings for each variable in four selected components after varimax rotation are graphically shown in Figure 6.3.

The second varifactor (VF2), that accounted for $17 \%$ of the total variance, had strong positive loadings on chl- $a$ and turbidity, and moderate positive loading on TSS and DO. The importance and possible sources of these components were discussed previously. Due to the strong relationship between chl- $a$, DO, turbidity, and TSS, and the precise study of the possible source of these parameters, it was revealed that both physicochemical and biological factors could be the main responsible sources for the high loadings of these parameters on VF2. These sources include fertilizers, soil erosion, and sewage treatment plant discharges runoff, stirred bottom sediments, and algal blooms. Therefore, VF2 is still representing "the physicochemical and biological non-point sources of pollution" in the dry season.

The third varifactor (VF3), accounting for $12.9 \%$ of the total variance, had moderate and positive loadings on ammonia-N and WT, moderate negative loading on DO, and a weak positive loading on TSS. It was found from the correlation matrix for the dry season dataset that DO was negatively correlated with ammonia-N and WT, which indicates that large amounts of DO in the dry season was consumed by large amounts of organic matters from urban and agriculture wastewater, and leads to an anaerobic fermentation process causing high levels of ammonia. With respect to the decreasing 
trend of DO and the increasing trend of ammonia-N from upstream to downstream, these correlations indicate that the wastewater from domestic and industrial area located in the downstream parts of the rivers and their organic load are disposed to the rivers. Therefore, VF3 was representing a group of "organic" source pollution indicator parameters.

Finally, the fourth varifactor (VF4), which accounted for $9.4 \%$ of the total variance, had strong positive loadings only on TKN, and hence, the fourth factor in the dry season is called the "Non-point sources of nutrients" factor. Results showed the first factor (VF1) with the largest proportion of the total variance $(35 \%)$ in the dry season, representing the point (municipal and industrial effluents) and nonpoint sources (agricultural runoff), is the main contributor of river water contamination in three major rivers of South Florida.

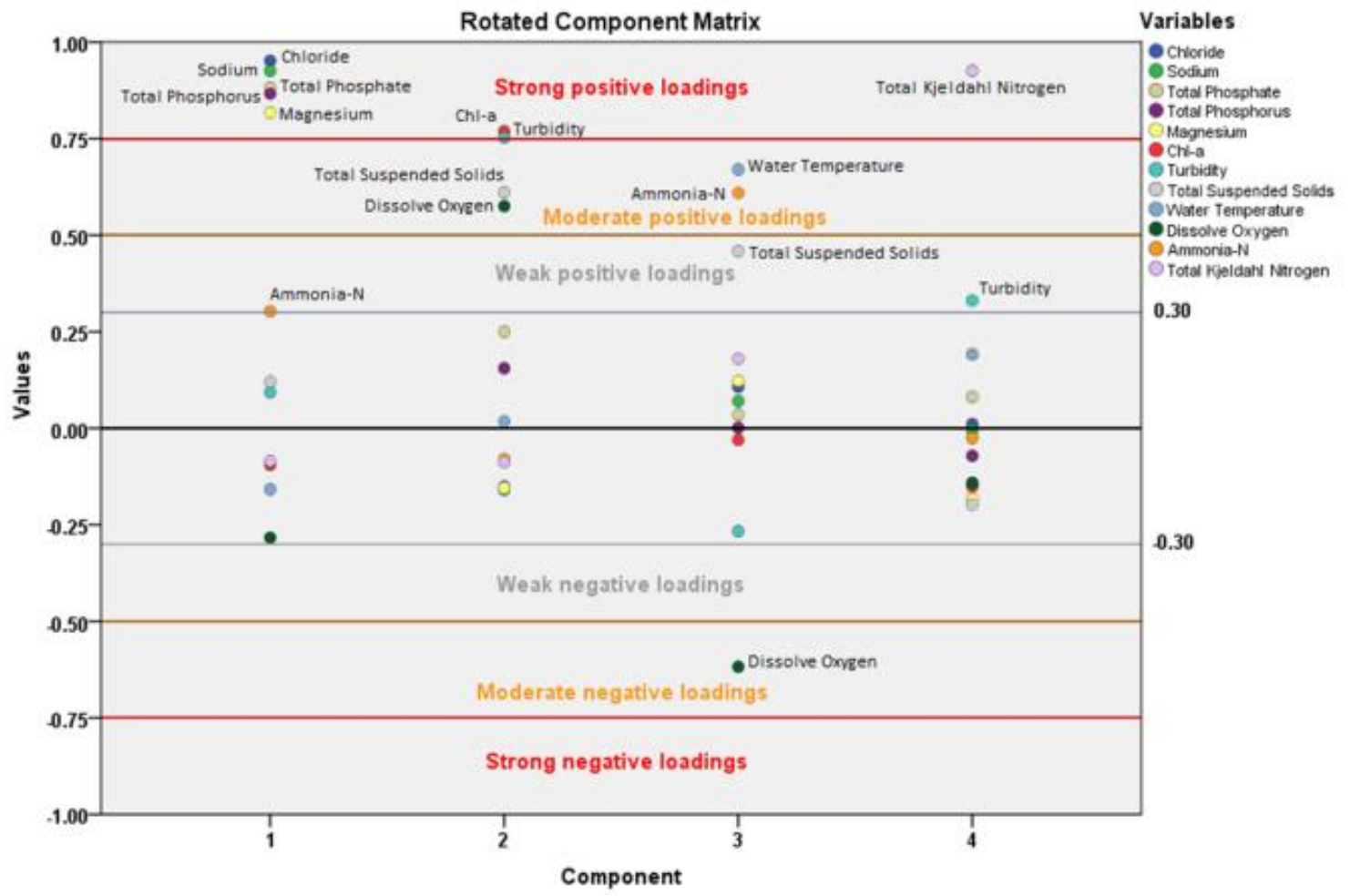

Figure 6.3. Component loadings for twelve variables after varimax rotation in dry season. 


\subsection{Source apportionment using APCS-MLR and PMF models}

After identifying possible pollution sources using the PCA/FA analysis, the contributions of each possible pollution source to different water quality variables were then apportioned using APCS-MLR. Twelve water quality parameters of three major rivers in South Florida were selected, and PCA/APCS model analyzed the sources of pollution in wet and dry seasons during the observation period (2000-2014). According to the results by Thurston and Spengler [44], when $n \geq m+50$ ( $n$ represents the number of samples and $\mathrm{m}$ represents the number of pollutants for analysis), a reliable PCA/FA result can be obtained. The number of data samples in the present study met this requirement. During the factor extraction process, the principle of eigenvalue $>1$ was adopted (Kaiser's criteria) to identify five and four primary factors in the wet and dry season, respectively, that significantly affect the variation of selected water quality parameters in the study area.

Results of source apportionment in two different seasons are presented in Tables 6.5 and 6.6. As shown in these tables, the $\mathrm{R}^{2}$ values of the concentrations of the 12 studied parameters obtained with the calculations using the receptor modeling and actual observations were both greater than 0.5 (in most cases more than 0.8 ), indicating that there was a good consistency between the modeled and observed values, and that the source apportionment results were reliable [7]. Further, the ratio of the mean observed and estimated values of almost all the water quality variables (Tables 6.5 and 6.6) suggest goodness of the receptor modeling approach to the source apportionment of river water. Moreover, the contributions of unidentified sources as estimated values of $\left(r_{0}\right)_{j}$ in Eq. (6.7) were considered. 
In wet season, most variables were primarily influenced by point sources pollution from industrial effluent and domestic wastewater (S1: Point source pollution discharges), representing the nutrients (TKN, 22.4\%; TP, 75.2\%; total phosphate, 69.5\%; and ammonia-N, 10.9\%) and the salt ions (magnesium, 95.2\%; chloride, 95.4\%; and sodium, $87.8 \%$ ), respectively. Contributions of physicochemical and biological non-point sources pollution (S2) for different water quality parameters were between $0.4 \%$ (WT) to $66.6 \%$ (DO). These sources accounted for $17.7 \%-49.7 \%$ of the water clarity parameters (TSS and turbidity, respectively) and $47.9 \%$ of the biological component (chl- $a$ ) in riverine water quality of the study area.

Contributions of non-point sources of nutrients (S3) for different variables were responsible accounting between $0.2 \%$ (WT) to $23.1 \%$ (TKN). The results of APCS-MLR also indicated that $15.3 \%$ of turbidity is related to non-point sources of nutrient. It was found that the contributions of organic pollutants (S4) to river water quality in the wet season accounted for between $0.1 \%$ (WT) to $67 \%$ (TSS). It was also observed that the highest percentage of ammonia-N (49.6\%) is related to organic pollutants. Furthermore, as Table 6.5 shows, $21.2 \%$ of turbidity is due to organic pollutants. Considering the high percentage of contribution of these sources to TSS (67\%), it can be concluded that S4 accompanied by S2 are the main sources of water murkiness and color in three selected rivers. The seasonal factor (S5) was responsible for $98.3 \%$ of WT and for 38.8\% of chl- $a$, respectively. This factor also accounted for 4.3-6.3\% of the nutrients concentrations and 7.3\% of turbidity. Apart from these, unidentified miscellaneous sources contributed to the river water pollution for most of the water quality variables and represented between $0.3 \%$ (WT) to $40.9 \%$ (TKN) in the wet season. It was also observed from the results of 
the receptor model that $23.2 \%$ of $\mathrm{DO}, 13.3 \%$ of ammonia-N, and $10.4 \%$ of total phosphate resulted from unidentified sources. This shows the necessity of field work to further identify the sources of the pollution. Average contributions indicated that point source pollution discharges (S1), physicochemical and biological non-point sources of pollution (S2), non-point sources of nutrients (S3), organic pollutants (S4), seasonal (S5), and unidentified sources for different variables concentrations in the wet season were $39.3 \%, 17.5 \%, 6.0 \%, 13.3 \%, 14.7 \%$, and 9.3\%, respectively (Figure 6.4-a)

In the dry season, most variables were primarily influenced by point sources of pollution from industrial effluent and domestic wastewater (S1), representing between $1.9 \%$ (DO) and $86.9 \%$ (TP). Point source pollution discharges accounted for $3.6 \%$ to $86.9 \%$ of the nutrients (TKN, 3.6\%; TP, $86.9 \%$; total phosphate, $63.7 \%$; and ammonia-N, $22.2 \%$ ) and $58.1-84.8 \%$ of the salt ions (magnesium, 58.1\%; chloride, $84.8 \%$; and sodium, 81\%). Contributions of physicochemical and biological non-point sources of pollution (S2) for different water quality parameters were between $1.4 \%(\mathrm{WT})$ and $93.2 \%$ $($ chl- $a)$. They were the main sources of the water clarity parameters (TSS, $85.3 \%$ and turbidity, 71.1\%), and the biological component (chl- $a, 93.2)$.

Physicochemical and biological non-point sources of pollution (S2) also accounted for $8.9 \%$ of TP, $16.4 \%$ of total phosphate, and $32.3 \%$ of DO in the riverine water quality of the study area. Contributions of organic pollutants (S3) for different variables were between $0.0 \%$ (TP) and $43.2 \%$ (WT). The results of APCS-MLR measurements indicated that the highest percentage of ammonia-N (40.6\%) and WT is related to organic pollutants. Generally, the WT, the movement or flow of the water body, and the amount of organic matter in the water can affect the amount of DO in the 
water. It was found that the contributions of non-point sources of nutrients (S4) to river water quality in the dry season accounted for between $0.1 \%$ (sodium) and $71.9 \%$ (TKN), which indicated that the highest percentage of $\mathrm{TKN}$, as an indicator of total nitrogen, resulted from these sources. Furthermore, $9.4 \%$ of turbidity and $6.3 \%$ of magnesium were represented by non-point sources of nutrients. However, the miscellaneous unidentified sources in the dry season also contributed to the river water pollution for most of the water quality variables were between $1.5 \%$ (TSS) and $41.3 \%$ (DO). It was observed from the results of the receptor model that high percentages of WT (35.8\%) and magnesium (22.2\%), and a significant percentage of nutrients (ammonia-N, 28.3\%; total phosphate, 16.6\%; and TKN, 12.9\%) also resulted from unidentified sources that shows the necessity of field work to further identify the sources of the pollution. Average contributions of point source pollution discharges (S1), physicochemical and biological non-point sources of pollution (S2), organic pollutants (S3), non-point sources of nutrients (S4), and unidentified sources for different variables concentrations in the dry season were $36.0 \%$, $29.0 \%, 10.2 \%, 9.2 \%$, and $15.5 \%$, respectively (Figure 6.4-b).
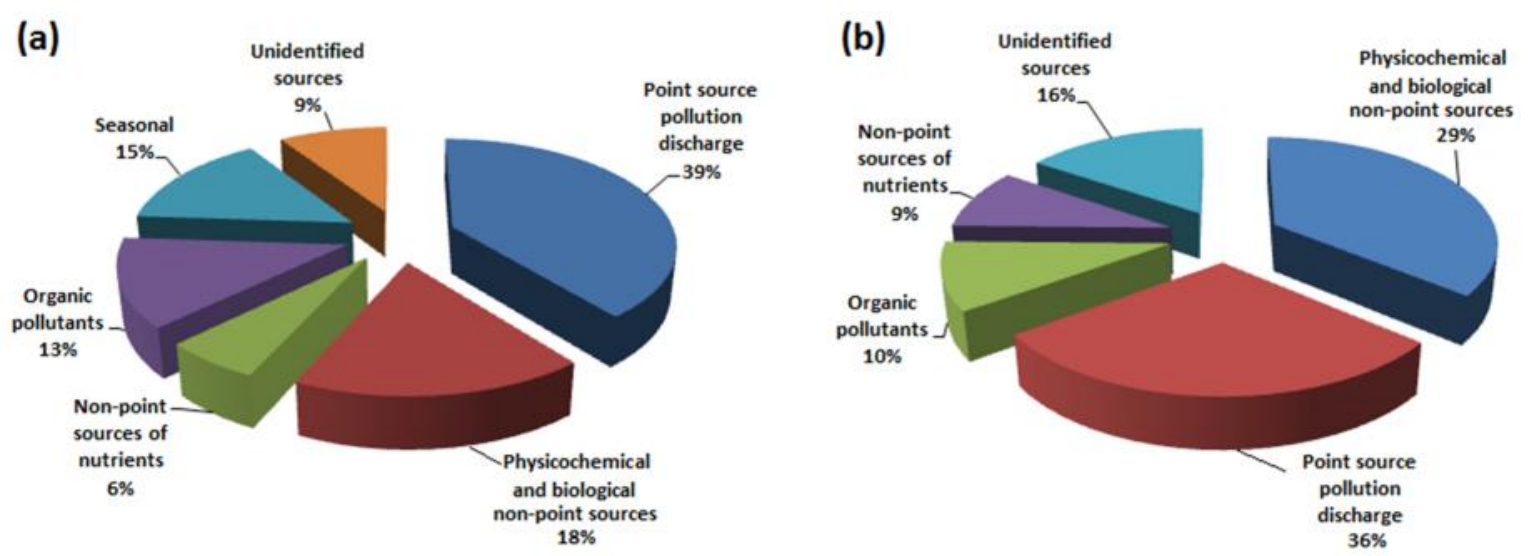

Figure 6.4. Average contributions of different pollution sources to water quality of three major rivers of South Florida in wet season (a) and dry season (b) using APCS-MLR model. 
In addition, the studied variables can be categorized into three groups of nutrients (TKN, TP, total phosphate, and ammonia-N), water murkiness conducive parameters (TSS, turbidity, and chl-a), and salt ions (magnesium, chloride, and sodium). Average contributions of different potential pollution sources to nutrients, water murkiness, and salt ions calculated based on their percentage in Tables 6.5 and 6.6, are presented as a pie chart in Figure 6.5 for wet and dry seasons. As shown in Figure 6.5, in the wet season, point source pollution discharges (S1) with $45 \%$ contribution and unidentified sources (UIS) with 18\% contribution, and in the dry season, point source pollution discharges (S1) with $44 \%$ contribution and non-point sources of nutrients (S4), were the major sources of nutrients in river water quality. Turbidity, TSS, and chl- $a$ were considered as parameters that affect the water clarity. Accordingly, in the wet season, physicochemical and biological non-point sources of pollution (S2) with $38 \%$ contribution and organic pollutants (S4) with 30\% contribution, and in the dry season, physicochemical and biological non-point sources of pollution (S2) with $83 \%$ contribution, were the major sources of water murkiness in river water quality. Point source pollution discharges (S1), in both wet and dry seasons with $93 \%$ and $75 \%$ contributions, respectively, were the major source of magnesium, chloride, and sodium in the three selected rivers of South Florida. 
Table 6.5. Mean source contributions to different variables concentrations in wet season.

\begin{tabular}{|c|c|c|c|c|c|c|c|c|c|c|}
\hline \multirow[b]{2}{*}{ Variable } & \multicolumn{6}{|c|}{ Source contribution $(\%) *$} & \multirow[b]{2}{*}{$\begin{array}{c}\text { Observed mean } \\
\text { concentration }\end{array}$} & \multirow[b]{2}{*}{$\begin{array}{l}\text { Estimated mean } \\
\text { concentration }\end{array}$} & \multirow{2}{*}{$\begin{array}{c}\text { Ratio } \\
\text { (Estimated/ } \\
\text { Observed) }\end{array}$} & \multirow[b]{2}{*}{$\mathbf{R}^{2}$} \\
\hline & S1 & $\mathbf{S 2}$ & S3 & S4 & S5 & $\begin{array}{c}\text { Unidentified } \\
\text { sources }\end{array}$ & & & & \\
\hline Chl- $a(\mu \mathrm{g} / \mathrm{L})$ & 3.9 & 47.9 & 1.6 & 2.4 & 38.8 & 5.3 & $17.10 \pm 11.24$ & $17.10 \pm 9.81$ & 1.07 & 0.76 \\
\hline Dissolved Oxygen (mg/L) & 2.9 & 66.6 & 3.9 & 2.2 & 1.1 & 23.2 & $4.47 \pm 1.50$ & $4.42 \pm 1.34$ & 1.02 & 0.80 \\
\hline Total Kjeldahl Nitrogen (mg/L) & 22. & 6.2 & 23.1 & 2.7 & 4.5 & 40.9 & $1.41 \pm 0.24$ & $1.41 \pm 0.21$ & 1.01 & 0.76 \\
\hline Total Phosphorus (mg/L) & 75. & 0.0 & 8.6 & 4.1 & 4.3 & 7.9 & $0.11 \pm 0.10$ & $0.11 \pm 0.10$ & 1.42 & 0.84 \\
\hline Total Phosphate (mg/L) & 69. & 0.3 & 9.3 & 4.9 & 5.6 & 10.4 & $0.11 \pm 0.10$ & $0.11 \pm 0.09$ & 1.36 & 0.85 \\
\hline Ammonia-N (mg/L) & 10. & 17.6 & 2.4 & 49.6 & 6.3 & 13.3 & $0.10 \pm 0.10$ & $0.10 \pm 0.09$ & 1.09 & 0.85 \\
\hline Water Temperature (Deg C) & 0.7 & 0.4 & 0.2 & 0.1 & 98.3 & 0.3 & $28.44 \pm 1.44$ & $28.44 \pm 1.35$ & 1.00 & 0.88 \\
\hline Total Suspended Solids (mg/L) & 1.5 & 17.7 & 3.0 & 67.0 & 3.7 & 7.0 & $7.96 \pm 5.55$ & $7.96 \pm 5.12$ & 1.06 & 0.85 \\
\hline Turbidity (NTU) & 5.6 & 49.7 & 15.3 & 21.2 & 7.3 & 0.8 & $4.56 \pm 2.86$ & $4.56 \pm 2.64$ & 1.03 & 0.86 \\
\hline Magnesium (mg/L) & 95. & 1.2 & 0.7 & 0.2 & 1.3 & 1.4 & $18.91 \pm 31.76$ & $18.91 \pm 29.81$ & 1.18 & 0.88 \\
\hline Chloride (mg/L) & 95. & 0.5 & 0.7 & 1.3 & 1.7 & 0.4 & $141.46 \pm 301.55$ & $141.46 \pm 288.85$ & 1.01 & 0.92 \\
\hline Sodium (mg/L) & 87. & 2.4 & 2.6 & 3.6 & 3.0 & 0.6 & $67.75 \pm 118.55$ & $67.75 \pm 114.49$ & 1.12 & 0.93 \\
\hline Mean & 39. & 17.5 & 6.0 & 13.3 & 14.7 & 9.3 & & & 1.11 & 0.85 \\
\hline
\end{tabular}

Notes: *: S1 = Point source pollution discharges, S2 = Physicochemical and biological non-point sources of pollution, $\mathrm{S} 3=$ Non-point sources of nutrients, $\mathrm{S} 4=$ Organic pollutants, and S5 = Seasonal.

Table 6.6. Mean source contributions to different variables concentrations in dry season.

\begin{tabular}{|c|c|c|c|c|c|c|c|c|c|}
\hline \multirow[b]{2}{*}{ Variable } & \multicolumn{5}{|c|}{ Source contribution $(\%) *$} & \multirow[b]{2}{*}{$\begin{array}{c}\text { Observed mean } \\
\text { concentration }\end{array}$} & \multirow[b]{2}{*}{$\begin{array}{l}\text { Estimated mean } \\
\text { concentration }\end{array}$} & \multirow{2}{*}{$\begin{array}{c}\text { Ratio } \\
\text { (Estimated/ } \\
\text { Observed) }\end{array}$} & \multirow[b]{2}{*}{$\mathbf{R}^{2}$} \\
\hline & S1 & S2 & $\mathbf{S 3}$ & S4 & $\begin{array}{l}\text { Unidentified } \\
\text { sources }\end{array}$ & & & & \\
\hline Chl- $a(\mu \mathrm{g} / \mathrm{L})$ & 1.9 & 93.2 & 0.4 & 2.7 & 1.8 & $11.35 \pm 7.16$ & $11.35 \pm 5.66$ & 1.18 & 0.62 \\
\hline Total Kjeldahl Nitrogen (mg/L) & 3.6 & 5.7 & 5.9 & 71.9 & 12.9 & $1.25 \pm 0.20$ & $1.25 \pm 0.19$ & 1.00 & 0.91 \\
\hline Total Phosphorus (mg/L) & 86.9 & 8.9 & 0.0 & 2.4 & 1.8 & $0.081 \pm 0.07$ & $0.084 \pm 0.07$ & 1.14 & 0.86 \\
\hline Total Phosphate (mg/L) & 63.7 & 16.4 & 0.8 & 2.4 & 16.6 & $0.078 \pm 0.06$ & $0.078 \pm 0.06$ & 1.14 & 0.85 \\
\hline Total Suspended Solids (mg/L) & 9.5 & 85.3 & 3.1 & 0.6 & 1.5 & $6.80 \pm 3.59$ & $6.80 \pm 3.03$ & 1.07 & 0.71 \\
\hline Turbidity (NTU) & 2.8 & 71.1 & 6.3 & 9.4 & 10.5 & $4.40 \pm 3.16$ & $4.40 \pm 2.75$ & 1.04 & 0.76 \\
\hline Magnesium (mg/L) & 58.1 & 9.7 & 3.6 & 6.3 & 22.2 & $25.52 \pm 43.47$ & $25.52 \pm 37.38$ & 1.15 & 0.74 \\
\hline Chloride (mg/L) & 84.8 & 7.6 & 2.4 & 0.3 & 4.8 & $163.20 \pm 315.48$ & $163.20 \pm 305.92$ & 0.98 & 0.94 \\
\hline Sodium (mg/L) & 81.0 & 8.7 & 1.7 & 0.1 & 8.5 & $67.75 \pm 118.55$ & $67.75 \pm 114.49$ & 1.05 & 0.89 \\
\hline Mean & 36.0 & 29.0 & 10.2 & 9.2 & 15.5 & & & 1.08 & 0.76 \\
\hline
\end{tabular}

Notes: *: S1 = Point source pollution discharges, S2 = Physicochemical and biological non-point sources of pollution, S3 = Organic pollutants, and $\mathrm{S} 4=$ Non-point sources of nutrients. 

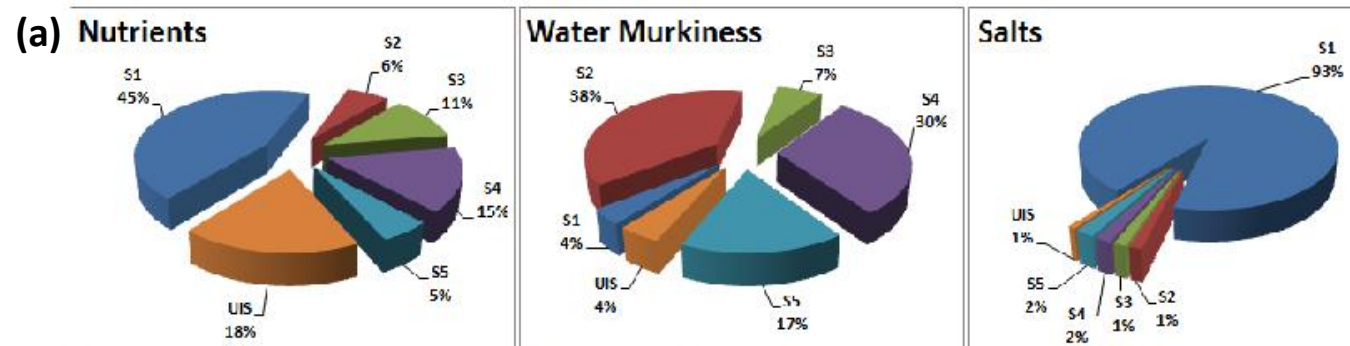

(b) Nutrients
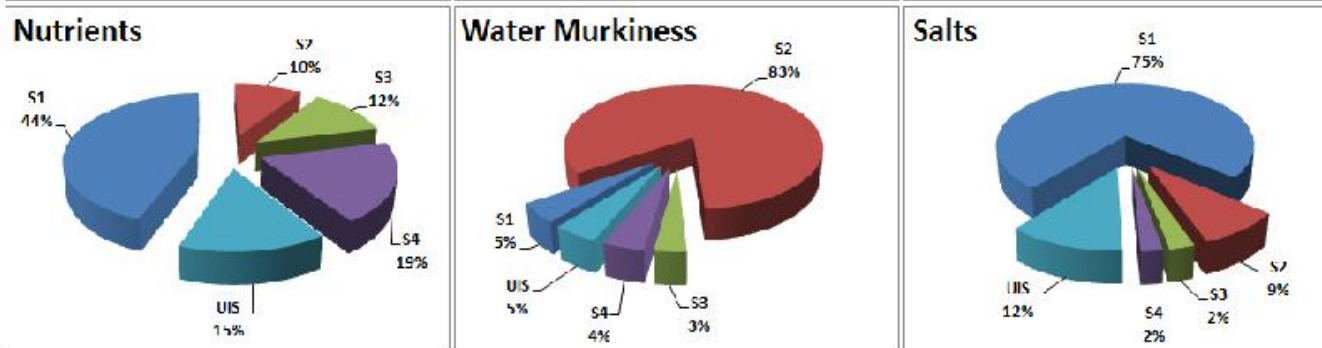

Figure 6.5. Average contributions of different pollution sources to nutrients, water murkiness, and salt ions in wet season (a) and dry season (b) using APCS-MLR model.

The data matrix was also subjected to PMF receptor model using the EPA PMF5.0 program and the two-way model described by Paatero and Tapper [55] was performed for the PMF analyses. The uncertainty of each data point are weighted in PMF model and only positive contributions are considered, which is an important advantage of this model $[55,76]$. The uncertainty estimated by the DBHYDRO for each variable was used for the apportionment procedure using PMF.

Based on the relationship among variables and their percentage of contribution in the same group, each six factors in the wet season and each five factors in the dry season were determined. Pollution sources consisted of factor taking into consideration of TP, total phosphate, magnesium, chloride, and sodium were signature of point source pollution discharges. The factor consisting of DO, chl- $a$, TSS, and turbidity, which are considered as the water murkiness index, were used as signature of physicochemical and biological non-point sources of pollution group. Non-point sources of nutrients factor 
were dominated by TKN, TP, total phosphate, and turbidity. Organic pollutants were dominated by Ammonia-N and TSS. The factor that was the main contributor to the WT was considered as the signature of seasonal factor. In connection with the results of PCA/FA, the sixth factor that had no explainable contribution to different variables was assigned to the unidentified sources (UIS) in order to make the comparison of the results more reasonable. Figure 6.6 shows the "Factor Figureprints" of twelve studied variables resulted from EPA PMF model in the wet and dry seasons, which demonstrate a schematic percentage of potential pollution contributions.

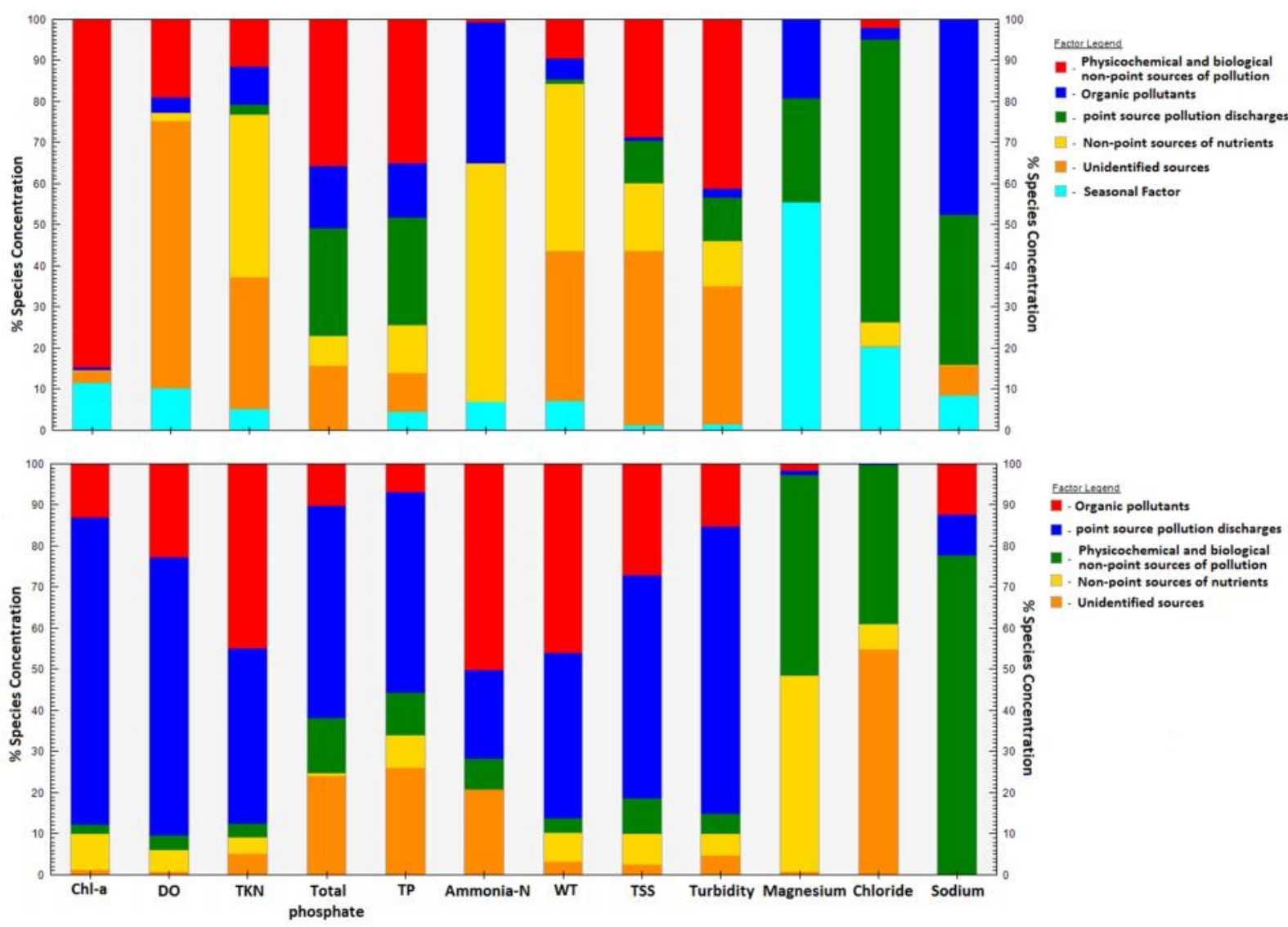

Figure 6.6. Factor Figureprints of twelve studied variables resulted from EPA P MF model in the wet (a) and dry (b) seasons.

Figure 6.7 shows the average contributions of different pollution sources to water quality of three major rivers of South Florida in wet and dry seasons obtained from the 
EPA PMF model. Average contributions indicated that point source pollution discharges, physicochemical and biological non-point sources of pollution, non-point sources of nutrients, organic pollutants, seasonal, and unidentified sources for different variables concentrations in the wet season were $17 \%, 22 \%, 16 \%, 13 \%, 11 \%$, and $20 \%$, respectively. Also, average contributions of point source pollution discharges, physicochemical and biological non-point sources of pollution, organic pollutants, nonpoint sources of nutrients, and unidentified sources for different variables concentrations in the dry season were $19 \%, 40 \%, 21 \%, 8 \%$, and $12 \%$, respectively.
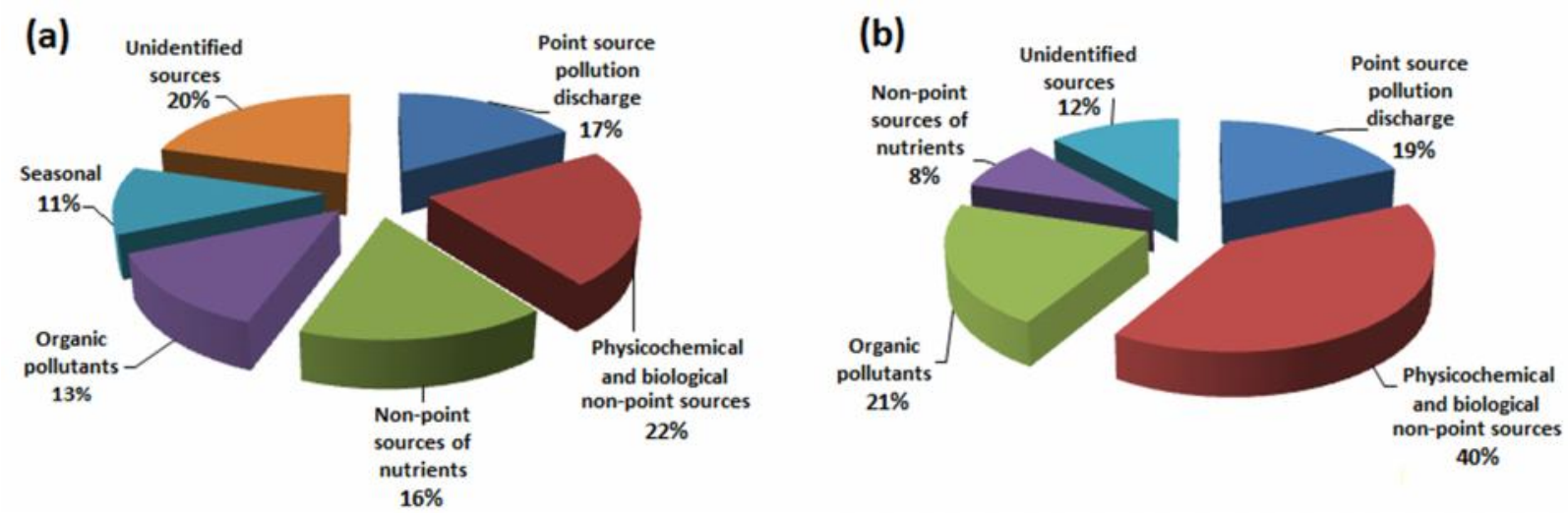

Figure 6.7. Average contributions of different pollution sources to water quality of three major rivers of South Florida in wet season (a) and dry season (b) using EPA PMF model.

Comparison of the obtained results from PMF and APCS-MLR models is graphed in Figure 6.8. This showed that there were some significant differences in estimated contribution for each potential pollution source, especially in the wet season. The more tremendous difference between the apportioned contributions using two models was observed for the point source pollution discharges. 


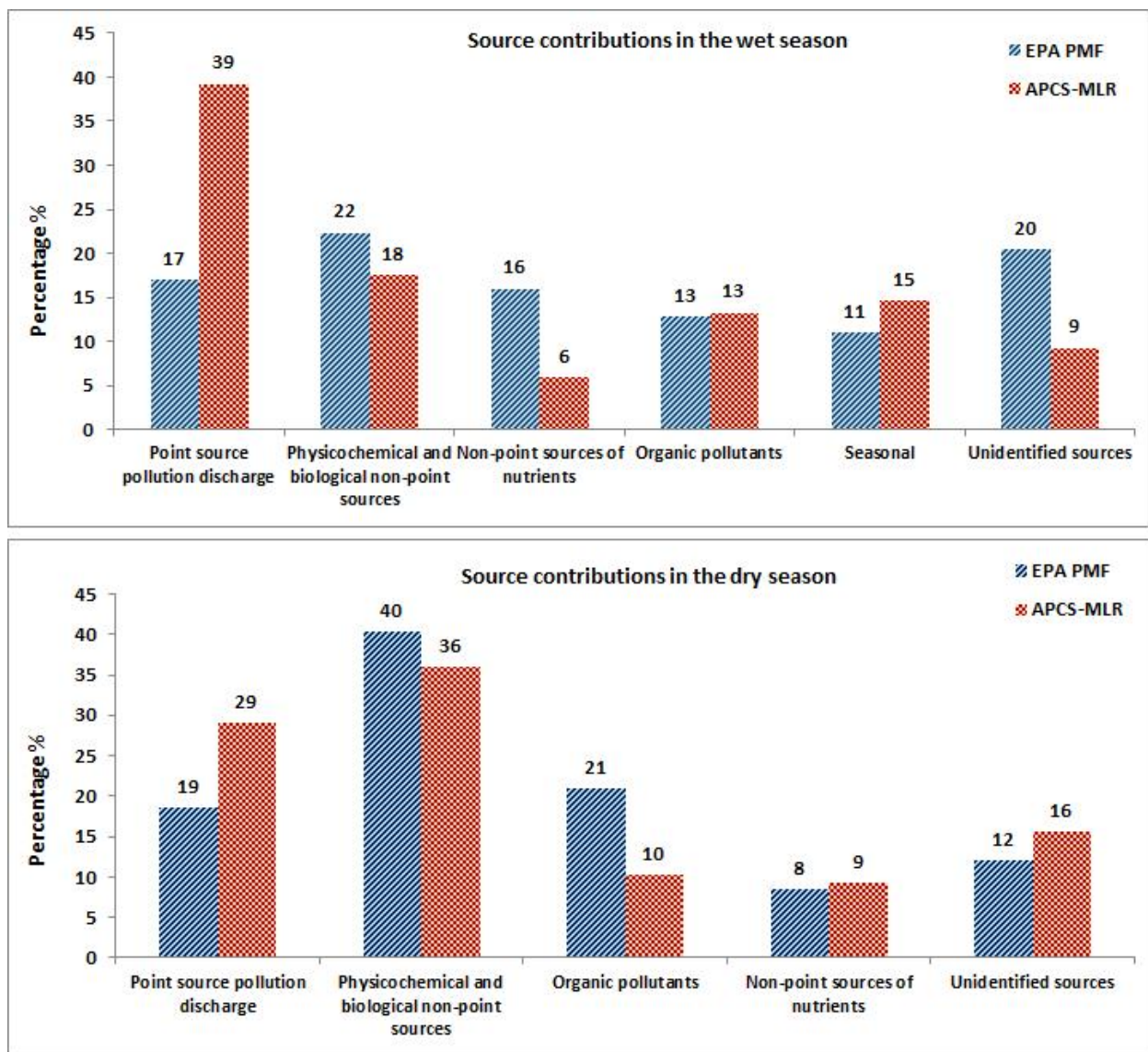

Figure 6.8. Source contribution variations based on the results of PMF and APCS-MLR models

To facilitate the comparison, predicted vs. observed scatter plots from the results of two PMF and APCS-MLR analyses were used for some chemical species (Figure 6.9). Analysis of the results and the R-squared values of the predicted/observed plots for most of the water quality variables showed better goodness-of-fit with the APCS-MLR receptor modeling approach to the pollution source apportionment in the studied river waters. Furthermore, in some variables, as an instance for WT, the results of APCS-MLR model showed a distinct correlation between this variable with the identified seasonal factor, whereas in PMF model there was not found a distinguished contribution to a certain factor. 

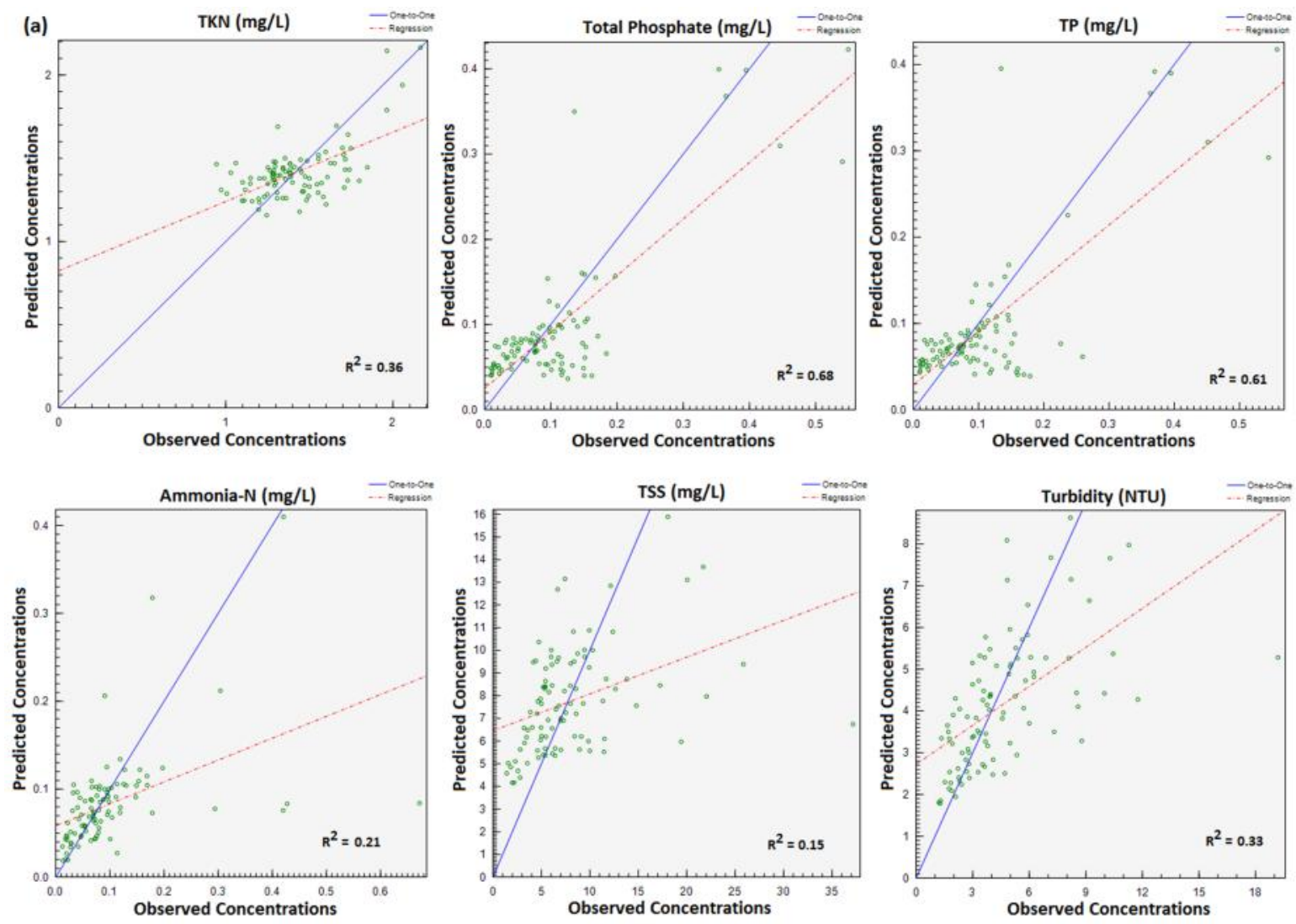

(b)
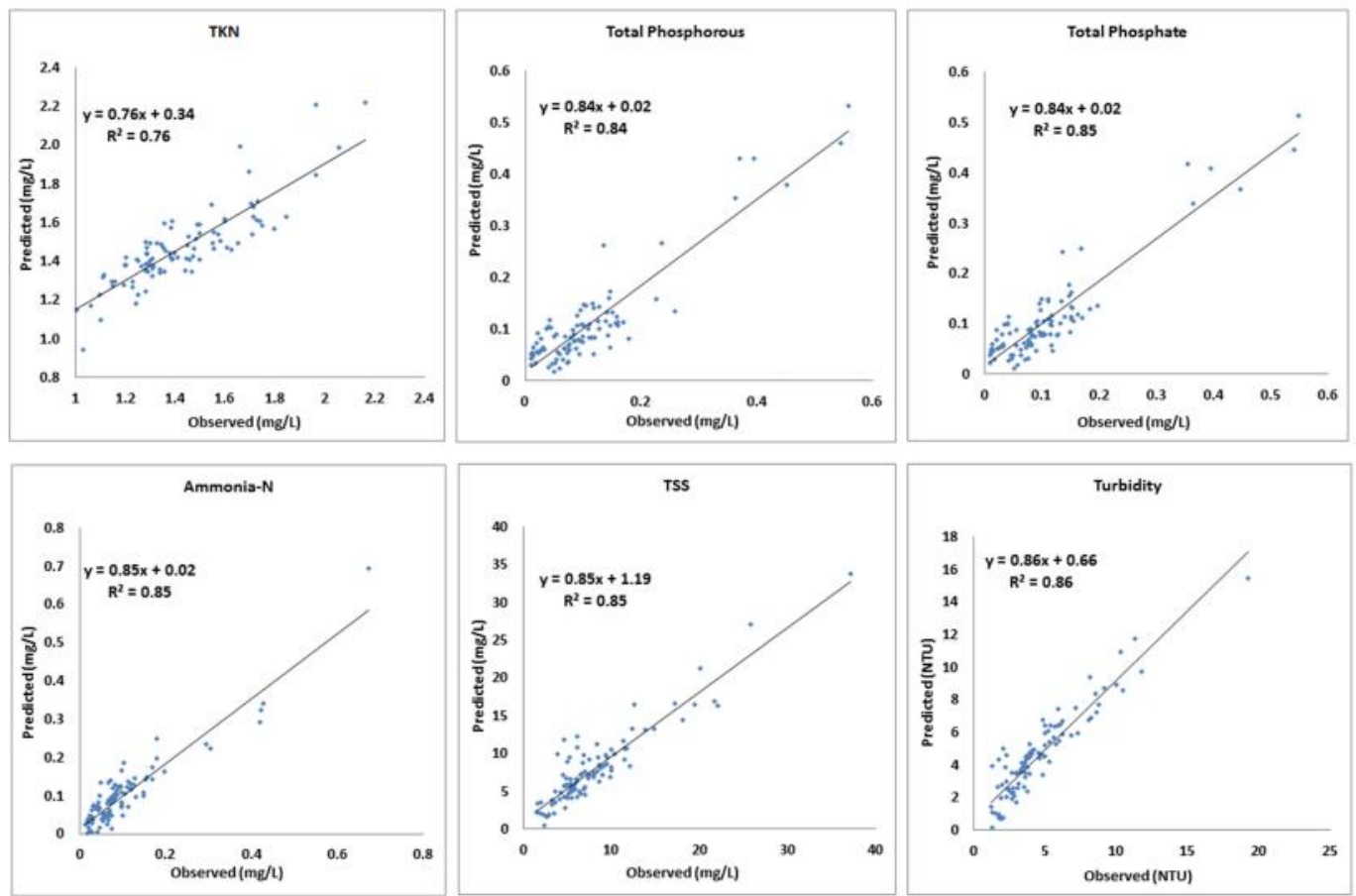

Figure 6.9. Scatter plots of the predicted and observed ratios for TKN, total phosphate, TP, ammonia-N, TSS, and turbidity in the wet season using the EPA PMF (a) and APCSMLR (b) models. 
Compared to PMF, the procedure involved in APCS-MLR analyses are relatively simple. To the extent of our knowledge, relatively few descriptions of the application of the PMF approach (than of APCS-MLR) to particle number concentration data have appeared in the literature. In particular, although PMF method has been widely used in air pollution studies, there is no many prior report of the application of PMF to the apportionment of pollution sources in the fields of water resources. Therefore, the results of APCS-MLR are more physically acceptable for the current study.

\section{Conclusion}

In this study, multivariate statistical analysis techniques, including PCA and FA, along with the APCS-MLR and PMF receptor modeling techniques, were used to assess the water quality and apportion the contributions of different potential pollution sources to each water quality variable in three major rivers of South Florida. For this purpose, a 15 year (2000-2014) dataset of 12 water quality variables covering 16 monitoring stations, and approximately 35,000 observations were used.

PCA and FA methods were applied to identify five and four potential pollution sources in wet and dry seasons, respectively. APCS-MLR was used to apportion their contributions to each water quality variable. Results showed that in the wet season, point source pollution discharges (S1) with $45 \%$ contribution and unidentified sources (UIS) with $18 \%$ contribution, and in the dry season, point source pollution discharges (S1) with $44 \%$ contribution and non-point sources of nutrients (S4) with 19\% contribution, were the major sources of nutrients in river water quality. Accordingly, in the wet season, physicochemical and biological non-point sources of pollution (S2) with $38 \%$ contribution and organic pollutants (S4) with $30 \%$ contribution, and in the dry season 
only physicochemical and biological non-point sources of pollution (S2) with $83 \%$ contribution were the major sources of water murkiness in river water quality. Point source pollution discharges $(\mathrm{S} 1)$ in both wet and dry seasons with $93 \%$ and $75 \%$ contributions, respectively, was the major source of magnesium, chloride, and sodium in three selected rivers of South Florida. In addition, two S154 and CES03 sites showed very greater amounts of some parameters, such as chl- $a, \mathrm{DO}, \mathrm{TKN}, \mathrm{TP}$, total phosphate, and ammonia-N in both wet and dry seasons compared to other sites. One of the possible reasons may be the effluent discharges of industrial and domestic wastewater, generally kept at a relatively steady level throughout the entire year. It can be concluded that the point source pollution discharges from anthropogenic factors due to the discharge of agriculture waste and domestic and industrial wastewater, were the major sources of river water contamination in three major rivers of South Florida.

The data matrix was also subjected to PMF receptor model using the EPA PMF5.0 program and the two-way model described were performed for the PMF analyses. Comparison of the obtained results of PMF and APCS-MLR models showed that there were some significant differences in estimated contribution for each potential pollution source, especially in the wet season. The more tremendous difference between the apportioned contributions using two models was observed for the point source pollution discharges. Analysis of the results and the R-squared values of the predicted/observed plots for the most of the water quality variables showed better goodness of fit with the APCS-MLR to the pollution source apportionment in the studied river waters. Eventually, it was concluded that the results of APCS-MLR are more physically acceptable for the current study. 
This study showed the feasibility and reliability of the combined use of these multivariate statistical techniques in river water quality research. It is desirable that both state and local agencies pay more attention and consideration in order to improve and protect the vulnerable river quality. Additional studies will be required to assess precisely the unidentified sources of pollution and variation of further water quality parameters that were not analyzed in this study.

\section{Acknowledgements}

This research was made possible by financial support that was provided by the Department of Civil and Environmental Engineering of Florida International University, Miami, U.S.A., through a Presidential Fellowship and a Graduate Assistantship to the main author. The observational data were obtained from South Florida Water Management District (SFWMD).

\section{References}

1. Carpenter, S.; Caraco, N.; Correll, D. .; Howarth, R. W.; Sharpley, A. N.; Smith, V. H. Nonpoint pollution of surface waters with phosphorus and nitrogen. Ecol. Appl. 1998, 8, $559-568$.

2. Jarvie, H. P.; Whitton, B. A.; Neal, C. Nitrogen and phosphorus in east coast British rivers: Speciation, sources and biological significance. Sci. Total Environ. 1998, 210211, 79-109.

3. Singh, K. P.; Malik, A.; Mohan, D.; Sinha, S. Multivariate statistical techniques for the evaluation of spatial and temporal variations in water quality of Gomti River (India) - A case study. Water Res. 2004, 38, 3980-3992.

4. Vega, M. Assessment of seasonal and polluting effects on the quality of river water by exploratory data analysis. Water Res. 1998, 32, 3581-3592.

5. Singh, K. P.; Malik, A.; Sinha, S. Water quality assessment and apportionment of pollution sources of Gomti river (India) using multivariate statistical techniques--a case study. Anal. Chim. Acta 2005, 538, 355-374.

6. Mustapha, A.; Aris, A. Z. Spatial aspects of surface water quality in the Jakara Basin, 
Nigeria using chemometric analysis. J. Environ. Sci. Health. A. Tox. Hazard. Subst. Environ. Eng. 2012, 47, 1455-65.

7. Simeonov, V.; Stratis, J. A.; Samara, C.; Zachariadis, G.; Voutsa, D.; Anthemidis, A.; Sofoniou, M.; Kouimtzis, T. Assessment of the surface water quality in Northern Greece. Water Res. 2003, 37, 4119-4124.

8. Juahir, H.; Zain, S. M.; Yusoff, M. K.; Hanidza, T. I. T.; Armi, A. S. M.; Toriman, M. E.; Mokhtar, M. Spatial water quality assessment of Langat River Basin (Malaysia) using environmetric techniques. Environ. Monit. Assess. 2011, 173, 625-641.

9. Shrestha, S.; Kazama, F. Assessment of surface water quality using multivariate statistical techniques: A case study of the Fuji river basin, Japan. Environ. Model. Softw. 2007, 22, 464-475.

10. Singh, S. P.; Sharma, N. K.; Sharma, B. K. Use of clustering to improve the standard of education system. Int. J. Appl. Inf. Syst. 2012, 1, 16-20.

11. Kowalkowski, T.; Zbytniewski, R.; Szpejna, J.; Buszewski, B. Application of chemometrics in river water classification. Water Res. 2006, 40, 744-752.

12. Wunderlin, A. D.; Díaz, M. D. P.; Amé, M. V.; Pesce, F. S.; Hued, A. C.; Bistoni, M. D. L. Á. Pattern recognition techniques for the evaluation of spatial and temporal variations in water quality. A case study: Suquía River basin (Córdoba-Argentina). Water Res. 2001, 35, 2881-2894.

13. Kim, J.-H.; Kim, R.-H.; Lee, J.; Cheong, T.-J.; Yum, B.-W.; Chang, H.-W. Multivariate statistical analysis to identify the major factors governing groundwater quality in the coastal area of Kimje, South Korea. Hydrol. Process. 2005, 19, 1261-1276.

14. Schaefer, K.; Einax, J. W. Analytical and chemometric characterization of the Cruces River in South Chile. Environ. Sci. Pollut. Res. 2010, 17, 115-123.

15. Xiao, M.; Bao, F.; Wang, S.; Cui, F. Water quality assessment of the Huaihe River segment of Bengbu (China) using multivariate statistical techniques. Water Resour. 2016, 43, 166-176.

16. Muangthong, S.; Shrestha, S. Assessment of surface water quality using multivariate statistical techniques: case study of the Nampong River and Songkhram River, Thailand. Environ. Monit. Assess. 2015, 187, 1-12.

17. Kumar, A. S.; Reddy, A. M.; Srinivas, L.; Reddy, P. M. Assessment of Surface Water Quality in Hyderabad Lakes by Using Multivariate Statistical Techniques, HyderabadIndia. Environ. Pollut. 2014, 4, 14.

18. Bhat, S. A.; Meraj, G.; Yaseen, S.; Pandit, A. K. Statistical assessment of water quality parameters for pollution source identification in Sukhnag stream: an inflow 
stream of lake Wular (Ramsar Site), Kashmir Himalaya. J. Ecosyst. 2014, 2014.

19. Duan, W.; He, B.; Nover, D.; Yang, G.; Chen, W.; Meng, H.; Zou, S.; Liu, C. Water Quality Assessment and Pollution Source Identification of the Eastern Poyang Lake Basin Using Multivariate Statistical Methods. Sustainability 2016, 8, 133.

20. Chen, H.; Teng, Y.; Yue, W.; Song, L. Characterization and source apportionment of water pollution in Jinjiang River, China. Environ. Monit. Assess. 2013, 185, 9639-9650.

21. Fisher, J. I.; Mustard, J. F. High spatial resolution sea surface climatology from Landsat thermal infrared data. Remote Sens. Environ. 2004, 90, 293-307.

22. Mustaffa, N. I. H.; Latif, M. T.; Ali, M. M.; Khan, M. F. Source apportionment of surfactants in marine aerosols at different locations along the Malacca Straits. Environ. Sci. Pollut. Res. 2014, 21, 6590-6602.

23. Nasir, M.; Samsudin, M.; Mohamad, I. River water quality modeling using combined principle component analysis (PCA) and multiple linear regressions (MLR): a case study at Klang River, Malaysia. World Appl. Sci. 2011.

24. Shrestha, S.; Kazama, F.; Nakamura, T. Use of principal component analysis, factor analysis and discriminant analysis to evaluate spatial and temporal variations in water quality of the Mekong River. J. Hydroinformatics 2008, 10, 43.

25. Su, S.; Li, D.; Zhang, Q.; Xiao, R.; Huang, F.; Wu, J. Temporal trend and source apportionment of water pollution in different functional zones of Qiantang River, China. Water Res. 2011, 45, 1781-1795.

26. Yang, L.; Mei, K.; Liu, X.; Wu, L.; Zhang, M.; Xu, J.; Wang, F. Spatial distribution and source apportionment of water pollution in different administrative zones of WenRui-Tang (WRT) river watershed, China. Environ. Sci. Pollut. Res. 2013, 20, 5341-5352.

27. Zhao, J.; Xu, Z.; Liu, X.; Niu, C. Source apportionment in the Liao River Basin. China Environ. Sci. 2013, 5, 13.

28. McPherson, B. F.; Hendrix, G. Y.; Klein, H.; Tyus, H. M. The environment of South Florida; a summary report; 1976.

29. Moreda-Piñeiro, a; Marcos, a; Fisher, a; Hill, S. J. Evaluation of the effect of data pre-treatment procedures on classical pattern recognition and principal components analysis: a case study for the geographical classification of tea. J. Environ. Monit. 2001, $3,352-360$.

30. Reid, M. K.; Spencer, K. L. Use of principal components analysis (PCA) on estuarine sediment datasets: The effect of data pre-treatment. Environ. Pollut. 2009, 157, 22752281. 
31. Gargouri, D.; Azri, C.; Serbaji, M. M.; Jedoui, Y.; Montacer, M. Heavy metal concentrations in the surface marine sediments of Sfax Coast, Tunisia. Environ. Monit. Assess. 2011, 175, 519-530.

32. Praveena, S. M.; Kwan, O. W.; Aris, A. Z. Effect of data pre-treatment procedures on principal component analysis: a case study for mangrove surface sediment datasets. Environ. Monit. Assess. 2012, 184, 6855-6868.

33. Introduction to Principal Components and FactorAnalysis.

34. Child, D. The essentials of factor analysis; Continuum, 2006.

35. Helena, B.; Pardo, R.; Vega, M.; Barrado, E.; Fernandez, J. M.; Fernandez, L. Temporal evolution of groundwater composition in an alluvial aquifer (Pisuerga River, Spain) by principal component analysis. Water Res. 2000, 34, 807-816.

36. Wood, F. Principal Component Analysis. 2009.

37. Chen, P.; Li, L.; Zhang, H. Spatio-temporal variations and source apportionment of water pollution in Danjiangkou Reservoir Basin, Central China. Water (Switzerland) $2015,7,2591-2611$.

38. Mustapha, A.; Abdu, A. Application of principal component analysis and multiple regression models in surface water quality assessment. J. Environ. earth Sci. 2012, 2, 1623.

39. Su, S.; Li, D.; Zhang, Q.; Xiao, R.; Huang, F.; Wu, J. Temporal trend and source apportionment of water pollution in different functional zones of Qiantang River, China. Water Res. 2011, 45, 1781-1795.

40. Kaiser, H. F. An index of factorial simplicity. Psychometrika 1974, 39, 31-36.

41. Hutcheson, G.; Sofroniou, N. The multivariate social scientist; 1999.

42. Manoj, K.; Padhy, P. K. Multivariate statistical techniques and water quality assessment: Discourse and review on some analytical models. Int. J. Environ. Sci. 2014, $5,607-626$.

43. Singh, K. P.; Malik, A.; Kumar, R.; Saxena, P.; Sinha, S. Receptor modeling for source apportionment of polycyclic aromatic hydrocarbons in urban atmosphere. In Environmental Monitoring and Assessment; 2008; Vol. 136, pp. 183-196.

44. Thurston, G. D.; Spengler, J. D. A quantitative assessment of source contributions to inhalable particulate matter pollution in metropolitan Boston. Atmos. Environ. 1985, 19, $9-25$.

45. Miller, S. L.; Anderson, M. J.; Daly, E. P.; Milford, J. B. Source apportionment of 
exposures to volatile organic compounds. I. Evaluation of receptor models using simulated exposure data. Atmos. Environ. 2002, 36, 3629-3641.

46. Guo, H.; Wang, T.; Louie, P. K. K. Source apportionment of ambient non-methane hydrocarbons in Hong Kong: Application of a principal component analysis/absolute principal component scores (PCA/APCS) receptor model. Environ. Pollut. 2004, 129, 489-498.

47. Tan, V. Percentage calculation with negative numbers | Polymath Programmer http://polymathprogrammer.com/2008/11/28/percentage-calculation-with-negativenumbers/.

48. US EPA, O. EPA Positive Matrix Factorization 5.0 Fundamentals and User Guide.

49. Al-Dabbous, A. N.; Kumar, P. Source apportionment of airborne nanoparticles in a Middle Eastern city using positive matrix factorization. Environ. Sci. Process. Impacts 2015, 17, 802-812.

50. Liu, Y.; Wang, S.; Lohmann, R.; Yu, N.; Zhang, C.; Gao, Y.; Zhao, J.; Ma, L. Source apportionment of gaseous and particulate PAHs from traffic emission using tunnel measurements in Shanghai, China. Atmos. Environ. 2015, 107, 129-136.

51. Manousakas, M.; Diapouli, E.; Papaefthymiou, H.; Migliori, A.; Karydas, A. G.; Padilla-Alvarez, R.; Bogovac, M.; Kaiser, R. B.; Jaksic, M.; Bogdanovic-Radovic, I.; Eleftheriadis, K. Source apportionment by PMF on elemental concentrations obtained by PIXE analysis of PM10 samples collected at the vicinity of lignite power plants and mines in Megalopolis, Greece. Nucl. Instruments Methods Phys. Res. Sect. B Beam Interact. with Mater. Atoms 2015, 349, 114-124.

52. Parworth, C.; Fast, J.; Mei, F.; Shippert, T.; Sivaraman, C.; Tilp, A.; Watson, T.; Zhang, Q. Long-term measurements of submicrometer aerosol chemistry at the Southern Great Plains (SGP) using an Aerosol Chemical Speciation Monitor (ACSM). Atmos. Environ. 2015, 106, 43-55.

53. Saeaw, N.; Thepanondh, S. Source apportionment analysis of airborne VOCs using positive matrix factorization in industrial and urban areas in Thailand. Atmos. Pollut. Res. 2015, 6, 644-650.

54. Li, H.; Hopke, P. K.; Liu, X.; Du, X.; Li, F. Application of positive matrix factorization to source apportionment of surface water quality of the Daliao River basin, northeast China. Environ. Monit. Assess. 2015, 187, 1-12.

55. Paatero, P.; Tapper, U. Positive matrix factorization: A non-negative factor model with optimal utilization of error estimates of data values. Environmetrics 1994, 5, 111126.

56. Ulbrich, I. M.; Canagaratna, M. R.; Zhang, Q.; Worsnop, D. R.; Jimenez, J. L. 
Interpretation of Organic Components from Positive Matrix Factorization of Aerosol Mass Spectrometric Data. Atmos. Chem. Phys. 2009, 9, 2891.

57. Guidance Document for PMF Applications with the Multilinear Engine - Google Scholar https://scholar.google.com/scholar?q=Guidance+Document+for+PMF+Applications+wit $\mathrm{h}+$ the+Multilinear+Engine \&btnG $=\& \mathrm{hl}=\mathrm{en} \& \mathrm{as} \_\mathrm{sdt}=0 \% 2 \mathrm{C} 10$.

58. Liu, C.-W.; Lin, K.-H.; Kuo, Y.-M. Application of factor analysis in the assessment of groundwater quality in a blackfoot disease area in Taiwan. Sci. Total Environ. 2003, $313,77-89$.

59. Huang, F.; Wang, X.; Lou, L.; Zhou, Z.; Wu, J. Spatial variation and source apportionment of water pollution in Qiantang River (China) using statistical techniques. Water Res. 2010, 44, 1562-1572.

60. Dils, R.; Leaf, S.; Robinson, R.; Sweet, N. Phosphorous in the Environment-Why Should Recovery be a Policy Issue? 1999.

61. Mullaney, J. R.; Lorenz, D. L.; Arnston, A. D. Chloride in Groundwater and Surface Water in Areas Underlain by the Glacial Aquifer System Northern United States; 2009.

62. Harvey, R. G.; Loftus, W. F.; Rehage, J. S.; Mazzotti, F. J. Effects of Canals and Levees on Everglades Ecosystems: Circular 1 Hydrologic Control of the South Florida Landscape. 2010.

63. Gholizadeh, M. H.; Melesse, A. M.; Reddi, L. Analysis of Spatiotemporal Trends of Water Quality Parameters Using Cluster Analysis in South Florida. In World Environmental and Water Resources Congress 2016; American Society of Civil Engineers: Reston, VA, 2016; pp. 519-528.

64. Fitch, K.; Kemker, C. Algae, Phytoplankton and Chlorophyll.” Fundamentals of Environmental Measurements.

65. Mallya, Y. J. The effects of dissolved oxygen on fish growth in aquaculture. United Nations Univ. Fish. Train. Program. Final Proj. pp30 2007.

66. Kemker, C. Turbidity, Total Suspended Solids and Water Clarity." Fundamentals of Environmental Measurements.

67. Patton, C. J.; Kryskalla, J. R. Methods of analysis by the US Geological Survey National Water Quality Laboratory: evaluation of alkaline persulfate digestion as an alternative to Kjeldahl digestion for determination of total and dissolved nitrogen and phosphorus in water; 2003.

68. Description of River Water Quality Parameters. 
69. Dale, V.; Bianchi, T.; Blumberg, A.; Boynton, W.; Conley, D. J.; Crumpton, W.; David, M.; Gilbert, D.; Howarth, R.; Kling, C. Hypoxia in the northern Gulf of Mexico: An update by the EPA Science Advisory Board; EPA-SAB-08-003. EPA Science Advisory Board: Washington, DC 333 pp, 2007.

70. Aziz, H. A.; Adlan, M. N.; Zahari, M. S. M.; Alias, S. Removal of ammoniacal nitrogen (N-NH3) from municipal solid waste leachate by using activated carbon and limestone. Waste Manag. Res. 2004, 22, 371-375.

71. Manios, T.; Stentiford, E. I.; Millner, P. a The removal of NH3-N from primary treated wastewater in subsurface reed beds using different substrates. J. Environ. Sci. Health. A. Tox. Hazard. Subst. Environ. Eng. 2002, 37, 297-308.

72. Mikkelsen, R. Ammonia emissions from agricultural operations: fertilizer. Better Crop. 2009, 93, 9-11.

73. Turbidity, Total Suspended Solids \&amp; Water Clarity - Environmental Measurement Systems http://www.fondriest.com/environmentalmeasurements/parameters/water-quality/turbidity-total-suspended-solids-water-clarity/.

74. Wu, E.; Kuo, S. Applying a multivariate statistical analysis model to evaluate the water quality of a watershed. Water Environ. Res. 2012.

75. Hamilton, P. A.; Miller, T. L.; Myers, D. N. Water quality in the nation's streams and aquifers: Overview of selected findings, 1991-2001; US Geological Survey, 2004.

76. Paatero, P. Least squares formulation of robust non-negative factor analysis. In Chemometrics and Intelligent Laboratory Systems; 1997; Vol. 37, pp. 23-35. 
CHAPTER VII

CONCLUSION AND RECOMMENDATIONS 
This study follows a multi-model/multi-approach/multi-scale procedure to understand water quality in South Florida. Multivariate statistical techniques including cluster analysis (CA), principal component analysis (PCA), factor analysis (FA), discriminant analysis (DA), were successfully applied to evaluate spatial and temporal variations in surface water quality of three major rivers of South Florida using 15 years (2000-2014) datasets of 12 water quality variables covering 16 sampling stations, and about 35,000 observations were used. In addition, the absolute principal component score-multiple linear regression (APCS-MLR) and PMF receptor modeling techniques were used to identify the contributions of different potential pollution sources to each water quality variable.

Agglomerative hierarchical CA grouped 16 monitoring sites into three groups (low pollution, moderate pollution, and high pollution) based on their similarity of water quality characteristics. PCA and FA methods were applied to reveal five potential pollution sources including: (1) point source pollution discharges, (2) physicochemical and biological non-point sources of pollution, (3) non-point sources of nutrients, (4) organic pollutants, and (5) seasonal factor in wet season and four potential pollution sources including: (1) point source pollution discharges, (2) physicochemical and biological non-point sources of pollution, (3) organic pollutants, and (4) non-point sources of nutrients, and then absolute principal component score-multiple linear regression (APCS-MLR) was used to identify their contributions to each water quality variable. In addition, the contributions of miscellaneous unidentified sources were considered as one of the latent factors in water quality in both wet and dry seasons that showed the necessity of field work to further identify the sources of the pollution. The 
data matrix was also subjected to PMF receptor model using the EPA PMF-5.0 program and the two-way model described were performed for the PMF analyses. Comparison of the obtained results from PMF and APCS-MLR models showed that there were some significant differences in estimated contribution for each potential pollution source, especially in the wet season. Eventually, it was concluded that the results of APCS-MLR are more physically acceptable for the current study. It came to the conclusion that the point source pollution discharges from anthropogenic factors due to the agriculture waste, domestic and industrial wastewater disposal was the major source of river water contamination in three major rivers of South Florida.

Discriminant analysis (DA), as an important data reduction method, and cluster analysis (CA) were used to assess the water pollution status and analysis of its spatiotemporal variation. In temporal DA, 12 months of raw data divided into two seasonal groups (wet and dry season) as the dependent variable, while all observed water quality parameters were independent variables. In spatial DA, sixteen monitoring sites classified by CA to three groups of relatively low pollution (LP), moderate pollution (HP), and high pollution (HP) regions were the grouping (dependent) variables, whereas all the observed parameters constituted the independent variables. It was found by the stepwise DA that five variables (chl-a, DO, TKN, TP and water temperature) are the most important discriminating water quality parameters responsible for temporal variations.

In spatial DA, the stepwise mode identified seven variables (chl-a, DO, TKN, TP, magnesium, chloride, and sodium) and six variables (DO, TKN, TP, turbidity, magnesium, and chloride) as the most important discriminating variables responsible for spatial variations in wet and dry season, respectively. Different patterns associated with 
spatial variations were identified depending on the variables and considered season, however the overall trend of environment pollution problems was found from the LP region to HP region. Nonetheless, two highly polluted sites of S154C and CES03 in Kissimmee River and Caloosahatchee River require more attention and considerations. The spatial DA using the identified groups of sites by CA confirmed the accuracy of cluster analysis results. This study showed the feasibility and reliability of the combined use of these multivariate statistical techniques in river water quality research.

In addition, the bio-physical parameters associated with water quality of two important waterbodies of Lake Okeechobee and Florida Bay investigated based on atmospherically corrected remotely sensed data. The principal objective of this study is to monitor and assess the spatial and temporal changes of water quality using the application of integrated remote sensing, GIS data, and statistical techniques. In the Lake Okeechobee the spatial and temporal changes of four water quality parameters including total suspended solids (TSS), chlorophyll-a (chl-a), total phosphate, and total kjeldahl nitrogen (TKN), by using the application of integrated remote sensing, GIS data, and statistical techniques. For this purpose, three dates of Landsat Thematic Mapper (TM) data in 2000 (February 29); 2007 (January 31), and one date of Landsat Operational Land Imager (OLI) in 2015 (February 6) in the dry season, and three dates of TM data in 2000 (July 6); 2007 (August 11), and one date of OLI data in 2015 (September 15) in the wet season of the subtropical climate of South Florida, were used to assess temporal and spatial patterns and dimensions of studied parameters in Lake Okeechobee, Florida. The simultaneous observed data of four studied parameters were obtained from 26 monitoring stations and were used for the development and validation of the models. The optical 
bands in the region from blue to near infrared and all the possible band ratios were used to explore the relation between the reflectance of waterbody and observed data.

The predictive models to estimate chl-a and TSS concentrations were developed through the use of stepwise multiple linear regression (MLR) and gave high coefficients of determination in dry season $\left(\mathrm{R}^{2}=0.84\right.$ for chl-a and $\mathrm{R}^{2}=0.67$ for TSS $)$ and moderate coefficients of determination in wet season $\left(\mathrm{R}^{2}=0.48\right.$ for chl-a and $\mathrm{R}^{2}=0.60$ for TSS $)$. Values for total phosphate and TKN were strongly correlated with chl-a and TSS concentration and some bands and their ratios, therefore, total phosphate and TKN were estimated using best-fit multiple linear regression models as a function of Landsat TM and OLI, and ground data and showed a high coefficient of determination in dry season $\left(\mathrm{R}^{2}=0.85\right.$ for total phosphate and $\mathrm{R}^{2}=0.88$ for $\left.\mathrm{TKN}\right)$ and in wet season $\left(\mathrm{R}^{2}=0.80\right.$ for total phosphate and $\mathrm{R}^{2}=0.86$ for $\left.\mathrm{TKN}\right)$.

In the Florida Bay, the spatiotemporal changes of four water quality parameters including turbidity, chlorophyll-a (chl-a), total phosphate, and total nitrogen (TN), by using the application of integrated remote sensing, GIS data, and statistical techniques. For this purpose, three dates of Landsat Thematic Mapper (TM) data in 2000 (February 13), 2007(January 31), and one date of Landsat Operational Land Imager (OLI) in 2015 (January 5) in the dry season, and three dates of TM data in 2000 (August 7), 2007 (September 28), and one date of OLI data in 2015 (September 2) in the wet season of the subtropical climate of South Florida, were used to assess temporal and spatial patterns and dimensions of studied parameters in Florida Bay, USA. The simultaneous observed data of four studied parameters were obtained from 20 monitoring stations and were used for the development and validation of the models. The optical bands in the region from 
blue to near infrared and all the possible band ratios were used to explore the relation between the reflectance of waterbody and observed data.

The predictive models to estimate chl-a and turbidity concentrations were developed through the use of stepwise multiple linear regression (MLR) and gave high coefficients of determination in dry season $(\mathrm{R} 2=0.86$ for chl-a and $\mathrm{R} 2=0.84$ for turbidity) and moderate coefficients of determination in wet season $(\mathrm{R} 2=0.66$ for chl-a and $\mathrm{R} 2=0.63$ for turbidity). Values for total phosphate and TN were correlated with chla and turbidity concentration and some bands and their ratios. Total phosphate and TN were estimated using best-fit multiple linear regression models as a function of Landsat TM and OLI, and ground data and showed a high coefficient of determination in dry season $(\mathrm{R} 2=0.74$ for total phosphate and $\mathrm{R} 2=0.82$ for $\mathrm{TN})$ and in wet season $(\mathrm{R} 2=$ 0.69 for total phosphate and $\mathrm{R} 2=0.82$ for $\mathrm{TN}$ ). The MLR models showed a good trustiness to monitor and predict the spatiotemporal variations of optically active and inactive water quality characteristics in Lake Okeechobee and Florida Bay.

This study showed that Landsat TM and OLI data and water quality parameters at various locations of Lake Okeechobee and Florida Bay can be related through a regression analysis and constitute a model that can be used to measure water quality parameters over the entire surface. The studied parameters were mapped by identifying the best set of band combinations and their interreltionship can then be used to describe the linkage between the spectral response to limnological data. The same method can also be applied to the trophic conditions for landsat images in different years.

The results of CA can be used to reduce the need for numerous sampling stations and frequency, and to optimize water quality monitoring program design and minimize 
the costs. The resulting recommendation is that, in future studies, the number of monitoring sites can be reduced by selecting only one site from each of the three groups. It is herein recommended for consideration that the results of apportionment can be a very useful method and tool for responsible agencies and authorities to control the pollution sources, and to protect the river water quality.

Additional studies are recommended to assess unidentified sources of pollution and variation of water quality parameters that were not analyzed in this study. The results, herein presented, are recommended as an approach to estimate spatial and temporal variations that should support the identification of polluted areas and control strategies. This study used an empirical approach to evaluate the spatio-temporal variations of water quality parameters in Lake Okeechobee and Florida Bay. It is also recommended to further this study that other approaches, like semi-empirical, analytical, and semi-analytical types, be assessed to compare with the results described here. The application of other imageries to determine and quantify the water quality in other water bodies of South Florida is also recommended as a way to enrich the understanding of water quality behavior, improving monitoring and data collection techniques, among others. It is also highly recommended to provide systematic mapping of pollution sources in order to enhance the effectiveness of water pollution control. 
VITA

MOHAMMAD HAJIGHOLIZADEH

\section{EDUCATION, AWARDS, AND HONORS}

Ph.D. Civil Engineering- Water Resources, Florida International University, November 2016

Dissertation: Water Quality Modelling Using Remote Sensing and Multivariate Statistical Analysis in South Florida

M.Sc. Natural Resources Engineering- Watershed Management, Tarbiat Modares University, Iran, 2004

Thesis: Study of Effects of Human Interferences on Flood Behavior Using Hec-Ras and GIS

B.S. Natural Resources Engineering- Watershed Management, Kurdistan University, Iran, 2002

2013 Worlds Ahead Graduate, Recognized as Outstanding PhD Student, office of Provost, FIU.

2013 FIU Presidential Fellowship Award for the entire of PhD program.

2002 Ranked 12 ${ }^{\text {th }}$ among the National Natural Resources Engineering M.Sc. Entrance Exam, Iran.

\section{SELECTED PUBLICATIONS}

2016 Gholizadeh, M.H., Melesse, A.M. and Reddi, L., 2016. Water quality assessment and apportionment of pollution sources using APCS-MLR and PMF receptor modeling techniques in three major rivers of South Florida.Science of The Total Environment, 566, pp.1552-1567.

2016 Gholizadeh, Mohammad Haji, Assefa M. Melesse, and Lakshmi Reddi. "Discriminant Analysis Application in Spatiotemporal Evaluation of Water Quality in South Florida." Journal of Hydroinformatics, p.jh2016023.

2016 Gholizadeh, Mohammad Haji, Assefa M. Melesse, and Lakshmi Reddi. "Spaceborne and airborne sensors in water quality assessment." International Journal of Remote Sensing 37, no. 14 (2016): 3143-3180.

2016 Gholizadeh, Mohammad Haji, Assefa M. Melesse, and Lakshmi Reddi. "Analysis of Spatiotemporal Trends of Water Quality Parameters Using Cluster Analysis in South Florida." World Environmental and Water Resources Congress 2016.

2016 Gholizadeh, Mohammad Haji, Assefa M. Melesse, and Lakshmi Reddi. "A Comprehensive Review on Water Quality Parameters Estimation Using Remote Sensing Techniques". Sensors, 16(8), p.1298. 
Sadeghi, SHR, M. Haji Gholizadeh, M. Vafakhah, and JK Singh. "Effects of Hydraulic Structures on Changing Flood Zones in Kan River, Iran." Journal of Soil and Water Conservation 8, no. 1 (2009): 01-08.

2007 Sadeghi, SHR, M. Haji Gholizadeh, M. Vafakhah, and H. Motiei. " Role of Drops on Inundation Depth and Area Variations in a Stretch of the Kan River; Technical Report." (2007): 84-87.

2007 Sadeghi, SHR, M. Haji Gholizadeh, and M. Vafakhah. "Comparative evaluation of bridges and culverts effect on flood depth and extension in a reach of Tehran Kan River. (2007): 64-67.

2006 Sadeghi, SHR, and M. Haji Gholizadeh. "Flood Hazard Study and Zoning in Tehran Eram Park", Journal of the Environmental Research Institute, 1(3):41-45 and 64.

2004 Hajigholizadeh, M., Study of Effects of Human Interferences on Flood Behavior in a Part of Tehran Kan River Using Hec-Ras and GIS, Master thesis, Tarbiat Modares University, Iran. 2004.

2016 Gholizadeh, M.H., and Hamedi, A., Niazi, A., and Eazi, M., 2016. "Optimal Design of Water-Supply Pipe System Using Economic and Technical Analysis". In World Environmental and Water Resources Congress 2016, pp. 284-293. 2016.

2016 Gholizadeh, M.H., Melesse, M.A., Reddi, L., 2016. “Analysis of Spatiotemporal trends of Water Quality Parameters Using Cluster Analysis in South Florida". In World Environmental and Water Resources Congress 2016, pp. 519-528. 2016.

2016 Gholizadeh, M.H., Melesse, M.A., Reddi, L., 2016. "Comparison of Space and Air-Borne Sensors' Capabilities in Water Quality Monitoring." In World Environmental and Water Resources Congress 2016, pp. 513-518. 2016.

2009 Sadeghi, S.H.R., Gholizadeh. M.H., and Jalali Rad, R., 2009. Flood Simulation in Two Urban Watersheds in Tehran Municipality, In: Proceedings of 1st National Conference on Urban Watershed (CD), Tehran. July 1, 2009: 233-248.

2005 Hajigholizadeh, M., 2005. Capability using high-resolution satellite images in distinguishes some erosion features in Tehran province, Iran. In Proceedings of the 3rd Erosion and Sediment National Conference (pp. 27-30).

2005 Gholizadeh, M.H, 2005. Study on Relationship between Main River System and Noor Urban Development, In: Proceedings of Seminar on Regional Development Strategies of Noor City, Iran, Mazandaran, May 12, 2005:21. 